\title{
Communication for participation
}

Citation for published version (APA):

Stans, S. E. A. (2018). Communication for participation: facilitating dialogue conversations between communication vulnerable people and healthcare professionals. [Doctoral Thesis, Maastricht University]. Maastricht University. https://doi.org/10.26481/dis.20181217ss

Document status and date:

Published: 01/01/2018

DOI:

10.26481/dis.20181217ss

Document Version:

Publisher's PDF, also known as Version of record

\section{Please check the document version of this publication:}

- A submitted manuscript is the version of the article upon submission and before peer-review. There can be important differences between the submitted version and the official published version of record.

People interested in the research are advised to contact the author for the final version of the publication, or visit the DOI to the publisher's website.

- The final author version and the galley proof are versions of the publication after peer review.

- The final published version features the final layout of the paper including the volume, issue and page numbers.

Link to publication

\footnotetext{
General rights rights.

- You may freely distribute the URL identifying the publication in the public portal. please follow below link for the End User Agreement:

www.umlib.nl/taverne-license

Take down policy

If you believe that this document breaches copyright please contact us at:

repository@maastrichtuniversity.nl

providing details and we will investigate your claim.
}

Copyright and moral rights for the publications made accessible in the public portal are retained by the authors and/or other copyright owners and it is a condition of accessing publications that users recognise and abide by the legal requirements associated with these

- Users may download and print one copy of any publication from the public portal for the purpose of private study or research.

- You may not further distribute the material or use it for any profit-making activity or commercial gain

If the publication is distributed under the terms of Article $25 \mathrm{fa}$ of the Dutch Copyright Act, indicated by the "Taverne" license above, 
ommunication

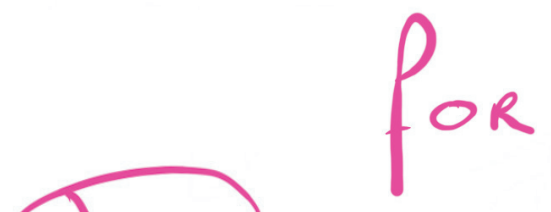

$\int$ articipation
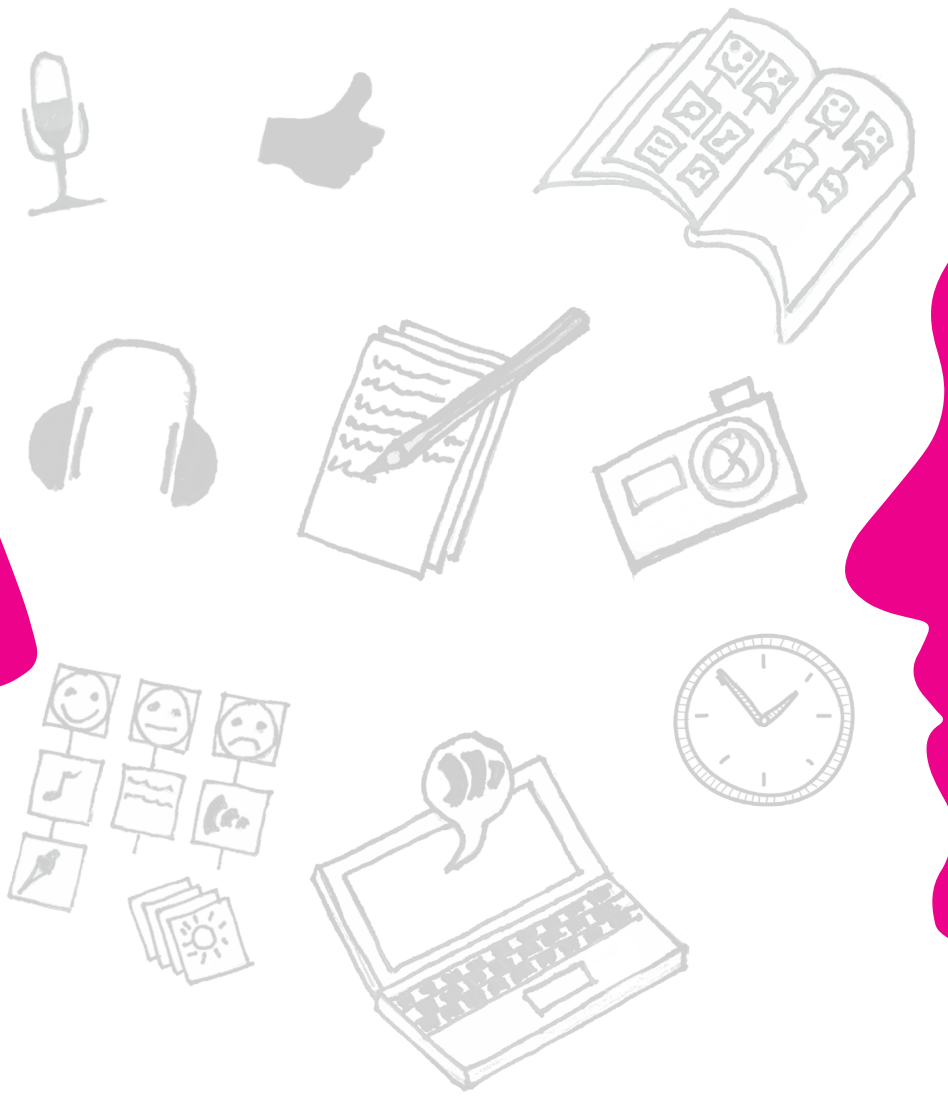

Facilitating dialogue conversations between communication vulnerable people and healthcare professionals 




\section{Communication for Participation}

Facilitating dialogue conversations between

communication vulnerable people and

healthcare professionals 
(C) Steffy Stans, Maastricht 2018

The research presented in this dissertation was conducted at:

School for Public Health and Primary Care (CAPHRI), Department of Family Medicine, Maastricht University. CAPHRI participates in the Netherlands School of Primary Care Research (CaRe).

and

Research Centre Autonomy and Participation for Persons with a Chronic Illness, Faculty of Health, Zuyd University of Applied Sciences, Heerlen, the Netherlands.

The research presented in this dissertation was funded by Zuyd.

All rights are reserved. No part of this book may be reproduced or transmitted in any form or by any means, without the written permission from the author or, where appropriate, the publisher of the article.

Layout: Gildeprint- Enschede

Cover: Jules Stans, in samenwerking met Sjors en Kirsten Stans en Patrick van de Berg

Printed by: Gildeprint- Enschede

ISBN: 978-94-6323-439-9 


\title{
Communication for Participation Facilitating dialogue conversations between communication vulnerable people and healthcare professionals
}

\author{
PROEFSCHRIFT \\ TER VERKRIJGING VAN DE GRAAD VAN DOCTOR \\ AAN DE UNIVERSITEIT MAASTRICHT,
}

OP GEZAG VAN RECTOR MAGNIFICIUS, PROF. DR. RIANNE M. LETSCHERT,

VOLGENS HET BESLUIT VAN HET COLLEGE VAN DECANEN,

IN HET OPENBAAR TE VERDEDIGEN OP

MAANDAG 17 DECEMBER 2018 OM 14.00 UUR

DOOR

STEFFY ELISABETH ALIDA STANS 


\section{Promotor:}

Prof. dr. A.J.H.M. Beurskens

\section{Co-promotores:}

Dr. R.J.P. Dalemans

Dr. U.R. Roentgen

\section{Beoordelingscommissie:}

Prof. dr. J.M.G.A. Schols (voorzitter), Maastricht University

Prof. dr. L.J.M. van Balkom, Radboud Universiteit

Prof. dr. F.J.M. Feron, Maastricht University

Dr. C.A.M. Neijenhuis, Hogeschool Rotterdam

Prof. dr. J.J.D.J.M. Rademakers, Maastricht University 




\section{Contents}

CHAPTER 1

General Introduction

\section{CHAPTER 2}

25

Challenges in the communication between communication vulnerable people and their social environment: an exploratory qualitative study.

Patient Education and Counseling, 2013: 2(3):302-12.

\section{CHAPTER 3}

Who said dialogue conversations are easy? The communication between communication vulnerable people and health-care professionals: A qualitative study

Health Expectations, 2018: 21(5):848-857.

\section{CHAPTER 4}

The role of the physical environment in conversations between people who are communication vulnerable and health-care professionals: a scoping review

Disability and Rehabilitation, 2017:39 (25):2594-2605.

\section{CHAPTER 5}

Using Talking Mats to support conversations with people who are communication vulnerable:a scoping review

submitted

\section{CHAPTER 6}

Choose to Communicate: a guide to support communication between practitioners and communication vulnerable people

Submitted

CHAPTER 7

Client participation in research through junior researchers' eyes: a qualitative analysis

Submitted

\section{CHAPTER 8}

General discussion

Summary 



\section{Chapter 1}

General Introduction 


\section{Communication}

Communication provides us the opportunity to live, to care, to joy, to travel, to work. Without communication we cannot build and expand relationships with others, we cannot belong to a group and we cannot participate in society. Communicating is not an end goal in itself, but rather a requirement for people to participate in life and to achieve their educational, vocational, social, personal and health-related goals. ${ }^{1}$

Early theories about communication focussed on the alternate activities of sending and receiving information. ${ }^{2}$ While the basics of this theory are still adhered to by scholars, overall communication is currently seen as a much more complex system. In this thesis, communication is regarded as part of a dynamic social process with the goal of reaching a joint establishment of meaning. Meaning is constructed through multiple channels (speech, gesture, facial expression, writing, technology) during a process of sending, transferring, receiving, and processing information, in which the environment (physical, social, cultural) also plays an important role. To be truly effective, communication needs to be a two-way process in which messages are negotiated until information is expressed and correctly understood by both parties. ${ }^{3,4}$

\section{Communication in healthcare}

In healthcare, communication is as important as in daily life. Communication between healthcare professionals and clients is necessary for clients to engage in shared decision making and self-management, and to provide client-centred care. ${ }^{5-8}$ Effective communication in healthcare is fundamental to achieve an overall quality of care that is high as well as consistant in quality. ${ }^{7}$ Not only is effective communication necessary for a high quality of care, ineffective communication can have negative effects, ${ }^{9}$ such as risks to client safety, ${ }^{10}$ poorer health outcomes, ${ }^{11}$ and lower satisfaction with healthcare. ${ }^{12}$ Traditionally, a more paternalistic role allocation existed in the communication between clients and professionals; a client was a layman, the listening and receiving party. However, the position of clients is now changing, and they are increasingly treated as an expert in their own right, a questioning party, with responsibility resting on their shoulders. , $^{8,1314}$ This development calls for a more active role of clients in conversations with professionals. ${ }^{15,16}$

Especially in long-term care, it is crucial that clients are enabled to take this active role and are able to express their needs, goals and values in conversations with healthcare professionals, because clients' lives often depend upon various types of professionals' support in such settings. ${ }^{17}$ The need for effective communication is probably most important in dialogue conversations. Dialogue conversations are essential exchanges between clients and healthcare professionals in healthcare environments which are of influence on the care process, and in which both clients and professionals should play a significant role. Such conversations concern, for example, health-related goals, activity and participation choices, 
diagnostics, discussing treatment options, and treatment evaluation.

A growing body of literature addressing communication in healthcare is further testament to the increased importance that is attributed to (effective) communication in this field. Research has so far focussed on process steps in communication; ${ }^{18}$ affective elements of communication; ${ }^{16,18,19}$ intercultural communication; ${ }^{20}$ the process of shared decision making; ${ }^{6}$ and self-management. ${ }^{8}$ Moreover, these insights are transferred to education in related communication skills of medical and allied health professionals and students. ${ }^{21}$

Even the internationally renowned CanMEDS roles, which have been used to develop curricula in healthcare education, include the 'communicator role', comprising elements such as diversity, empathy, and nonverbal communication. ${ }^{22}$ However, one particular aspect, namely the impact of communication vulnerability on dialogue conversations, is often overlooked, both in daily practice, where professionals may not be aware of clients' communication vulnerability, as well as in research, where communication vulnerable clients* have received scant attention. ${ }^{23-25}$

\section{Dialogue conversations between communication vulnerable clients and healthcare professionals}

Communication vulnerable people experience functional communication difficulties in particular situations, due to medical conditions. They experience difficulties expressing themselves or understanding professionals, and/or professionals experience difficulties understanding these clients. ${ }^{3,10,26,27}$ They may experience mild to severe communication difficulties, related to their sensory, emotional, physical or cognitive abilities. ${ }^{24}$

According to Blackstone and colleagues five client groups are considered at risk for communication vulnerability, namely children and adults with: ${ }^{28}$

a) 'speech, language, hearing, vision, and cognitive impairments, including those with complex communication needs,

b) limited proficiency in the language spoken by healthcare providers,

c) limited health literacy (i.e., little knowledge about health and how to negotiate health care systems),

d) cultural, ethnic, sexual orientation, gender identity, or religious differences that providers either do not understand or do not accept,

e) temporary conditions that often preclude successful communication, such as intubation, a recent head injury, or heavy sedation'28 (p. 70).

In this thesis we focus on communication vulnerable adults experiencing functional communication difficulties in particular situations, due to medical conditions (a and e). Communication vulnerability does not solely depend on their medical condition. Rather, communication vulnerability includes a 
complex interplay of factors influencing communication, such as personal and environmental factors. Two fictional examples are given of communication vulnerable clients and professionals who reflect upon the difficulties in their dialogue conversation.

Reflections on a dialogue conversation between Carla and Mieke:

I am Carla. I moved to this nursing home recently because I have difficulty remembering things. I don't really like it here because this is not my home. I had a conversation with a nurse this morning, I was very nervous because I was afraid that I had done something wrong. She kept asking a lot of difficult questions about 'meaningful things'? That made me more nervous. I just said that the most important thing is to walk the dog three times a day.'

I am Mieke, I had an important conversation with Carla this morning about her goals for meaningful activities during the day. Carla has dementia and was admitted last week. Carla did not seem to understand my questions, so I tried reframing them. However, she kept talking about walking her dog that died many years ago. I want to know what is important for her, but I didn't know how to get that information out of her.

Reflections on a dialogue conversation between John and Frank:

'I am John, I live in a supported living facility. I cannot live alone because I had a stroke, which is why I use an electric wheelchair and can only say a few words. Before my accident, I was a professional gardener, I worked on a lot of gardens in this neighbourhood. Every six months I have an evaluation with Frank who is responsible for my care. We had the conversation yesterday, in the kitchen. I had difficulty concentrating with the dishwasher on. I tried to explain my passion for gardening, doesn't he understand that in winter you have to prune everything?'

I am Frank, I had an evaluation with John yesterday, to talk about his goals. It is difficult for him to talk, but I can understand a lot by looking at his facial expressions. He seemed somewhat unhappy about the activity gardening, but I cannot help that plants don't grow in the winter, doesn't he understand that? I didn't know how to check this with him, so I said that we are going to buy new plants in April and talked further about his social activities.'

The complexity of factors influencing communication vulnerability can be further illustrated using the International Classification of Functioning, Disability and Health (ICF). The ICF is the World Health Organisations' (WHO) framework for measuring and describing health and disability. The ICF explains the functioning of an individual as a complex, dynamic and unpredictable interaction between health conditions (diseases, disorders and injuries), personal factors, and environmental factors. ${ }^{29}$ Figure 1.1 illustrates the complexity of communication between Carla and Mieke using the ICF model..$^{30-33}$ 


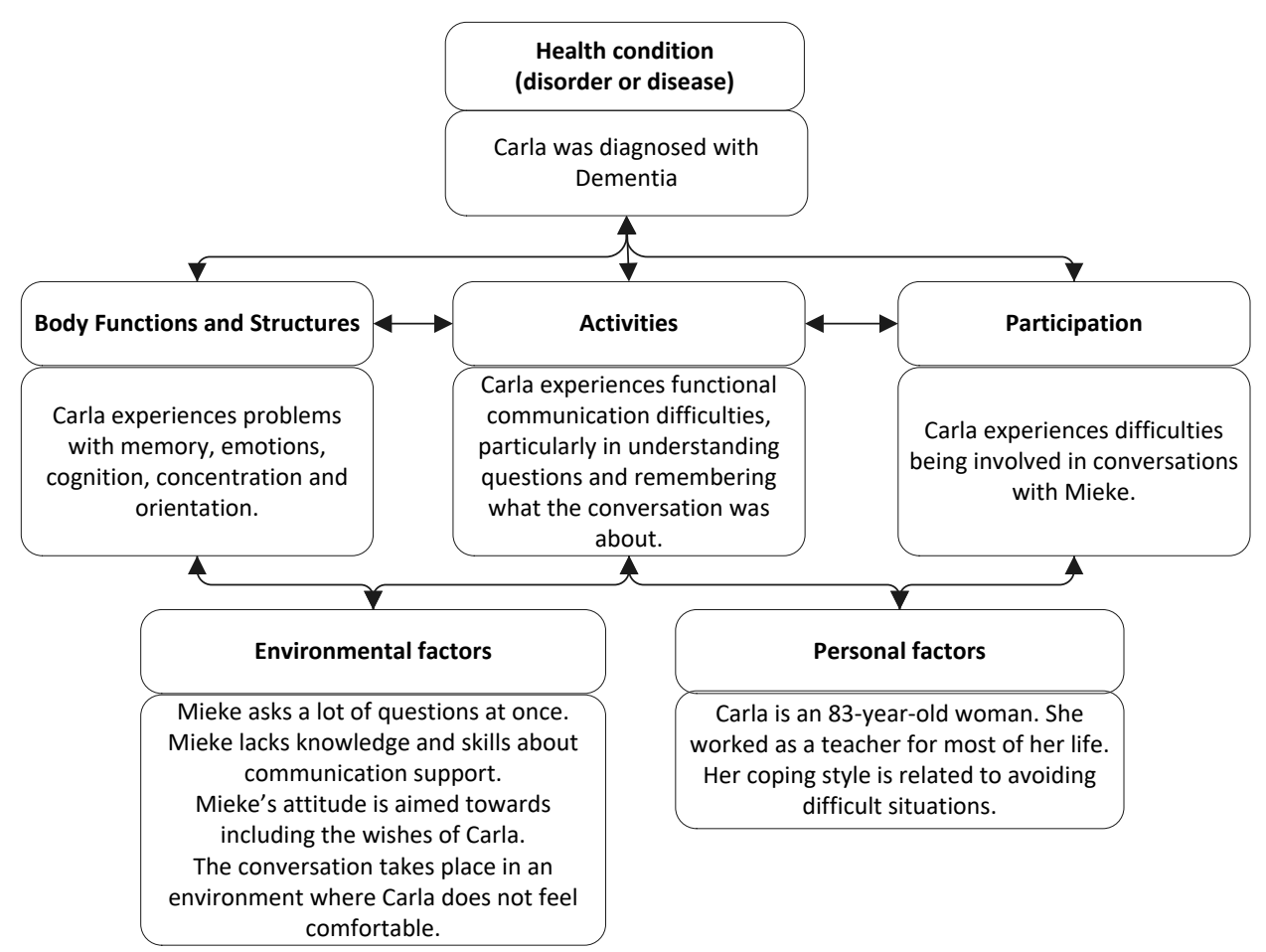

Figure 1.1. Illustration of the complexity of communication using the ICF ${ }^{34}$

Research about clients with various communication difficulties reports that conversations between communication vulnerable clients and professionals are experienced as difficult, frustrating or unsuccessful by both parties. ${ }^{35-37}$ Professionals often circumvent conversations with these clients or rely on information from their family. ${ }^{37}$

Attention for the shared communication difficulties of communication vulnerable clients could be useful to support clients in participating in dialogue conversations. In the example of Carla and John, they have different diagnosis, however, they both have difficulties communicating when a professional uses difficult words or when there is background noise. However, the complexity of communication and the concept of communication vulnerability is not enough acknowledged in healthcare practice and literature. Often, the focus lies on people's diagnosis (e.g. autism, aphasia, or dysarthria), instead of acknowledging the large group of communication vulnerable people.

A focus on communication vulnerability would enable us to provide insights into how people experience functional communication, what their communication needs are, and would enable us to support them in being more involved in dialogue conversations. ${ }^{24}$ However, little is known about the challenges regarding communication that are faced in long-term care settings by communication vulnerable clients 
and the professionals who work with them.

A large number of clients in long-term care settings is probably communication vulnerable, since many health conditions (e.g. dementia, strokes, traumatic acquired brain injuries, and learning disabilities) as well as external factors (e.g. physical environment, skills of communication partner) could lead to communication vulnerability. $24,32,38,39$ Furthermore, the group of communication vulnerable clients in long-term care is expected to increase due to medical advances, an aging population, and an increase in the amount of people with chronic conditions. ${ }^{40}$ However, estimates on prevalence are difficult since such measurements are mostly disorder-based, or non-existing. ${ }^{24}$ One could question whether professionals in long-term care settings are aware that a large number of clients with whom they interact are communication vulnerable. Functional communication difficulties are, in contrast to physical limitations, not easily seen or identified. Studying the challenges of communication vulnerable people and looking at improvements that can be made will likely help a large number of people. In order to provide communication support to improve dialogue conversations in long-term settings, insights are needed into the challenges that are experienced by communication vulnerable clients and professionals when they communicate with each other, as well as into factors that influence these experiences.

\section{Communication support in dialogue conversations between communication vulnerable clients and healthcare professionals}

So far, research about improving conversations with clients with communication difficulties has mostly focussed on body functions and structures (e.g. providing therapy), and skills of persons in the social environment (e.g. communication partner training). ${ }^{41,42}$ However, as shown in figure 1, the physical environment also has an important influence on dialogue conversations with communication vulnerable people. ${ }^{43,44}$ Especially in long-term care settings a focus on the environment is valuable because persons are in a chronic phase of their condition where treatment has often been stopped and improvements on impairment level (e.g. comprehension of language) are often not to be expected. ${ }^{24,45,46}$

While some research about the impact of the physical environment and its potential to support communication exists, there is no overview of factors in the physical environment that have impact on dialogue conversations between communication vulnerable clients and healthcare professionals. Insights into factors in the physical environment that could hamper or support dialogue conversations between professionals and communication vulnerable people are needed.

Augmentative and Alternative communication (AAC) can, in line with the ICF, be considered as an element of the physical environment, and research has shown that communication can be supported by the use of AAC. The use of AAC can help people to communicate, by empowering them to play an active role in their care process and make shared decisions with profesionals. ${ }^{47-49}$ AAC includes any method, strategy or resource that can help people communicate more successfully, ${ }^{50}$ including formal 
assistive devices (e.g. speech generating devices), communication tools (e.g. picto-books), conventional semiotic communication (e.g. handwriting), unaided resources (e.g. gesture), and commonplace objects (e.g. maps or smartphones). ${ }^{51} \mathrm{~A}$ lot of research is available about custom-made individual dedicated communication devices which can have major benefits for people with speech deficits in daily life. ${ }^{32}$ However, less knowledge is available about easy to use and readily available communication tools and commonplace objects (e.g. communication boards, Talking Mats, writing, iPad), while these specifically could have potential for ad hoc communication support in dialogue conversations. ${ }^{39,52}$ Moreover, existing research mostly focusses on the use of AAC for people with complex communication needs, ${ }^{4,37,53}$ in daily life, ${ }^{51}$ or in the rehabilitation phase. ${ }^{27}$ One could wonder whether clients and professionals use AAC to support their dialogue conversations, since clients in long-term care settings often do not receive (communication) treatment anymore. ${ }^{54}$ Therefore, a more in-depth understanding is needed about challenges that both communication vulnerable clients and professionals encounter during dialogue conversations in long-term care settings, and what types of communication support they use, or do not use, to overcome these difficulties.

Talking Mats is an example of an AAC that has potential to improve dialogue conversations, and has received increased attention in the AAC research community. ${ }^{55-57}$ It has been described as suitable for people who experience a variety of communication difficulties. ${ }^{58}$ As an example of AAC suitable for dialogue conversations, Talking Mats seems to be worthwhile to study in more detail. It is not known how effective it is, or what essential elements make it suitable for this large target group. An overview of knowledge about Talking Mats is required to provide healthcare professionals with information about whether, when, and how Talking Mats can be used.

Although AAC has potential to improve dialogue conversations, it is not known how clients can be involved in the selection of ad hoc AAC. Moreover, current research about communication support is mostly limited to providing training to professionals and thus does not take clients' views on communication challenges into account in the assessment of current situations and the search for (AAC) solutions. ${ }^{17,37,53,59}$ In order to enable clients to be meaningfully involved in dialogue conversations within long-term care settings, there is an urgent need to study how clients and professionals can search together for easily available ad hoc AAC to support their communication.

\section{Client participation in research}

As communication vulnerable clients can provide valuable insights into the challenges and possible solutions in dialogue conversations between themselves and professionals, and can assist in tailoring communication support to daily practice, client participation in research is of high importance for this study. ${ }^{25,60}$ Furthermore, involving clients in research is thought to improve the quality of results, the accessibility of healthcare, and usability of innovations in healthcare. ${ }^{60}$ The core belief underlying client participation in research, is that people who are affected by the outcomes of research have a right to 
participate during the process of research. ${ }^{61}$

Clients can be involved in various stages of research (e.g. in data collection, analysis, or dissemination of results), and in different ways (from being consulted during interviews, being asked for advice about research strategies, to engaging in a partnership, and being a research principal). ${ }^{62}$ However, client participation in research is not yet standard practice and communication vulnerable people have frequently been excluded from contributing to research ${ }^{25}$ because of their difficulties with communication. Still, some progress is being made. For example, several strategies have been reported that can support the participation of people with aphasia in research. ${ }^{63,64}$ In the current thesis, these as well as other strategies are explored to involve a variety of communication vulnerable clients.

Literature provides insights into the impact of client participation on the outcomes of research, but only a few studies describe the process of client involvement in detail. The experiences of junior researchers applying client participation in research are, so far, rather unexplored. There is a lack of understanding about how junior researchers experience the process of client participation in research, including what challenges they face, and what strategies are helpful for them. ${ }^{61}$ Such insights are needed to guide researchers in applying client participation in future research.

\section{Aim of the study and outline of the thesis}

Communication vulnerability can problematise the efforts of clients and professionals to talk about what really matters, to establish meaning together, and to create self-advocacy for clients in dialogue conversations.

The aim of this research is to explore how communication vulnerable clients and professionals experience their communication in dialogue conversations in long-term care and how they can best be supported in improving their communication in these conversations.

To achieve this, the following questions are addressed:

1. Which challenges do communication vulnerable clients and those in their social environment experience in their communication in dialogue conversations in the context of long-term care settings?

2. How can communication vulnerable clients and professionals together support their communication, using easily available ad hoc AAC, during dialogue conversations in long-term care settings?

3. How can researchers include (communication vulnerable) clients in research projects?

An exploratory research project was designed to answer these central research questions. To provide an answer to the first question, a first qualitative study was performed to investigate challenges that communication vulnerable clients and their social environment experience in communication (chapter 
2). Knowledge about experiences of these clients and factors that influence their experiences was needed, to provide insights into functional communication in long-term care settings.

A second qualitative study zoomed in on dialogue conversations between communication vulnerable clients and professionals (chapter $\mathbf{3}$ ). Both interviews and observations were used to gather insights about experiences in communication of clients and professionals during dialogue conversations in long-term care settings.

To provide insight into the available knowledge about communication support for dialogue conversations, two scoping reviews were conducted. This was done because, as was illustrated in figure 1 , in addition to the social environment of clients, the physical environment also plays an important role in communication. Although some research about the physical environment existed, an overview of factors in the physical environment that impact dialogue conversations with communication vulnerable people was needed. A scoping review was conducted about the physical environment (chapter 4), while a second scoping review studied one specific AAC tool: Talking Mats (chapter 5). As Talking Mats seemed to be a promising and accessible AAC tool for communication vulnerable people, an overview was needed about the effectiveness of this tool and about which clients it could be used for. Moreover, insights into the effective elements of Talking Mats could provide valuable insights for the implementation of other AAC tools.

In the study described in chapter 6, results of all above-mentioned studies and reviews were used to answer the second research question, by way of the development of a guide which facilitates professionals and communication vulnerable clients in selecting ad hoc usable AAC, to support their dialogue conversations. A user-centred design process was followed to iteratively develop the guide in collaboration with future users: communication vulnerable clients and professionals.

An important element of all studies in this thesis is client participation. To provide insight into the challenges and influencing factors that junior researchers encounter, a qualitative inquiry was conducted about experiences of junior researchers with client participation. Their experiences are described in chapter 7.

Chapter 8 finalises the thesis with a discussion of the main findings, methodological considerations, and lessons learnt. Furthermore, recommendations for future research as well as suggestions for the clinical application of the findings of this study are given.

* Note. The research team supports the use of people-first-language. However, to enhance the readability of this thesis we chose to use the term 'communication vulnerable people', instead of 'people who are communication vulnerable'. 


\section{References}

1. Light J, McNaughton D. Designing AAC Research and Intervention to Improve Outcomes for Individuals with Complex Communication Needs. Augment Altern Commun. 2015;31(2):1-12.

2. Shannon CE, Weaver W. The mathematical theory of communication. Urbana: University of Illinois Press; 1949.

3. The Joint Commission. Advancing effective communication, cultural competence, and patient and family centred care: A roadmap for hospitals. Oakbrook Terrace, IL; 2010.

4. Blackstone, Williams MB, Wilkins DP. Key principles underlying research and practice in AAC. Augment Altern Commun. 2007;23(3):191-203.

5. Lewin S, Skea Z, Entwistle VA, Zwarenstein M, Dick J. Interventions for providers to promote a patient-centred approach in clinical consultations. The Cochrane library. 2009(1).

6. Elwyn G, Frosch D, Thomson R, et al. Shared decision making: a model for clinical practice. J Gen Intern Med. 2012;27(10):1361-1367.

7. de Haes $\mathrm{H}$, Bensing J. Endpoints in medical communication research, proposing a framework of functions and outcomes. Patient Educ Couns. 2009;74(3):287-294.

8. Lawn S, Schoo A. Supporting self-management of chronic health conditions: common approaches. Patient Educ Couns. 2010;80(2):205-211.

9. Hemsley B, Balandin S. A metasynthesis of patient-provider communication in hospital for patients with severe communication disabilities: informing new translational research. Augment Altern Commun. 2014;30(4):329-343.

10. Bartlett G, Blais R, Tamblyn R, Clermont RJ, MacGibbon B. Impact of patient communication problems on the risk of preventable adverse events in acute care settings. CMAJ. 2008;178(12):1555-1562.

11. Pincus T, Holt N, Vogel S, et al. Cognitive and affective reassurance and patient outcomes in primary care: a systematic review. Pain. 2013;154(11):2407-2416.

12. Hoffman JM, Yorkston KM, Shumway-Cook A, Ciol MA, Dudgeon BJ, Chan L. Effect of communication disability on satisfaction with health care: a survey of medicare beneficiaries. Am J Speech Lang Pathol. 2005;14(3):221-228.

13. Joseph-Williams N, Elwyn G, Edwards A. Knowledge is not power for patients: a systematic review and thematic synthesis of patient-reported barriers and facilitators to shared decision making. Patient Educ Couns. 2014;94(3):291-309.

14. Wagner EH, Bennett SM, Austin BT, Greene SM, Schaefer JK, Vonkorff M. Finding common ground: patient-centeredness and evidence-based chronic illness care. J Altern Complement Med. 2005;11 Suppl 1:S7-15.

15. Elwyn G, Buetow S, Hibbard J, Wensing M. Measuring quality through performance. Respecting the subjective: quality measurement from the patient's perspective. BMJ. 2007;335(7628):1021-1022.

16. Bensing JM, Deveugele M, Moretti F, et al. How to make the medical consultation more successful from a patient's perspective? Tips for doctors and patients from lay people in the United Kingdom, Italy, Belgium and the Netherlands. Patient Educ Couns. 2011;84(3):287-293.

17. McGilton KS, Boscart V, Fox M, Sidani S, Rochon E, Sorin-Peters R. A systematic review of the effectiveness of communication interventions for health care providers caring for patients in residential care settings. Worldviews Evid Based Nurs. 2009;6(3):149-159.

18. Kurtz S, Silverman J, Draper J. Teaching and Learning Communication Skills in Medicine, Second Edition. Boca Raton: CRC Press; 2004.

19. Mazzi MA, Rimondini M, Deveugele M, et al. What do people appreciate in physicians' communication? An international study with focus groups using videotaped medical consultations. Health Expect. 2013;18(5):1215-1226.

20. Paternotte E, van Dulmen S, van der Lee N, Scherpbier AJ, Scheele F. Factors influencing intercultural doctor-patient communication: a realist review. Patient Educ Couns. 2015;98(4):420-445.

21. Makoul G. The SEGUE Framework for teaching and assessing communication skills. Patient Educ Couns. 2001;45(1):23-34.

22. CanMEDS Physician Competency Framework. 2015

23. Hemsley B, Sigafoos J, Balandin S, et al. Nursing the patient with severe communication impairment. J Adv Nurs. 2001;35(6):827-835 
24. Wylie K, McAllister L, Davidson B, Marshall J. Changing practice: implications of the World Report on Disability for responding to communication disability in under-served populations. Int J Speech Lang Pathol. 2013;15(1):1-13.

25. Dalemans R, Wade DT, van den Heuvel WJ, de Witte LP. Facilitating the participation of people with aphasia in research: a description of strategies. Clin Rehabil. 2009;23(10):948-959.

26. O'Halloran R, Hickson L, Worrall L. Environmental factors that influence communication between people with communication disability and their healthcare providers in hospital: a review of the literature within the International Classification of Functioning, Disability and Health (ICF) framework. Int J Lang Commun Disord. 2008;43(6):601-632.

27. O'Halloran R, Hickson L, Worrall L. Environmental factors that influence communication between people with communication disability and their healthcare providers in hospital: a review of the literature within the International Classification of Functioning, Disability and Health (ICF) framework. International Journal of Language \& Communication Disorders. 2008;43(6):601-632.

28. Blackstone S, Pressman H. Patient Communication in Health Care Settings: new Opportunities for Augmentative and Alternative Communication. Augment Altern Commun. 2016;32(1):69-79.

29. WHO. How to use the ICF. Available at.http://www.who.int/classifications/drafticfpracticalmanual2.pdf?ua=1

30. van Balkom H. Communicatie op eigen wijze. Leuven: Uitgeverij Acco; 2009.

31. Kielhofner G. Model of Human Occupation. Baltimore: Lippincott Williams \& Wilkins; 2008.

32. Blackstone S. Augmentative communication news. Augmentative communication. 2009;21(2):1-5.

33. Raghavendra P, Bornham J, Granlund M, Bjorck-Akesson E. The World health organziation's International classificiation of functioning disability and helath: Implications for clinical and research practice in the field of augmentative and alternative communication. Augmentative and Alternative Communication. 2007;23:349-361.

34. WorldHealthOrganization. International classification of functioning, disability and health: ICF. 2001.

35. Morris MA, Dudgeon BJ, Yorkston K. A qualitative study of adult AAC users' experiences communicating with medical providers. Disabil Rehabil Assist Technol. 2013;8(6):472-481.

36. Murphy J. Perceptions of communication between people with communication disability and general practice staff. Health Expectations. 2006(9):1-12.

37. Finke EH, Light J, Kitko L. A systematic review of the effectiveness of nurse communication with patients with complex communication needs with a focus on the use of augmentative and alternative communication. J Clin Nurs. 2008;17(16):2102-2115.

38. O'Halloran R, Lee YS, Rose M, Liamputtong P. Creating communicatively accessible healthcare environments: perceptions of speech-language pathologists. Int J Speech Lang Pathol. 2014;16(6):603-614.

39. O'Halloran R, Grohn B, Worrall L. Environmental Factors That Influence Communication for Patients With a Communication Disability in Acute Hospital Stroke Units: A Qualitative Metasynthesis. Arch Phys Med Rehabil. 2012;93(1):S77-85.

40. Blackstone SW, Beukelman DR, Yorkston KM. Building bridges to effective patient-provider communication. In: Blackstone SW, Beukelman DR, Yorkston KM, eds. Patient-provider communication:Roles of speech-language pathologists and other health care providers. San Diego, CA: Plural Publishing, Inc; 2015:1-8.

41. Dalemans R. Denken voorbij de stoornis: een participatiegerichte benadering. Logopedie en Foniatrie. 2009(12):380-383.

42. Levy-Storms L. Therapeutic communication training in long-term care institutions: recommendations for future research. Patient Educ Couns. 2008;73(1):8-21.

43. Kagan A. A-FROM in action at the Aphasia Institute. Semin Speech Lang. 2011;32(3):216-228.

44. Kagan A, LeBlanc K. Motivating for infrastructure change: toward a communicatively accessible, participation-based stroke care system for all those affected by aphasia. J Commun Disord. 2002;35(2):153-169.

45. Dalemans RJ, de Witte L, Wade D, van den Heuvel W. Social participation through the eyes of people with aphasia. Int J Lang Commun Disord. 2010;45(5):537-550.

46. Buntinx WHE, Schalock RL. Models of Disability, Quality of Life, and Individualized Supports: Implications for Professional Practice in Intellectual Disability. Journal of Policy and Practice in Intellectual Disabilities. 2010;7(4):283-294.

47. Fried-Oken M, Beukelman DR, Hux K. Current and future AAC research considerations for adults with acquired cognitive and communication impairments. Assist Technol. 2011;24(1):56-66.

48. Shane HC, Blackstone S, Vanderheiden G, Williams M, DeRuyter F. Using AAC technology to access the world. Assist Technol. 2011;24(1):3-13

49. Wallace T, Bradshaw A. Technologies and strategies for people with communication problems following brain injury or stroke. 
NeuroRehabilitation. 2011;28(3):199-209.

50. Fried-Oken M, Mooney A, Peters B. Supporting communication for patients with neurodegenerative disease. NeuroRehabilitation 2015;37(1):69-87.

51. Clarke M, Bloch S. AAC practices in everyday interaction. Augment Altern Commun. 2013;29(1):1-2.

52. McNaughton D, Light J. The iPad and mobile technology revolution: benefits and challenges for individuals who require augmentative and alternative communication. Augment Altern Commun. 2013;29(2):107-116.

53. Jacobs B, Drew R, Ogletree BT, Pierce K. Augmentative and Alternative Communication (AAC) for adults with severe aphasia: where we stand and how we can go further. Disabil Rehabil. 2004;26(21-22):1231-1240.

54. Light J, McNaughton D. The changing face of augmentative and alternative communication: past, present, and future challenges. Augmentative and Alternative Communication. 2012;28(4):197-204.

55. Ferm U, Sahlin A, Sundin L, Hartelius L. Using Talking Mats to support communication in persons with Huntington's Disease. Int J Lang Commun Disord. 2010;45(5):523-536.

56. Hallberg L, Mellgren E, Harelius L, Ferm U. Talking Mats in a discussion group for people with huntington's disease. Disabil Rehabil Assist Technol. 2013;8(1):67-76.

57. Cameron L, Watson J, Murphy J. Talking Mats: A focus group tool for people with learning disability. Communication Matters. 2004;18(1):33-35.

58. Murphy J. Talking Mats: A study of communication difficulties and the feasibility and effectiveness of a low-tech communication framework (PhD Thesis) Discussion, University of Stirling; 2009.

59. McGilton KS, Sorin-Peters R, Sidani S, Boscart V, Fox M, Rochon E. Patient-centred communication intervention study to evaluate nurse-patient interactions in complex continuing care. BMC Geriatr. 2012;12:61.

60. Crawford MJ, Rutter D, Manley C, et al. Systematic review of involving patients in the planning and development of health care. BMJ. 2002;325(7375):1263.

61. Staley K. Exploring Impact: Public Involvement in NHS, Public Health and Social Care Research. INVOLVE, Eastleigh. 2009.

62. Abma TA, Nierse CJ, Widdershoven GA. Patients as partners in responsive research: methodological notions for collaborations in mixed research teams. Qual Health Res. 2009;19(3):401-415.

63. Dalemans RJP. Stroke survivors with aphasia and their social participation Maastricht, Maastricht University; 2010.

64. Swinburn, K. Including People with Communication Disability in Stroke Research and Consultation. Connect Press. 2007. 



\section{Chapter 2}

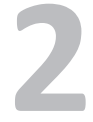

Challenges in the communication between communication vulnerable people and their social environment: an exploratory qualitative study 


\section{Abstract}

\section{Objective}

Communication vulnerable people are often unable to communicate effectively within their social environment, hindering client-centered care and participation in daily life. This study aims to explore the experiences of communication and the factors that influence this in long term care settings.

\section{Methods}

A qualitative study using the critical incident method. Communication vulnerable clients and people within their immediate environment were interviewed about their communication experiences.

\section{Results}

Thirty-nine individuals in three settings participated in the interviews, of which 14 were clients. Specific challenges in communication were presented in different relationships. The main influencing factors in the communication between clients and professionals were: effort put into improving the communication, knowledge of the professional, augmentative and alternative communication, time for communication and the influence and power of the client.

\section{Conclusion}

Communication vulnerable people and people within their immediate environment face daily challenges in communicating with each other. In particular, communication among clients, can be very difficult. Augmentative and alternative communication tools are only rarely used.

\section{Practice implications}

Professionals need to develop adequate knowledge and skills to improve their communication. Also, more attention should be focussed on use of AAC, communication between professionals and family members, and support in the communication among clients. 


\section{Introduction}

People who are communication vulnerable experience difficulties in communicative activities, which impact on their participation in social activities and on their role in the health care process. ${ }^{1}$ To provide a client centered health care process, effective communication with clients is extremely important. ${ }^{2,3}$ However, communication vulnerable people are not always able to communicate effectively and their disability creates a challenge for self-advocacy. ${ }^{4,5}$

Communication vulnerable people are defined as those who struggle to communicate in a particular environment. ${ }^{6}$ They experience difficulties in expressing their needs and/or in understanding information. Their primary disability may be communication, or their communication issues may be secondary to another disability. ${ }^{4}$ Limitations in any one of the several areas of functioning can lead to someone being classed as communication vulnerable; for example, those with sensory, emotional, physical and cognitive difficulties. ${ }^{1,7}$ Considering that any of these areas can impact upon communication, many people are probably not acknowledged as communication vulnerable. Wylie and colleagues, therefore, argue that communication vulnerable people may not be accurately represented in estimates of disability, due to the primary or secondary source of their disability. ${ }^{4}$

Apart from the influence of the communication difficulties on the involvement of communication vulnerable people in their own health care process, the difficulties also have a significant impact upon their communication during activities and participation in life. The framework of the International Classification of Functioning, Disability and Health (ICF) ${ }^{8}$ can be used to explore the participation of communication vulnerable people in their daily lives. ${ }^{9}$ According to this framework, communication during activities and levels of participation, is not only influenced by a person's communication related impairments (body functions and structures), but also by the personal and environmental factors. The environment can be divided into physical and social environment. In this study the emphasis is on the immediate social environment. "Immediate environment" refers to the micro-level, encompassing the social interaction systems in which a person takes part, e.g. with family, friends, colleagues, health care professionals, other clients, etc. ${ }^{10}$

This study will focus on the communication between communication vulnerable people staying in long term care settings and people within their immediate social environment. In long term care settings, care professionals are an important part of a client's immediate social environment. They aim to facilitate their clients' participation in life by providing client-centered care. This is, however, a challenge when effective communication is not evident, and communication problems between care professionals and communication vulnerable clients are commonly reported. ${ }^{11,12}$

Insights into the experiences of communication within the immediate social environment of clients staying in long term care settings, and the factors that influence this communication are necessary. 
These insights are needed to enable clients and people within their environment to communicate more successfully, with the ultimate aim of better participation in daily life and more opportunities for self-advocacy in clients' health care process.

Therefore, the aim of this study was to explore experiences of communication between communication vulnerable people staying in long term care settings and people within their immediate social environment, and the factors that influence this communication.

\section{Method}

A qualitative study was performed, using interviews guided by the critical incident method. ${ }^{13}$

\section{Setting and participants}

To ensure the collection of a rich dataset from a heterogenic sample, three different care institutions were asked to participate in the study: a long term care setting for people with brain injuries, a care center for people with dementia, and a rehabilitation unit for people with neurological disorders. During earlier network meetings, the speech and language pathologists and managers of these institutions indicated that they wanted to improve the communication in their institution. Of the first-mentioned organization, five representative sites (of the 40) were included in this study. These were selected by the management as representative of that particular institution. The factors used in this decision were: variation in geographical location, size, type of setting, and medical conditions of clients.

A purposive sampling procedure was used to select participants in these institutions. In each setting, two clients (with optional family member), two professionals (nurses or daily activity supervisors), the manager, and the speech and language pathologists (varying from 1 to 3 ) were invited to take part in an interview.

The professionals were selected by their managers. Clients were selected who, according to the professionals who knew them, had communication difficulties, but would be able to express themselves verbally during an interview. The clients could each choose whether a family member was present during their own interview, was invited for a separate interview, or was not invited at all. All those selected were approached by the speech and language pathologist working in that institution. Those who agreed verbally to participate, received a letter describing the study. Thereafter, the researchers (SS, RD) contacted them to explain the goal and setting of the study and to make an appointment for the interview. 


\section{Data collection}

Each interview was conducted by two trained interviewers in a private room in the care institution. The interviewers were researchers with experience in interviewing communication vulnerable people, had different professional backgrounds - occupational therapist, physiotherapist, speech and language pathologist - and were not working in the participating care institutions. During the interviews one interviewer was asking the questions, the second observed and documented non-verbal behavior, and was particularly vigilant to non-verbal signs that indicated misunderstandings by the participant during the interview.

The critical incident method was used to guide the interviews. The interviewer began by asking the participant to describe one or more critical incidents he or she had experienced or observed concerning effective or non-effective communication. Each response was probed for more in-depth information about what had contributed and what could have been done differently. The questions were adapted for each participant (Appendix 1: Interview Guide). Researchers used facilitating strategies such as: paraphrasing, speaking slowly, allowing sufficient time to answer the question, providing visual images and using pen and paper. ${ }^{14}$

\section{Data analysis}

The interviews were audiotaped and transcribed verbatim. The transcripts were analyzed by data driven coding. One researcher read and re-read the interviews and selected text fragments that characterized, clarified or explained aspects of communication. Thereafter, the fragments were coded as critical incidents. During this process, it appeared that participants experienced the critical incidents in three different relationships: communication between clients and professionals, among clients, and between family members of clients and professionals. To stay close to this data, the further data analysis was performed for each of these relationships. The critical incidents of the three different relationships were grouped around a common theme, per relationship. From these themes the researcher analyzed which factors, emerging from the critical incidents, influenced these experiences. Each step of this process was verified with two other researchers. Any disagreements were discussed between the researchers until consensus was reached.

During a focus group meeting, the experiences and factors emerging from the data were anonymously presented to all of the participants within one care institution, as a member-check. The participants were invited to react to the data set, and possible misconceptions were amended. Several strategies were used to make the presentation accessible to the clients, for example: the use of pictograms in the presentation, a clear structure with central topics, clear conversation rules such as one speaker at a time, a quiet environment, and enough time breaks. 


\section{Ethical considerations}

The research was approved by the local Human Research Ethics Board of Atrium Medical Center, Orbis Medical Center and Zuyd University of Applied Sciences (Heerlen, The Netherlands). All participants gave written consent for the interviews to be audio-taped. For the clients the informed consent was made communication friendly. ${ }^{14}$ (Appendix 2: informed consent).

\section{Results}

In total, 39 individuals participated in the interviews, Fig. 2.1 gives an overview of these research participants. Table 1 presents information about the clients who participated in the interviews. Five clients had aphasia, and the remainder had other impairments which substantially influenced their communication. The interviews each lasted between $45 \mathrm{~min}$ and $1.5 \mathrm{~h}$. 


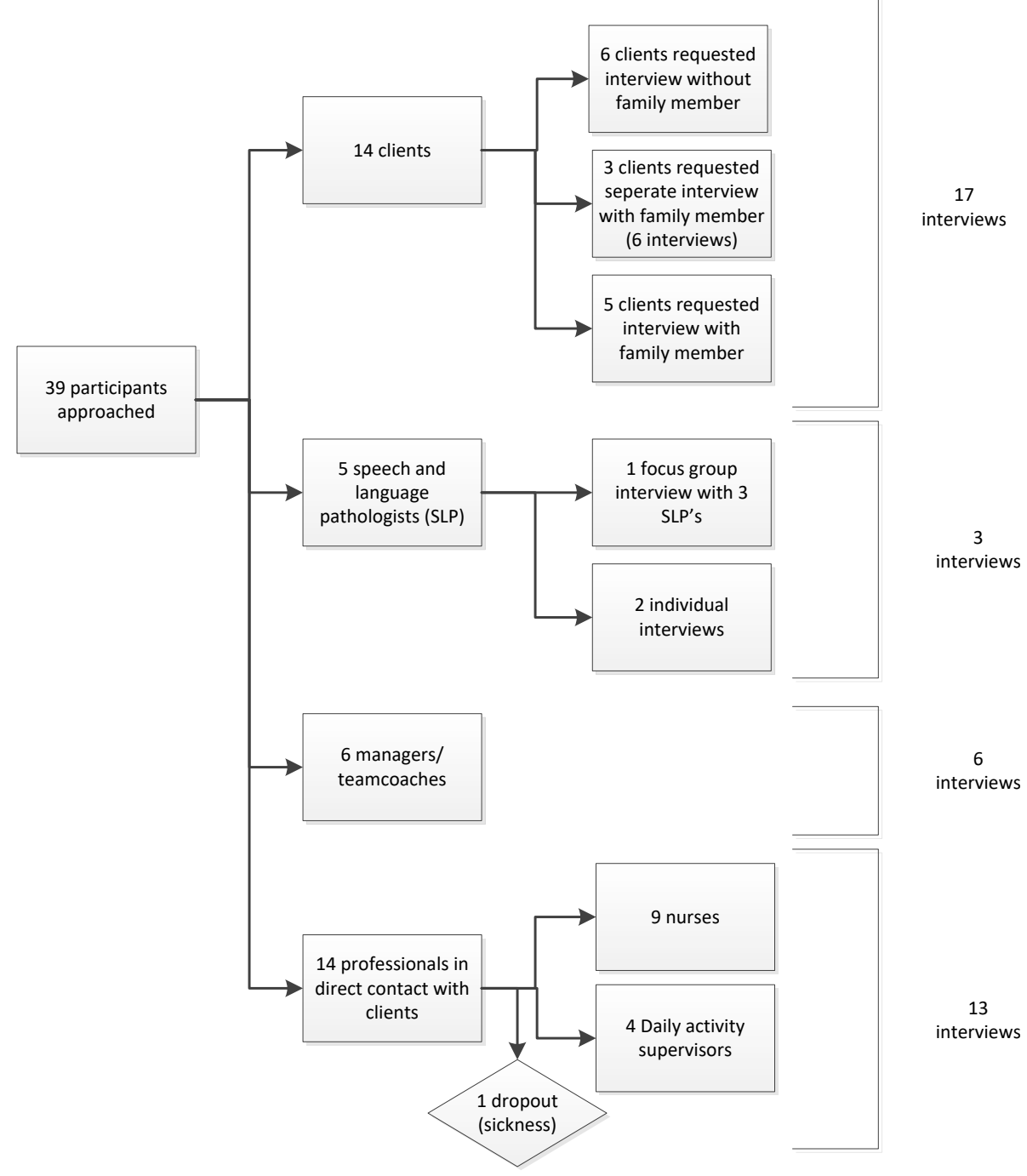

Figure 2.1 Description of the research participants. 
Table 2.1 Characteristics of the clients participating in the interviews.

\begin{tabular}{lll}
\hline Gender & Age & Diagnoses of clients \\
\hline Male & 90 & Dementia, hearing impairment \\
70 & Aphasia, dysarthria, visual impairments, hearing impairment \\
67 & Aphasia and dysarthria \\
60 & CVA, aphasia \\
56 & CVA, information processing problems \\
53 & CVA, amnesia \\
45 & Visual impairments, information processing problems \\
& 45 & Cerebral Palsy, cognitive impairments \\
& 24 & Cerebral Palsy, cognitive impairments \\
& 85 & Dementia, hearing impairment \\
70 & CVA, amnesia, aphasia \\
67 & CVA, aphasia \\
56 & CVA, information processing problems \\
53 & Acquired Brain injury, cognitive impairments \\
\hline
\end{tabular}

In this section, two prominent critical incidents will be described to give a sense of the situations communication vulnerable people and people within their immediate environment experienced.

Critical incident: Anna, who has aphasia and suffers from memory problems, described the communication with another client (she cannot remember her name) who has severe aphasia. She explained that the client herself has a lot of perseverance to communicate, but also the personnel and Anna are motivated to communicate with her.

Anna (client: stroke, amnesia, aphasia): "She always says 'jikwik' and then another client says 'what's up'?, 'jikwik!!' (...) Well and then she only points to what she wants, and she bravely goes on until you understand her. It is wonderful to see! And everybody does their best to understand what she wants."

Critical incident: The wife of Charles explained that, in the first period after her husband had had a stroke and as a consequence aphasia, the communication between him and the professionals at the institution was extremely difficult. She and her husband felt that the professionals did not try to communicate with him because they had the assumption that he would not understand them, and they would not understand him.

Partner of Charles (client: stroke, aphasia) : "It was so bad, that they thought, he didn't function normally. That he couldn't think normally and everything. And that took a long time. So they didn't try at all in the beginning. (..) I had the feeling that they thought 'he doesn't understand us anyway'."

Charles (client: stroke, aphasia): "And there was one nurse, she just went to, then she went to ask 
there and then she came back and then she knew... I thought that was very stupid. A very difficult situation. Yeah, because I wanted to tell her directly, but, honestly, that wasn't possible for me."

Despite positive and negative experiences, all participants described experiencing difficulties adjusting their communication to the needs of communication vulnerable clients.

As discussed in the method section, the participants described their experiences of three social relationships: communication between clients and professionals, communication among clients, and between family members of clients and professionals. Therefore, in the next section the factors influencing communication will be presented as regards such social relationship (Fig. 2). Critical incidents and citations are added to give insight into the situations people experienced.

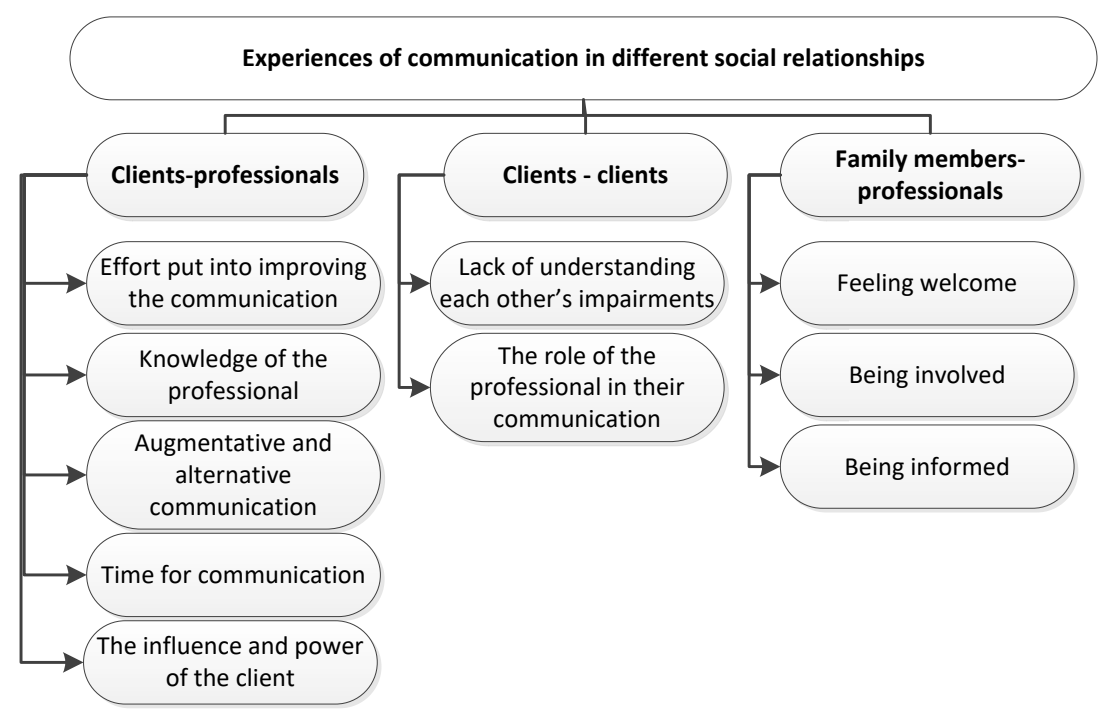

Figure 2.2 Experiences of communication in different relationships.

\section{Communication between clients and professionals}

Five main factors that influenced the communication between clients and professionals emerged from the experiences of the participants: effort put into improving communication, knowledge of the professional, use of augmentative and alternative communication, time for communication, and the influence and power of the client. 


\section{Effort put into improving communication}

Several participants reported that it is extremely important to have an inner drive to communicate effectively with a person who has difficulties communicating, and to adjust your communication to the abilities of this person. A nurse explains this in the next critical incident.

Critical incident: Brenda, a nurse, explained that she is motivated to communicate with clients who have communication difficulties. However, it is difficult for her and she gets frustrated when she and the client do not understand each other.

Brenda (nurse): "well, that's disappointing. You could say like: you just ask short questions and let them answer, but in practice it isn't that easy. You just don't get a 'yes' or 'no'. It's more difficult than you'd expect."

The nurses and daily activity supervisors themselves reported taking initiatives to solve communication issues with clients. They, for example, contacted a colleague or a family member of the client to discuss the preferred actions to be taken. However, one manager described that more initiative to discuss communication problems with clients is preferred.

Mark (manager): "I think that the professionals are on the right track, I just think that I hear too little in the team meetings, like, 'this is what I find difficult', or 'I notice that the communication with that client, is not going as I would like it to be."

Apart from some positive aspects, the experiences mostly represented situations in which the professionals did not try hard enough to improve their communication with clients. As illustrated in the next citation, clients felt that professionals often quickly guessed their message instead of trying to understand them.

Betty (client: acquired brain injury, cognitive impairments and difficulties articulating): "Then they don't understand me and guess something. But then it doesn't make sense at all."

The speech and language pathologists described that the professionals in the institutions were stubborn and refused to act on advice to improve the communication.

Paulette (speech and language pathologist): "That some professionals are stubborn, knowing it better and not thinking about it. That you made agreements and 'oh yeah but that isn't necessary', (...) or "I have known her for so long I don't need a communication aid'."

The professionals also acknowledged that communication was not always on their mind/agenda. They found it important, but when distracted or enthusiastically involved in their work, they forgot to pay attention to the different communication needs while interacting with clients. 


\section{Knowledge of the professional}

Knowledge is a key to good communication; having knowledge of the illness of the client and how it affects communication as well as knowing the client is essential for good communication.

The participants experienced that some employees of the care institutions did not have enough knowledge about the illnesses or were not sufficiently aware how the illness of clients could influence communication. This is explained in the next critical incident by a speech and language pathologist.

Critical incident: Kate, a speech and language pathologist explains that different staff members do not have enough knowledge about communication difficulties; for example, nurses and physiotherapists, but also the in-house hairdresser. The communication difficulties are often misinterpreted as a lack of cognitive skills.

Kate (speech and language pathologist): "Judging the cognitive skills of a client, based on his poor speaking. People can be called insane, if they speak a little strange, and will be treated that way.(...) I walked with Mister H. to the hairdresser, and he doesn't speak that well. The hairdresser acts like 'what does he want, what time does he want to come, I don't understand him' (over articulating and speaking very loudly). But he does understand everything, he just has dysarthria."

The nurses and daily activity supervisors did not have enough knowledge about the relationship between frustration in communicating and aggressive behavior. The father of Johan and a speech and language pathologist provide an example of their experience in this matter.

Father of Johan (client: Cerebral Palsy, cognitive impairments): "For instance, bingo. Johan calls us crying 'I cannot participate anymore because I had the number but I saw it too late and then everything was over' (...)The staff said 'now your chance is over'. He throws everything off the table then. The staff do not know how to cope with it. Why not write the numbers down so that everybody can see them."

Becky (speech and language pathologist): "For example, someone who gets that cup of coffee three weeks every day, and can't say 'I want tea'. Then they get angry and throw that cup of coffee on the floor! Then they are referred to the psychologists, because he is aggressive..."

Knowing the client was described as an important factor positively influencing the communication. Clara, a nurse, explains in the next example that she can better understand clients she has seen for a couple of days. However, as evident in the story of Paulette earlier, knowing the client can also be overrated, and lead to the situation that nurses think they do not need advice to improve the communication.

Clara (nurse): "For example, Miss H., yes, her speech is difficult to understand and not really in whole 
sentences, but then she says words between it. But if you have cared for her a couple of days, then you can notice, like, what she means. (...) if you know her better, then you think yeah, you understand her better what she is saying."

\section{Augmentative and alternative communication and supporting communication aids}

The participants talked about tools that could support communication. We use the universal term AAC to describe a huge range of techniques that support or replace communication, such as symbols, word boards, books and voice output communication aids. ${ }^{15}$ Supporting communication aids could be, for example, hearing aids.

Critical incident: Paulette, a speech and language pathologist, explains that nurses do not always see the potential of augmentative and alternative communication aids and, therefore, do not support clients to use it. The day before the interview, she went to a lady who had trouble communicating.

Earlier, she advised a technological communication tool and, while practicing, noticed that this lady was able to use the tool which helped her communicate. To her surprise the tool was put into a closet and the battery was not charged. The nurse said 'we don't need that thing, we know what Miss $X$ wants, her world is very small so we can do without the tool.' Paulette explains that she finds this very disappointing and does not know how to get the nurses to use it.

As in the example, speech and language pathologists explained that tools were available, but often neither used nor maintained.

Paulette (speech and language pathologist): The personnel are sometimes stubborn, think they know it better, or just don't think about it or notice it. (...) Like a communication card, then they say 'it takes too long', but I don't understand what exactly takes too long"

Christine (speech and language pathologist): "I noticed that there are people who have two hearing aids, both not working, two empty batteries. Yeah and then we talk about difficulties in communication, just start with checking the batteries!"

Overall, participants explained that few augmentative and alternative communication (AAC) tools and supporting communication tools were adequately used to improve communication. The nurses and daily activity supervisors stated that they did not have enough knowledge about which tools were available, or which tools could be helpful for clients, as illustrated by Brenda.

Brenda (nurse): "I never looked into it, but maybe a form with some symbols would be helpful for this person, but I don't know if that would be helpful. (...) On the department those (communication aids) are not used a lot, at least not since I work here." 


\section{Time for communication}

Professionals indicated that there is often a time constraint in their work. Their limited time prevented them from talking to clients, getting to know clients, and applying communication advice. They also found it difficult to divide their time between communicating with clients, and doing administrative work and care tasks.

Amy (daily activity supervisor): "That's maybe a good example, I have had for three weeks, maybe four, a new client, I am the contact person. He doesn't know it yet. I didn't have the time yet. But that is also someone who I have difficulty communicating with. I have to take the time to sit with him in a quiet situation. We don't have time. There are a lot of sick personnel. I can't whisper in his ear: 'I am your new contact person and we will chat sometime soon'. That's not good, it doesn't feel good. Today I also don't have time for it. (...) I am really embarrassed for it."

However, clients felt that some professionals, did take their time to talk to them, as described by Anna.

Anna (client: stroke, amnesia, aphasia): "People who talk badly, they take time to listen to them, for example our Emma from the kitchen, she is really good at that."]

Both professionals and clients remarked that clients who did not need much medical help or did not take the initiative, tended to receive less attention and were given less time for a chat with the professionals.

Amanda (client: stroke, cognitive impairments): "People who are still quite independent get less attention. Certain people demand the attention of the nurse, (...) you shouldn't demand too much attention from others, but other people here do so."

Helen (nurse): "There are some who shout the loudest, they always have priority. Those who never ask something are really forgotten, it is really like that."

\section{The influence and power of the client}

Not only the characteristics of professionals influenced communication, clients also played an important role in adjusting communication to their own needs and impairments. The participants explained that a client's character influences communication; in particular, taking the initiative and daring to express feelings rather than being a calm or shy person.

Some described how clients took the initiative to write something down, asked someone to draw something for them or repeat the information. Some clients, as in the first critical incident of this chapter, reported great perseverance. Brian also explains how he asks other people to adjust their communication to his personal capabilities.

Brian (client, severe visual impairment, information processing problems): "Then I say 'say that 
again, repeat it please' (...) Because of my brain damage I hear it, but I have to store the information and that doesn't always go very well. (...)They shouldn't talk very fast to me. Because then I say ho, ho, wait a minute!"

\section{Communication among clients}

The second communication relationship the participants talked about, was communication among clients. The amount and nature of communication among clients varied, but overall the communication among them was described as difficult and poor. The main factors influencing the communication in this relationship were the lack of understanding of each other's impairments, and the role of the professional in their communication.

First of all, while the professionals have the opportunity to read about the illness or needs of clients in their files, peer clients do not have this information. Consequently, they do not have the opportunity to adjust their communication to the specific needs. Secondly, some disorders affect people's ability to understand illnesses and communication difficulties of other clients. This results in clients not being able to understand each other and to adjust their communication for each other, which hinders their relationships. And thirdly, some disorders affect people's ability to have empathy. The following experiences of different participants describe these factors.

Brian (client: severe visual impairment, information processing problems): "When I'm alone with someone with a speech problem and I have to listen to him, then I have to say a lot 'can you say that again'. Because I hear some noise or something. And sometimes those people, they get agitated of course. That's too bad, but I don't always hear what they are saying."

Daughter of Annabel (client: dementia, hearing impairment) : "and then she (client) says "I get nervous from it, he mustn't be here'. And yeah, then she also begins swearing, something that doesn't fit with my mother's character (..) and then I say 'that man is ill too,', 'he is not ill!!', you know..."

Kitty (daily activity supervisor): "There is so much difference (...) yeah you notice that persons, that they yeah are annoyed by the persons with less cognitive capabilities. They feel like they are better than the other persons and say like 'I have told this three times now, do they still not get it?' Yeah no, they really do not get it.(...) They don't accept each other the way they should (...) I think we cannot do a whole lot about this."

Both clients and professionals described that professionals often intervened to enhance the communication between clients or to avoid conflicts between them. Some clients appreciated the professionals' interventions and some did not. Anna explains that she thinks professionals only 
intervene when necessary.

Anna (client: stroke, amnesia, aphasia): "Yeah just like in normal life, it happens that you just don't like another person, and a conflict can occur (...) If they see it is necessary they intervene, but they let them solve it themselves first."

Professionals could also intervene to improve the contact between clients; an intervention that was described several times is the table arrangement. Furthermore, one family member mentioned that the professionals did not provide enough opportunities for the clients to meet other people outside the institution.

Mother of Johan (client: Cerebral Palsy, cognitive impairments): "Also, for example, the search for a girl-friend for him, provide opportunities! For example, he got an invitation for a birthday party, but we were on holiday, Johan couldn't go because the professionals didn't have time to arrange it."

\section{Communication between family members of clients and professionals}

The third relationship the participants described was the communication between family members and professionals. The critical incidents in this communication represented very positive but also very negative experiences. Factors that influenced these experiences were: whether one felt welcome, was involved and informed.

Critical incident: The daughter of John does not feel welcome at the institution where her father lives, an institution for people with acquired brain injuries. She wants to be involved in his life and in decisions about his care in the institution, but she feels that this is not appreciated by the professionals.

Daughter of John (client: stroke, information processing problems): "The whole team sees me as a bogeyman; according to them my engagement is exceptional." ]

The negative experiences of family members were mostly described in terms of 'not feeling welcome' and 'not being involved'. The partner of Peter and the mother of Johan describe these feelings.

Mother of Johan (client: Cerebral Palsy, cognitive impairments) : "Also towards us, they just ignore us 'there she is again!' (relating to the thoughts of a nurse)."

Partner of Peter (client: aphasia, dysarthria, visual impairments, hearing impairment) : "They don't talk a lot with family members, sometimes with a note. This can be better. They should involve us more."

However, family members also describe very positive experiences in their communication with 
professionals. These positive experiences were mostly linked to receiving support from the professionals and being given enough information. The daughter of Annabel feels involved and appreciates the initiatives of the professionals to help her communicate with her mother.

Daughter of Annabel(client: dementia, hearing impairment): "At the beginning I didn't know how to cope with it (...) So I was constantly in conflict with my mother, because I didn't realize she, yeah, had early stages of dementia. Yes and with help from here, from the personnel, they really, yes, that I could accept it, and that I could get along with my mother again."

Daughter of Henry (client: dementia, hearing impairment): "But even the smallest thing, then they call me and say 'listen, don't get startled, nothing happened but."'

\section{Discussion and conclusion}

\section{Discussion}

This study explored the experiences of clients, family members and professionals, concerning their communication with communication vulnerable people in long term care settings. From these experiences several factors emerged that influenced the communication within three types of social relationships in the immediate social environment of the clients. The communication, in these social relationships in long term care settings, was often experienced as difficult.

Of these three social relationships, we found two social relationships that were very important for communication vulnerable people in long term care settings and often do not receive a lot of attention: the communication amongst communication vulnerable people, and between family members and professionals. The communication in these relationships was perceived as important and often experienced as both challenging and difficult. Other research has often focused primarily on communication between professionals and clients, ${ }^{2,16-18}$ or between clients and their social environment at home. ${ }^{17,19,20}$

Within the communication between professionals and family members, family members found it important to feel welcome, involved and informed. Professionals should be more aware of these needs of family members, as the presence of family is found to be a facilitating factor in communication. ${ }^{18}$ Also, the communication amongst clients should receive more attention in daily practice and in communication research. Factors that prevented them from communicating effectively were: the lack of information about each other's communication impairments and needs, understanding these and not always being able to have empathy for each other. 
Apart from these two relationships, the communication between clients and professionals was also experienced as an important relationship in the immediate social environment. Factors that seem to influence communication between clients and professionals are: effort put into improving communication, knowledge of the professional, the use of augmentative and alternative communication, time for communication, and the influence and power of the client. As described hereafter these factors are in line with other research.

We found that professional attributes impact communication, such as motivation to improve communication and knowledge about communication vulnerability. Other studies have described similar professional attributes or communication partners' attributes that have impact on the communication with communication vulnerable people, such as skills, knowledge of communication related impairments, individual characteristics and attitudes. ${ }^{17,19}$ Professionals' attitudes, including respect for the client, are essential for successful communication. ${ }^{18,21-23}$ From our study it appeared that professionals were frequently found to lack awareness and knowledge of communication vulnerability. This finding is supported by $\mathrm{O}^{\prime} \mathrm{Halloran}$ et al., ${ }^{18}$ who suggested that professionals are not always aware that different impairments can make clients communication vulnerable.

Moreover, participants in our research emphasized the importance of knowing clients personally. Such knowledge could help professionals to empower clients in their communication and support shared decisions and client centered care.

Apart from professionals' attributes, our study found that the characteristics of clients also have a large influence on their communication. Especially taking initiative to communicate and expressing feelings about their communication needs, facilitated their communication. Dalemans similarly identified the influence and power of the client as a factor that can influence communication. ${ }^{19}$

Although augmentative and alternative communication strategies and techniques offer the potential to improve the quality of life of communication vulnerable people, ${ }^{6}$ our research exposed that in these long term care settings AAC was used infrequently. This situation has been highlighted by Blackstone ${ }^{6}$ who, suggests that, available solutions are, as yet used too rarely to offer maximum benefit to patients and their healthcare outcomes. Blackstone described six principles of AAC that promote effective use of AAC: (1) the active participation of communication vulnerable people, (2) grounded theoretical constructs for use of AAC, (3) use of ergonomics in the design and development, (4) the importance of communication partners in the use of AAC, (5) focus on societal roles and relationships and (6) measuring AAC outcomes. ${ }^{6}$ From the experiences in our study, it appeared especially important to involve professionals and peer clients as communication partners (4) in the use of AAC. Therefore theoretical constructs (2) should enable professionals (such as nurses) to understand the meaning and importance of AAC use. 


\section{Methodological considerations}

The critical incident method yielded the depth of information, whilst the diversity of settings and participants resulted in a wide range of experiences.

Clients were selected and approached to participate by the professionals who knew them. This may have biased the findings, as they could select clients who were in general very positive or very critical. Furthermore, although the informed consent form stated that answers would be anonymous and would not influence delivery of care, some clients might have been reluctant to divulge negative experiences related to professionals. This could have led to a falsely positive impression. Several family members encouraged clients to have confidence in the interviewer and to share their negative as well as positive experiences.

Because interviews were used to collect the data, clients who were unable to express themselves verbally were not included. It would be interesting to also gather their experiences. Additional AAC strategies could be used to enable these clients to express themselves in future research. One such is the Talking Mats framework, this framework could be used to include people with severe communication difficulties in research. ${ }^{24}$

No measurement instrument was used to rate the communication vulnerability of clients because we did not focus on the relationship between the nature of the communication disability and the experiences. We used a broad definition of the term 'communication vulnerability', therefore, many clients in long term care settings could rightly be considered as communication vulnerable. Furthermore, three of the interviewers were speech and language pathologists and could use their professional skill to judge whether the client was indeed communication vulnerable.

In this study, we were interested in how the people experienced the communication and, therefore, used interviews instead of for example observations. Due to the use of the critical incident technique, people were asked to indicate good and bad incidents retrospectively. For people with communication problems (who sometimes also have memory problems), the critical incidents might not be an exact representation of the real life situation. However, the way the participants remember incidents shapes their feelings about communication. Personal bias was limited by using different interviewers with different backgrounds, two interviewers per interview, and by ensuring a consensus between the researchers during the data analysis.

The communication between clients and their family members did not emerge as a theme, possibly because they were often interviewed simultaneously. Furthermore, it may appear that the social networks of the clients were limited to their family member, the professionals and fellow clients at each institution. This may not accurately reflect their situation; it would be interesting to investigate, in future research, whether the social networks of people living in long term care institutions are really so small, whether clients are satisfied with this, or whether they desire a more heterogeneous social network. 


\section{Conclusion}

Communication vulnerable people and those in their environment face daily challenges in their communication. Professionals need to develop adequate attitudes, awareness, knowledge and skills to improve their communication with clients and to be confident in using appropriate communication strategies. In addition, more attention should be directed toward the use of augmentative and alternative communication. AAC tools and techniques are currently used infrequently and inadequately, but offer the potential for significantly improving communication. The communication among clients, requires more attention as they are part of each other's social environment and communication between them is experienced as difficult. Family members want to work together with professionals, but are often not included, uninformed and are made to feel unwelcome.

\section{Practice implications}

Professionals need targeted training to equip them with the right awareness, skills and tools to

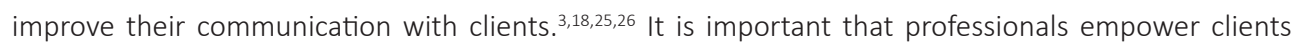
to find solutions to their communication problems, as the clients themselves are an important factor influencing the communication process. Professionals should also be provided with information about which augmentative and alternative communication tools there are and how to use these tools. Implementation of broadly applicable augmentative and alternative communication tools in long term care settings is, therefore, desirable.

Furthermore, professionals should put more effort in getting to know the clients: knowing them as a person, knowing their communication impairments and their communicative needs/wishes. Clients have to be screened for communication-influencing impairments to alert professionals and enable them to adjust their communication. ${ }^{18}$

Strategies should focus on empowering clients to communicate with other clients in their immediate social environment. Some professionals suggested that the table arrangements could positively influence communication between clients.

However, this is only a small strategy, more research should be done on, what clients wish and need to communicate with each other, and how these needs could be realized. Strategies to improve the communication and relationship amongst clients might be: getting to know each other's life history and values, informing each other about communication needs and problems, learning how to communicate with each other, and learning to use each other's AAC tools.

Professionals should also focus on involving the family members of clients and giving them the opportunity to play a more central role in the care process. For this reason, it is necessary to ask family 
members how they want to be involved, and how often and in what way they would like to communicate with professionals. The Family Needs Questionnaire, a self-report questionnaire originally developed to measure family members' perceived needs after the brain injury of a client, might be appropriate. ${ }^{27}$ 


\section{References}

1. Verdonschot M, de Witte LP, Reichrath E, Buntinx WH, and Curfs LM. Impact of environmental factors on community participation of persons with an intellectual disability: a systematic review. J Intellect Disabil Res 2009; 53: pp. 54-64.

2. Wynia MK. Making it easier to do the right thing: a modern communication QI agenda. Patient Educ Couns 2012; 88: pp. 364-366.

3. Lagacé M, Tanguay A, Lavallée M, Laplante J, and Robichaud S. The silent impact of ageist communication in long term care facilities: elders perspectives on quality of life and coping strategies. J Aging Stud 2012; 26: pp. 335-342.

4. Wylie K, McAllister L, Davidson B, and Marshall J. Changing practice: implications of the World Report on Disability for responding to communication disability in under-served populations. Int J Speech Lang Pathol 2013; 15: pp. 1-13.

5. Hedberg B, Johanson $M$, and Cederborg AC. Communicating stroke survivors' health and further needs for support in care-planning meetings. J Clin Nurs 2008; 17: pp. 1481-1491.

6. Blackstone SW. Augmentative communication news. Augmentative Communication 2009; 21: pp. 1-5.

7. Yorkston KM, Bourgeois MS, and Baylor CR. Communication and aging. Phys Med Rehabil Clin N Am 2010; 21: pp. 309-319.

8. WHO : World Health Organization, ICF.

9. Dalemans RJP, de Witte L, van den Heuvel W, and Wade D. A description of social participation in working age people with aphasia: a review of the literature. Aphasiology 2008; 22: pp. 1071-1091.

10. Stucki G, Cieza A, and Melvin J. The International Classification of Functioning, Disability and Health (ICF): a unifying model for the conceptual description of the rehabilitation strategy. J Rehabil Med 2007; 39: pp. 279-285.

11. Lewin S, Skea Z, Entwistle VA, Zwarenstein M, and Dick J. Interventions for providers to promote a patient-centred approach in clinical consultations. The Cochrane Library, 2009. pp. 1.

12. Finke EH, Light J, and Kitko L. A systematic review of the effectiveness of nurse communication with patients with complex communication needs with a focus on the use of augmentative and alternative communication. J Clin Nurs 2008; 17: pp. 2102-2115

13. Redfern S, and Norman I. Quality of nursing care perceived by patients and their nurses: an application of the critical incident technique. Part 1. J Clin Nurs 1999; 8: pp. 407-413.

14. Dalemans R, Wade DT, van den Heuvel WJ, and de Witte LP: Facilitating the participation of people with aphasia in research: a description of strategies. Clin Rehabil 2009; 23: pp. 948-959.

15. Communication Matters. Available at: https://www.communicationmatters.org.uk/page/what-is-aac

16. Levy-Storms L. Therapeutic communication training in long-term care institutions: recommendations for future research. Patient Educ Couns 2008; 73: pp. 8-21.

17. Howe TJ, Worrall LE, and Hickson LMH. What is an aphasia-friendly environment. Aphasiology 2004; 18: pp. 1015-1037.

18. O'Halloran R, Worrall L, and Hickson L. Environmental factors that influence communication between patients and their healthcare providers in acute hospital stroke units: an observational study. Int J Lang Commun Disord 2011; 46: pp. 30-47.

19. Dalemans RJ, de Witte L, Wade D, and van den Heuvel W. Social participation through the eyes of people with aphasia. Int J Lang Commun Disord 2010; 45: pp. 537-550.

20. Johansson MB, Carlsson M, and Sonnander K. Communication difficulties and the use of communication strategies: from the perspective of individuals with aphasia. Int J Lang Commun Disord 2012; 47: pp. 144-155.

21. Cottrell S, and Davies A. Supporting conversation, providing information. R Coll Speech Lang Therap Bull 2004; 630: pp. $12-13$.

22. Cumella S, and Martin D. Secondary healthcare and learning disability. J Learn Disabil 2004; 8: pp. 30-40.

23. Lezzoni LI, O'Day B., Killeen M, and Harker H. Communicating about health care: observations from persons who are deaf or hard of hearing. Ann Intern Med 2004; 140: pp. 356-362.

24. Hubbard G, Downs MG, and Tester S: Including older people with dementia in research: challenges and strategies. Aging Ment Health 2003; 7: pp. 351-362.

25. Hemsley B, Sigafoos J, Balandin S, Forbes R, Taylor C, Green VA, et al: Nursing the patient with severe communication impairment. J Adv Nurs 2001; 35: pp. 827-835.

26. Burgio LD, Allen-Burge R, Rith DL, Bourgeois MS, Dijkstra K, Gerstle J, et al: Come talk with me: improving communication between nursing assistants and nursing home residents during care routines. Gerontologist 2000; 41: pp. 449-460.

27. Kreutzer JS. Family needs questionnaire. Richmond, VA: Rehabilitation Research and Training Center on Severe Traumatic Brain Injury, Medical College of Virginia, 1998. 


\section{Appendix 1 Interview Guides}

\section{Interview with a client}

\section{Critical incidents}

Can you give an example in which communication went well?

- What was the reason for this?/What helps?

Can you give an example in which communication did not go well?

- What was the reason for this?/What made it so difficult?

\section{Additional questions}

What kind of problems do you experience in communication?

When you consider professionals:

- What kind of behaviour of the professionals helps you in communicating?

- What kind of behaviour of the professionals makes communicating difficult for you?

What within the situation makes it possible or difficult to know:

- what is going on

- what you are able to do

- How to make yourself clear to others

- what is important information for you

When you consider yourself:

- When do you find it difficult to communicate?

- When do you find it easy to communicate?

- How do the professionals cope with your difficulty to communicate?

\section{Interview with family members}

The following questions were asked about the communication between the client and his or her environment and between the family member and the professionals.

\section{Critical incidents}

Can you give an example in which communication went well?

- What was the reason for this?/What helps?

Can you give an example in which communication did not go well?

- What was the reason for this?/What made it so difficult?

Are you satisfied with the communication?

- With what are you satisfied?

- What do you think can be better? 


\section{Additional questions}

- Are you satisfied with the way you receive information?

- Is the communication between the professionals and your family member appropriate?

- Do the professionals know how to cope with the communication problems of your family member?

When you consider the communication with the professionals:

- What role do the professionals play in the communication?

- What behaviour of professionals supports communication and what behaviour of professionals makes communication hard?

- What role do you play in communication? What behaviour of yours supports communication/ hampers communication?

\section{Interview with professionals}

\section{Critical incidents}

Can you give an example of a situation in which communication between clients and people in their environment went well? (may refer to themselves or a situation they observed at others)

- What was the reason for this?/What helps?

Can you give an example of a situation in which communication between clients and people in their environment did not go well? (may refer to themselves or a situation they observed at others)

- What was the reason for this?/What helps?

\section{Additional questions}

What kind of problems do you experience in communication with clients?

- What supports this communication?

- What hampers this communication?

How do employees cope with the current communication problems?

- When a communication problem occurs, what strategies do you and others use?

- Do employees have enough knowledge of the communication problems of clients?

- Do employees have enough skills to cope with these communication problems of clients?

- Which roles are fulfilled by which disciplines concerning giving communication advice and prescribing communication aids? 
Appendix 2 Informed Consent

\section{Authorization form}

Title of project:

Optimal Communication for Optimal healthcare Zuyd University of applied sciences

\section{Participant:}

I declare that I have been informed about:

$\Rightarrow$ The type of research

$\Rightarrow$ The method used in this research

$\Rightarrow$ The purpose of this research

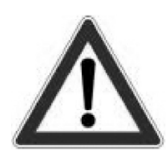

$\Rightarrow$ I am aware of the possible risks of this research
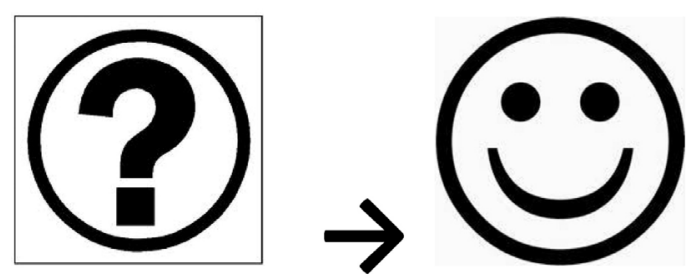

$\Rightarrow$ My questions have been answered 
$\Rightarrow$ I received written information about the research.

I participate in:

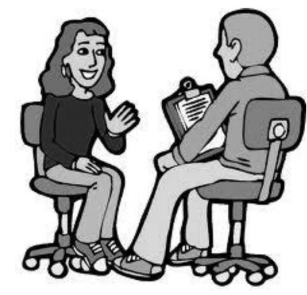

$\Rightarrow$ An interview

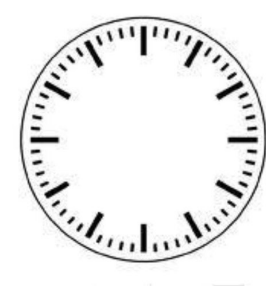

of 50-90 minutes
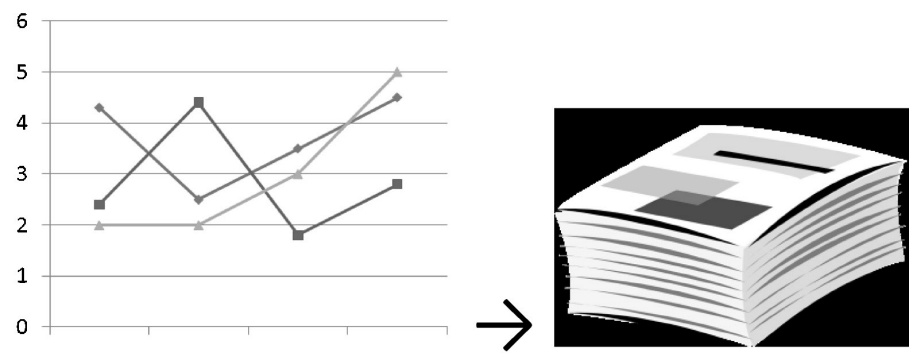

$\Rightarrow$ I receive a report of the results 


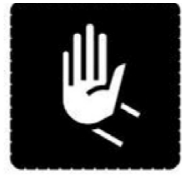

I can always stop

I do not have to give a reason to stop

I participate voluntarily

I do not need to answer all questions
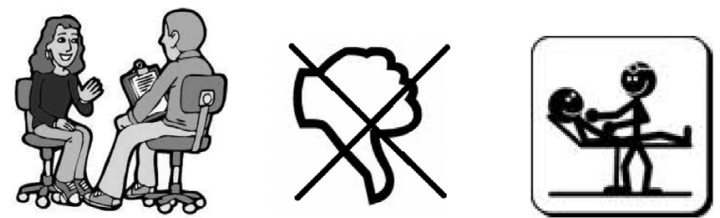

This interview has no consequences for my future treatment
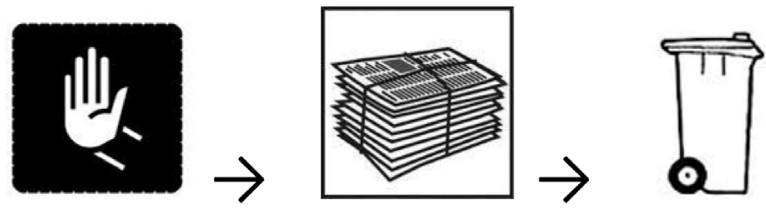

If I stop before the end of the research, my data will be deleted. 

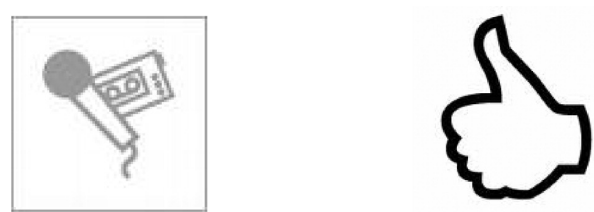

I give consent for audio-recording

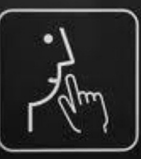

My personal information will be used anonymously

Name of participant:

City:

Date:

Signature: 


\section{Researcher}

I have given verbal and written information about the research. I declare that I will answer any questions of the participant to the best of my abilities. I declare that I will perform the research as described in the information given to the participant. I declare that I will guarantee the privacy of the participant. If the interview is not done in the home environment of the participant, travel costs will be compensated.

Name researcher:

City, date:

Signature: 



\section{Chapter 3}

Who said dialogue conversations are easy? The communication between communication vulnerable people and healthcare professionals: A qualitative study

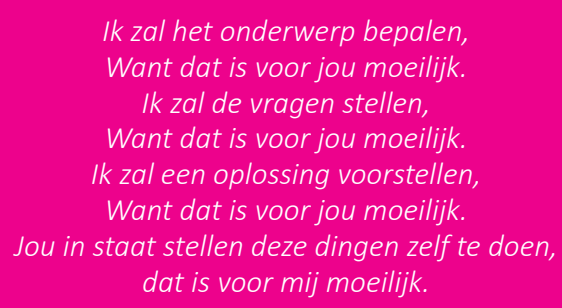

Stans $S$,

Dalemans $\mathrm{R}$,

Roentgen $U$,

Smeets $\mathrm{H}$.

Beurskens A. 


\section{Abstract}

\section{Objective}

To gain insight into how communication vulnerable people and health-care professionals experience the communication in dialogue conversations, and how they adjust their conversation using augmentative and alternative communication (AAC) or other communication strategies.

\section{Methods}

Communication vulnerable clients and health-care professionals in a long-term care institution were observed during a dialogue conversation $(n=11)$ and subsequently interviewed $(n=22)$ about their experiences with the conversation. The clients had various communication difficulties due to different underlying aetiologies, such as acquired brain injury or learning disorder. Results from the observations and interviews were analysed using conventional content analysis.

\section{Results}

Seven key themes emerged regarding the experiences of clients and professionals: clients blame themselves for miscommunications; the relevance of both parties preparing the conversation; a quiet and familiar environment benefitting communication; giving clients enough time; the importance and complexity of nonverbal communication; the need to tailor communication to the client; prejudices and inexperience regarding AAC. The observations showed that some professionals had difficulties using appropriate communication strategies and all professionals relied mostly on verbal or nonverbal communication strategies.

\section{Conclusion}

Professionals were aware of the importance of preparation, sufficient time, a suitable environment and considering nonverbal communication in dialogue conversations. However, they struggled with adequate use of communication strategies, such as verbal communication and AAC. There is a lack of knowledge about AAC, and professionals and clients need to be informed about the potential of AAC and how this can help them achieve equal participation in dialogue conversations in addition to other communication strategies. 


\section{Introduction}

Conversations between clients and health-care professionals are widely recognized as important because of their contribution to quality of care. ${ }^{1-4}$ We define these conversations as dialogue conversations, in which essential exchanges between a client and any health-care professional take place and in which both play a significant role. The exchanges concern, for example, health-related goals, activity and participation choices, and evaluation of treatment. Dialogue conversations have a particularly large impact on client involvement in the health-care process. ${ }^{1}$ In these conversations, effective communication is important and associated with patient satisfaction, patient safety and client-centred care. ${ }^{2,5}$

Effective communication can be defined as the successful joint establishment or co-construction of meaning, using a variety of strategies, including the simultaneous use of common modalities (speech, nonverbal communication, augmentative and alternative communication (AAC)). ${ }^{6}$ To be truly effective, communication requires a two-way process (expressing and understanding) in which messages are negotiated until the information is correctly understood by both parties. ${ }^{7}$ The present study used a broad definition of AAC, which includes formal assistive communication systems (eg voice output communication aids), conventional semiotic systems (eg handwriting), as well as commonplace objects (eg pictograms, or letters). Nonverbal communication (eg gesturing) is discussed separately. ${ }^{8}$

Dialogue conversations can be problematic for communication vulnerable clients, since their communication difficulties make it challenging for them to be actively involved. ${ }^{9}$ We define communication vulnerable people as people who experience difficulties communicating in particular situations. They struggle to express their needs, wishes and values, and/or to understand the information in conversations with professionals. This may be the result of mild to severe communication difficulties, related to their sensory, emotional, physical or cognitive abilities. ${ }^{10}$ Numerous underlying aetiologies and diagnoses can lead to functional communication difficulties. Acquired brain injury can lead to aphasia, dysarthria, apraxia and paralysis, which can lead to difficulties in speech and use of language. Learning disorders can lead to difficulties in understanding, memory and concentration. And physical or sensory disabilities can lead to speaking or hearing difficulties. In line with the ICF ${ }^{11}$ and recent developments in health care, ${ }^{12}$ we used a top-down approach to examine communication vulnerability and the functional communication in conversations. This relates to the client's participation, and to the activities and participation levels defined in the ICF, ${ }^{11}$ and means that we focused on the experiences of clients in functional communication in conversations, rather than on the client's diagnosis (bottomup).${ }^{13}$ It is important to acknowledge a person's experiences and elements of their environment, rather than focussing primarily on the diagnosis. ${ }^{11,13}$

Professionals are often not aware of the clients' communication vulnerability or do not know which strategies they can use to enable clients to express themselves or to understand the professional during dialogue conversations. ${ }^{10,14}$ Other studies have reported that professionals can experience feelings of anxiety, fear and inadequacy when communicating with people with aphasia. ${ }^{15}$ 
However, existing studies on dialogue conversations have often focussed on a specific group of people with one specific diagnosis (eg aphasia) or do not provide in-depth information about the functional communication problems that both professionals and clients experience. ${ }^{16-18} \mathrm{It}$ is important to address the broad target group of communication vulnerable people, regardless of their underlying diagnosis or symptoms, ${ }^{19}$ to be able to focus on ways of adapting communication to the specific needs of an individual client. ${ }^{20}$

Furthermore, research about communication in clinical practice is mostly targeted at the process steps of dialogue conversations ${ }^{21}$ or affective factors such as trust, respect and empathy, missing a focus on communication and AAC. ${ }^{22,23}$ There is a lack of knowledge about the communication experiences of both communication vulnerable people and professionals, especially with regard to the way they overcome communication problems and use communication strategies during dialogue conversations., ${ }^{5,10}$ Research into the communication experiences of communication vulnerable people is challenging, due to their communication difficulties. ${ }^{10,24}$ Although quantitative data can be used, this does not provide in-depth information about the way they experience their communication during dialogue conversations. Such insights are needed to advise professionals on how to engage with communication vulnerable clients.

Therefore, the purpose of this study was to gain insight into how communication vulnerable people and health-care professionals experience the communication in dialogue conversations, and how they adjust their conversations using AAC or other communication strategies.

\section{Methods}

A qualitative study was conducted, based on general tenets of naturalistic inquiry, focussing on communication in the natural setting of a care institution. ${ }^{25}$ Observations were followed by semistructured interviews with both clients and professionals.

\section{Setting and participants}

This study was conducted in a long-term care institution for people with acquired brain injury and physical limitations in the Netherlands. The local client advisory board advised the researchers about selected sites where they could find clients with a variety of communication difficulties who required various types of support (eg medical, living, daily activities). Professionals who regularly had dialogue conversations with clients were recruited by the managers using convenience sampling. Clients were recruited by the selected professionals using purposive sampling based on the following selection criteria: being older than 18 , not completely blind or deaf, able to communicate experiences (with or without $\mathrm{AAC}$ ), having at least one dialogue conversation every 6 months with the professional, and providing more than two "yes" answers on the communication vulnerability screening list (Appendix 1). 


\section{Data collection}

Between March and July 2015, two researchers (SS, HS) observed dialogue conversations between pairs of professionals and clients. Immediately afterwards, the client was interviewed first (to prevent problems of recalling the conversation), followed by the professional. Each interview was conducted by two trained interviewers (SS, HS) using a self-developed interview guide that focussed on experiences of communication, adaptations and AAC. The questions were formulated using the literature about communication and $A A C,{ }^{5,6,10}$ supplemented by several additional items that emerged during the observations. The interview guide was discussed with the local client advisory board to enhance its accessibility. Different types of questions were tailored to the abilities of the clients, with or without pictograms showing several answer options, using short sentences and high-frequency words and providing sufficient time and short breaks. ${ }^{24}$

In addition, probing questions were used and the researchers took care to note nonverbal behaviour that indicated understanding of the questions. Field notes were taken after each observation and interview.

\section{Data analysis}

The interviews and observations were audiotaped, transcribed verbatim and analysed using conventional content analyses. ${ }^{26}$ Two researchers (SS, HS) read the transcripts repeatedly and assigned codes to relevant fragments using the qualitative analysis software NVivo 11. Coding was derived directly from the text, focussing on experiences, adapting communication to the clients and the use of AAC. During their discussions, overarching themes emerged from the data, and the codes and themes were constantly compared between the observations, field notes and interviews. Other researchers $(R D, A B, U R)$ took part in peer debriefing sessions where they reflected on the analysis. ${ }^{25}$ The themes were adjusted until a final thematic structure was decided on by all researchers. After 20 interviews and 10 observations, no new themes emerged and therefore we assumed that thematic saturation had been attained; the final two interviews served to confirm and verify the content analysis.

To ensure internal validity, the preliminary analysis of the first three interviews was discussed with the client advisory board as an intermediate member check. After full analysis, another member check was performed by sending the participants a summary of the thematic results in accessible form. ${ }^{24}$

\section{Ethical considerations}

The local Human Research Ethics Board Z (Heerlen, The Netherlands), which verifies if studies are conducted in accordance with the Declaration of Helsinki ${ }^{27}$ and other appropriate $\mathrm{EU}$ regulations and laws, approved this study. Those willing to participate first provided verbal consent to the professional 
who had recruited them, and additionally written or audiotaped informed consent to the researchers in accessible format. ${ }^{24}$

\section{Results}

In total, 11 observations and 22 interviews were conducted. The clients represented a heterogeneous group with considerably different scores on the communication vulnerability screening list (see Table 1). At the time of the study, none of the clients was consulting a speech and language pathologist, and only one of the clients occasionally used an AAC, namely a picto-book. The aim of the dialogue conversations differed, ranging from issues such as goal setting to the client's satisfaction with the care process. The median duration of the conversations was 14 minutes (range 5-47). 


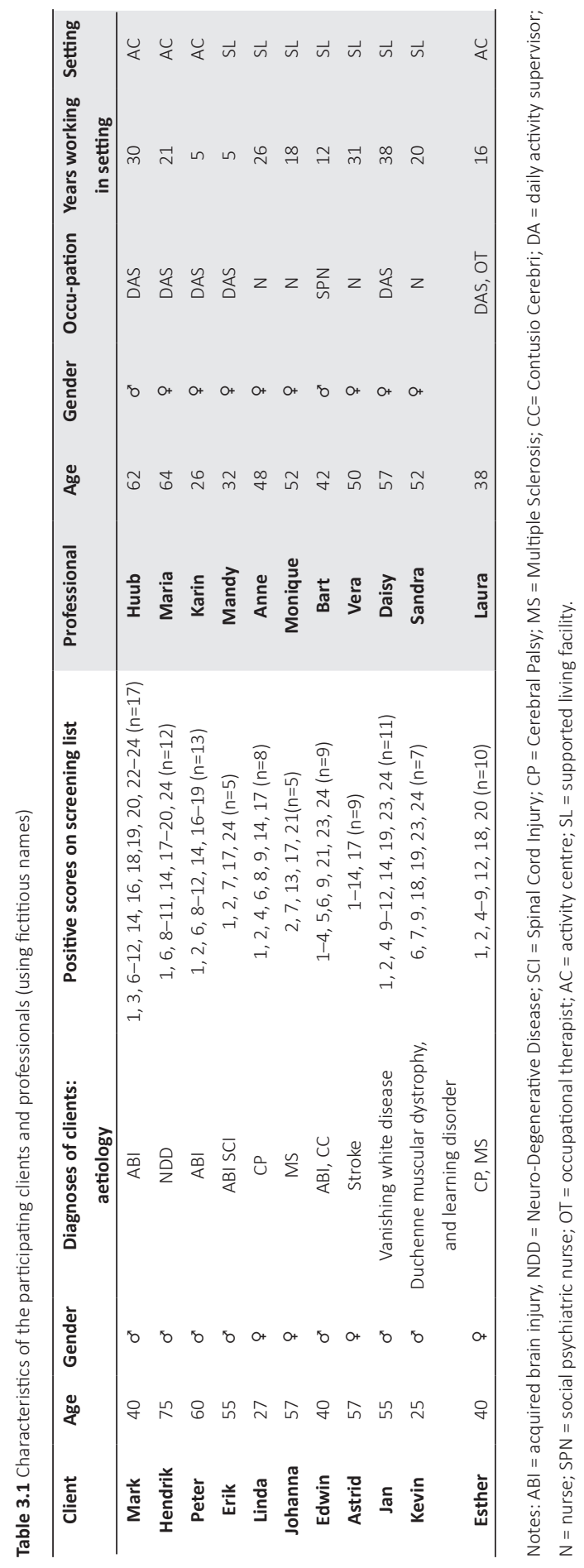


The content analysis revealed seven key themes (Figure 3.1). The results of the interviews and observations reinforced each other and are therefore presented together in the results section. Within each theme, we describe the perspectives of clients and professionals, as well as our insights from the observations.

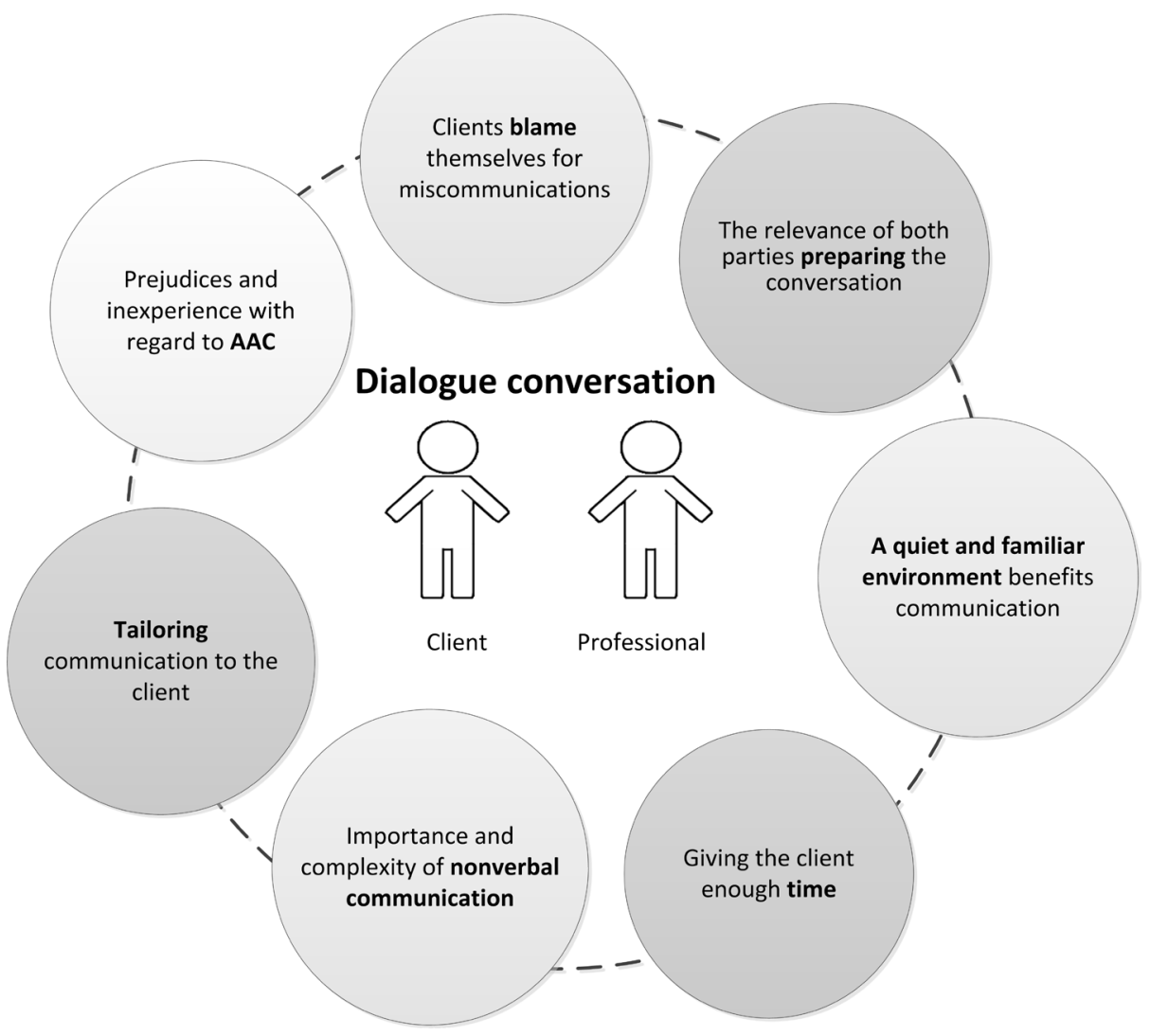

Figure 3.1. Themes relating to the experiences regarding the dialogue conversations, and the adjustments made. 


\section{Clients blame themselves for miscommunications}

The clients tended to take responsibility for communication problems during the conversations: they blamed their own disability. They explained that they could not understand difficult words because of their cognitive problems or that the professional did not understand them because of their speech problems.

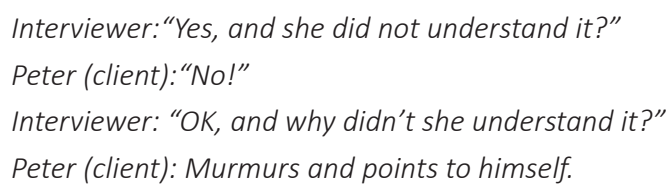

The professionals did not mention this topic explicitly, but they did describe a need for adapting their communication to the client's disabilities. The question of blame was not discussed during the observed conversations.

\section{The relevance of both parties preparing the conversation}

Both clients and professionals found it important to prepare the conversation and found it helpful to receive written information prior to the conversation. Several clients mentioned that this gave them time to think about the subject.

Some professionals prepared the conversation by preparing a fixed structure of topics to discuss. Others described supporting the clients by asking them to think about what they wanted to discuss.

Anne (professional): "If she is very tense then nothing comes out, but if she has a reminder on paper, then she thinks "Oh right, that's what I wanted to talk about"; for her, that's a kind of preparation."

The observations showed that most professionals prepared the conversation, but only for themselves. The clients were not always informed about the structure or content in advance and often seemed to follow the professionals' lead. For example, in conversation 2 the professional had brought along a list of goals to evaluate, which she used as a support for herself; the client had not received this information. However, in observation 9, the structure prepared by the professional was appropriately tailored to the client who had memory problems and he could follow the structure. 


\section{A quiet and familiar environment benefits communication}

The clients and professionals expressed that a calm and quiet environment without distractions is important in conversations. Noise makes it difficult for clients to concentrate or remember what the conversation is about. Background noise also hampered the professionals' ability to understand their clients. The clients specifically mentioned that it helped them to express themselves if the conversation took place in an environment where they felt comfortable, for example in their own living environment. Interviewer: "Do you always have the conversations here [ie his own apartment]?" Kevin (client): "Yes, I feel comfortable here, it's more comfortable, and quiet, right?"

The researchers also observed that the conversations in the supported living facilities mostly took place in the client's own room, which was a quiet environment, with the door closed, and no other people present.

\section{Giving the client enough time}

The clients found the professionals' time investment and patience very important, because they often need a lot of time to express what they wanted to convey, to complete their sentences or to come up with words.

Linda (client): "Let me complete my sentences, don't do the talking for me, let me talk."

Some clients had had unfavourable experiences, feeling that there was not enough time available for them to express themselves, or that the professionals completed their sentences for them.

\footnotetext{
Interviewer: "How could she have helped you to make that clear?"

Peter (client): "Yes but erm...it makes...waiting...but that erm..."

Interviewer: "(...). And do you have the feeling she took enough time to discuss that with you?"

Peter: "No."
}

Others had had favourable experiences, for example when the professional showed patience while the client stuttered.

A few professionals also emphasized the importance of giving clients enough time, time to stutter, to find their words, or to process the information.

Monique (professional): "We must be careful, because you've worked here for so long, you know a lot about clients, that you do not quickly erm, provide the answer yourself (...) then you tend to, if they say one letter, to fill the rest in for them." 
The researchers observed that time was not always used efficiently. Conversations that took longer did not necessarily mean that clients had more time to express themselves. For example, while conversation 2 took 28 minutes, the professional talked fast, used long sentences, completed the client's sentences and asked multiple questions at a time. These actions meant that less in-depth information was received from the client. By contrast, the researchers observed that in conversation 5, which took only 9 minutes, the client who stuttered was encouraged to complete her own sentences and to initiate topic shifts.

\section{Importance and complexity of nonverbal communication}

The clients stated that nonverbal communication was very important for them to express themselves, for example using gestures in combination with speech.

Interviewer: "Do you use any aids to help you communicate, talk?"

Peter: "Yes (makes a lot of gestures)."

Interviewer: "Gestures?"

Peter: "Yes." (keeps making gestures).

The professionals also reported that nonverbal communication, specifically facial expressions, body language and eye contact, was important to understand the client better or to ascertain whether the client understood them.

However, the professionals also explained that the nonverbal communication of communication vulnerable clients was complex and often difficult to interpret, due to physical disabilities such as spasms. Knowing the client well helped them interpret the nonverbal communication.

Vera (professional): "At a specific moment you just notice, (...) for example that she keeps adjusting the seating position of her electric wheelchair, she cannot sit still any more, yes then the conversation is taking too long."

The researchers observed that clients used a lot of nonverbal communication, mainly gestures, and the professionals did pay attention to this. In fact, some professionals relied almost entirely on nonverbal communication. The client and professional in conversation 1 had a conversation relying only on nonverbal signs and the client's yes/no/hmm answers. This, however, restricted the client in introducing a topic, feeling, or thought of his own.

Huub (professional): "I think I already see in your eyes what you want to do?" 


\section{Tailoring communication to the client}

The next three subthemes describe the experiences of clients and professionals as regards tailoring the communication.

\section{Tailoring communication speed and complexity}

The clients described that the professionals had helped them to better understand the conversation, by repeating information and speaking slowly. However, some of the clients could not always understand the professionals, because they used difficult words, talked too fast, used sentences that were too long, or gave too much information.

Interviewer: "Not quite, okay, ... what didn't you understand?"

Kevin (client): "The difficult words."

Professional 5 explained that using simple language helped the client to understand her.

The professionals emphasized the importance of adapting the conversation to the clients' degree of tiredness and their concentration, mood and cognitive abilities.

The researchers observed that in conversations 1 and 2 the professionals talked fast and used long sentences, they asked for clarification many times (13 and 14 times), indicating difficulties in understanding each other (Table 3.2), and clients had difficulties following the conversation or responding to questions. In other conversations, the professionals talked calmly and clearly and enhanced understanding using examples. 


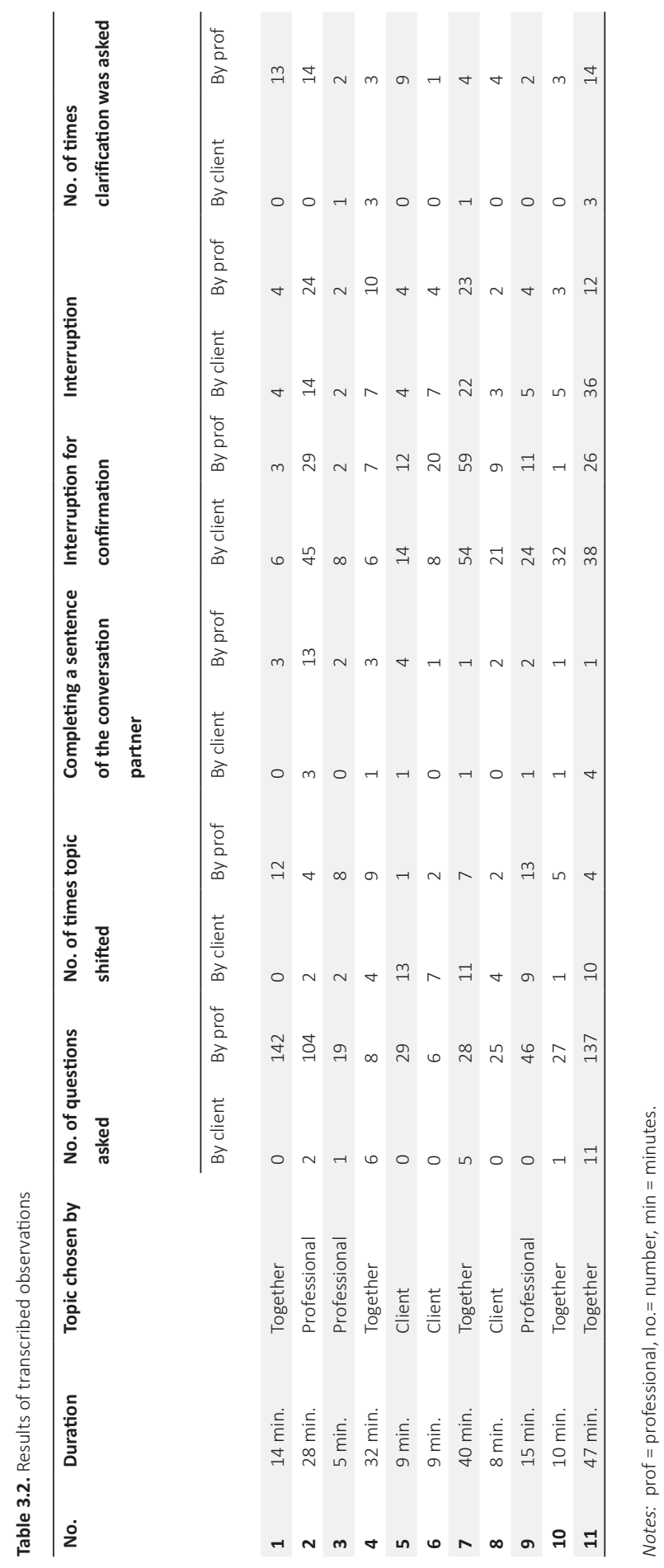




\section{Preparing a structure for both professional and client}

The professionals emphasized the importance of structuring the conversation, using a predefined structure, summarizing, paraphrasing and guiding the client back to the topic of conversation. The clients did not mention the concept of structure.

The observations showed that some clients had difficulties staying on topic and following the conversation. In conversations 4, 6, 7 and 9, the professionals managed to guide the clients back to the topic while also giving them enough time to tell their story. Their strategies involved: paraphrasing, asking questions, clearly indicating a topic shift and pointing it out to them when they deviated from the topic.

Bart (professional): "Of course that has to do with his brain injury (...), then you have to get him back to the subject we were talking about (...) I first let him talk, then I say "okay fine, but let's go back to the topic we were talking about"."

\section{Tailoring questions to the client's needs}

The professionals described that it helps the clients to ask one question at a time; the clients did not mention this strategy. However, the observations showed that not all professionals used this strategy. In conversations 2 and 3 , the professionals asked multiple questions at a time, leading to unclear answers from the clients.

Karin (professional): "But, do you think, like, I need to keep working on this goal? Or do you say, now I'm ready? Now it's ready, now I don't need to work on it."

Hendrik (client): "Yes that's right."

The professionals used both open and closed questions and reported that using closed questions could help the clients. However, the observations showed that using too many closed questions led to a lack of depth in conversations 1, 2 and 3 and that in these situations clients struggled to initiate a topic shift. During conversation 2, the professional initiated 12 topic shifts and the client none (Table 2).

In contrast, other observations showed that professionals who used mostly open questions and followup questions supported the client in initiating topic shifts. Observation 5 shows that the professional asked 28 questions, the client none, but the open questions enabled the client to introduce 13 topic shifts (Table 2).

\section{Prejudices and inexperience with regard to AAC}

The clients did not know if they would like to use AAC, due to a lack of experience. Some clients thought pictograms were childish, while others found them helpful during the interview with the researchers. 
Interviewer

"Do these pictograms help you?"

Mark (client)

"Yes!"

A few clients explained that it is helpful to use conventional semiotic systems, such as writing, to express themselves during a conversation.

Interviewer

"What could she have done to enable you to tell it? Except for giving more time."

Peter (client)

"Plants, pen."

Interviewer

"Pen? Oh, she could have written it down? (client shakes his head) Oh, she could have given you the pen?"

Interviewer gives Peter paper to write on, Peter writes down "plant" to indicate which topic he wanted to discuss.

The professionals explained that they did not use formal assistive communication devices or pictograms because they thought it was not necessary, it was childish, or it was for "stupid" or "crazy people".

Interviewer: "And do you ever use communication devices to talk to him?"

Sandra (professional): "Yes, he uses the clock he has with pictograms, but apart from that no, that is totally not necessary'(...) 'That's because he's not stupid right, it's more like yeah he's not stupid."

Two of the professionals indicated that clients could benefit from photos or a picto-book, but did not use this strategy during the observed conversations.

Other professionals described that written information would probably help the client to understand them, or to remember what was said. Such written information had to be adapted to the client's abilities, presenting it in large font, including only a limited amount of information, and using simple words.

Anne (professional): "Then I write it down on paper in advance, using a larger font, so that she can read it more easily (...) No difficult words and not too much information."

The observations showed that only one professional, Laura, used written information, by using the computer. Client and professional described that it was helpful for the client to hear as well as read the information. 
Even though the use of formal assistive communication systems, pictograms, written information and writing were sometimes mentioned as helpful, the researchers observed that these were not used in the dialogue conversations.

\section{Discussion}

The purpose of this study was to gain insight into how communication vulnerable people and healthcare professionals experience the communication in dialogue conversations, and how they adapt their conversations to their clients using AAC or other communication strategies. Seven key themes emerged: the question of blame, preparing the conversation, the environment of the conversation, giving clients enough time, nonverbal communication, tailoring communication and prejudices regarding AAC.

Clients and professionals acknowledged the wide range of communication strategies, but our observations showed that they mostly relied on verbal and nonverbal communication, and did not use AAC.

Clients were often insufficiently enabled to express themselves, whereas client-centred care and shared decision-making require an active role of clients in dialogue conversations. ${ }^{28}$ It is striking that the clients thought they were to blame for difficulties in the conversation. Clients were not aware that professionals could have used AAC to enable them to become more involved.

Sufficient time was considered important by clients and professionals; however, more time was not always the solution. The duration of the conversations we observed fluctuated, regardless of where they took place, that is at an activity centre or assisted living facility. Time must be used efficiently, using the right communication strategies tailored to the client, supporting effective communication and involving clients in their health-care process. ${ }^{1,2,19}$

Professionals and clients agreed about the importance of preparing conversations and ensuring a suitable environment, which has also been emphasized in previous research. ${ }^{29}$ Our observations showed that environmental issues were taken into account, but the preparation mostly did not include the clients.

The current study showed that the professionals had difficulties using adequate communication strategies. Whenever clients found it difficult to talk and remained silent, some professionals filled the silence with information or questions. This finding is in agreement with those reported by Wylie and colleagues, who stressed that communication vulnerable people often do not receive the support they need to overcome their communication difficulties. ${ }^{14}$ The three conversations in which the professionals and clients had the most difficulties in their conversations all took place in an activity centre. However, we cannot link the lack of skills and awareness shown by the professionals to the type of facility, since 
this study had a limited number of participants.

This study showed that asking more questions appeared to be not necessarily better or worse, but that the types of question need to be tailored to the client and his or her communication difficulties.

The study by Gordon and colleagues, including people with aphasia and dysarthria, also found that nurses often controlled the topic of the conversation, while clients were limited to responding to closed questions. ${ }^{16}$ Another study found that clients are often not enabled to initiate a new topic or provide new information..$^{30}$ It could be concluded that awareness of communication vulnerability ${ }^{10,14}$ and awareness regarding effective use of communication strategies are both needed in order to enable clients to be more involved.

In the current study, the professionals and clients did not use formal assistive communication devices such as picto-books, dynamic communication devices or conventional semiotic AAC, such as writing, drawing or photographs, which are readily available. This is remarkable considering the communication vulnerable group. This lack of AAC use was noticed both in activity centres and in assisted living facilities. Blackstone and colleagues also identified a lack of AAC use in hospitals. ${ }^{31}$ It is a striking result, since AAC could support clients in expressing their views and preferences, ${ }^{32,33}$ providing them with the opportunity to be more fully engaged in the conversation. Some professionals in the current study also had negative prejudices about AAC, which indicates some sort of stigma on using AAC. ${ }^{34,35}$ Therefore, it is important to pay attention not only to diagnostic factors but also to environmental and psychosocial factors when choosing communication strategies. Some professionals in this study were aware of the client's diagnosis, but did not always understand the relation between the diagnosis and the difficulties emerging in the communication, indicating a lack of knowledge about communication disability.

This is in accordance with previous studies, which indicated that professionals are insufficiently aware of the communication vulnerability and the potential of $A A C .{ }^{10} \mathrm{AAC}$ is frequently seen as a last resort, while professionals can involve the clients in choosing and using AAC from the moment a difficulty in communicating arises. ${ }^{33}$

\section{Strenghts and limitations}

In our qualitative design, data triangulation was ensured by combining field notes, observations and interviews. The heterogeneous sample of clients with various communication difficulties, and the description of the contexts (thick description) ${ }^{25}$ may imply transferability of the thematic results. However, professionals should take cultural differences and the relatively small sample of this study into account.

Including communication vulnerable people in this study required significant time and effort, but provided much added value. Many studies about communication do not include the views of the clients or the users of AAC, whereas this vulnerable group in particular needs to have a voice and be heard. ${ }^{4}$ 14, 36 
Weaknesses of this study relate to potential bias due to sampling and socially acceptable answers. ${ }^{25}$ The professionals could have chosen the clients who they thought were satisfied with the conversations, and the managers could have chosen professionals who they thought had good or poor communication skills. We used a preliminary member check with clients, but did not include the views of professionals. Furthermore, we cannot be sure that no socially acceptable answers were given during the interviews. The information letter and informed consent, however, clearly indicated confidentiality. The qualitative nature of this study and the heterogeneity of the participants prohibit the investigation of interrelations between certain characteristics of participants (eg diagnosis), setting (eg activity centre or supported living) and the functional communication difficulties experienced. Future research with a more homogeneous target group and a larger sample could provide insights into the association between functional communication difficulties experienced, diagnosis and effective communication strategies.

\section{Conclusion}

Both clients and professionals appreciated the benefits of preparing the conversation, ensuring a suitable environment for the conversation, giving clients enough time, using nonverbal communication and tailoring communication to the clients. However, appropriate application appears to be complex and difficult. Our findings show that these conversations are skewed towards the professionals, their preparation, their structure, their topics and their opinions about AAC. There is room for improvement since clients are often insufficiently supported in expressing themselves or understanding the professional, thereby limiting their involvement in the conversation. Professionals could use the screening list we developed to identify hidden communication difficulties. This study highlights that professionals are often unaware that using AAC can empower clients to be more involved in conversations.

Future research should examine how professionals and clients can select and use communication strategies, including $A A C$, to help them achieve equal participation in dialogue conversations. Studies about the link between the functional communication experienced and the communication strategies/AAC tools, and about shared decision making, would be particularly interesting for dialogue conversations. 


\section{References}

1. Hemsley B, Georgiou A, Hill S, Rollo M, Steel J, Balandin S. An in-tegrative review of patient safety in studies on the care and safety of patients with communication disabilities in hospital. Patient Educ Couns. 2015;99:501-511.

2. Elwyn G, Edwards A, Kinnersley P. Shared decision-making in pri-mary care: the neglected second half of the consultation. Br J Gen Pract. 1999;49:477-482.

3. Elwyn G, Frosch DL, Kobrin S. Implementing shared decision- making: consider all the consequences. Implement Sci. 2016;11:114.

4. Lawrence M, Kinn S. Defining and measuring patient-centred care: an example from a mixed-methods systematic review of the stroke literature. Health Expect. 2012;15:295-326.

5. Hemsley B, Balandin S. A metasynthesis of patient-provider com-munication in hospital for patients with severe communication disabilities: informing new translational research. Augment Altern Commun. 2014;30:329-343.

6. Blackstone SW, Williams MB, Wilkins DP. Key principles under-lying research and practice in AAC. Augment Altern Commun.2007;23:191-203.

7. The Joint Commission. Advancing effective communication, cultural competence, and patient and family centred care: A roadmap for hospi-tals. Oakbrook Terrace, IL; 2010.

8. Clarke M, Bloch S. AAC practices in everyday interaction. Augment Altern Commun. 2013;29:1-2.

9. Hemsley B, Balandin S, Worrall L. Nursing the patient with complex communication needs: time as a barrier and a facilitator to success-ful communication in hospital. J Adv Nurs. 2012;68:116-126.

10. Stans SE, Dalemans R, de Witte L, Beurskens A. Challenges in the communication between 'communication vulnerable' people and their social environment: an exploratory qualitative study. Patient Educ Couns. 2013;92:302-312.

11. World Health Organization, ICF. home page on the internet. Available at: http://www.who.int/classifications/icf/en/. Accessed November 8, 2017.

12. Huber M, van Vliet M, Giezenberg $M$, et al. Towards a 'patient- centred' operationalisation of the new dynamic concept of health: a mixed methods study. BMJ Open. 2016;6:e010091.

13. Brown T, Chien C-W. Top-down or bottom-up occupational therapy assessment: which way do we go? Br J Occup Ther. 2010;73:95-96.

14. Wylie K, McAllister L, Davidson B, Marshall J. Changing practice: implications of the World Report on Disability for responding to communication disability in under-served populations. Int J Speech Lang Pathol. 2013;15:1-13.

15. Parr S, Pound C, Hewitt A. Communication access to health and social services. Top Lang Disorders. 2006;26:189-198.

16. Gordon C, Ellis-Hill C, Ashburn A. The use of conversational anal-ysis: nurse-patient interaction in communication disability after stroke. J Adv Nurs. 2009;65:544-553.

17. Horton S, Clark A, Barton G, Lane K, Pomeroy VM. Methodological issues in the design and evaluation of supported communication for aphasia training: a cluster- controlled feasibility study. BMJ Open. 2016;6:e011207.

18. Heard R, O'Halloran R, McKinley K. Communication partner training for health care professionals in an inpatient rehabilitation setting: a parallel randomised trial. Int J Speech Lang Pathol. 2017;19:277-286.

19. Burns M, Baylor C, Dudgeon BJ, Starks H, Yorkston K. Asking the stakeholders: perspectives of individuals with aphasia, their family members, and physicians regarding communication in medical in-teractions. Am J Speech Lang Pathol. 2015;24:341-357.

20. Fried-Oken M, Mooney A, Peters B. Supporting communication for patients with neurodegenerative disease. NeuroRehabilitation. 201 5;37: 69-87.

21. Kurtz S, Silverman J, Draper J. Teaching and Learning Communication Skills in Medicine, 2nd edn. Boca Raton, FL: CRC Press; 2004.

22. Mazzi MA, Rimondini M, Deveugele $M$, et al. What do people ap-preciate in physicians' communication? An international study with focus groups using videotaped medical consultations. Health Expect. 2013;18:1215-1226.

23. Bensing JM, Deveugele M, Moretti $F$, et al. How to make the medical consultation more successful from a patient's perspec-tive? Tips for doctors and patients from lay people in the United Kingdom, Italy, Belgium and the Netherlands. Patient Educ Couns. 2011;84:287-293. 
24. Dalemans R, Wade DT, van den Heuvel WJ, de Witte LP. Facilitating the participation of people with aphasia in research: a description of strategies. Clin Rehabil. 2009;23:948-959.

25. Lincoln YS, Guba EG, eds. Naturalistic Inquiry. Beverly Hills, CA: SAGE; 1985.

26. Hsieh HF, Shannon SE. Three approaches to qualitative content analysis. Qual Health Res. 2005;15:1277-1288.

27. World Medical Association. World medical association declaration of helsinki: ethical principles for medical research involving human subjects. JAMA. 2013;310:2191-2194.

28. Elwyn G, Frosch D, Thomson R, et al. Shared decision making: a model for clinical practice. J Gen Intern Med. 2012;27:1361-1367.

29. Stans SE, Dalemans RJ, de Witte LP, Smeets HW, Beurskens AJ. The role of the physical environment in conversations between people who are communication vulnerable and health-care professionals: a scoping review. Disabil Rehabil 2017;39:2594-2605

30. Jones A. Nurses talking to patients: exploring conversation analysis as a means of researching nurse-patient communication. Int J Nurs Stud. 2003;40:609-618.

31. Blackstone S, Beukelman D, Yorkston K. Patient-Provider Communication Roles for Speech-Language Pathologists and Other Health Care Professionals. San Diego, CA: Plural; 2015.

32. Fried-Oken M, Beukelman DR, Hux K. Current and future AAC re-search considerations for adults with acquired cognitive and com-munication impairments. Assist Technol. 2011;24:56-66.

33. Blackstone SW, Pressman H. Patient Communication in Health Care Settings: new Opportunities for Augmentative and Alternative Communication. Augment Altern Commun. $2016 ; 32: 69-79$.

34. Light J, McNaughton D. Designing AAC Research and Intervention to Improve Outcomes for Individuals with Complex Communication Needs. Augment Altern Commun. 2015;31:1-12.

35. lacono $\mathrm{T}$, Lyon $\mathrm{K}$, Johnson $\mathrm{H}$, West $\mathrm{D}$. Experiences of adults with complex communication needs receiving and using low tech AAC: an Australian context. Disabil Rehabil Assist Technol. 2013;8:392-401.

36. Baxter S, Enderby P, Evans P, Judge S. Barriers and facilitators to the use of high-technology augmentative and alternative communication devices: a systematic review and qualitative syn-thesis. Int J Lang Commun Disord. 2012;47:115-129. 


\section{Appendix 1 Screening List Communication Vulnerability}

Instruction: Please answer all questions on this page by crossing the boxes per question.

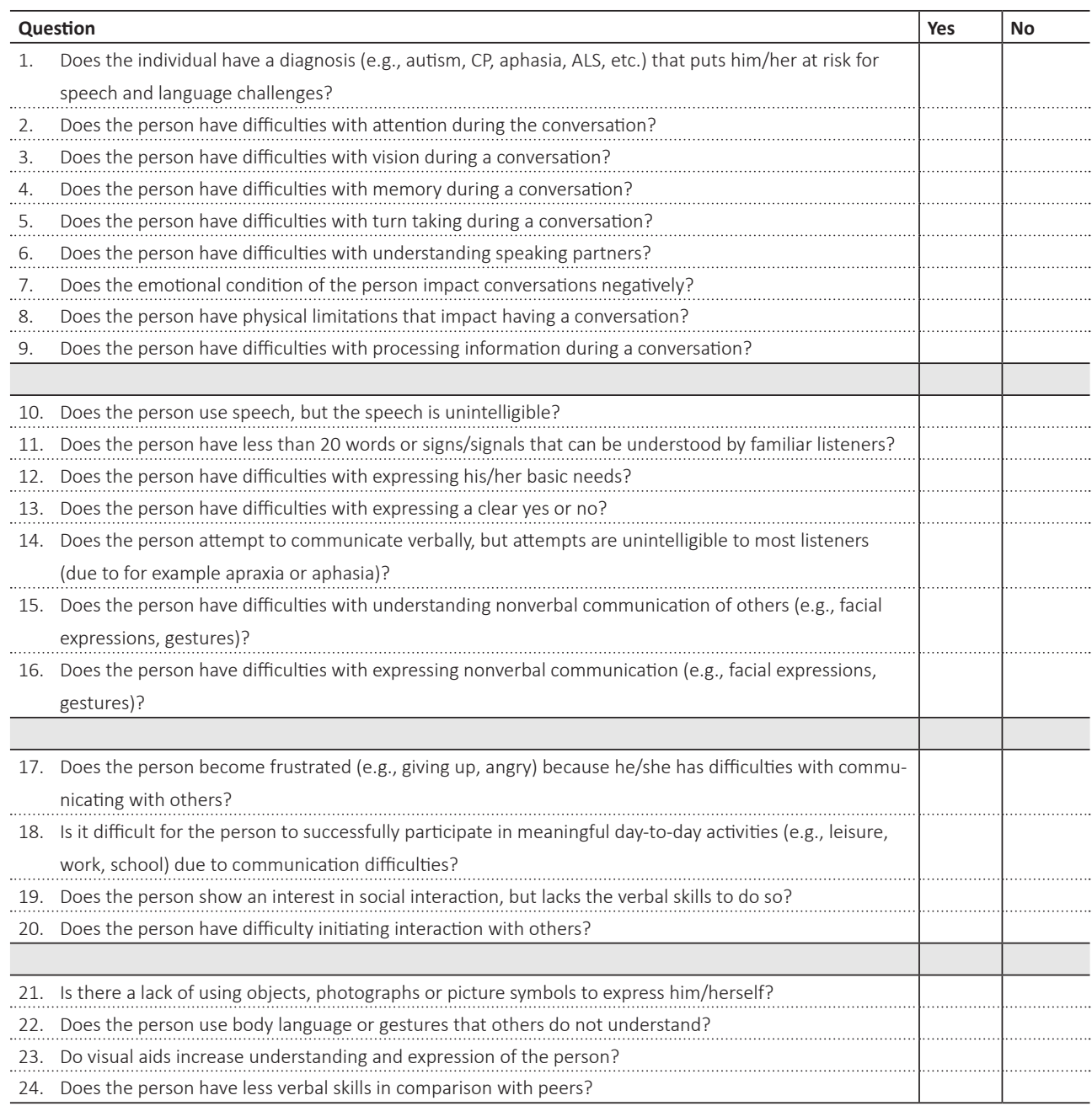

\section{Number of yes answers:....}

Remarks:

This screening list is developed by Zuyd University of applied sciences, research center of Autonomy and Participation of people with a chronic illness. The list is based upon the 'Communication Success Screening' of Dynavox Mayer-Johnson; the screening list 'starten met ondersteunde communicatie?' by Modem; and the developmental model of 'Taal Centraal' (2009) of prof. van Balkom. 



\section{Chapter 4}

The role of the physical environment in conversations between people who are communication vulnerable and health-care professionals: a scoping review 


\section{Abstract}

\section{Purpose}

The role of the physical environment in communication between health-care professionals and persons with communication problems is a neglected area. This study provides an overview of factors in the physical environment that play a role in communication during conversations between people who are communication vulnerable and health-care professionals.

\section{Method}

A scoping review was conducted using the methodological framework of Arksey and O'Malley. The PubMed, PsycINFO, CINAHL and Cochrane Library databases were screened, and a descriptive and thematic analysis was completed.

\section{Results}

Sixteen publications were included. Six factors in the physical environment play a role in conversations between people who are communication vulnerable and health-care professionals: (1) lighting, (2) acoustic environment, (3) humidity and temperature, (4) setting and furniture placement, (5) written information, and (6) availability of augmentative and alternative communication (AAC) tools. These factors indicated barriers and strategies related to the quality of these conversations.

\section{Conclusions}

Relatively small and simple strategies to adjust the physical environment (such as adequate lighting, quiet environment, providing pen and paper) can support people who are communication vulnerable to be more involved in conversations. It is recommended that health-care professionals have an overall awareness of the potential influence of environmental elements on conversations.

\section{Implications for rehabilitation}

- The physical environment is an important feature in the success or disturbance of communication.

- Small adjustments to the physical environment in rehabilitation can contribute to a communication-friendly environment for conversations with people who are communication vulnerable.

- Professionals should consider adjustments with regard to the following factors in the physical environment during conversations with people who are communication vulnerable: lighting, acoustic environment, humidity and temperature, setting and furniture placement, written information, and availability of AAC (augmentative and alternative communication tools). 


\section{Introduction}

Effective communication in conversations between clients and professionals plays an important role in client-centred care, shared decision making and preventable adverse events in healthcare. ${ }^{1-5}$ Their conversations often relate to (health-related) goals, activity choices, medical treatment, and the evaluation of treatment. Such conversations between clients and health-care professionals are often complicated and multidimensional; this is partly due to the complexity of communication itself, but is also due to time constraints, emotions, different expectations and factors in the social and physical environment. ${ }^{5}$

Conversations are even more challenging if a client is communication vulnerable. ${ }^{6}$ There are different definitions of people who are communication vulnerable in literature. ${ }^{7,8}$ We define people who are communication vulnerable as people who, due to a disease or medical condition, have difficulty expressing themselves and/or understanding information in particular environments or situations. Their communication difficulties can be mild to severe, and can be due to their sensory, emotional, physical, or cognitive (dis)abilities. ${ }^{9}$ In this paper we focus on people who are communication vulnerable due to neurological disorders. ${ }^{10}$

According to the International Classification of Functioning, Disability and Health (ICF), ${ }^{11}$ the physical, social and attitudinal environment has an impact on conversations. A great deal of research has been conducted regarding the impact of the social and attitudinal environment on conversations, and more specifically the personal skills required to communicate effectively with clients in conversations. ${ }^{12-14}$ Less attention has been paid to the impact of the physical environment on conversations in general and in particular to the quality of conversations between people who are communication vulnerable and health-care professionals. The physical environment has an influence on people's abilities to participate and engage in activities. ${ }^{11}$ The ICF defines the physical environment as the natural environment, human-made changes to the environment and products and technology. ${ }^{15}$ Products and technology involve naturally occurring things (e.g. trees and plants), fabricated things (e.g. chairs, written information) and technological objects (e.g. computers). ${ }^{11,16}$ Research has shown that factors in the physical environment have an impact on the activities and communication of people who experience communication difficulties. ${ }^{17}$ Examples of factors influencing conversations are noise and the arrangement of furniture. ${ }^{17}$

Since the physical environment and other ICF environmental factors (support and relationships, attitudes, and services, systems and policies) have a reciprocal relationship, ${ }^{18}$ more knowledge is needed about the impact of the physical environment in order for professionals and health-care systems to create communication friendly environments. Adapting or modifying existing physical environments, and designing new environments that promote universal communication access, is important. ${ }^{19}$ 
A literature review by O'Halloran and colleagues concentrated on the acute hospital setting when describing the environmental (both social and physical) barriers and facilitators that play a role in the communication between professionals and people with communication disability. ${ }^{20}$ Other studies focus on how the physical environment can be adjusted for a group of people with a specific illness or characteristic, such as aphasia friendly environments ${ }^{17}$ or environments for people with dementia. ${ }^{21}$ O'Halloran concludes that more insights are needed about the factors in physical environments when communicating with people who have had a stroke, traumatic brain injury or who have dementia. ${ }^{20}$ Neurological disorders often lead to communication difficulties. People with different diagnoses experience different communication difficulties and needs, and therefore physical environments should be created that contribute to the communicative needs of specific individuals.

Many of these communicative needs, however, may be applicable for more than one person, or for more than one diagnosis. When looking at the communicative needs of a larger target group, communication accessible environments can be created that support communication for a large group of people who are communication vulnerable, irrespective of a specific diagnosis.

The role of the physical environment in communication is a neglected area, and an up-to-date review of the literature is missing. A better understanding of communication friendly environments for conversations with health-care professionals can contribute to more accessible and empowering client-centred care for people who are communication vulnerable. ${ }^{20,22}$

This literature review takes a broad look at health-care settings, and focuses on the target group of people who are communication vulnerable due to neurological disorders, since many people with neurological disorders are communication vulnerable. The aim of this scoping review is to provide an overview of factors in the physical environment that play a role in communication during conversations between people who are communication vulnerable and health-care professionals.

\section{Methods}

A scoping review was conducted to provide an extensive overview of the literature related to factors in the physical environment that play a role in communication between people who are communication vulnerable and health-care professionals. Scoping reviews are suitable for studying broad topics, are used to comprehensively and systematically map the relevant literature, and to identify key concepts and gaps in research. ${ }^{23,24}$ The current scoping review was conducted using the methodological framework of Arksey and O'Malley. ${ }^{23}$ This framework identifies five stages in conducting a scoping study; the methods used in the current review will be described according to these stages. 


\section{Identifying the research question}

The research question for this review was: which factors in the physical environment play a role in communication between people who are communication vulnerable and health-care professionals, during conversations in health-care settings?

\section{Identifying relevant studies}

Published scientific literature was searched via electronic scientific databases (PubMed, PsycINFO, CINAHL and the Cochrane Library) and reference lists in order to obtain a comprehensive set of literature on this topic. The research team developed a list of search terms and filtering options based on orientation searches, which led to search outcomes that best fitted the research question. A library expert was consulted for advice on search strategies in the electronic databases. A strategy for searching PubMed was used as the main protocol, and modified for other databases. The keywords were applied to titles and abstracts.

Three main keywords were combined using the Boolean term "AND". The first main terms were "adult" AND "communication disorders" in combination with neurological disorders that may affect communication: OR aphasia, OR dementia, OR Parkinson's disease, OR dysarthria, OR amyotrophic lateral sclerosis, OR multiple sclerosis, OR brain injuries, OR stroke. We chose to do a broad search on communication disorders and used some specific diagnoses (using "OR") to search for more literature about diagnoses which are often linked to communication difficulties due to neurological conditions in the literature. Our first objective was to search only "communication disorders", however, we found during several orientation searches that adding some neurological search terms that are often linked to communication difficulties gave more relevant search outcomes. We therefore used the Boolean term 'OR', so as not to exclude any other neurological diagnosis.

The second main keyword "environment" was used including the following related terms: OR environment design, OR health facility environment, OR hospital design, OR construction. Finally, the third main keyword, "communication", was used with the following related terms: OR health communication, OR communication barriers, OR communication aids for disabled OR interpersonal relations. The keyword "conversations" was specifically not used because in Medical Subject Headings (MESH) this is linked to interviews, and pilot searches revealed that this led to irrelevant search outcomes. The MESH term "dialogue" was not used because it led to outcomes related to drama. The MESH term "discussion" was also not used because it led to outcomes related to ethics, focus groups and motivational interviewing. The keywords "computer communication networks" and "social environment" were excluded using the Boolean term "NOT", since these produced irrelevant output, with no focus on the physical environment. No publication date restriction was used in the search. The following general inclusion criteria were used to filter the search: published in English, Dutch or German languages, adults and research about health-care settings. 


\section{Study selection}

In the study selection phase, the relevance of the literature was assessed in three steps: title level, abstract level and full text level. In the first selection step, three researchers (SS, RD, HS) assessed the titles independently, using a three-point scale ( 0 irrelevant; 1 possibly relevant; 2 relevant). These scores were totalled and articles with scores of 2 or more were included in the sample. Consequently, any uncertainties or discrepancies at this early stage in the review did not eliminate publications for assessment at the abstract level. Predefined inclusion criteria at the title level were: (a) people who are communication vulnerable and healthcare professionals as the target groups, (b) communication as a main theme or subtheme, and (c) physical environment as a main theme or subtheme.

During the second selection step, at the abstract level, two researchers (SS, HS) assessed the included publications for relevance by reading the abstracts, using the same scoring procedure as in step one. These scores were summed and articles with scores of 1 or more were included in the sample. The predefined additional inclusion criteria for this level were: (a) the study had to reflect a natural (not laboratory) environment; (b) the participants in the study were communication vulnerable due to neurological disorders; (c) focus on conversations with professionals.

Exclusion criteria were: (a) studies focusing only on the environment in non-health surroundings and settings (e.g. public spaces) (studies about conversations between health-care professionals and people in the home environment were included), (b) studies focusing only on communication between professionals or between people who are communication vulnerable, (c) studies about "snoezelen" (Dutch for controlled multisensory stimulation environment), or (d) studies merely about "wayfinding".

In the third selection step, two researchers (SS, HS) assessed the remaining full texts. To define the inclusion criteria for this level, a small subset of studies (15) was used. The final inclusion criteria were: (a) the study had to present information relevant to conversations between people who are communication vulnerable and health-care professionals, (b) the study had to present a direct association between the physical environment and conversations with professionals. The inclusion of information was not limited by the methodological quality of the research. ${ }^{23-25}$ Each article was discussed by the two researchers to decide upon inclusion or exclusion. Inconsistencies or uncertainties were discussed with a third researcher (RD) who also checked the article for the selection criteria. The reference lists of the publications included in this third step were checked for additional relevant publications.

\section{Charting the data}

After the final full text inclusion, a data extraction form was developed based on a small set of full texts and a research team consultation. This data extraction form consisted of descriptive elements (author, year, location and aim of the study, study design, study population, and setting). Two researchers (SS, 
HS) independently charted the data and subsequently discussed inconsistencies.

\section{Collating, summarizing and reporting the results}

A summary was made of the main characteristics of the literature, using the descriptive elements of the data extraction form. Thereafter, the researchers conducted a thematic analysis of the information in the publications. In the first phase of the thematic analysis, two researchers (SS, HS) read the publications independently and highlighted text fragments related to the scoping review research question. In the second phase, these text fragments were independently placed in an Excel file and, based on discussion, a final Excel file including all relevant information was developed. In the third phase, labels were added to the text fragments independently by the two researchers (SS, HS) and the text fragments were ordered according to these labels. Three researchers discussed the formulated labels, and developed factors and sub-factors.

\section{Results}

Based on the initial 5048 hits in the databases, 16 publications were included in this review (Figure 4.1), published between 1989 and 2015. Two publications were included in the final selection based upon the reference list search. Of the 152 excluded publications in the full text phase, 115 publications were excluded because they were not about conversations between people who are communication vulnerable due to a neurological condition and health-care professionals. The other 37 publications were excluded because no direct association was made between communication and physical environment. The included publications comprised book chapters, discussion reports and articles about empirical research. 


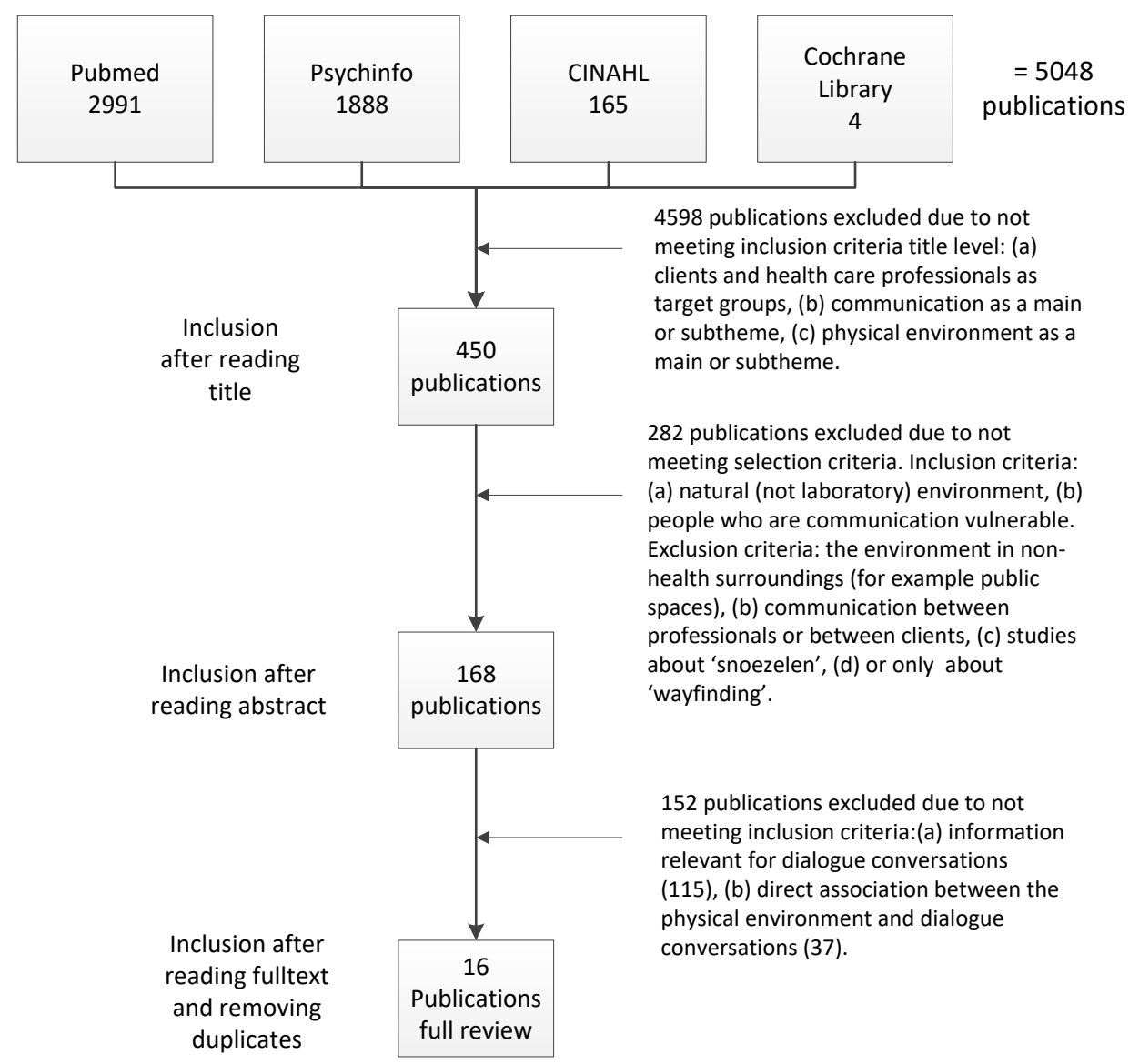

Figure 4.1. This Figure illustrates the number of publications included during each phase of this review.

\section{Descriptive summary of the articles}

The characteristics of the publications are presented in Table 4.1, in which the author, year and country, aim of the study, study design, study population and the setting of the studies are described. A total of 16 publications were included, consisting of two qualitative studies, seven quantitative studies, one mixed method research, one discussion report and four literature reviews. One book chapter was included. The research articles embraced a wide range of settings and target groups. These settings were: long-term care settings, hospitals, dementia facilities, acute stroke units, ALS clinics, speech and language therapy practices, and professionals visiting the home environment. Various target groups within the scope of "people who are communication vulnerable" were included in the publications: for example people with dysarthria, aphasia, dementia, Parkinson's disease, or ALS. 

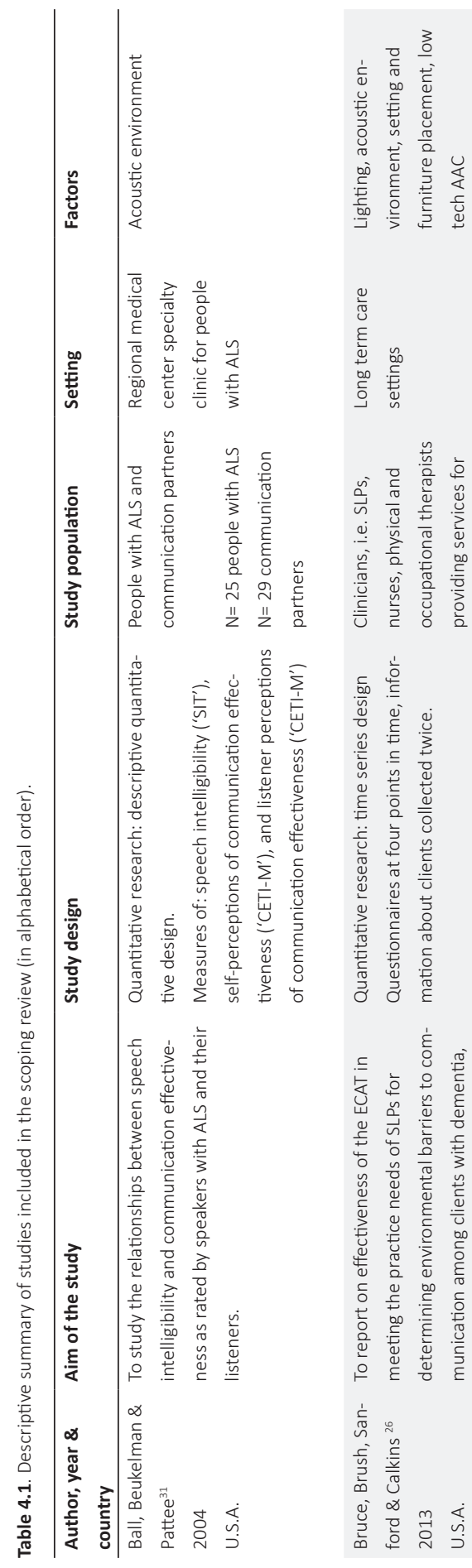

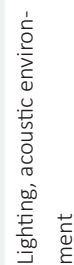

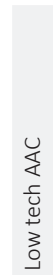

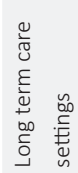

营

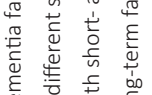

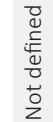

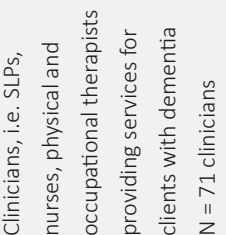

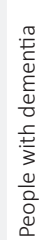

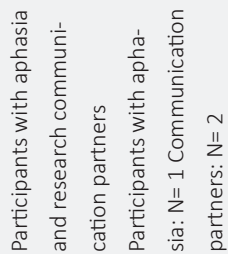

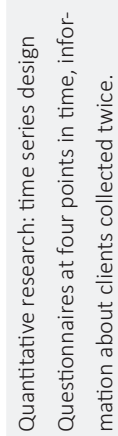

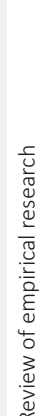

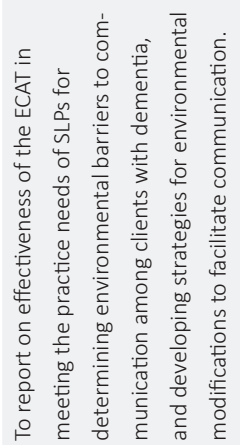

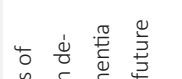

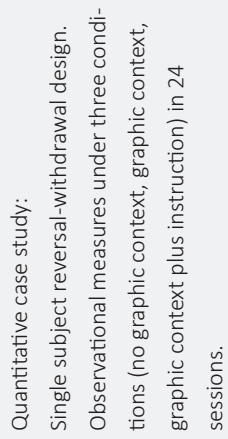

4

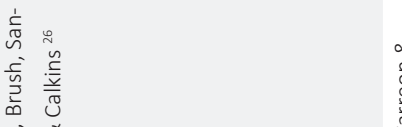

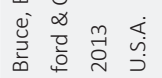

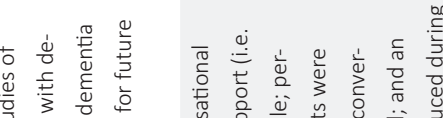

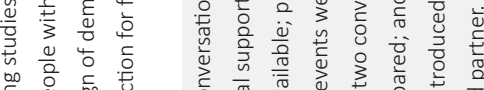

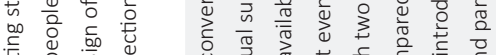

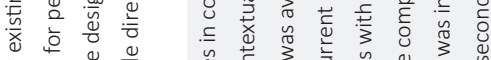

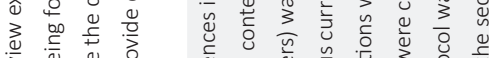

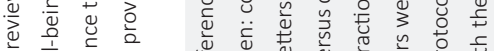

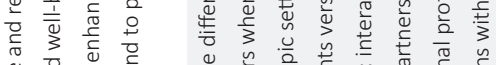

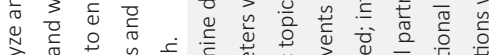

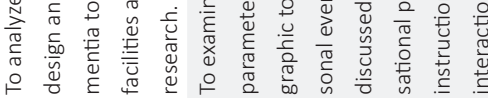

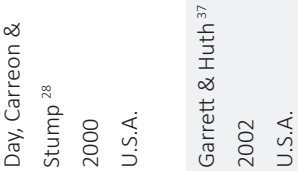




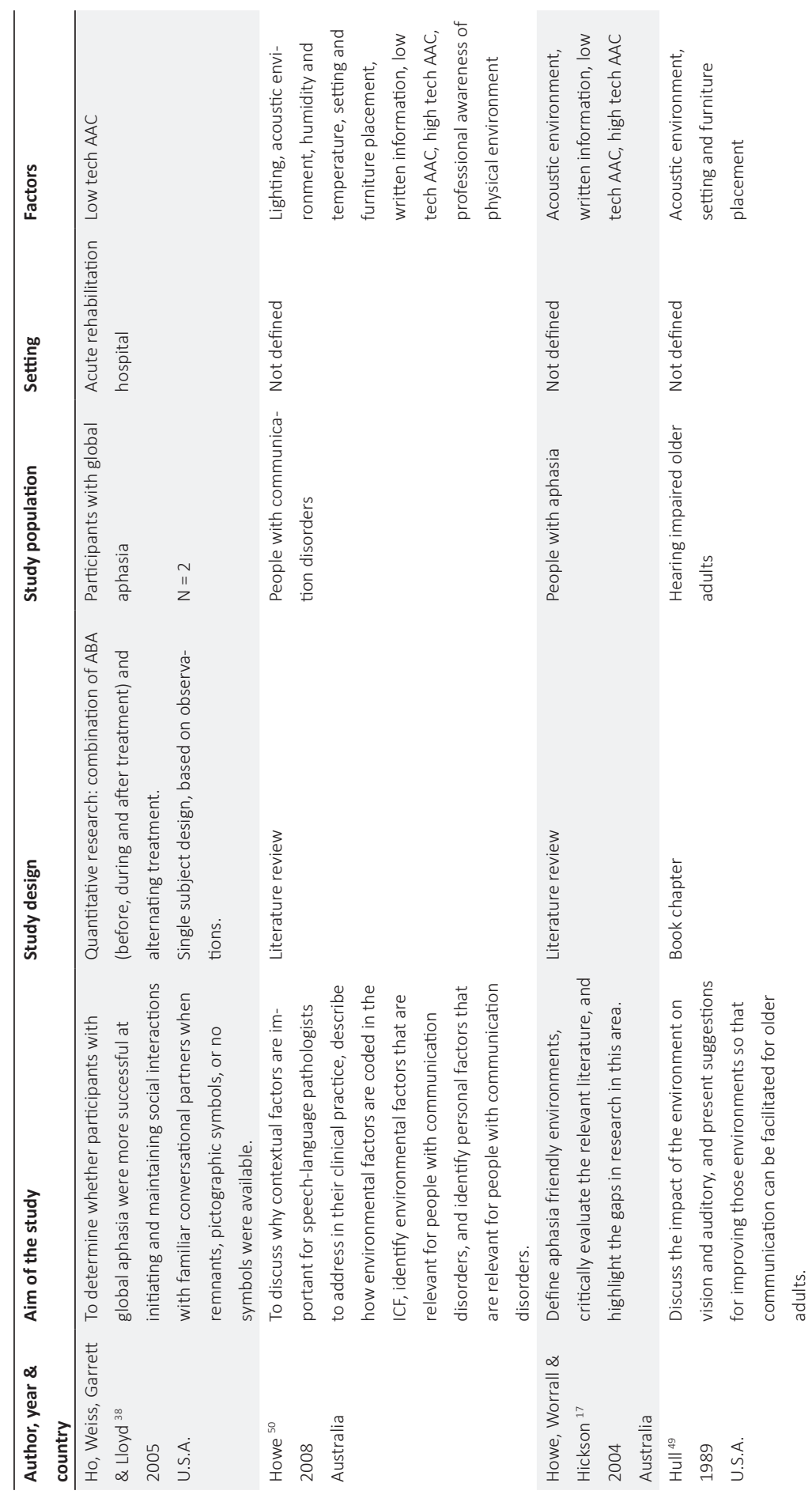




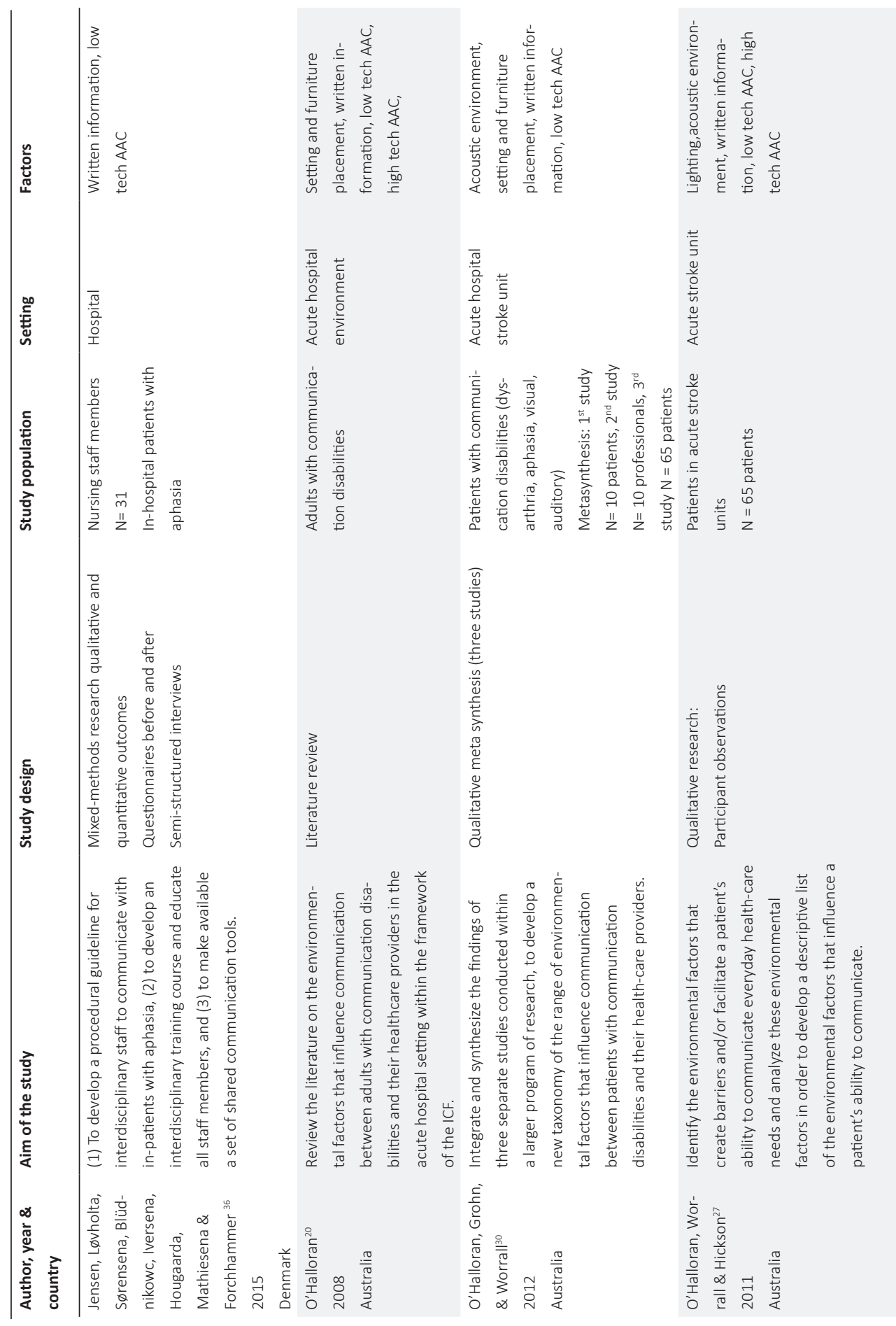




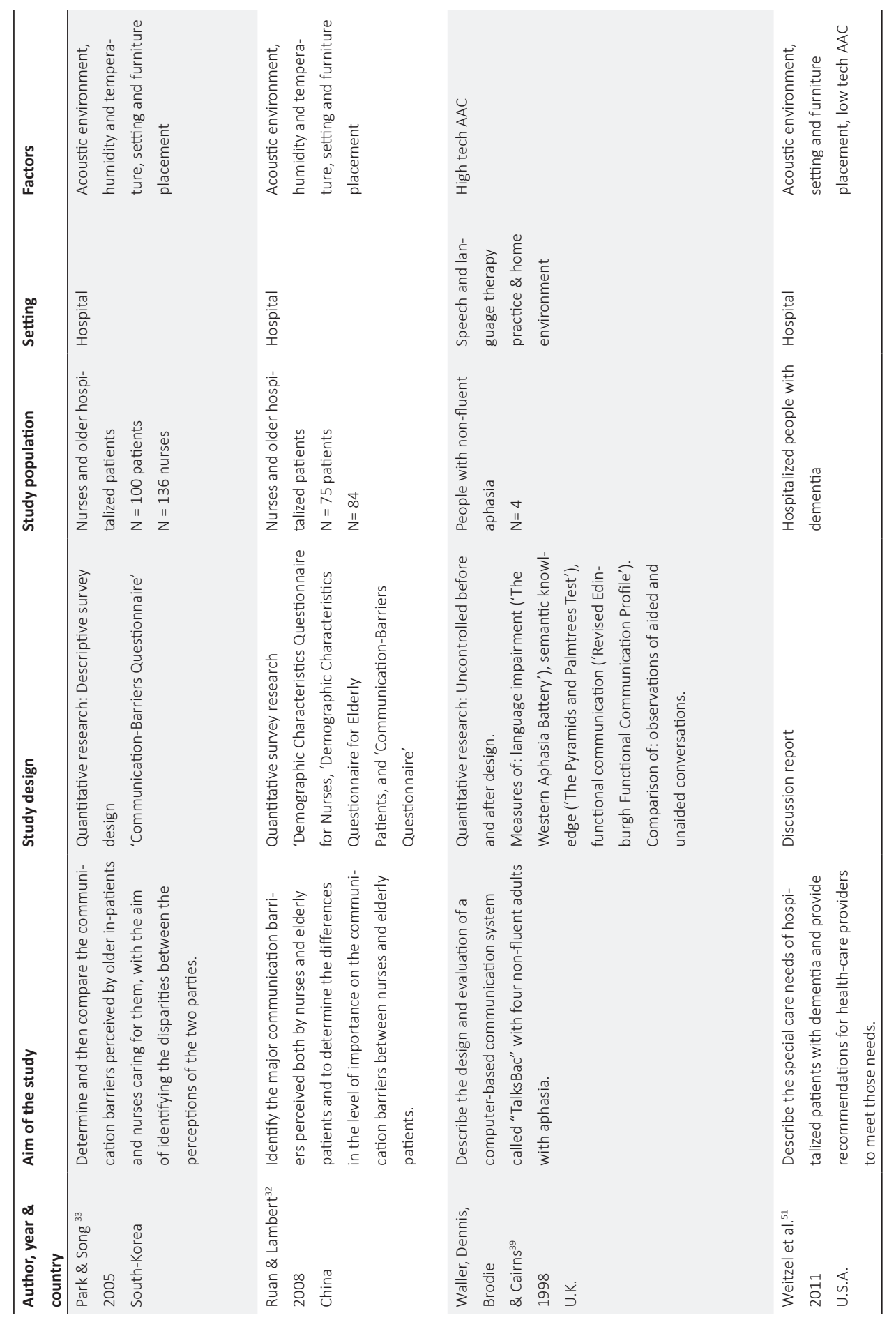

88 | Chapter 4 


\section{Thematic summary of the articles}

A thematic analysis of the articles revealed factors in the physical environment that influence the conversations between people who are communication vulnerable and health-care professionals. These factors were: (1) lighting ( 3 articles); (2) acoustic environment (11 articles); (3) humidity and temperature ( 3 articles); (4) setting and furniture placement ( 8 articles); (5) written information (5 articles); and (6) availability of augmentative and alternative communication (11 articles). Some articles describe more than one factor. The factors are further described using sub-factors in which barriers and strategies were identified (Figure 4.2). First, the factors with regard to human-made changes to the environment are described, followed by the factors related to products and technology (written information and $\mathrm{AAC}) .{ }^{15}$ Since the results are a thematic summary, the order of the factors does not give an indication of their relevance or priority. 


\begin{tabular}{|c|c|}
\hline \multicolumn{2}{|l|}{ Factors in the physical environment } \\
\hline \multicolumn{2}{|l|}{ Lighting } \\
\hline $\begin{array}{l}\text { Barriers: } \\
\text { - } \quad \text { Poor lighting } \\
\text { - } \quad \text { Poorly lit rooms } \\
\text { - } \quad \text { Compromised light } \\
\text { - } \quad \text { Standing in front of a light source }\end{array}$ & $\begin{array}{l}\text { Strategies: } \\
\text { - } \quad \text { Adjustable light } \\
\text { - Brighting the light } \\
\text { - Indirect light } \\
\text { - Natural light } \\
\text { - Light providing visual contrast }\end{array}$ \\
\hline \multicolumn{2}{|l|}{ Acoustic environment } \\
\hline $\begin{array}{l}\text { Barriers: } \\
\text { - Noise } \\
\text { - } \text { Background noise } \\
\text { - Reverberation }\end{array}$ & $\begin{array}{l}\text { Strategies: } \\
\text { - } \quad \text { Modifying sound levels } \\
\text { - } \quad \text { Acoustic materials } \\
\text { Quiet environment }\end{array}$ \\
\hline \multicolumn{2}{|l|}{ Humidity and temperature } \\
\hline \multicolumn{2}{|l|}{$\begin{array}{l}\text { Barriers: } \\
\text { - Temperature changes } \\
\text { - Environmental irritants in the air } \\
\text { - Humidity } \\
\text { - Uncomfortable room temperature }\end{array}$} \\
\hline \multicolumn{2}{|l|}{ Rooms and furniture } \\
\hline $\begin{array}{l}\text { Barriers: } \\
\text { - Unfamiliar environment } \\
\text { - } \quad \text { Lack of single rooms } \\
\text { - } \quad \text { Visual distractions }\end{array}$ & $\begin{array}{l}\text { Strategies: } \\
\text { - } \quad \text { Familiar and constant environment } \\
\text { - Sitting at eye level } \\
\text { - } \quad \text { All persons are visible } \\
\text { - Sitting 3-6 feet from each other }\end{array}$ \\
\hline \multicolumn{2}{|l|}{ Written information } \\
\hline \multicolumn{2}{|c|}{$\begin{array}{l}\text { - Written information } \\
\text { - Pen and paper } \\
\text { - Communication accessible written information: a large print, the use of short sentences, sufficient white space } \\
\text { surrounding the words, less detailed information and graphic representations of the topics. }\end{array}$} \\
\hline \multicolumn{2}{|l|}{ Availability of AAC } \\
\hline \multicolumn{2}{|c|}{$\begin{array}{l}\text { AAC low tech } \\
\text { Visual tools: signs or cue cards, alphabet boards, pictures (charts), communication boards, pain charts, graphic topic } \\
\text { setters, pictographic books, picture pointing board, Talking Mats } \\
\text { Memory tools: remnant books, diaries and watches, memory aids, memory wallets, memory books (with } \\
\text { autobiographical information), external memory aids, labeling items, daily schedules with prompts, real objects }\end{array}$} \\
\hline \multicolumn{2}{|c|}{$\begin{array}{l}\text { AAC high tech } \\
\text { synthesized speech devices, "TalksBac", "Dragon naturally speaking", "Write: outloud", "Co: Writer", pocket talker, } \\
\text { hearing aids and amplified speech. }\end{array}$} \\
\hline
\end{tabular}

Figure 4.2. Factors in the physical environment which play a role in conversations between people who are communication vulnerable and healthcare professionals. 


\section{Lighting}

In studies about conversations with people with dementia ${ }^{26}$ or a stroke, ${ }^{27}$ lighting was described as having an influence on communication. Both the type of light and the position of lighting were considered important. Barriers mentioned were poor lighting, compromised light and standing in front of a light source. ${ }^{27}$ Day and colleagues explain that light particularly affects people with dementia because they often suffer from visual deficits, such as difficulties with colour discrimination, depth perception and sensitivity to contrast. ${ }^{28}$ Strategies mentioned to overcome light as a barrier to communication were using adjustable light, brightening the light, using indirect lighting sources, using natural light, and using light providing visual contrast. ${ }^{26,29}$ Direct light can also be filtered through sheer draperies and shades, and professionals can observe whether the faces of people speaking are in good light. ${ }^{26}$

\section{Acoustic environment}

Sound in an environment, such as (excessive) noise and background noise, was often described as disturbing to conversations between people who are communication vulnerable and healthcare professionals. Several studies mentioned that noise is a barrier to communicating for people with aphasia, $^{30}$ cognitive communication barriers, ${ }^{20,27}$ spasmodic dysphonia, ${ }^{29}$ stroke, ${ }^{20,27}$ dementia, ${ }^{26,28}$ $\mathrm{ALS}^{29,31}$ and hospitalized elderly people..$^{32,33}$ In the studies of Park and Song ${ }^{33}$ and Ruan and Lambert, ${ }^{32}$ noisy environments were rated as one of the most important environmental barriers to communication by patients and nurses. O'Halloran and colleagues describe examples such as oxygen being delivered through a facemask, which can create between 75 and $90 \mathrm{~dB}$ of background noise at the level of the person's ears, and radiology equipment which also creates significant background noise. ${ }^{20}$ Hull and Griffin ${ }^{34}$ described how the acoustic characteristics of environments were often not suitable for communication; hard surfaces and square or rectangular spaces create an unusual amount of reverberation and, therefore, distortion of the sound (and speech) in that environment. ${ }^{34}$

Strategies to change the acoustic environment, such as modifying sound levels (shutting doors and windows), using better acoustic materials, or moving to a quiet environment, were often mentioned as strategies to facilitate conversations between people who are communication vulnerable and professionals..$^{26,31,35}$ Carpeting, softer furniture and drapes could be helpful to absorb sound and reduce reverberation. ${ }^{34}$ According to Bruce and colleagues changes in the auditory environment led to more focused and less stressful interactions for the target group of people who suffered from dementia. ${ }^{26}$ Light and sound level meters were also reported as useful for monitoring environmental barriers and for making appropriate adjustments. ${ }^{26}$ Howe ${ }^{29}$ noted, however, that noise can also be a facilitator for people with Parkinson's disease, as they spoke more loudly when background noise was present.

\section{Humidity and temperature}

Humidity and temperature were identified in three articles as important factors during conversations. Howe ${ }^{29}$ reported in her review that temperature changes, environmental irritants in the air and humidity can be barriers for people who are communication vulnerable. In the studies of Park and Song ${ }^{33}$ and Ruan and Lambert, ${ }^{32}$ uncomfortable room temperature and poorly lit rooms were identified by elderly 
patients and professionals as possible communication barriers in conversations.

\section{Setting and furniture placement}

The characteristics of the setting and furniture placement were also identified in the literature as having an impact on conversations. For example, unfamiliar (hospital) environments could hinder conversations between people who are communication vulnerable and professionals. ${ }^{32,33,35}$ Weitzel and colleagues ${ }^{35}$ explained that people who suffer from dementia in particular can be impaired by an unfamiliar environment, since it limits their ability to understand explanations, follow directions, report symptoms, ask for help, and maintain relationships with professionals. Excessive stimuli (e.g. visual or acoustic distractions) in the immediate environment can hinder people who are communication vulnerable from focusing on a conversation, ${ }^{29,30}$ especially people who suffer from dementia. ${ }^{20}$ The lack of single rooms in a health-care facility can limit the opportunity to have conversations about difficult topics requiring privacy and/or fewer distractions. ${ }^{30}$

Strategies put forward to overcome barriers in rooms and furniture include using a familiar and constant environment, rearranging furniture in the room to make sure that people sit at eye level, and that all people are completely visible and sitting at a distance between 3-6 feet from each other. 26,29,34,35

Park and Song advise providing a detailed admission orientation in which necessary adjustments are discussed, ${ }^{33}$ as the factors may contradict each other. For example rearranging the furniture may make the environment of the person who is communication vulnerable less familiar.

\section{Written information}

The availability of written information was described as a facilitator in conversations with people who are communication vulnerable, to help them understand information from professionals. ${ }^{27,30}$ Research shows that people who had a stroke or with cognitive communication impairments benefited from written information. O'Halloran and colleagues found that clients with cognitive communication impairments did not receive any written information to help them recall the detailed information given to them verbally during discharge..$^{30}$ When providing written information it is essential that the written information is communicatively accessible for the different target groups. ${ }^{17,20}$ Suggested strategies to enhance the communication accessibility of written information are: large print, the use of short sentences, sufficient white space surrounding the words, less detailed information, and graphic representations of the topics. ${ }^{17,27,29,30}$ The use of pen and paper can also be beneficial in conversations between these target groups and professionals. ${ }^{17}$ Pen and paper can be used as a strategy to write keywords, use drawings or prompt clients to write. ${ }^{36}$ Dialog notebooks can be used in which patients or professionals write their notes during conversations. ${ }^{36} \mathrm{O}^{\prime} \mathrm{Halloran}$ and colleagues noted that is it important that pen and paper are directly available during conversations, to help clients to express themselves. ${ }^{20}$

\section{Augmentative and alternative communication}

Several articles noted the availability of augmentative and alternative communication tools (AAC) as 
communication-facilitating objects in the physical environment. ${ }^{17,20,26,27,30}$ According to the literature, the availability of AAC can facilitate and support communication between people who are communication vulnerable and professionals..$^{17,20,26} \mathrm{AAC}$ should be tailored to the needs of the person concerned..$^{17,27,30}$ Both low tech AAC (non-electronic) and high tech AAC (electronic) were mentioned in the included publications.

\section{Low tech AAC}

The literature explains that people who are communication vulnerable can benefit from non-electronic visual tools or information during conversations, ${ }^{20}$ such as signs or cue cards, ${ }^{26}$ alphabet boards,,$^{17,20,30}$ pictures (charts), ${ }^{30,36}$ communication boards, ${ }^{30}$ pain charts, ${ }^{30}$ graphic topic setters, ${ }^{17,37}$ pictographic books, ${ }^{38}$ picture pointing boards, ${ }^{36}$ translated picture resources, ${ }^{36}$ and tools such as Talking Mats. ${ }^{17,29}$ Visual cues were used to increase communication effectiveness (e.g. for people who suffer from dementia), or to help with following instructions (e.g. for people with communication disabilities). ${ }^{27,30}$ Weitzel and colleagues ${ }^{35}$ and Bruce and colleagues ${ }^{26}$ described that augmentative aids which focus on compensating memory have also proved to be valuable in improving conversations. Examples of these aids are: remnant books, diaries and watches, memory aids, memory wallets, memory books (with autobiographical information), external memory aids, labelling items, daily schedules with prompts and the use of real objects to aid communication. . $6,35^{26}$

\section{High tech $A A C$}

High tech electronic AAC were mentioned to support conversations, mostly facilitating verbal expression. Examples are synthesized speech devices, ${ }^{29}$ "TalksBac", ${ }^{17,29}$ "Dragon naturally speaking", ${ }^{17}$ "Write: outloud", ${ }^{17}$ "Co: Writer", ${ }^{17}$ and amplified speech. ${ }^{27}$ Howe and colleagues reported in two publications ${ }^{17,29}$ that electronic AAC systems such as synthesized speech devices serve as facilitators to support conversations for people with aphasia and dysarthria. Another AAC that appeared to be helpful in supporting communication for people who suffer from severe aphasia, was the program "TalksBac". ${ }^{17,29,39}$

Waller and colleagues, ${ }^{39}$ found that the use of TalksBacled to an increase in the communication-vulnerable person's control of the conversation, and an increase in the communication partner's understanding of the person who is communication vulnerable. Amplified speech of good sound quality can also support conversations with professionals for people who, for example, suffer from a communicative impairment. ${ }^{27}$ 


\section{Discussion}

This scoping review aimed to provide an overview of factors in the physical environment that contribute to communication in conversations between people who are communication vulnerable and health-care professionals. In total, 16 publications were included, containing various types of publications (book chapters, discussion papers, and research articles) and different types of research (literature reviews, qualitative and quantitative designs). The findings revealed six factors that can have an influence on conversations: (1) lighting, (2) acoustic environment, (3) humidity and temperature, (4) setting and furniture placement, (5) written information, and (6) the availability of AAC.

The findings of the studies in the current review did not always explain why the factors in the physical environment had a positive or negative influence on conversations. For example, in the studies by Park and Song ${ }^{33}$ and Ruan and Lambert, ${ }^{32}$ a questionnaire was used to explore the communication barriers perceived by older patients and nurses. The results of this questionnaire included, for example, the factors "uncomfortable room temperature" and "poorly lit room". Due to the nature of the data collection method, there was no further insight about how and why room temperature and poorly lit rooms influenced communication.

The results in the included studies were based upon observations from the perspective of the researcher, ${ }^{27,30,37-39}$ the views of health-care professionals, ${ }^{26,30,32,33}$ the existing literature or the knowledge of the authors themselves. . $^{20,28,29,34,35}$ It was striking that in most of the included studies the perspective of people who are communication vulnerable themselves is lacking; although their point of view should be leading. Only four studies included the views of people who were communication vulnerable in their research, ${ }^{30-33}$ leading to an insufficient insight into the experienced facilitators and barriers of people who are communication vulnerable.

Since this study did not examine the quality of the studies reviewed, readers should not perceive the results as proven effects, but (according to the aim of this scoping review) as factors that are important to consider during conversations between people who are communication vulnerable and health-care professionals. The methodologies and designs in the articles were not always described in detail; for example in the Howe study ${ }^{29}$ the method was described as a "review", but it did not specify what kind of review. In this review the well-established Arksey and O'Malley framework ${ }^{23}$ was used to systematically conduct a scoping review from scientific databases.

The use of the ICF as a theoretical foundation to describe the physical environment contributed to a widespread acknowledged interdisciplinary definition of the studied area. In this review, reports written in English, Dutch as well as German were considered, however it is possible that studies written in other languages could also have met the inclusion criteria. 
Several challenges relating to the search strategy will be further discussed. Searching for literature about the physical environment was a challenge since the term is not commonly used in research, and it is not a MESH term, although the term "physical environment" is an acknowledged term in the ICF. We used multiple synonyms to ensure that all relevant publications about the physical environment were included. Furthermore, in the search process we used the keyword "communication disorders" to include studies about people with communication disorders. We added neurological diagnoses that are often linked to communication difficulties with the Boolean operator "OR" to further expand our literature search. We did not include all neurological search terms, since this would lead to an enormous number of terms and therefore also publications. If a publication was found about another neurological diagnosis which was not included as a MESH term, but was related to the communication difficulties of the client, it was included during the study selection phase. Despite the rigorous search process, some studies could have been missed.

Although AAC are part of the physical environment as "objects", we did not specifically include AAC in our search strategy since we did not focus on AAC as dedicated devices for individuals, but as objects that could be present in the physical environment to support conversations. The research on AAC is extensive, and focusing on specific AAC would blur the emphasis on the physical environment.

The current scoping review excluded studies about children, because their communication difficulties often relate to their development and require different, specific adjustments. Conversations with children also have a different process, as parents most often play an important role in their health-care process and decisions.

In this review, we specifically searched for information about the role of the physical environment in health-care settings, since effective communication is essential in these settings for clientcentred care and shared decision making. ${ }^{1,4}$ The first setting to provide communication friendly environments should be the health-care setting, since these settings are fundamentally aimed at supporting people with an impairment. Health-care environments could set an example for other environments, such as public spaces.

Current research about communication between clients and professionals often focuses on the attitudinal and social environment; for example verbal communication strategies are studied, such as types of questions, double checking, listening etc. ${ }^{40,41}$ This scoping review reveals that factors in the physical environment also have an important impact on conversations. These factors might also be supportive for conversations with clients who are not necessarily communication vulnerable. We can wonder why we provide wheelchair access ramps, but are often unaware that we can also provide communication access ramps. ${ }^{42,43}$

The literature described strategies that can be used to implement changes to the physical environment: the awareness of health-care professionals, and the use of toolkits or questionnaires. An overall 
awareness by health-care professionals of the potential influence of environmental elements on conversations is recommended. O'Halloran and colleagues $^{30}$ argued, therefore, that professionals should receive knowledge about interventions related to adjusting the physical environment to improve conversations. Howe ${ }^{29}$ focused on speech and language pathologists, who should address both personal and environmental factors when providing interventions for people who are communication vulnerable.

Bruce and colleagues ${ }^{26}$ developed a toolkit, the Environment and Communication Assessment Toolkit (ECAT) which provides an assessment of the physical environment, information about the impact of the environment on communication, and resources to make recommendations and implement interventions. This toolkit includes, for example, a tool that helps to identify the appropriate text size for a person with dementia. ${ }^{26}$ The results of their study showed that the ECAT increased the awareness of environmental modifications, influenced the practice of recommending environmental modifications, and was beneficial in diverse elements of clinical practice. The current review revealed no other assessments that examine the physical environment. Such assessments do exist; however, these probably did not emerge in this search because they often contain only a small number of questions about the environment in relation to communication. Examples are: the Craig Handicap Assessment and Reporting Technique (CHART), ${ }^{44}$ Measure of the Quality of the Environment (MQE), ${ }^{45}$ Measure of the Stroke Environment (MOSE), ${ }^{46}$ and the Stroke and Aphasia Quality of Life Scale-39 (SAQOL-39). ${ }^{47}$ Furthermore, assessments often focus on one diagnosis, such as the Profile of the Communication Environment of the Adult Aphasic. ${ }^{48} \mathrm{~A}$ systematic review looking at all measures which include questions about communication friendly environments might be valuable.

\section{Clinical implications and future research}

Health-care professionals need to have a broader view of the impact of the environment and the broad range of supportive adjustments in the physical environment when communicating with people who are communication vulnerable. However, professionals often have to work in inappropriate environments ${ }^{49}$ and do not have the ability to change this environment. Professionals need the support of institutional governance and health-care systems to make the physical environments of institutions communication accessible. ${ }^{19}$ On the other hand, as the results of this review reveals, small adjustments can contribute to a communication friendly environment for conversations.

The findings of this review reveal the need for greater awareness in health-care professionals with regard to factors in the physical environment. Educational training should pay attention to the importance of the six factors, an awareness of the impact of the physical environment on conversations, and skills to adjust the environment.

Most articles in this review described observational research, and research studying the needs of people who are communication vulnerable from their own perspective, is lacking. More research is needed to 
address these gaps, in order to better understand the impact of the physical environment for people who are communication vulnerable, and to provide professionals with relevant tools and strategies to improve their conversations. Qualitative methods could be used in future research to better understand how people who are communication vulnerable and health-care professionals perceive the influence of the physical environment during conversations. Quantitative methods could be used to study the effect which the factors identified in this research have on conversations. Tools such as the ECAT ${ }^{26}$ could be combined for use as quantitative measurements of the physical environment.

\section{Conclusions}

Our review found that relatively small and simple strategies to adjust the environment (e.g. improving lighting, reducing noise, using pen and paper, and using AAC such as talking mats) can support communication in conversations. Adjusting the physical environment can enable people who are communication vulnerable to express themselves better, understand others better, and be involved in decisions affecting their care and daily life. It is recommended that health-care professionals have an overall awareness of the potential influence of environmental factors on conversations. To date, as this scoping review confirms, little attention has been paid to how and why these factors influence conversations, and how people who are communication vulnerable perceive them. 


\section{References}

1. McGilton KS, Sorin-Peters R, Sidani S, et al. Patient-centred communication intervention study to evaluate nursepatient interactions in complex continuing care. BMC Geriatr. 2012;12:61.

2. Bartlett G, Blais R, Tamblyn R, et al. Impact of patient communication problems on the risk of preventable adverse events in acute care settings. Cmaj. 2008;178:1555-1562.

3. Dalemans RJ, De Witte LP, Beurskens AJ, et al. An investigation into the social participation of stroke survivors with aphasia. Disabil Rehabil. 2010;32:1678-1685.

4. Elwyn G, Edwards A, Kinnersley P. Shared decision-making in primary care: the neglected second half of the consultation. Br J Gen Pract. 1999;49:477-482.

5. Sheldon LK, Barrett R, Ellington L. Difficult communication in nursing. J Nurs Scholarsh. 2006;38:141-147.

6. Hemsley B, Balandin S, Worrall L. Nursing the patient with complex communication needs: time as a barrier and a facilitator to successful communication in hospital. J Adv Nurs. 2012;68:116-126.

7. Blackstone SW. Augmentative communication news. Augment Commun. 2009;21:1-5.

8. Costello JM, Patak L, Pritchard J. Communication vulnerable patients in the pediatric ICU: Enhancing care through augmentative and alternative communication. J Pediatr Rehabil Med. 2010;3:289-301.

9. Stans SE, Dalemans R, de Witte L, et al. Challenges in the communication between 'communication vulnerable' people and their social environment: An exploratory qualitative study. Patient Educ Couns. 2013;92:302-312.

10. WHO. 2015 What are neurological disorders? 2015; [cited 30-11-2015]. Available from: http://www.who.int/features/ qa/55/en/

11. World Health Organization. Geneva: World Health Organization; 2001; [cited 2015 Dec 15]. Available from:http://www.who.int/ classifications/icf/icfbeginnersguide.pdf? ua $1 / 41$

12. Silverman J, Kurtz S, Draper J. Vaardig communiceren in de gezondheidszorg. Den Haag: Boom Lemma uitgevers; 2014.

13. Mazzi MA, Rimondini M, Deveugele M, et al. What do people appreciate in physicians' communication? An international study with focus groups using videotaped medical consultations. Health Expect. 2013;18:1215-1226.

14. Uitterhoeve RJ, Bensing JM, Grol RP, et al. The effect of communication skills training on patient outcomes in cancer care: a systematic review of the literature. Eur J Cancer Care (Engl). 2010;19:442-457.

15. WorldHealthOrganization. International classification of functioning, disability and health: ICF. Geneva: World Health Organization; 2001. [cited 2015 Nov 30]. Available from: http://www.who.int/classifications/icf/en/.

16. Kielhofner G. Model of human occupation. Baltimore: Lippincott Williams \& Wilkins; 2008.

17. Howe TJ, Worrall LE, Hickson LMH. What is an aphasiafriendly environment? Aphasiology 2004;18:1015-1037.

18. Bricout JC, Gray DB. Community receptivity: the ecology of disabled persons' participation in the physical, political and social environments. Sjdr. 2006;00:1-21.

19. Hammel J, Jones R, Smith J, et al. Environmental barriers and supports to the health, function, and participation of people with developmental and intellectual disabilities: report from the State of the Science in Aging with Developmental Disabilities Conference. Disabil Health J. 2008;1:143-149.

20. O'Halloran R, Hickson L, Worrall L. Environmental factors that influence communication between people with communication disability and their healthcare providers in hospital: a review of the literature within the International Classification of Functioning, Disability and Health (ICF) framework. Int J Lang Commun Disord. 2008;43:601-632.

21. Soril LJ, Leggett LE, Lorenzetti DL, et al. Effective use of the built environment to manage behavioural and psychological symptoms of dementia: a systematic review. PLoS One 2014;9:e115425.

22. Wylie K, McAllister L, Davidson B, et al. Changing practice: implications of the World Report on Disability for responding to communication disability in under-served populations. Int J Speech. Lang Pathol. 2013;15:1-13.

23. Arksey H, O’Malley L. Scoping studies: towards a methodological framework. Int J Soc Res Methodol. 2005;8:19-32.

24. Halas G, Schultz AS, Rothney J, et al. A scoping review protocol to map the research foci trends in tobacco control over the last decade. BMJ Open 2015;5:e006643.

25. Levac D, Colquhoun H, O’Brien KK. Scoping studies: advancing the methodology. Implement Sci. 2010;5:69.

26. Bruce C, Brush JA, Sanford JA, et al. Development and evaluation of the environment and communication assessment toolkit 
with speech-language pathologists. Semin Speech Lang. 2013;34:42-51.

27. O'Halloran R, Worrall L, Hickson L. Environmental factors that influence communication between patients and their healthcare providers in acute hospital stroke units: an observational study. Int J Lang Commun Disord. 2011; 46:30-47.

28. Day K, Carreon D, Stump C. The therapeutic design of environments for people with dementia: a review of the empirical research. Gerontologist 2000;40:397-416.

29. Howe TJ. The ICF Contextual Factors related to speech-language pathology. Int J Speech Lang Pathol. 2008;10:27-37.

30. O'Halloran R, Grohn B, Worrall L. Environmental factors that influence communication for patients with a communication disability in acute hospital stroke units: a qualitative metasynthesis. Arch Phys Med Rehabil. 2012;93:S77-S85.

31. Ball LJ, Beukelman DR, Pattee GL. Communication effectiveness of individuals with amyotrophic lateral sclerosis. J Commun Disord. 2004;37:197-215.

32. Ruan J, Lambert VA. Differences in perceived communication barriers among nurses and elderly patients in China. Nurs Health Sci. 2008;10:110-116.

33. Park EK, Song M. Communication barriers perceived by older patients and nurses. Int J Nurs Stud. 2005;42:159-166.

34. Hull RH, Griffin KM. Environmental factors in communication with older persons. Communication disorders in aging. Thousand Oaks, CA, US: Sage Publications; 1989.

35. Weitzel T, Robinson S, Barnes MR, et al. The special needs of the hospitalized patient with dementia. MEDSURG Nursing 2011;20:13-19.

36. Jensen LC, Lovholt AP, Sorenson IR, et al. Implementation of supported conversation for communication between nursing staff and in-hospital patients with aphasia. Aphasiology 2015;29:57-80.

37. Garrett KL, Huth C. The impact of graphic contextual information and instruction on the conversational behaviours of a person with severe aphasia. Aphasiology 2002;16: 523-536.

38. Ho KM, Weiss SJ, Garrett KL, et al. The effect of remnant and pictographic books on the communicative interaction of individuals with global aphasia. Aac. 2005;21:218-232.

39. Waller A, Dennis F, Brodie J, et al. Evaluating the use of TalksBac, a predictive communication device for nonfluent adults with aphasia. Int J Lang Commun Disord. 1998;33: 45-70.

40. Jesus TS, Silva IL. Toward an evidence-based patientprovider communication in rehabilitation: Linking communication elements to better rehabilitation outcomes. Clin Rehabil. 2016;30:315-328.

41. Kurtz S, Silverman J, Draper J. Teaching and learning communication skills in medicine. 2nd ed. Oxford: Radcliffe Medical Press; 2005.

42. Dalemans RJP. Stroke survivors with aphasia and their social participation Maastricht: Maastricht University; 2010.

43. Kagan A, Gailey GF. Functional is not enough: training conversation partners for aphasic adults. San Diego: Singular Publishing Group; 1993

44. Whiteneck GG, Charlifue SW, Gerhart KA, et al. Quantifying handicap: a new measure of long-term rehabilitation outcomes. Arch Phys Med Rehabil. 1992;73:519-526

45. Foley KR, Girdler S, Bourke J, et al. Influence of the environment on participation in social roles for young adults with down syndrome. PLoS One 2014;9:e108413.

46. Babulal GM, Tabor Connor L. The measure of stroke environment (MOSE): development and validation of the MOSE in post-stroke populations with and without aphasia. Top Stroke Rehabil. 2016;1-10.

47. Hilari K, Byng S, Lamping DL, et al. Stroke and Aphasia Quality of Life Scale-39 (SAQOL-39): evaluation of acceptability, reliability, and validity. Stroke 2003;34: 1944-1950.

48. Lubinski R, editor. Environmental systems approach to adult aphasia: New York: Lippincott, Williams \& Williams; 2001.

49. Hull RH. Environmental factors in communication with older persons. In: Hull RH, Griffin KM, editors. Communication disorders in aging. Michigan: SAGE Publications; 1989. p. 153-161.

50. Howe TJ. The ICF contextual related to speech-language pathology. Int J Speech Lang Pathol. 2008;10:27-37.

51. Weitzel T, Robinson S, Barnes MR, et al. The special needs of the hospitalized patient with dementia. Medsurg Nurs. 2011;20:13-18. quiz 9. 



\section{Chapter 5}

\section{Using Talking Mats to support conversations with people who are communication vulnerable: a scoping review}




\section{Abstract}

\section{Background}

Talking Mats ${ }^{\mathrm{TM}}$ is a framework developed to support communication with communication vulnerable people.

\section{Objective}

The objective was twofold: to provide an overview of the objectives, target groups and settings for which Talking Mats has been used (Part 1), and an overview of empirical scientific knowledge on the use of Talking Mats (Part 2).

\section{Methods}

In this scoping review scientific and grey literature was searched in PubMed, Cinahl, Psychinfo, Google, and Google Scholar. Articles that described characteristics of Talking Mats or its use were included. For Part 2, additional selection criteria were applied to focus on empirical scientific knowledge.

\section{Results}

The search yielded 73 publications in Part 1, 12 of which were included in Part 2. Talking Mats was used for functional objectives (e.g. goal setting) and to improve communication and involvement. Part 2 showed that Talking Mats had positive influences on technical communication, effectiveness of conversations, and involvement and decision making in conversations. However, the level of research evidence is limited.

\section{Conclusions}

Talking Mats can be used to support conversations between professionals and communication vulnerable people. More research is needed to study the views of people who are communication vulnerable and to study the effects of Talking Mats. 


\section{Introduction}

Effective communication is essential in healthcare. ${ }^{1,2}$ However, conversations between communication vulnerable people and professionals are problematic, and the communicative difficulties of communication vulnerable people lead to major challenges in achieving self-advocacy and participation in healthcare decision making. ${ }^{3,4}$ Different definitions of communication vulnerable people have been proposed in the literature. ${ }^{5,6}$ We define them as those who struggle to communicate in a particular environment due to a medical condition. They experience difficulties in expressing their needs and/or in understanding information. Communication may be their primary disability, or their communication issues may be secondary to another disability. Limitations in any of the several areas of functioning can lead to someone being classified as communication vulnerable; for example, those with sensory, emotional, physical and cognitive difficulties. ${ }^{7}$

Augmentative and alternative communication (AAC) tools can enable communication vulnerable people to express themselves and understand others, supporting self-advocacy. Such tools can also support professionals in understanding clients and enabling a partnership. This paper uses the broad definition of AAC by Clarke and Bloch, ${ }^{8}$ which incorporates different forms of AAC: formal communication aid systems (e.g. voice output communication aids), conventional semiotic systems (e.g. handwriting), as well as unaided resources (e.g. gesture) and commonplace objects (e.g. maps or letters).

Talking Mats is an AAC tool that cannot be classed under a specific type of AAC, but seems to have the potential to support a wide range of communication vulnerable people. Talking Mats is a visual framework, which has been developed in the United Kingdom. Its main features are that it visualises views (feelings, opinions) and choices in a conversation, and structures the conversation. ${ }^{9}$ The process of using Talking Mats is as follows (see figure 5.1):

1. Central topic symbol: The two persons having the conversation decide on a topic they want to talk about and place a symbol representing this topic at the bottom of the mat (for example, "activities you want to learn").

2. Option symbols: A set of option symbols related to the central topic is available (for example, "cooking", "gardening", and "biking"). The professional/caregiver presents option symbols one by one to the person who is communication vulnerable asking them how they feel or think about this option.

3. Top scale symbols: The top scale symbols indicate the person's feeling or opinion (for example, "positive", "don't know", and "negative"). The communication vulnerable person can indicate their feelings or opinions about each option by placing the option symbol under the top scale. The professional/caregiver then asks questions to confirm this placement. The person who is communication vulnerable is always meant to be in control by indicating the placement of the symbols through verbal cues, pointing, or eye movement. ${ }^{10}$

4. Visual summary: The professional/caregiver recapitulates the discussion and asks for more confirmation regarding the feelings/opinions expressed by the person. The mat presents a visual 
summary of the conversation (the mats are often photographed at the end of the conversation to preserve the content of the conversation). ${ }^{11}$

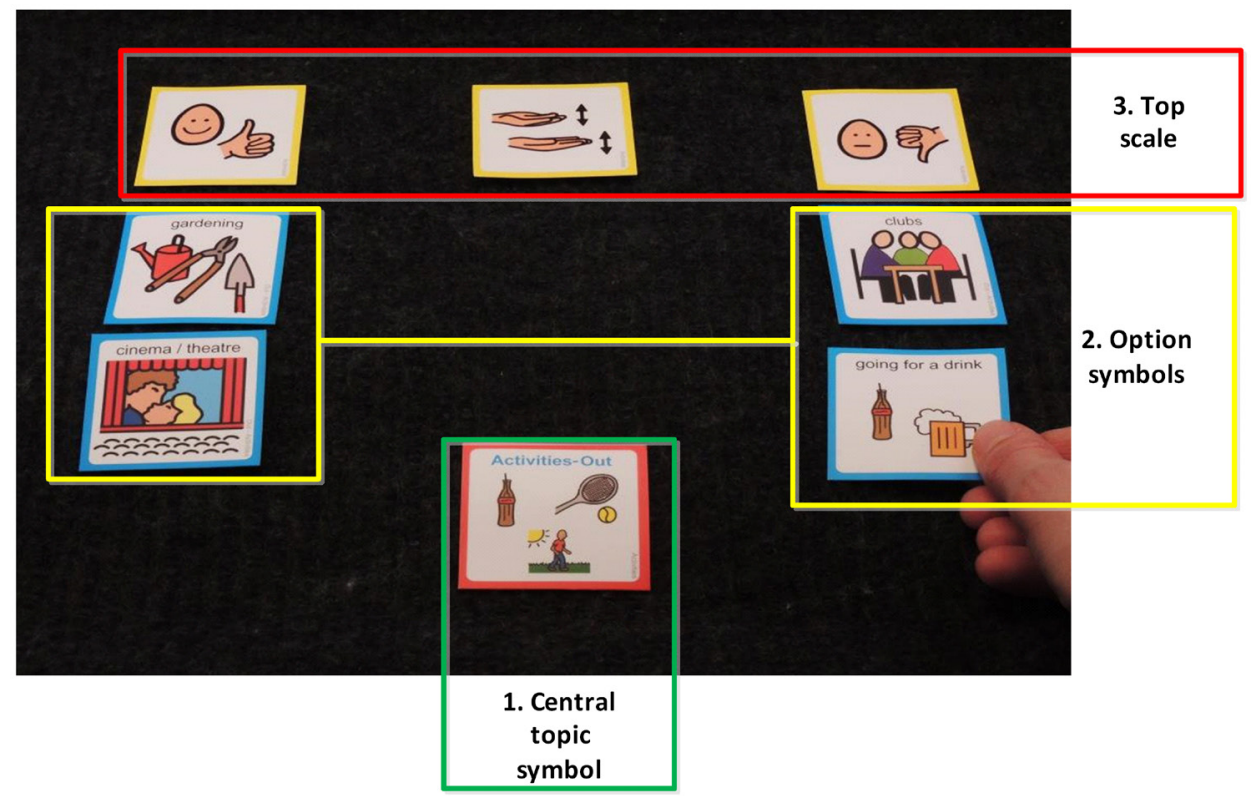

Figure 5.1. Example of a completed Talking Mats. The materials used originate from Talking Mats Limited organisation.

Talking Mats has been variously characterised as a low-technology tool, ${ }^{12}$ a visual framework, ${ }^{13}$ a procedure, ${ }^{9}$ a technique, ${ }^{14}$ a resource, ${ }^{15}$ or a method. ${ }^{16}$ It has been used with different target groups, including people with dementia but also children. The literature is also inconsistent about the objectives for which one should use Talking Mats, for example for a casual conversation or for therapy goal setting. ${ }^{17-19}$ Furthermore, there is no review available about the evidence for the effects of Talking Mats on different target groups. While Talking Mats seems to be used widely in the UK, an overview of its objectives, the target groups and settings for which it can be used, and its effectiveness is lacking.

Talking Mats is a different form of AAC than conventional AAC tools, as it both uses visualisation and provides a structure for a conversation. Studying the characteristics and use of Talking Mats and evidence for its effectiveness is therefore valuable for both research into AAC and for professionals and clients in healthcare. An overview of such knowledge about Talking Mats is needed to provide healthcare professionals with information about whether, when, and how they can use Talking Mats. The purpose of this scoping review is twofold: to provide an overview of the objectives, settings, and target groups in which Talking Mats has been used (Part 1), and an overview of the empirical scientific knowledge about the use of Talking Mats (Part 2). 


\section{Method}

This review was guided by the methodological framework for scoping reviews by Arksey and O'Malley. ${ }^{20}$ Scoping reviews are suitable for studying the current state of knowledge on a topic, in order to comprehensively and systematically map the relevant literature, and identify key concepts and gaps in research ${ }^{21}$. The present literature review included two parts:

Part 1: An overview of the objectives, settings and target groups for which Talking Mats has been used, for which we included peer reviewed and grey literature.

Part 2: An overview of empirical scientific knowledge about the use of Talking Mats within the objectives identified in Part 1. For this part, only peer-reviewed scientific literature was included. The methods used in this scoping review are described below according to the stages of the Arksey and O'Malley framework, making a distinction between Parts 1 and 2 .

\section{Identifying relevant studies}

A combination of search methods was used, including (a) the scientific databases PubMed, Cinahl, and Psychinfo, (b) the electronic search engine Google (including Google Scholar), (c) a publication list on the "Talking Mats Limited" website (the organisation that developed Talking Mats). ${ }^{22}$ The search term "Talking Mats" was used, restricted to title and abstract in the scientific databases, and as a free text word combination in Google (and Google Scholar). The search was restricted to materials published in English, Dutch, and German (the foreign languages with which the researchers are familiar) and published between 1998 and 2016 (Talking Mats appeared in the literature for the first time in 1998). The search using Google and Google Scholar was continued until saturation (no new articles after 100 hits). Duplicates were immediately ignored. The search was used for both Part 1 and Part 2, and was completed in December 2016.

\section{Study Selection}

During the study selection for Part 1, one researcher (SS) identified publications in which Talking Mats was mentioned in the title or abstract. The selected articles were then read and screened independently at full-text level by two researchers (SS and RD). Full-text articles were included if characteristics of Talking Mats were described, and/or if Talking Mats was used as an intervention in a study. Articles were excluded at full-text level if Talking Mats was merely mentioned, without being described, used, or studied. Due to the broad scope of Part 1, we imposed no restrictions on research type during the selection phases. After the inclusion of full texts, the researchers screened the reference lists of the selected articles for additional relevant publications. When necessary, two other researchers (AB \& LD) were involved in the consensus process during the selection. 
To focus specifically on scientific literature in Part 2, additional selection criteria were applied to the full-text publications included in Part 1.

These selection criteria were: publication in a peer-reviewed journal, empirical study, and evaluation of the use of Talking Mats described in the study aims. The researchers used no restriction for research type, as scoping reviews are suitable for studying broad topics, and the inclusion of information in scoping reviews is not limited by the methodological quality of the research. ${ }^{20,21}$ Two researchers (SS, $\mathrm{RD}$ ) independently performed the selection process, and differences of opinion were discussed until consensus was reached. When necessary, two other researchers ( $A B$ and $L D$ ) were involved in the consensus process.

\section{Charting the data and collating, summarising and reporting the results}

For part 1, one researcher (SS) charted the data by reading and extracting descriptive data (i.e. year, author, country, target group, setting). Thereafter, an analysis focussing on the objectives of Talking Mats was performed by two researchers (SS, RD), following the principles of conventional content analysis. ${ }^{23}$ First, text related to the objectives of the use of Talking Mats was highlighted in the publications. Second, these text fragments were given codes describing the type of objective they described. Third, these codes were arranged in overarching themes relating to the objectives of Talking Mats.

For part 2, we extracted from each publication the author, year, country, aim of the study, participants and setting, target population and settings, objectives of Talking Mats, methods, and results. The results of the studies were then described, linked to the objectives of Talking Mats identified in Part 1.

Furthermore, an overview was made of quality-related elements that had (+) or had not (-) been included in the publications. To achieve this for the quantitative studies, we used a list based on a quality measure for scoping reviews developed by Bastawrous and colleagues ${ }^{24}$. For the qualitative studies, we used a list based on the Critical Appraisal Skills Programme's (CASP) tool. ${ }^{25}$ For mixed methods studies, both lists were used. One researcher (SS) applied these lists, and checked unclear cases with a second researcher (RD). 


\section{Results}

Seventy-three articles were included in Part 1. After the additional selection criteria had been applied, 12 publications were included in Part 2. See figure 5.2 for a detailed summary of the abstract, full text, and inclusion numbers.

\section{About Talking Mats}

Talking Mats is a commercially available tool. It was originally developed by a group of speech and language pathology researchers to support people with cerebral palsy in the UK. ${ }^{26}$ Based on positive experiences, it has since also been used in research and practice for many different target groups. ${ }^{27,28}$ The literature indicates that Talking Mats provides a structure in which topics/options are broken down into small units or chunks. Such a structure can enable a person to consider topics or options in relation to each other, focusing solely on the essential words/topics. This could also reduce cognitive load, help people process concepts more easily, reduce distractibility, and reduce memory demands. ${ }^{3,9,18,29}$ Talking Mats can be applied to discuss a specific topic, and is intended to be a supplement to a person's individual communication skills and strategies. ${ }^{18}$

Talking Mats has been described as a flexible communication framework, which should be used as a dynamic process that changes and reflects the person's opinions at a specific time. ${ }^{30}$ According to published descriptions, Talking Mats does not replace verbal, non-verbal, or other AAC-supported communication, but aims to support these communication modes in conversations by using a picture-based framework. ${ }^{16}$ The literature indicates that Talking Mats can encourage a person to use different channels for communication: auditory (talking about views), as well as tactile (placing symbols on a mat) and visual (symbols for the theme, the options, and choices). ${ }^{29}$ The main feature of Talking Mats is that it visualises views (feelings, opinions) and choices in a conversation, also described as "building a picture of your views". ${ }^{9}$ A visual summary of the choices made as a result of the conversation is then displayed on the mat. ${ }^{11}$ 


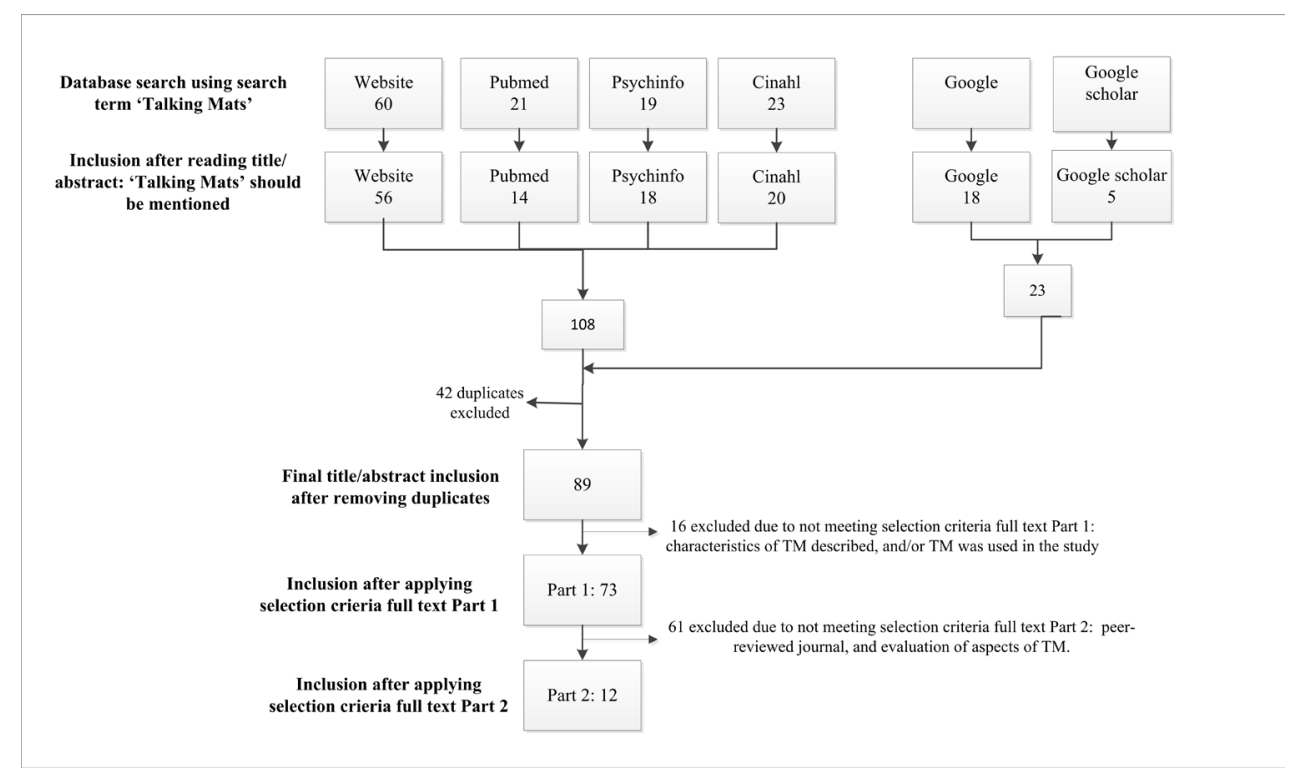

Figure 5.2 Number of studies included in the review during each phase.

\section{Part 1: Overview of the objectives, settings and target groups for which Talking Mats has been used}

Part 1 included publications from several countries: the UK (62 publications), Sweden (four publications), South Africa (four publications), Norway (1 publication), Malta (1 publication), and the Netherlands (1 publication). Included were peer-reviewed journal articles, research reports, book chapters, website reports, and conference abstracts. The objectives for which Talking Mats has been used, as well as an overview of settings and target groups are described below. A full overview of the details of the included articles can be found in table 5.1.

\section{Objectives}

Three main themes emerged regarding the objectives of using Talking Mats: facilitating communication, facilitating involvement, and functional use. Figure 5.3 provides an overview of these themes and subthemes. 


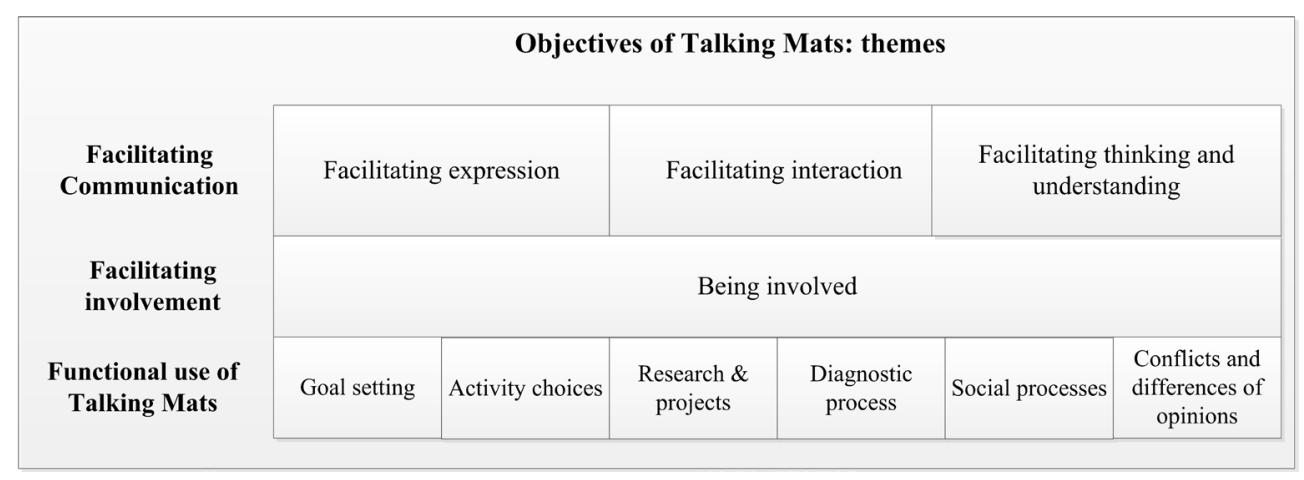

Figure 5.3 Visual presentation of the results of the thematic analysis of the objectives of Talking Mats.

\section{Facilitating communication}

Within the theme of "facilitating communication", the following subthemes were identified: facilitating expression, facilitating interaction, and facilitating thinking and understanding by structuring conversations into small units. ${ }^{3,16,31}$ The subtheme of facilitating expression included expressing opinions, thoughts, or feelings. ${ }^{3,16,31}$

\section{Facilitating involvement}

The "facilitating involvement" theme included facilitating involvement in interactions with individuals or groups, and facilitating involvement in decision-making. ${ }^{30,32,33}$

\section{Functional use of Talking Mats}

Six subthemes were identified with regard to "functional use of Talking Mats":

- Goal setting: enabling people to identify, set, and review their own goals ${ }^{34}$.

- Enabling people to make activity choices, 27,35 including exploring which activities people want to do on a daily basis. ${ }^{27,35}$

- Supporting people's participation in research and projects. ${ }^{36,37}$ For example, Talking Mats could support the process of obtaining consent for research. Talking Mats could also support an interview procedure or project meeting, or make standard questionnaire items accessible to communication vulnerable people. ${ }^{36,37}$

- Facilitating a diagnostic process. ${ }^{38}$ For example, Talking Mats was used to assess anxiety in children before an operation. ${ }^{38}$

- Improving social processes..27,29 For example Talking Mats could help people get to know someone or develop and maintain relationships. ${ }^{27,29}$

- Resolving conflicts and differences of opinion. . $^{939}$ 


\section{Settings and target groups}

The use of Talking Mats was described in a wide variety of settings, such as home environments, institutional care, rehabilitation, schools, and prisons. Target groups for which Talking Mats was used were:

- People with specific communication difficulties (17 publications);

- People with learning disabilities (19 publications);

- people with dementia (12 publications);

- Older people who are frail (2 publications);

- People with Huntington's disease (3 publications);

- Children with and without communication impairments (7 publications);

- "Various target groups", i.e. describing research in different settings with target groups not specifically mentioned, or not part of the above target groups (13 publications).

Related to the target groups for which Talking Mats can be used are the skills required to use it. The following skills were reported:

- Physical skills to indicate the placement of the symbols, such as hand pointing or eye movements. ${ }^{29,39}$

- Sufficient vision to see the picture symbols. . $^{9,39,40}$

- Cognitive skills to understand the symbols..$^{39,41}$ and to understand the verbal instructions containing two or three information-carrying words. ${ }^{9,28,29}$

- Expressive skills to indicate a reliable yes/no (verbal or non-verbal).9.39

Talking Mats can be tailored to the specific needs of target groups. The types and number of symbols, and the size, colour, and texture of the symbols and mat can be adjusted depending on the person's communication challenges. For example, one can use a range of two to five top scale symbols (e.g. like/ dislike), depending on the person's cognitive ability. In most cases, Picture Communication Symbols $\left(\mathrm{PCS}^{\mathrm{TM}}\right)$, Talking Mats Communication Symbols, ${ }^{22}$ Sclera's pictograms, ${ }^{42}$ or photographs are used for the symbols. Some symbol sets have been developed to reflect the World Health Organization's International Classification of Functioning, Disability and Health (ICF) model, describing 9 different neutral domains of activity and participation. ${ }^{30,43,44}$

Talking Mats is a partner-assisted communication framework. Although the intention of Talking Mats is to put the person who is communication vulnerable in control as much as possible, the communication partner has considerable influence. ${ }^{14}$ The communication partner preselects the conversation topics and therefore has control over which items/topics are visually presented, and thus which topics are communicated about. ${ }^{14}$ Furthermore, the quality of the conversation when using Talking Mats, e.g. the effects on facilitating communication and facilitating involvement, depends greatly on the support of the communication partner. ${ }^{17}$ Factors that could possibly impact the quality of using Talking Mats are: the conversation partners' questioning style; their prompting or making assumptions; ${ }^{14}$ their preparation of the topics and symbols; ${ }^{45}$ and their awareness of the symbols' abstract nature. ${ }^{11,46}$ Ferm and colleagues ${ }^{17}$ described that Talking Mats presupposes a speaking partner who is open-minded and respectful and who knows how to use Talking Mats. 


\section{Part 2: Overview of the research evidence on the effects of using Talking Mats}

Twelve articles reported research evidence for Talking Mats. The details of these articles are presented in table 5.2. We found no systematic reviews, randomized controlled trials or cohort studies. There were seven cross-over studies in which the patients had a conversation without Talking Mats and a conversation with Talking Mats (numbers of patients ranging from 4 to 48) and five descriptive case series (numbers of patients ranging from 9 to 12). One of the case series was a qualitative study, another used mixed methods. Six of the 12 studies were carried out by researchers involved in Talking Mats Limited organization.

The studies in Part two focused on the target groups: people with aphasia, learning disabilities, dementia or Huntington's disease, and children. No studies in Part 2 examined the skills required to use Talking Mats which were discussed in Part 1. Tables 5.3 and 5.4 present an overview of the quality elements identified in the included publications.

The qualitative studies often did not report the qualitative methods and data analyses in detail (table 5.3), nor how the relationship between researcher and participants may have influenced the qualitative data gathering and analysis. In the quantitative studies, the design was often not described (table 5.4). Moreover, in several studies the sample size was not justified and a convenience sample was mostly used. The results are presented for each objective of Talking Mats: facilitating communication, facilitating involvement, and functional use of Talking Mats. Some studies reported on multiple objectives and are therefore described under several headings.

\section{Facilitating communication}

Ten publications reported on facilitating communication. They all reported results in favour of using Talking Mats. Six of these studies used quantitative variables (based on observations) clustered in coding frameworks. $3,17,18,40,45,47$ These six studies used three slightly different coding frameworks (see box 1). Some of the elements of the coding frameworks were: participants' understanding of the topic of discussion, participants' engagement with each other, participants' confidence, and researcher's understanding of persons' views. ${ }^{47}$. The results show that the scores on these coding frameworks were higher when using Talking Mats (compared to usual conversation, structured conversation, or unstructured conversation) for young people with a learning disability, ${ }^{3,40}$ people with aphasia, ${ }^{45,47}$ and people with Huntington's disease. .77,18 $^{17}$ 


\section{Box 1. Details about the coding frameworks}

The first coding framework that Cameron and Murphy used in their 2000 and 2002 studies included the following concepts: participants' understanding of topics, participants' confidence in manipulating symbols, confirmation of the researchers' interpretation, and satisfaction about each completed mat. ${ }^{40,45}$ The results of the 2000 study showed that the scores on the coding framework were higher when using Talking Mats compared to usual communication methods for people with aphasia. ${ }^{45}$ The study by Cameron and colleagues reported the use of the coding framework, but reported no quantitative results on this framework. ${ }^{40}$

In Murphy and Cameron's 2008 study, they adjusted the coding framework by adding the concept of engagement, and changed "confirmation of the researchers' interpretation" to "interviewer's understanding of participant's views". This study, with people with a learning disability, found higher scores on the coding framework when using Talking Mats compared to using usual communication methods. ${ }^{3}$

These coding frameworks were further developed into a third coding framework, the effectiveness framework of functional communication. This framework contained the following concepts: participants' understanding of the topic of discussion; participants' engagement with each other; participants' confidence; and researcher's understanding of the person's views. In studies of people with dementia, ${ }^{47}$ and people with Huntington's disease $\mathrm{e}^{17,18}$ the researchers reported that the scores on the effectiveness framework were higher when using Talking Mats than those for usual communication.

Within the objective of facilitating communication, the use of Talking Mats was also studied with regard to more technical aspects of communication, based on researcher observations. 3,17,33,47 Three studies focussing on these technical aspects reported positive results when using Talking Mats on the duration of the conversation, the number of topics, task behaviour, and perseveration. These results were identified for people with learning disabilities, dementia, and Huntington's disease.

One study focussing on the use of language by people with dementia did not find a difference when using Talking Mats. The details of the results are as follows:

- Duration of conversation: In studies of people with dementia, Huntington's disease and learning disabilities, the conversation lasted longer when using Talking Mats compared to an unstructured or usual conversation. ${ }^{3,17,47}$

For example, in the study of people with Huntington's disease, the conversations with Talking Mats had a mean duration of $28.31 \mathrm{~min}$., compared to $3.67 \mathrm{~min}$. for an unstructured conversation, and 15.19 min. for a structured conversation. ${ }^{17}$

- Number of topics: Significantly more topics were discussed in conversations with Talking Mats than in usual communication, as was observed in a study of persons with a learning disability. ${ }^{3}$

- On-task behaviour (engagement of the participant with the conversation): A study of people with a learning disability reported more on-task behaviour when using Talking Mats than with usual communication. ${ }^{3}$ In a study of people with dementia, significantly more on-task behaviour was observed by people with moderate and late-stage dementia, compared to a structured 
conversation. By contrast, the on-task behaviour was not significantly greater among people with moderate dementia, when compared to an unstructured conversation. ${ }^{47}$

- Perseveration: In a study of people with dementia, less perseveration of the persons with dementia was observed when using Talking Mats compared to structured and unstructured conversations. ${ }^{47}$

- Use of language: In conversations between people with Alzheimer's disease and their family members, the use of language did not differ significantly between conversations with and without Talking Mats. The use of language was studied by observing seven typical language aspects of persons with Alzheimer's disease..$^{33}$

The study by Hallberg and colleagues was a mixed-methods study, and reported some qualitative results when using Talking Mats in a discussion group. The people with Huntington's disease described favourable experiences with regard to ease of use, remembering, talking, and controlling the discussion. Two participants had difficulty handling the photos. The discussion leader described that Talking Mats had helped to stay on topic. However, the Talking Mats discussion was experienced as less spontaneous, more time-consuming, and needing more preparation than the discussion without Talking Mats. The discussion without Talking Mats was experienced as more self-sustaining, more natural, and less controlled. ${ }^{18}$

\section{Facilitating involvement}

Two studies reported results about the objective of facilitating involvement. These studies on involvement showed positive results of using Talking Mats for people with dementia. In the study by Murphy and Oliver ${ }^{19}$ the "participant involvement questionnaire" was used to explore the influence of using Talking Mats. The results showed that persons with dementia and their communication partners reported more feelings of involvement when using Talking Mats compared to usual communication. Communication partners also felt significantly more satisfied with the discussion using Talking Mats. ${ }^{19}$ The study by Reitz and Dalemans focussed on shared decisions between people with Alzheimer's disease and their family members. They reported that the scores on the OPTION scale were significantly higher when using Talking Mats, compared to conversations without Talking Mats. ${ }^{33}$ This study also reported positive experiences related to ease of use, finding out more about the conversation partners' thoughts, and making decisions. Two of the six participants were not sure about the effect of Talking Mats. ${ }^{33}$

\section{Functional use of Talking Mats}

Three studies reported results about functional objectives. These studies focussed on activity choices, goal setting and diagnostic processes, and reported descriptive results on the use of Talking Mats. One publication studied the influence of repeatedly using Talking Mats on making activity choices.

In this study of young people with learning disabilities, Talking Mats was used twice to elicit views about photographed activities, and $92 \%$ of the photographs were placed on the same Talking Mats symbol on the second occasion. ${ }^{35}$ Regarding the objective of goal setting, a study used Talking Mats to investigate both clients' and their assigned rehabilitation professionals' perceptions of the importance 
of ICF activities and participation domains for inclusion in their rehabilitation programme. The results showed that there were no statistically significant differences in ratings of the importance of ICF domains between patients and professionals when using Talking Mats. ${ }^{34}$ One study focussed on using Talking Mats in a diagnostic process, ${ }^{38}$ and included an initial validation with Talking Mats as part of the measurement instrument. The results showed that children older than seven years were able to use a modified anxiety instrument (to measure anxiety before surgery) with the help of Talking Mats. ${ }^{38}$

To conclude, almost all studies using quantitative measurements reported positive outcomes when using Talking Mats, compared to conversations without Talking Mats, though the Dalemans study reported no difference in language use. No studies reported negative outcomes when using Talking Mats. Several functional objectives identified in Part 1 have not been studied in scientific research, namely supporting the participation of people in research and projects, improving social processes, and resolving conflicts and differences of opinions. Furthermore, none of the studies in Part 2 examined the skills required to use Talking Mats as reported in Part 1.

\section{Discussion}

This scoping review included 73 publications about Talking Mats in Part 1, and 12 publications describing the empirical scientific knowledge about Talking Mats in Part 2. The results reported in Part 1 highlight the use of Talking Mats for a variety of objectives in different settings and for people with different communication difficulties, such as learning disabilities, dementia and Huntington's disease, older people who are frail, and children with and without communication impairments. The studies discussed in Part 2, mainly descriptive, cross-over and case studies, highlight important empirical findings with regard to the use of Talking Mats. These empirical studies reported that Talking Mats could have a positive influence on technical communication aspects, facilitating communication, and involvement in communication and decision making. However, the included studies were small-scale, mainly descriptive studies with a limited amount of research per target group.

\section{Using Talking Mats for specific target groups}

Part 1 of this review reveals that the strength of Talking Mats is its flexibility and use for different target groups. The use of AAC tools is often limited to a specific target group, with specific physical or cognitive capabilities and/or limitations, requiring person-centred consultation from speech-language pathologists or occupational therapists. The literature does not show whether advice from such specialists is needed for Talking Mats. The question is whether Talking Mats could be used as a standard framework for visualising conversations by communication vulnerable people in healthcare. Although most of the research findings were positive, Bunning ${ }^{48}$ warns that the value of Talking Mats can depend on the individual participants' communicative ability. There is a lack of empirical evidence about the 
requirements or skills that people should have in order to use Talking Mats. Available information about these requirements seems to come from researchers' insights and experiences (Part 1), rather than from scientific research (Part 2). Research into these requirements could help professionals determine for which people they can use Talking Mats.

\section{Objectives of Talking Mats}

The objectives identified in Part 1 were only partly evaluated in the empirical studies in Part 2. For example, the outcome measures in Part 2 focussed mainly on technical aspects and not on expression and thinking and understanding. The only element of the effectiveness framework which links to this was "participants' understanding of the topic of discussion". However, this element was only observed, and the persons who were communication vulnerable were not asked about this. The second objective, facilitating involvement, has been used as an outcome measure in only two studies in Part 2. ${ }^{19,33}$ With regard to the functional use of Talking Mats, only one study in Part 2 reported on the validity of using Talking Mats (with another questionnaire) in a diagnostic process. ${ }^{38}$ None of the studies in part 2 measured the outcomes of using Talking Mats in research or projects, or for the purpose of improving social processes and discussing conflicts \& differences of opinions. More research is needed with regard to the objectives of Talking Mats, specifically focussing on user experiences.

\section{Partner-assisted AAC}

Several publications in Part 1 emphasised that Talking Mats is a partner-assisted communication framework. The person who is communication vulnerable may not have enough influence on the options (subtopics) that are discussed. Also, some persons might be confused about what the available symbols are supposed to represent. These issues may interfere with the reliability and trustworthiness of Talking Mats, and are important issues for professionals to be aware of. To enhance the reliability and trustworthiness, the same communication partner could repeat the interview, or other persons could be asked to validate the information. ${ }^{49}$ When communicating with persons with severe cognitive disabilities, the communication partner should, in addition to using Talking Mats, use other communication strategies, such as adjusting the pace of the conversation, paraphrasing, and reading non-verbal behaviour. Professionals and other communication partners should be aware of their own communication skills and how these impact on the use of Talking Mats. Talking Mats Limited organisation recommends attending a training course in the use of Talking Mats. The literature does not describe in detail how people have been taught to use Talking Mats. In some articles the communication partner received formal training or instructions, ${ }^{18,33,50}$ while in others, the communication partners were researchers with experience using Talking Mats. ${ }^{17}$ The research in Part 2 did not consider the influence of the partners when using AAC. Future studies should incorporate this in their research about Talking Mats. 


\section{Empirical evidence of Talking Mats}

Part 2 of this scoping review reveals that most of the evidence about Talking Mats points to positive results. Except for the Hallberg study, ${ }^{18}$ these studies report no limitations of Talking Mats. In the Hallberg study, the discussion group leader thought that discussions without Talking Mats were more self-sustaining, felt more natural and less controlled, and that Talking Mats was time-consuming in use and in preparation. ${ }^{18}$

The results of Part 2 confirm that people with an intellectual disability, dementia, or Huntington's disease did take longer to express themselves when using Talking Mats in a conversation than they did in unstructured conversations., ${ }^{3,1747}$ According to Ferm and colleagues, ${ }^{17}$ visually supported communication may take longer because communication partners use fewer words, focus on important information, and speak more slowly. This slower pace could be seen as a disadvantage, since time in healthcare is expensive and limited. However, it can also be viewed as a benefit, as it enabled people who have difficulties communicating to interact with others for significantly longer periods of time. ${ }^{3}$ Moreover, persons who are communication vulnerable often benefit from slower communication. ${ }^{17}$

This scoping review does not provide insights into the elements of Talking Mats that account for the positive findings. Talking Mats could be compared with other AAC tools aiming at visualisation, such as graphic topic setters, communication boards, pictographic books or picture pointing boards. ${ }^{51}$ Both quantitative research using validated observation lists and qualitative research focussing on the experiences of communication vulnerable people would provide valuable information on the effective elements of Talking Mats. Information is also needed about effective implementation strategies for using Talking Mats in daily life/practice for communication vulnerable people. Part 2 of this review included disparate studies about Talking Mats. The qualitative studies often lacked an in-depth analysis of the experiences of persons using Talking Mats. The included quantitative publications were descriptive or pilot studies, using different outcome measures. Some empirical studies in this review reported to have investigated the effects of Talking Mats using the "effectiveness framework of functional communication". ${ }^{17,47}$ However, no data about the content or construct validity of this framework were provided, which makes it difficult for professionals and researchers to assess the validity of this framework.

Talking Mats was developed in the UK, and we saw that almost all research about Talking Mats has also been done in the UK. Much of this research has been supported by Talking Mats Limited and has been published by the same authors. There is a need for research done by other research groups and in other countries. 


\section{Strengths and limitations}

Strengths of this review include the use of the well-established Arksey and O'Malley framework ${ }^{20}$ to systematically conduct the scoping review, and the use of both scientific databases and an open search in Google. However, despite the rigorous search process, relevant publications could have been missed, particularly in the grey literature. Furthermore, the overview of the countries in which Talking Mats was used might not be complete, since some data sources did not specifically report where the study was performed. Describing the methodological quality of studies in this scoping review was a challenge, since all types of study design were included. We used two rather generic lists to get some idea of the quality, but we did not perform a thorough quality assessment using design-specific criteria lists.

However, our global assessment was enough to get an overview of the empirical scientific knowledge, which was the aim of this study.

\section{Conclusion}

Talking Mats can be used to support communication and involvement and for functional objectives during the healthcare process. The empirical studies showed that Talking Mats had a positive influence on several communication aspects and involvement in conversations for people with aphasia, learning disabilities, dementia and Huntington's disease. This supports the use of Talking Mats in conversations between communication vulnerable people and professionals or caregivers.

However, the body of scientific knowledge about Talking Mats is limited, due to the designs of the studies and the limited number of studies per target group. Establishing evidence-based recommendations for using Talking Mats in daily practice requires more scientific knowledge.

The focus for future research should be on rigorous research involving in-depth qualitative user-reported research, feasibility of Talking Mats, criteria for using Talking Mats, and effectiveness of Talking Mats.

\section{End notes}

1. Talking Mats is the registered trademark of the Talking Mats Centre, Stirling University Innovation Park, Stirling FK9 4NF, Scotland. See www.talkingmats.com. 


\section{References}

1. Wynia MK. Making it easier to do the right thing: a modern communication QI agenda. Patient Educ Couns. 2012;88(3):364-366.

2. Jesus TS, Silva IL. Toward an evidence-based patient-provider communication in rehabilitation: Linking communication elements to better rehabilitation outcomes. Clin Rehabil. 2015.

3. Murphy J, Cameron L. The effectiveness of Talking Mats for people with intellectual disability. Br J Learn Disabil. 2008;36:232-241.

4. Watson J, Cameron L, Murphy J. 'Don't just make the font bigger'. Learning Disability Practice. 2003;6(7):20-23.

5. Blackstone S. Augmentative communication news. Augmentative communication. 2009;21(2):1-5.

6. Costello JM, Patak L, Pritchard J. Communication vulnerable patients in the pediatric ICU: Enhancing care through augmentative and alternative communication. J Pediatr Rehabil Med. 2010;3(4):289-301.

7. Stans SE, Dalemans R, de Witte L, Beurskens A. Challenges in the communication between 'communication vulnerable' people and their social environment: An exploratory qualitative study. Patient Educ Couns. 2013;92(3):302-312.

8. Clarke M, Bloch S. AAC practices in everyday interaction. Augment Altern Commun. 2013;29(1):1-2.

9. Bell D, Cameron L. From Dare I say...? to I dare say: a case example illustrating the extension of the use of Talking Mats to people with learning disabilities who are able to speak but unwilling to do so. Br J Learn Disabil. 2007;36:122-127.

10. Cox S, Murphy J, Gray CM. Communication and dementia: how effective is the Talking Mats approach? Journal of Dementia Care. 2008;May/June:35-38.

11. Murphy J, Boa S. Using the WHO-ICF with Talking Mats as a goal setting tool. Augment Altern Commun. 2012;28(1):52-60.

12. Macer J, Fox P. Using a communication tool to help clients express their health concerns. Learning disability practice. 2010;9(1).

13. Murphy J, Gray CM, Cox S. Communication and Dementia: Talking Mats- Helping People with Dementia to Express their Views. Full Report Joseph Rowntree Foundation 2007.

14. Brewster SJ. Putting words into their mouths? Interviewing people with learning disabilities and little/no speech. Br J Learn Disabil. 2004;32 (4):166-169.

15. Whitehurst T. Liberating silent voices-perspectives of children with profound \& complex learning needs on inclusion. Br J Learn Disabil. 2006(35):55-61.

16. Ferm U, Eckerholm W, Gelfgren E, Hartelius L. Communication between Huntington's disease patients, their support persons and the dental hygienist using talking mats. Huntington disease- Core Concept and Current Advances Intech. 2012.

17. Ferm U, Sahlin A, Sundin L, Hartelius L. Using Talking Mats to support communication in persons with Huntington's Disease. Int J Lang Commun Disord. 2010;45(5):523-536.

18. Hallberg L, Mellgren E, Harelius L, Ferm U. Talking Mats in a discussion group for people with huntington's disease. Disabil Rehabil Assist Technol. 2013;8(1):67-76.

19. Murphy J, Oliver T. The use of Talking Mats to support people with dementia and their carers to make decisions together. Health Social Care Community. 2013;21(2):171-180.

20. Arksey H, O’Malley L. Scoping studies: Towards a Methodological Framework. Int J Social Research Methodology. 2005;8(1):19-32.

21. Levac D, Colquhoun H, O’Brien KK. Scoping studies: advancing the methodology. Implement Sci. 2010;5:69.

22. TalkingMats. Talking Mats. 2016; http://www.talkingmats.com/index.php/our-publications. Accessed 20-11-2016.

23. Hsieh HF, Shannon SE. Three approaches to qualitative content analysis. Qual Health Res. 2005;15(9):1277-1288.

24. Bastawrous M, Gignac MA, Kapral MK, Cameron JI. Factors that contribute to adult children caregivers' well-being: a scoping review. Health Soc Care Community. 2015;23(5):449-466.

25. CASP checklists. 2013; http://www.casp-uk.net/\#!casp-tools-checklists/c18f8. Accessed 5 march, 2016.

26. Murphy J. Talking Mats: speech and language research in practice. Speech \& Language therapy in practice. 1998:11-14.

27. Murphy J, Gray CM, Cox S. Using talking mats to help people with dementia to communicate. Report Joseph Rowntree Foundation;2007.

28. Wright K. Researching the views of pupils with multiple and complex needs. Is it worth doing and whose interests are served by it? Support for Learning. 2008;23(1):32-40.

29. Murphy J, Cameron L. Talking Mats: A Resource to Enhance Communication. 2005.

30. Bornman J, Murphy J. Using the ICF in goal setting: clinical application using Talking Mats. Disabil Rehabil Assist Technol. 
2006;1(3):145-154.

31. Murphy J, Oliver T, Cox S. Talking mats help involve people with dementia and their carers in decision making, Findings. Joseph Rowntree foundation;2010.

32. Murphy J. Perceptions of communication between people with communication disability and general practice staff. Health Expectations. 2006(9):1-12.

33. Reitz C, R D. The use of 'Talking Mats'by persons with alzheimer in the Netherlands: increasing shared decision-making by using a low tech communication aid. Journal of Social Inclusion. 2016;7(2):36-47.

34. Harty M, Griesel M, van der Merwe A. The ICF as a common language for rehabilitation goal-setting: comparing client and professional priorities. Health and quality of life outcomes. 2011;9(87).

35. Germain R. An exploratory study using cameras and talking mats to access the views of young people with disabilities on their out-of-school activities. Br J Learn Disabil. 2004;32:170-174.

36. Bunning K, Steel G. Self-concept in young adults with a learning disability from the Jewish community. Br J Learn Disabil. 2007;35(1):43-49.

37. Murphy J, Cameron L. The acute hospital experience for adults with complex communication needs. Communication matters. 2006;20(2):7-11.

38. Nilsson S, Buchholz M, Thunberg G. Assessing children's anxiety using the modified short state-trait anxiety inventory and talking mats: a pilot study. Nurs Res Pract. 2012.

39. Cameron L, Murphy J. Views of young adults at the time of transition. Communication Matters. 2001;15(1):31-32.

40. Cameron L, Murphy J. Enabling young people with a learning disability to make choices at a time of transition. Br J Learn Disabil. 2002;30:105-112.

41. Murphy J, McCallan S, Aitken J. Helping People make decisions about PEG feeding. RCSLT Bulletin. 2003(618):10-11.

42. Sclera pictograms. www.sclera.be.

43. Boa S, MacFadyen L. Goal Setting for People with Communication Difficulties. Communication Matters. 2003;17 (3):31-33.

44. World Health Organization, ICF. home page on the internet. Available at: http://www.who.int/classifications/icf/en/. Accessed september 8, 2012.

45. Murphy J. Enabling people with aphasia to discuss quality of life. BJTR. 2000;7(11):454-457.

46. Murphy J. Talking Mats: A study of communication difficulties and the feasibility and effectiveness of a low-tech communication framework (PhD Thesis) Discussion, University of Stirling; 2009.

47. Murphy J, Gray CM, Cox S, van Achterberg T, Wyke S. The effectiveness of the Talking Mats Framework in helping people with dementia to express their views on well-being. Dementia. 2010;9(4):454-472.

48. Bunning K, Heath B, Minnion A. Communication and Empowerment: A Place for Rich and Multiple Media? J Appl Res Intellect Disabil. 2009;22(4):370-379.

49. Murphy J. Talking Mats: A study of communication difficulties and the feasibility and effectiveness of a low-tech communication framework (PhD Thesis) Introduction. , University of Stirling; 2009.

50. Murphy J, Strachan Y. Talking mats: extending the reach into goal setting practices for health and social care staff in Edinburgh. In: centre TM, ed2011.

51. Stans SE, Dalemans RJ, de Witte LP, Smeets HW, Beurskens AJ. The role of the physical environment in conversations between people who are communication vulnerable and health-care professionals: a scoping review. Disabil Rehabil. 2016:1-12.

52. Beringer A, Tönsing K, Bornman J. The self-determined and partner-predicted topic preferences of adults with aphasia. Aphasiology. 2013;27(2):227-251.

53. Buchholz M, Ferm U, Holmgren K. Including persons with complex communication needs in research- a structured methodology based on Talking Mats. Isaac Conference 2016; Toronto.

54. Dinwoody D, Macer J. Talking Mats for literacy target setting. LITERACY Today. 2010;March:15-16.

55. Gillespie A, Murphy J, Place M. Divergences of Perspective Between People With Aphasia and their Family Caregivers. Aphasiology. 2010; 24(12):1559-1575.

56. Murphy J. Helping people with severe communication difficulties to express their views: a low tech tool. Communication Matters Journal. 1998;12(2): 9-11.

57. Murphy J. A focus on social issues: a response to Baladin. Advances in speech-language pathology. 2002;4(2):123-127. 
58. Murphy J, Place M, Gillespie A. Using Talking Mats to see each other's point of view. Speech and Language Therapy Bulletin 2012; June:20-21.

59. Pettit LK, Tonsing KM, Dada S. The perspectives of adults with aphasia and their team members regarding the importance of nine life areas for rehabilitation: a pilot investigation. Top Stroke Rehabil. 2017;24(2):99-106.

60. Bell D, Cameron L. The assessment of the sexual knowledge of a severe learning disability and a severe communication disorder. Br J Learn Disabil. 2003;31:123-129.

61. Bell D, Turnbull A, Bruce K. Differential diagnosis of dementia in the field of learning disabilities: a case study. Br J Learn Disabil. 2009;37(1):56-65.

62. Brown L, Dendy M, Murphy J. Respite Review: Obtaining the Views of the Users. Communication Matters Journal. 2000;14(2):25-26.

63. Bunning K, Alder R, Proudman L, Wyborn H. Co-production and pilot of a structured interview using Talking Mats ${ }^{\circledR}$ to survey the television viewing habits and preferences of adults and young people with learning disabilities. $\mathrm{Br} J$ Learn Disabil. 2017;45(1):1-11.

64. Cameron L, Boa S. Advocating partnership. Speech and Language Therapy in Practice 2009;Spring:8-10.

65. Cameron L, Murphy J. Obtaining consent to participate in research: the issues involved in including people with a range of learning and communication disabilities. Br J Learn Disabil. 2006;35:113-120.

66. Cameron L, Watson J, Murphy J. Talking Mats: A focus group tool for people with learning disability. Communication Matters. 2004;18(1):33-35.

67. Mitchell W. 'I know how I feel': Listening to Young people with life-limiting conditions who have learning and communication impairments. Qual Soc Work. 2010;9(2):185-203.

68. Small N, Raghavan R, Pawson N. An ecological approach to seeking and utilising the views of young people with intellectual disabilities in transition planning. J Intellect Disabil. 2013;17(4):283-300.

69. Hubbard G, Downs M, Tester S. Including older people with dementia in research: challenges and strategies. Aging and Mental Health. 2003;7(5):351-362.

70. Macer J, Murphy J. Training care home staff to use talking mats with people who have dementia. 2009; http://ebookbrowse. com/jrfresearchtraining-in-use-of-talking-mats-summary-pdf-d174918238. Accessed 04-10-2013.

71. Macer J. Talking Mats: training for care home staff. Journal of Dementia Care. 2011;19(1):37- 39.

72. Murphy J. Talking Mats and Families Living with Dementia. Communication Matters. 2014 28(3):23-25.

73. Murphy J, Oliver T, Cox S. Talking Mats and involvement in decision making for people with dementia and family carers. 2012.

74. Murphy J, Tester S, Hubbard G, Downs M, McDonald C. Enabling Frail Older People with a Communication Difficulty to Express their Views: the use of Talking Mats ${ }^{\mathrm{TM}}$ as an interview tool. Health and Social Care in the Community. 2005;13(2):95-107.

75. Tester S, Hubbard G, Downs M, MacDonald C, Murphy J. Exploring perceptions of quality of life of frail older people during and after their transition to institutional care. Research Findings 24;2003.

76. Borg S, Agius M, Agius L. A User and Their Family's Perspective of The Use of a Low-Tech Vs A High-Tech AAC System. Stud Health Technol Inform. 2015;217:811-818.

77. Hooton J, Westaway A. The voice of the child with Down syndrome. Down syndrome research and practice. 2008;12(3):25-29.

78. Midtlin HS, Naess KA, Taxt T, Karlsen AV. What communication strategies do AAC users want their communication partners to use? A preliminary study. Disabil Rehabil. 2015;37(14):1260-1267.

79. Turner L. Case study: empowering vulnerable children and their parents using Talking Mats.

80. Material training course Talking Mats. Talking Mats Ltd;2012.

81. Boa S. 'You will know when it feels right' Speech and Language Therapy in Practice. 2005;Autumn:27-28.

82. Barrie K, Miller E. Talking Points- A personal outcomes approach: using talking mats. Joint improvement team. 2010; http:// www.jitscotland.org.uk/action-areas/talking-points-user-and-carer-involvement/communication-skills/. Accessed 3-7-2013.

83. Boardman L, Crichton C, Butterworth S. When you can't talk about it. Probation Journal. 2016;63(1):72-79.

84. Glendinning C, Mitchell W, Brooks J. Ambiguity in practice? Carers' roles in personalised social care in England. Health Soc Care Community. 2015;23(1):23-32.

85. Gridley K, Brooks J, Glendinning C. Good practice in social care: the views of people with severe and complex needs and those who support them. Health Soc Care Community. 2014;22(6):588-597. 
86. Ferm U, Bloch S, Saldert C. Negotiating disagreement in picture symbol supported decision making. Journal of Interactional Research in Communication Disorders. 2015;6(2):131-156.

87. Murphy J. Enabling People with Motor Neurone Disease to Discuss their Quality of Life. Communication Matters Journal. 1999;13(2):2-6.

88. Murphy J, Boa S. Presentation: using the WHO ICF with talking mats as a goal setting tool. Talking Mats Limited, Scotland; 2012.

89. Murphy J, Cameron L. Communication disability and crime. Talking Mats research and development centre.

90. Murphy J, Mackay M. Will anyone listen to us? What matters to young people with complex and exceptional health needs and their families during health transitions. 2015. 


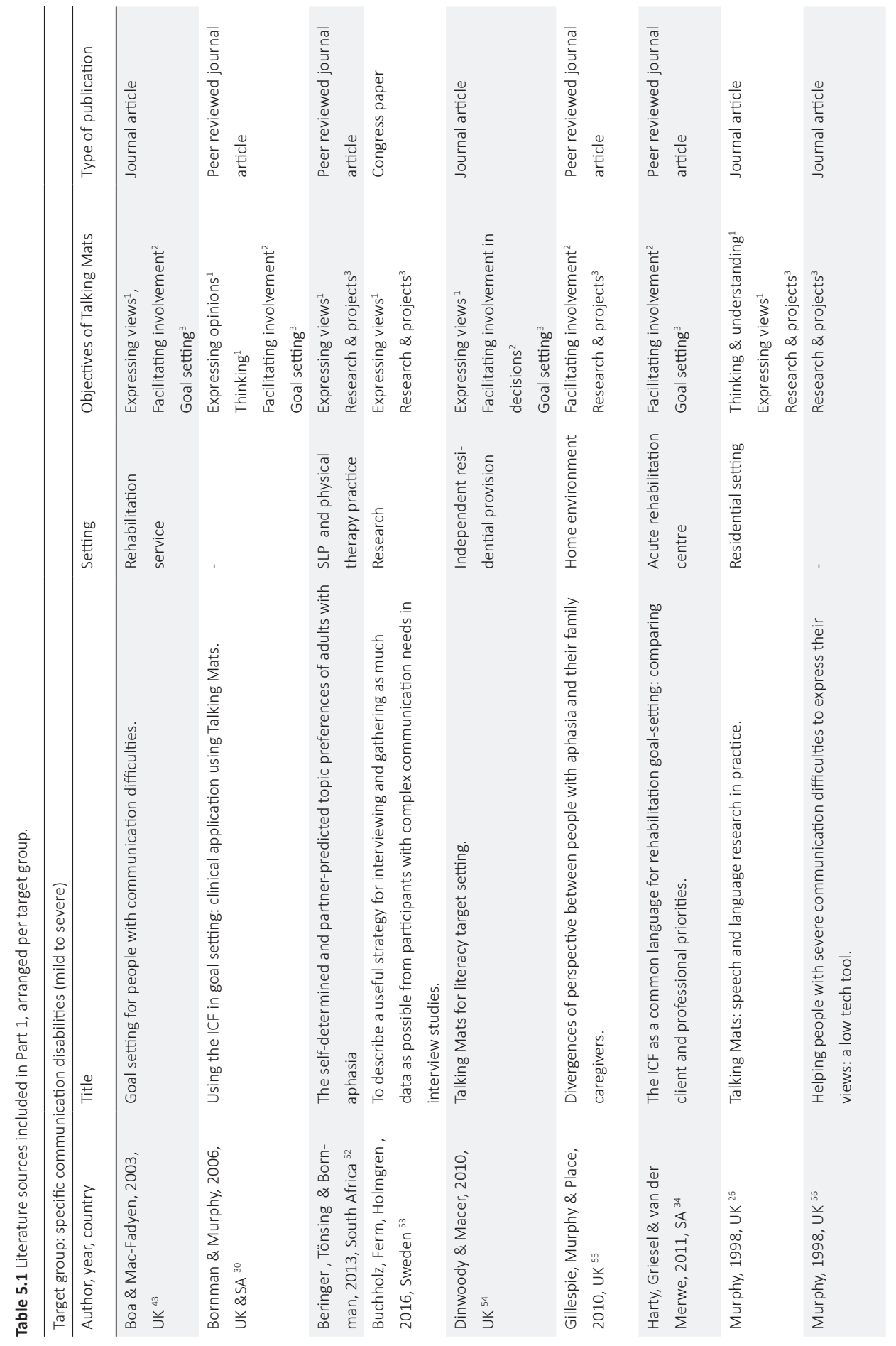




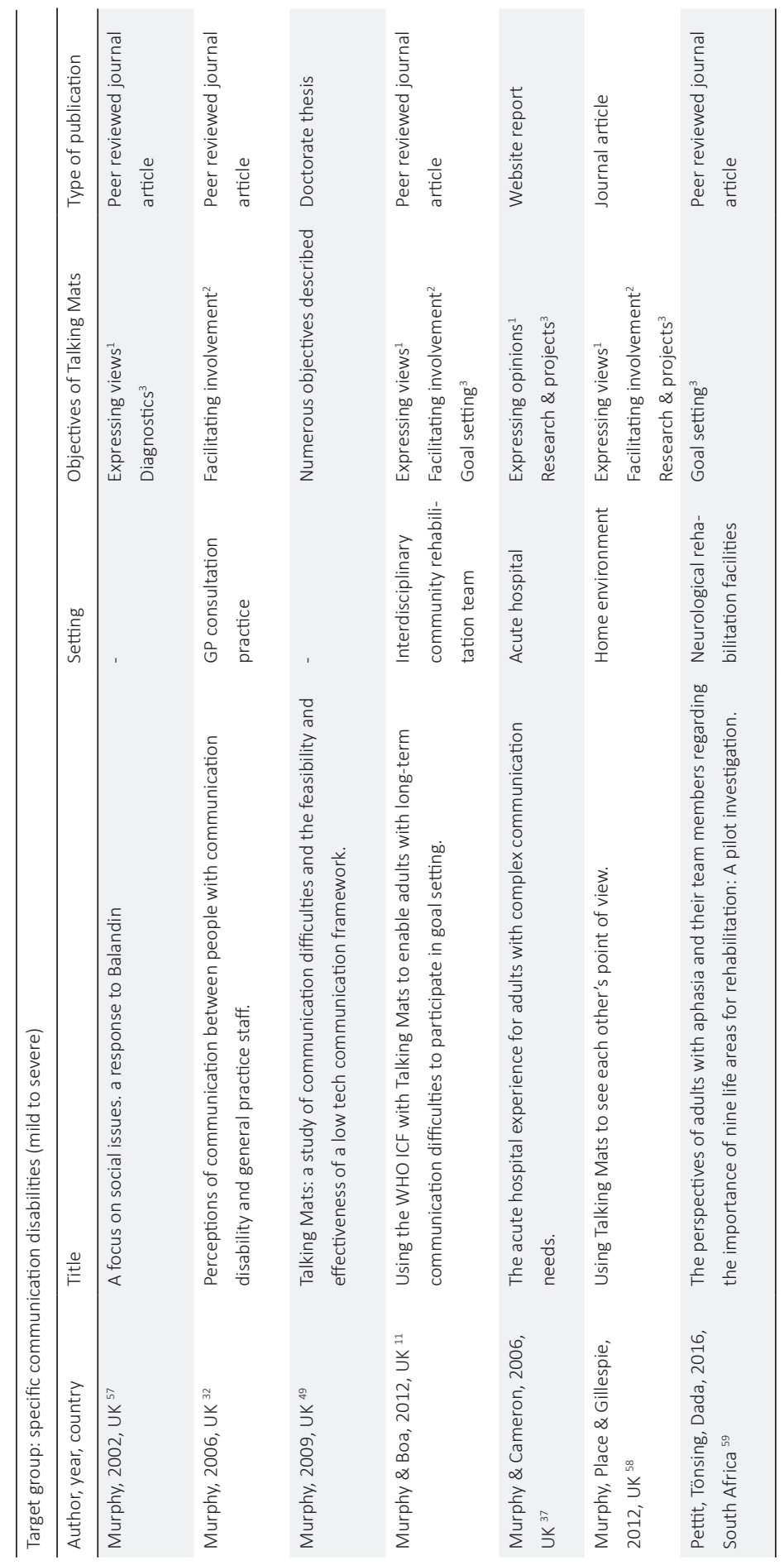




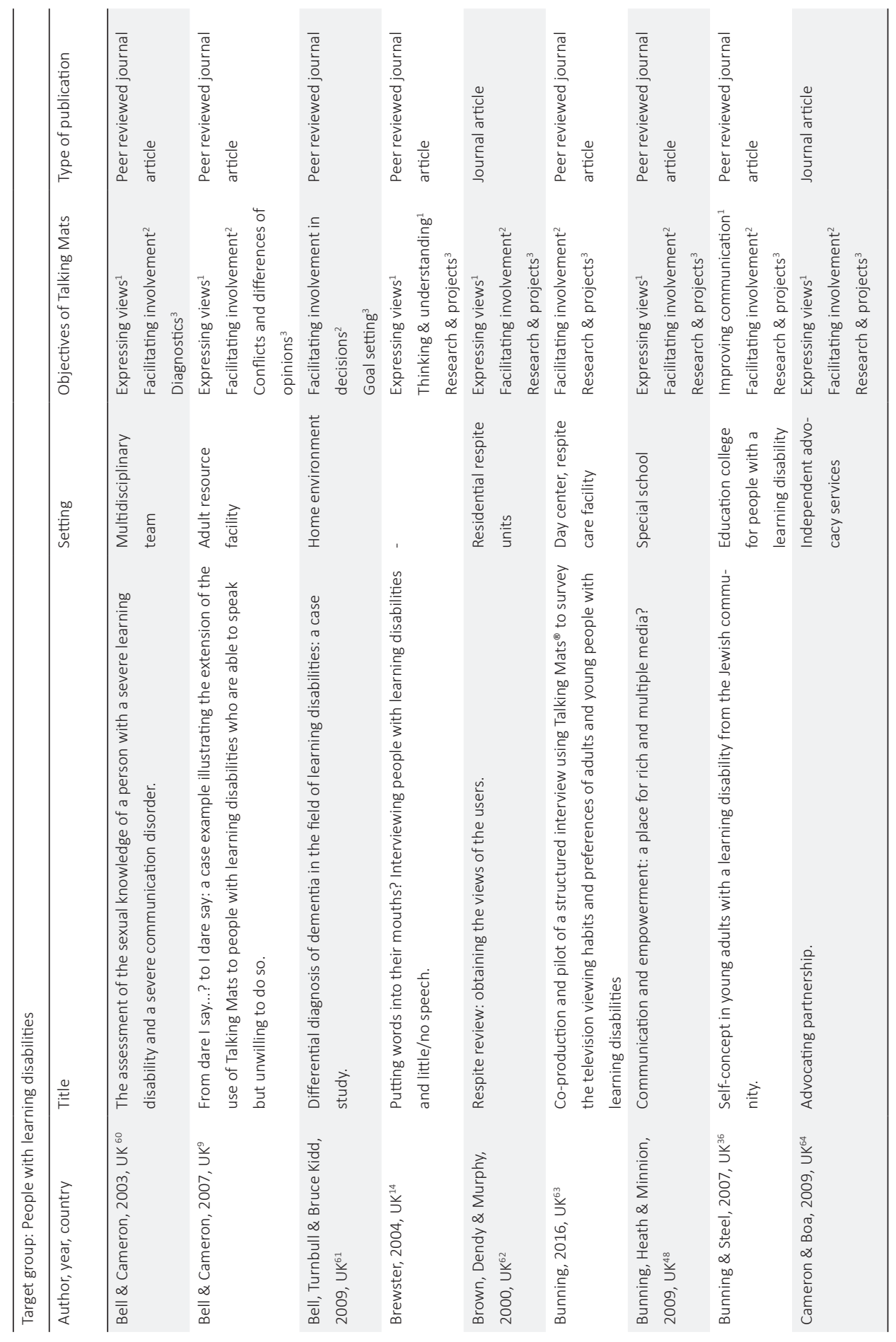




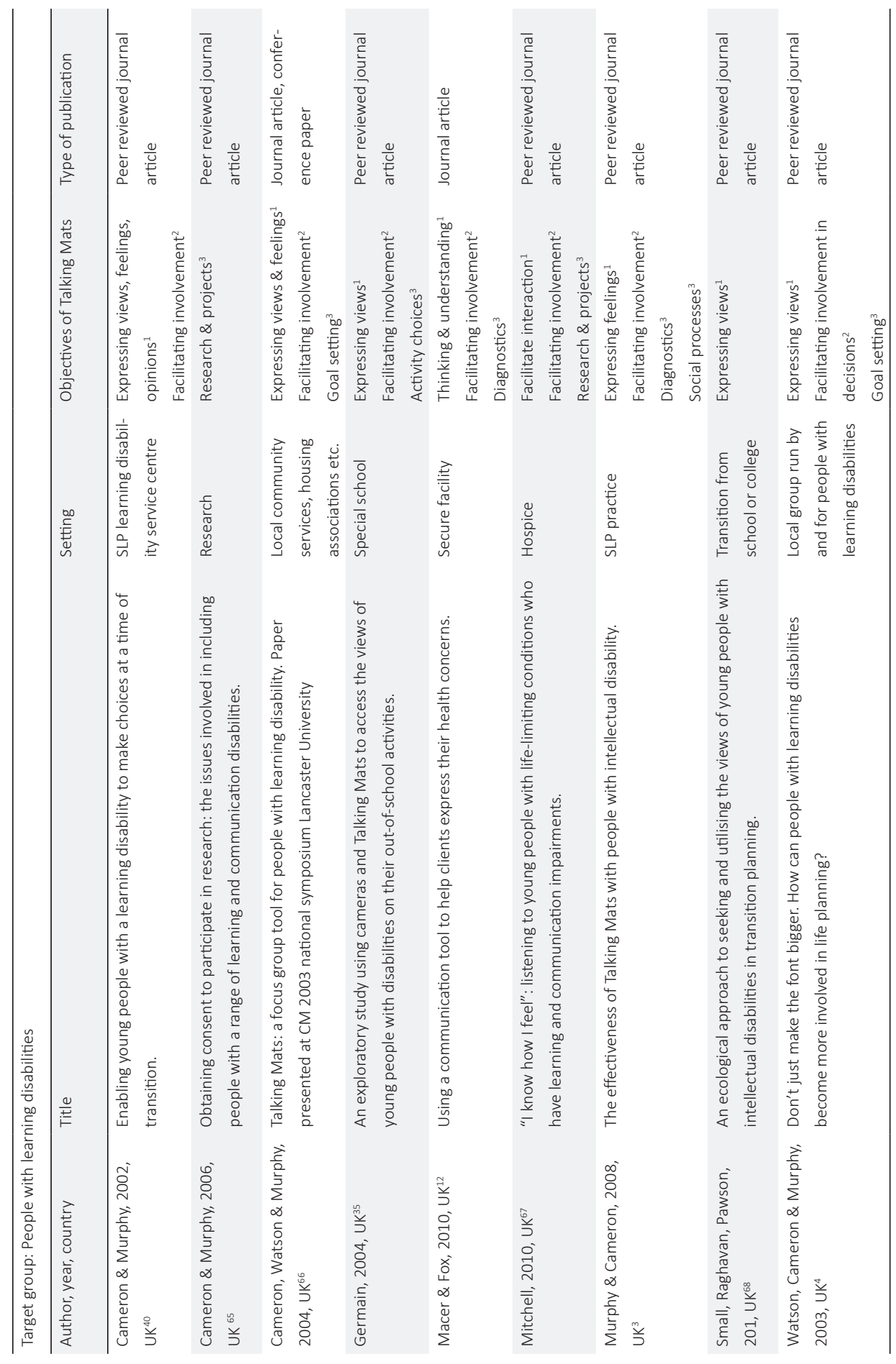




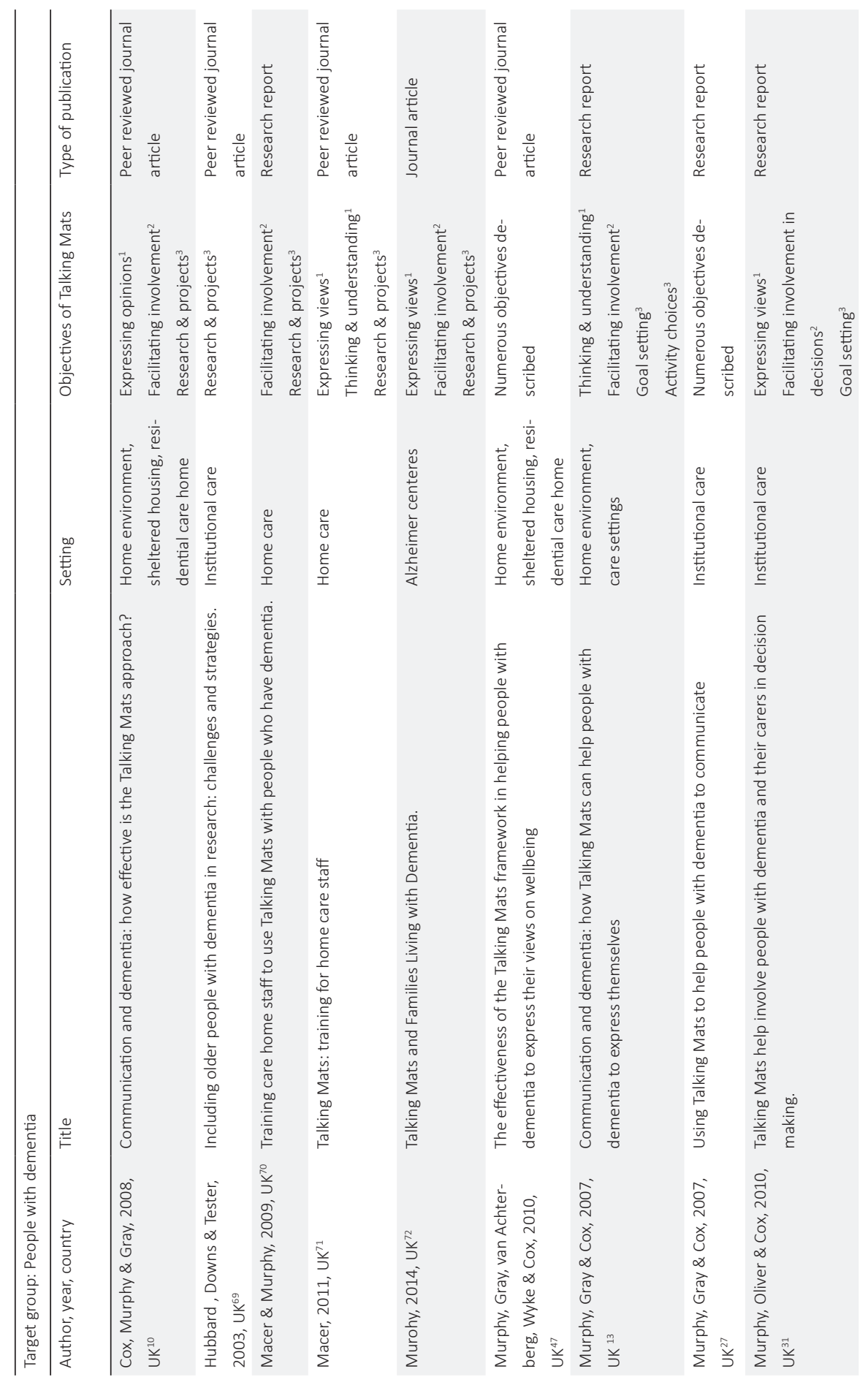




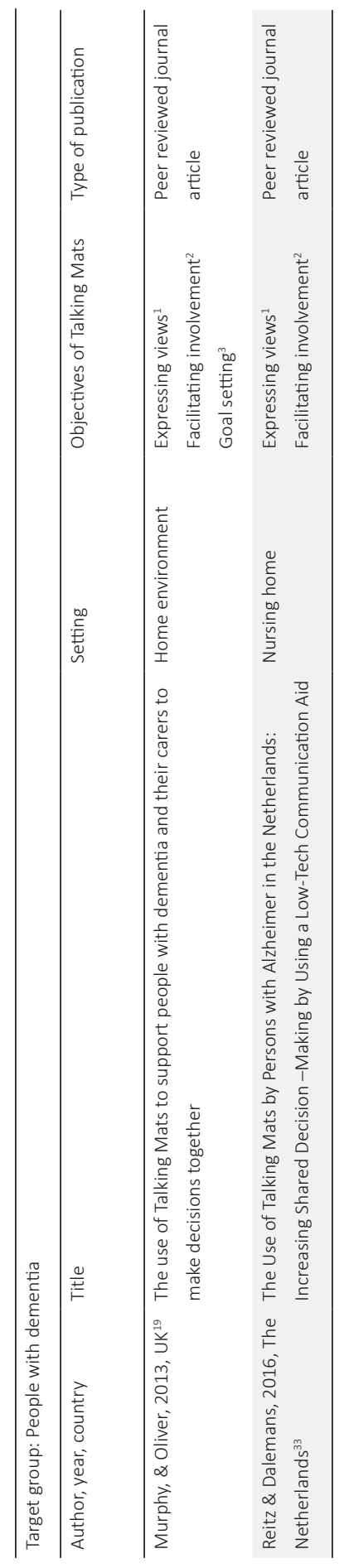




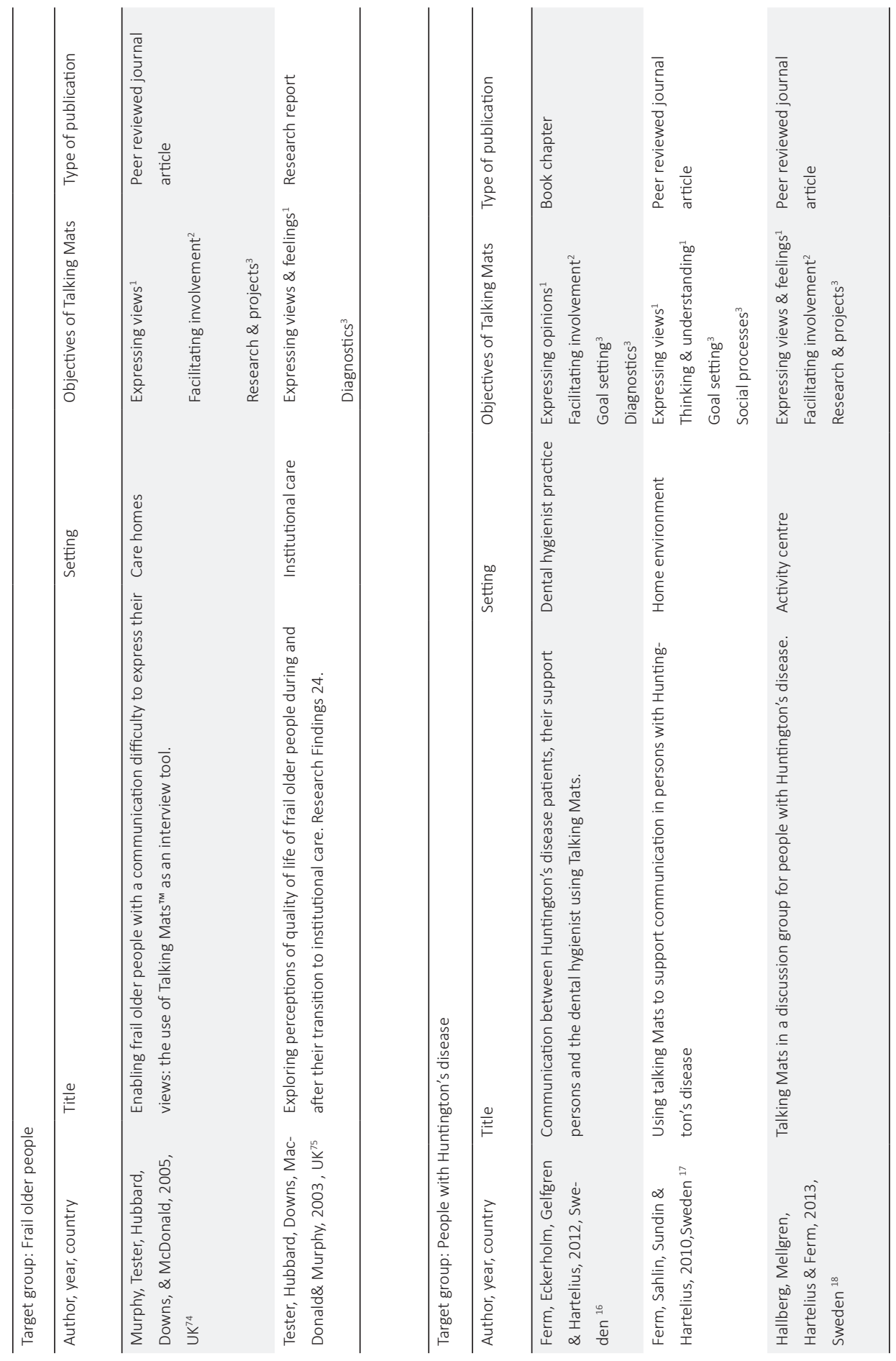




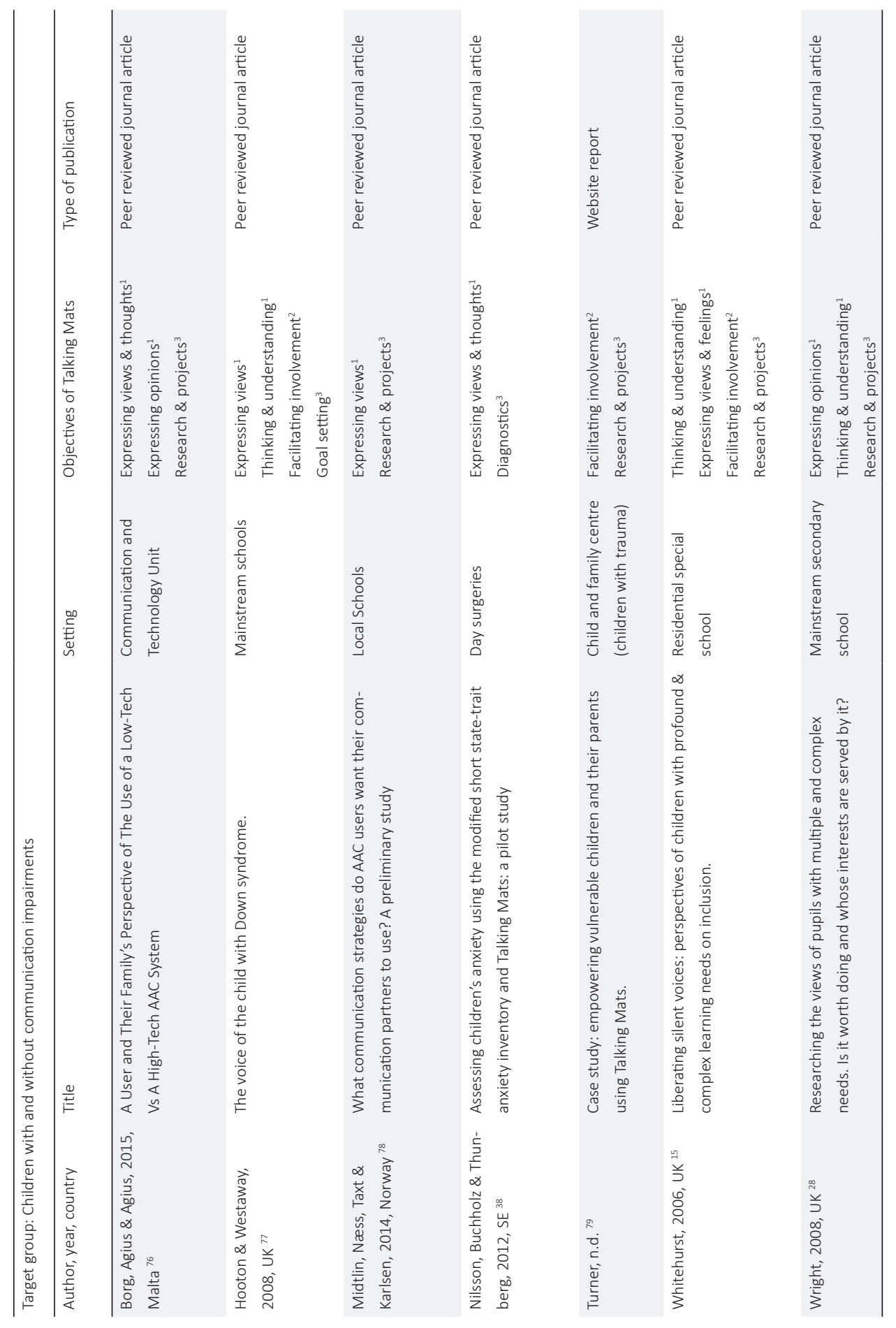




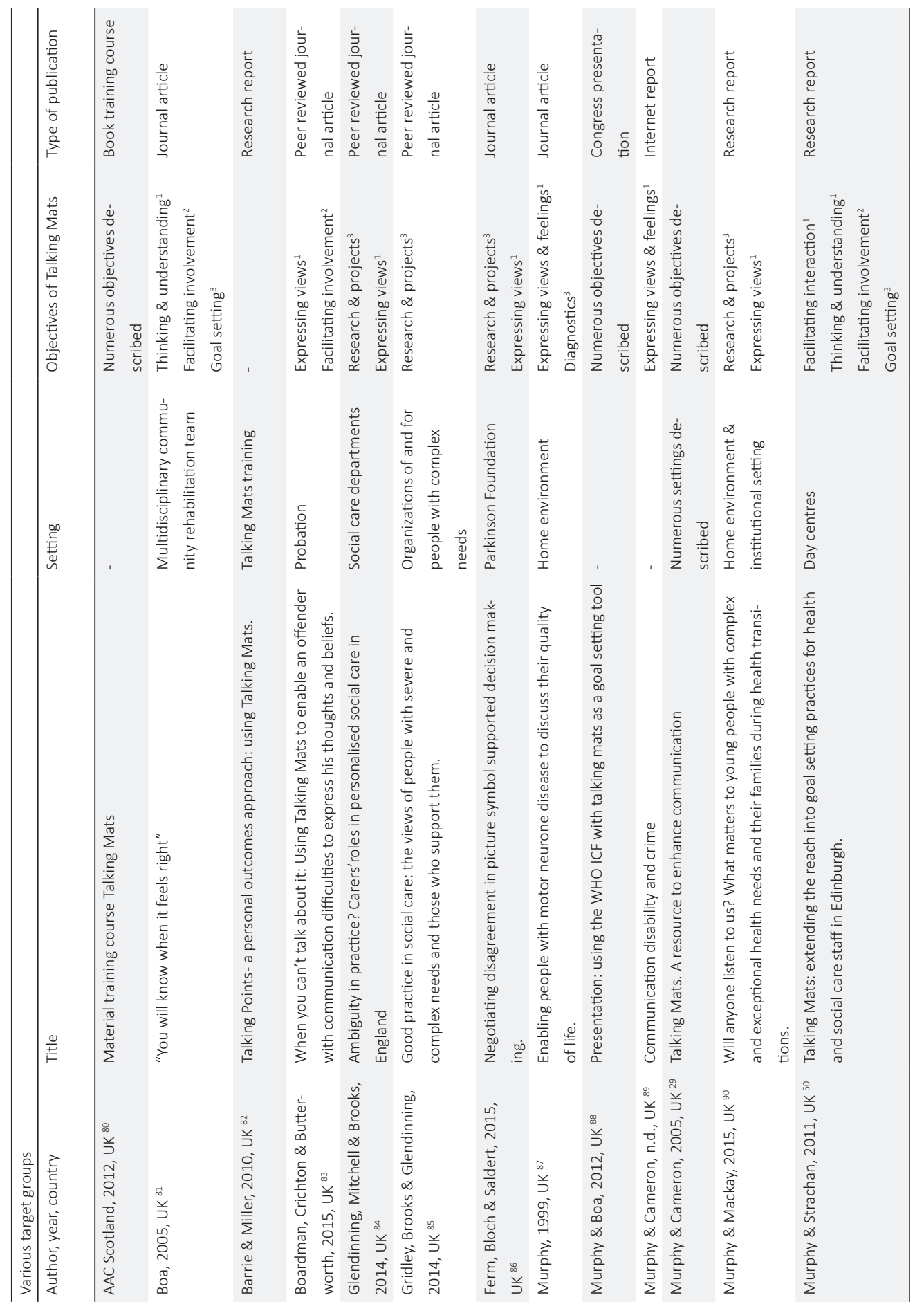




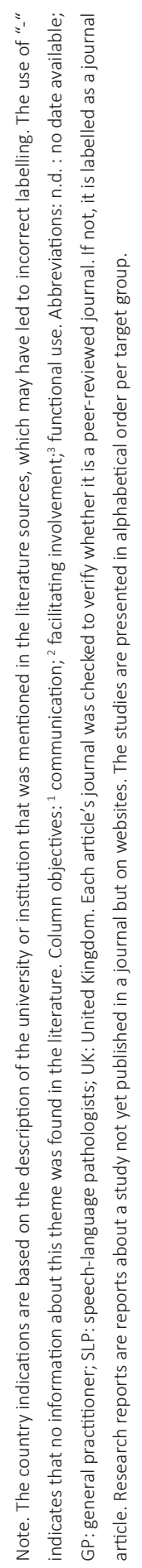

5

Using Talking Mats to support conversations with people who are communication vulnerable | $\mathbf{1 3 1}$ 


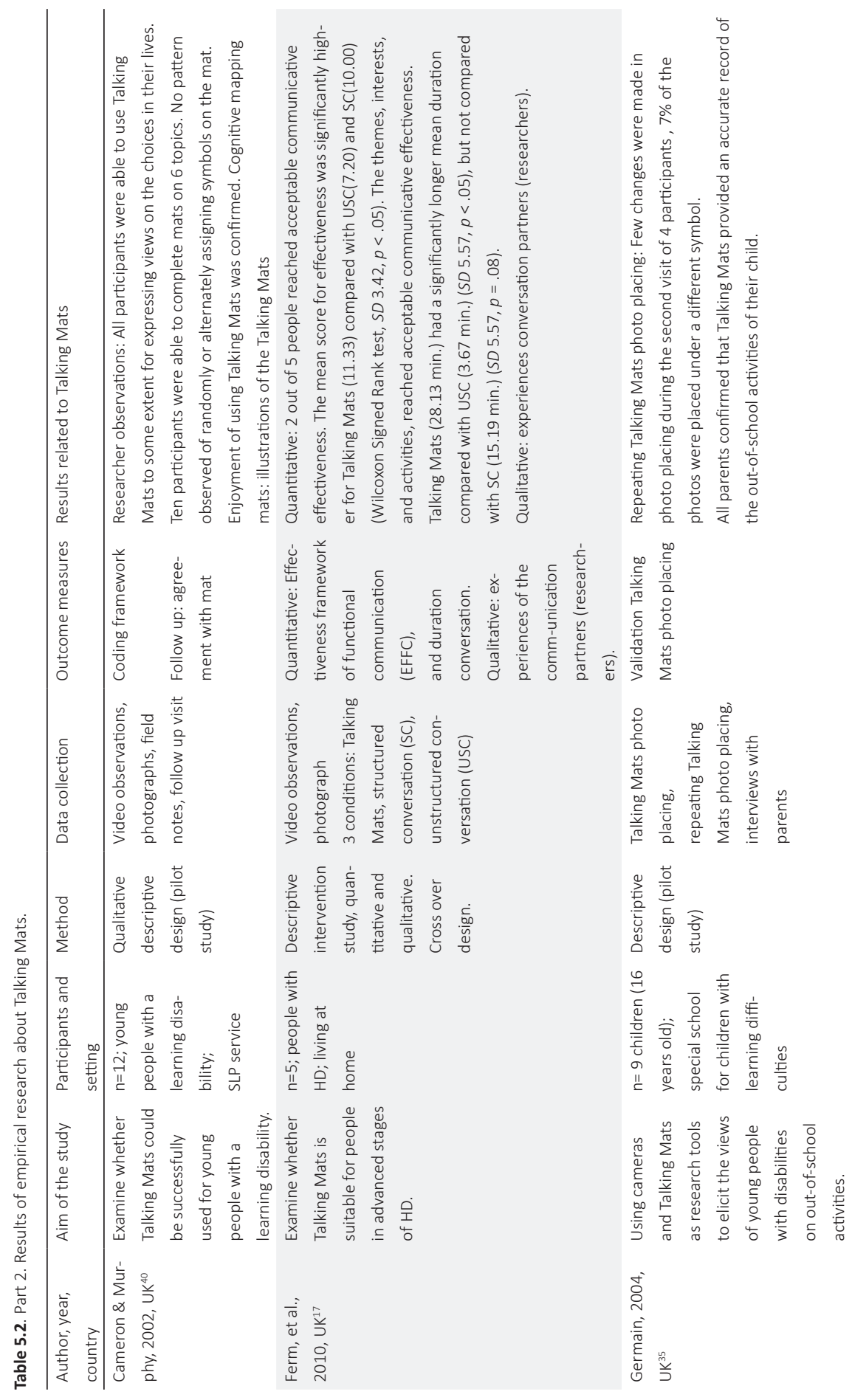




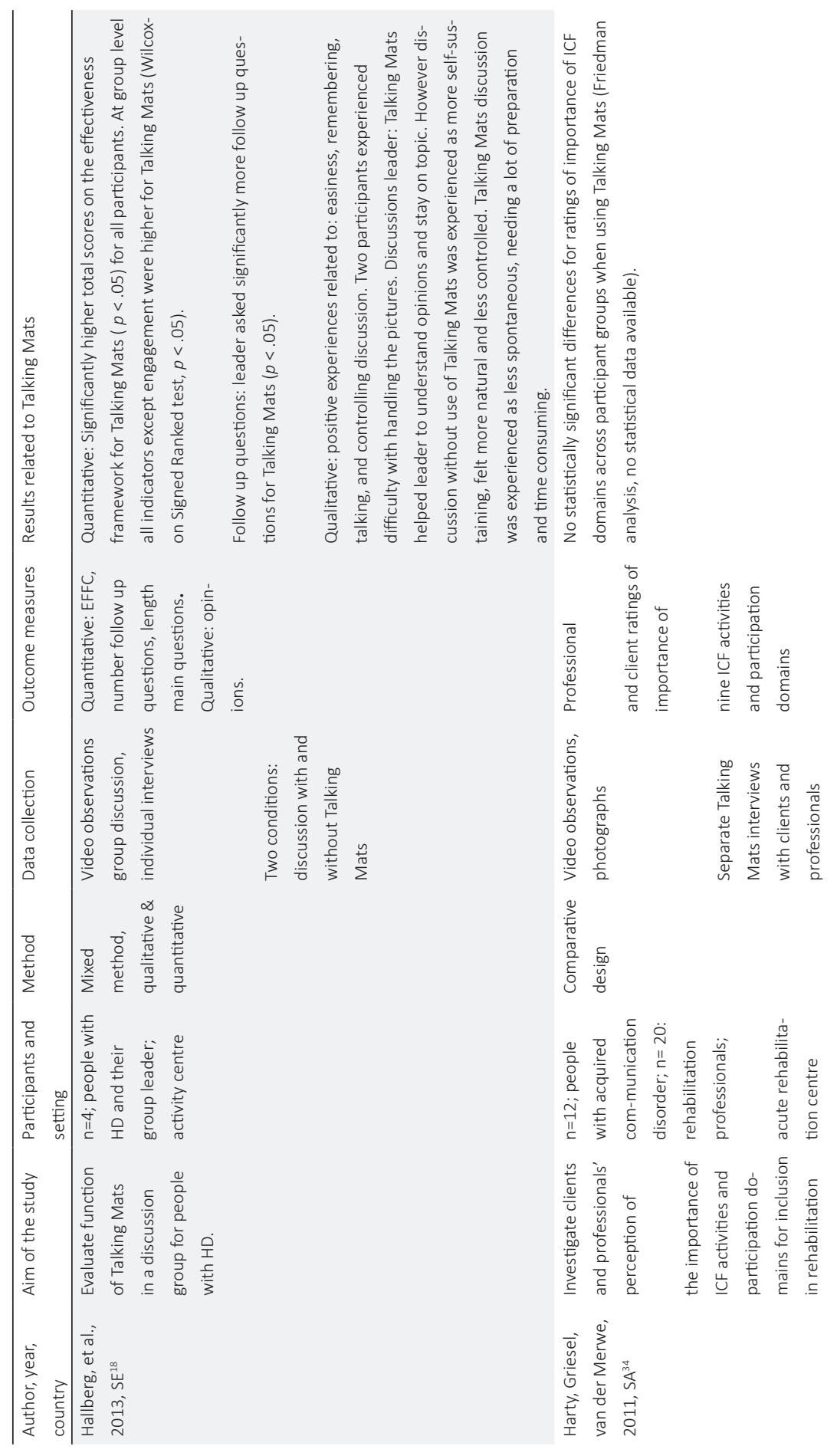




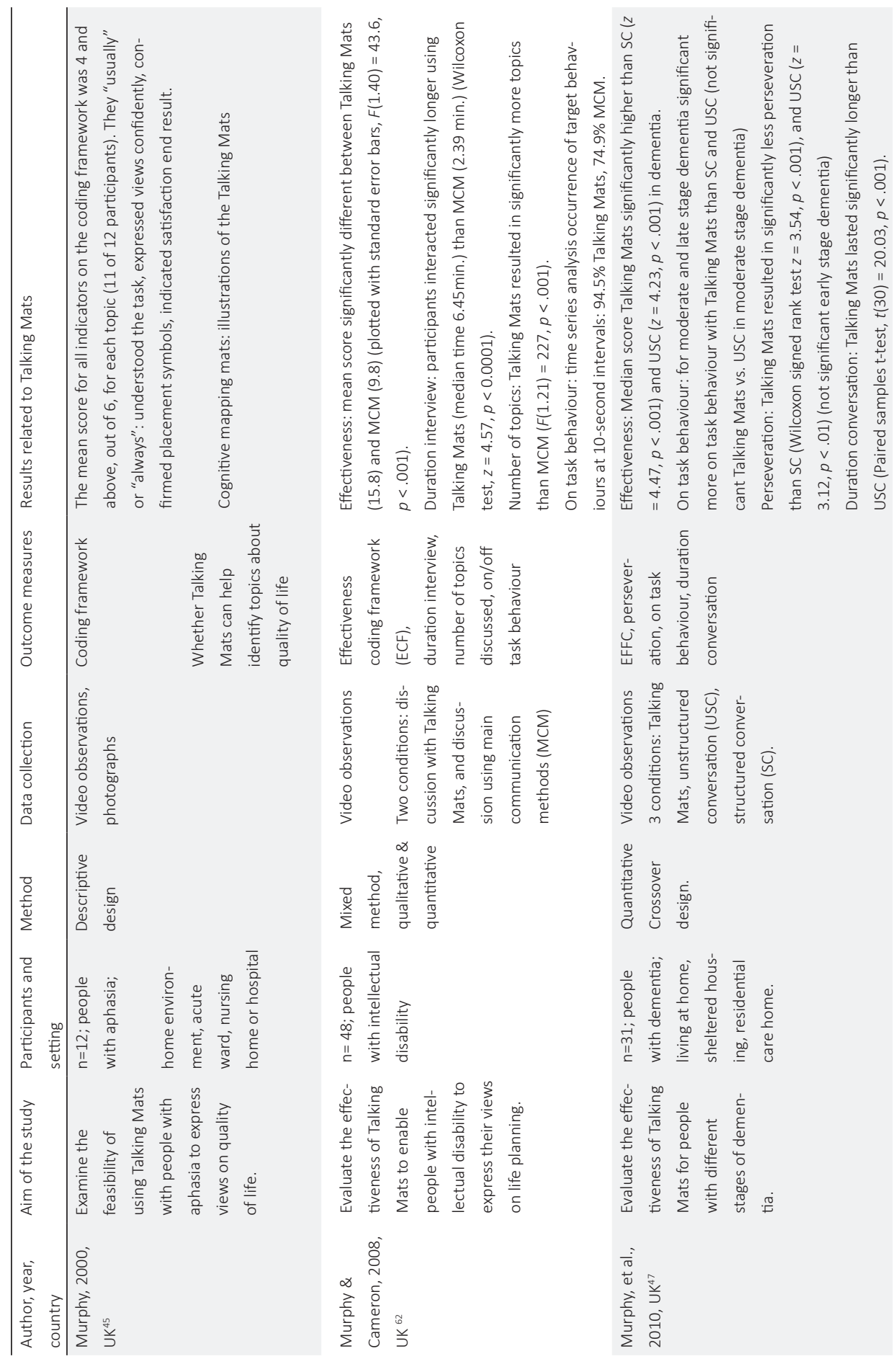




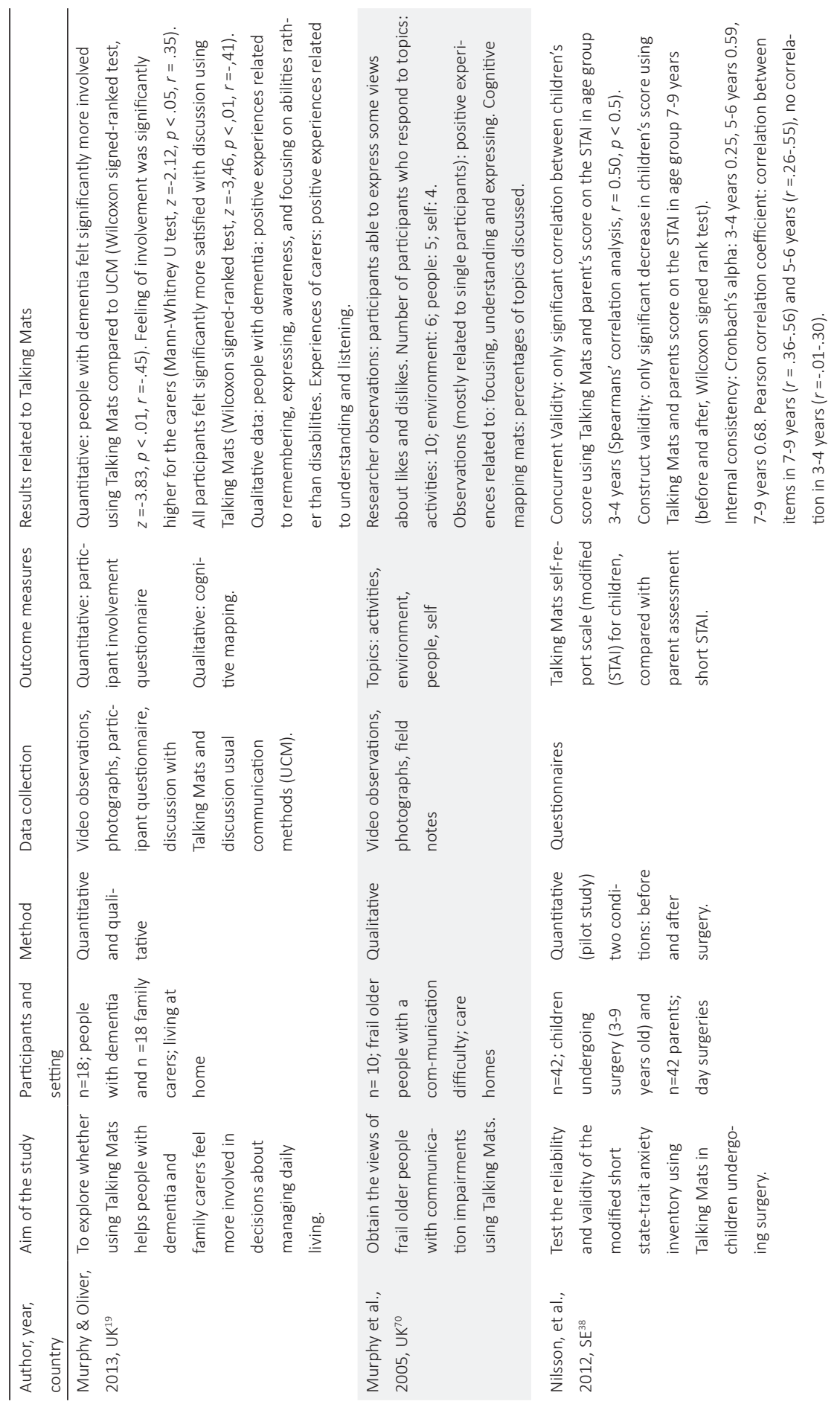




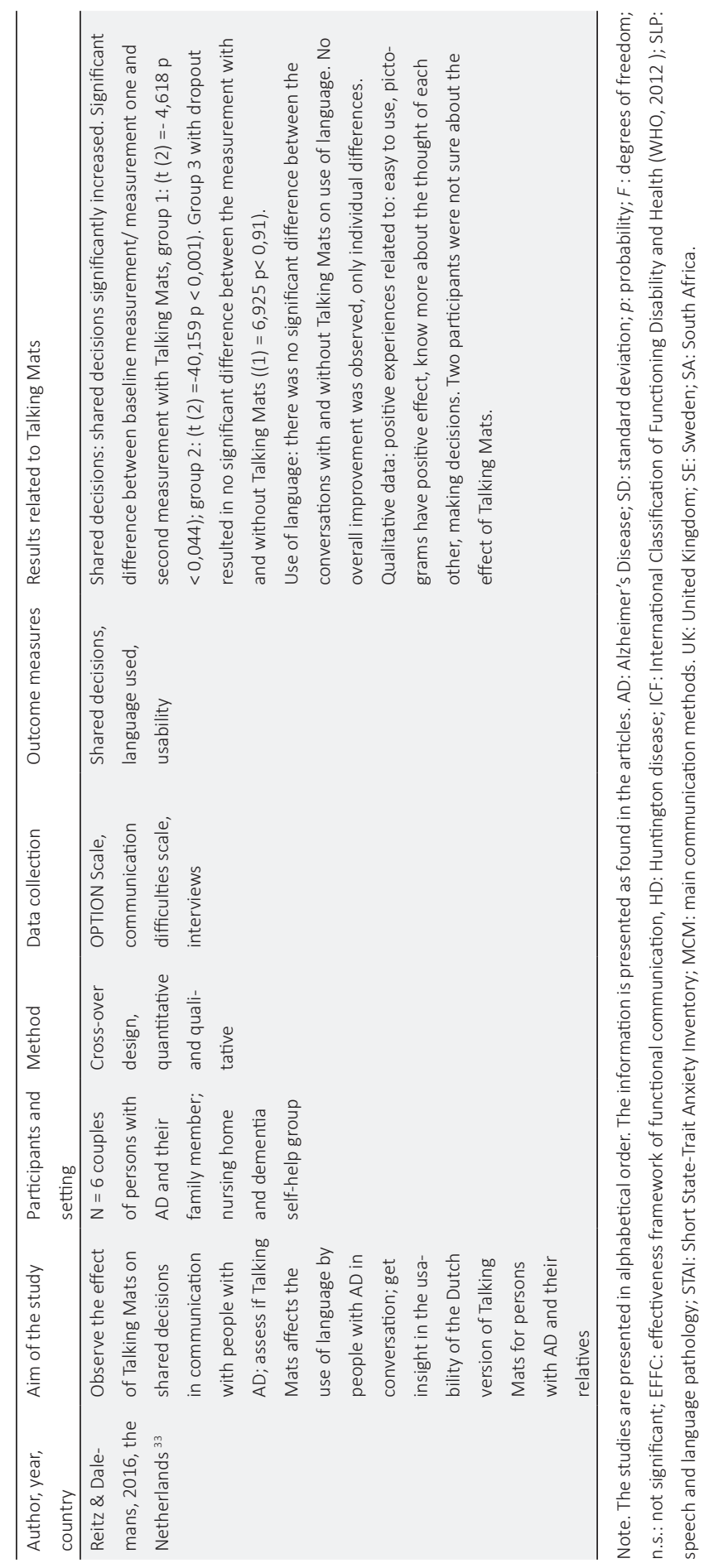




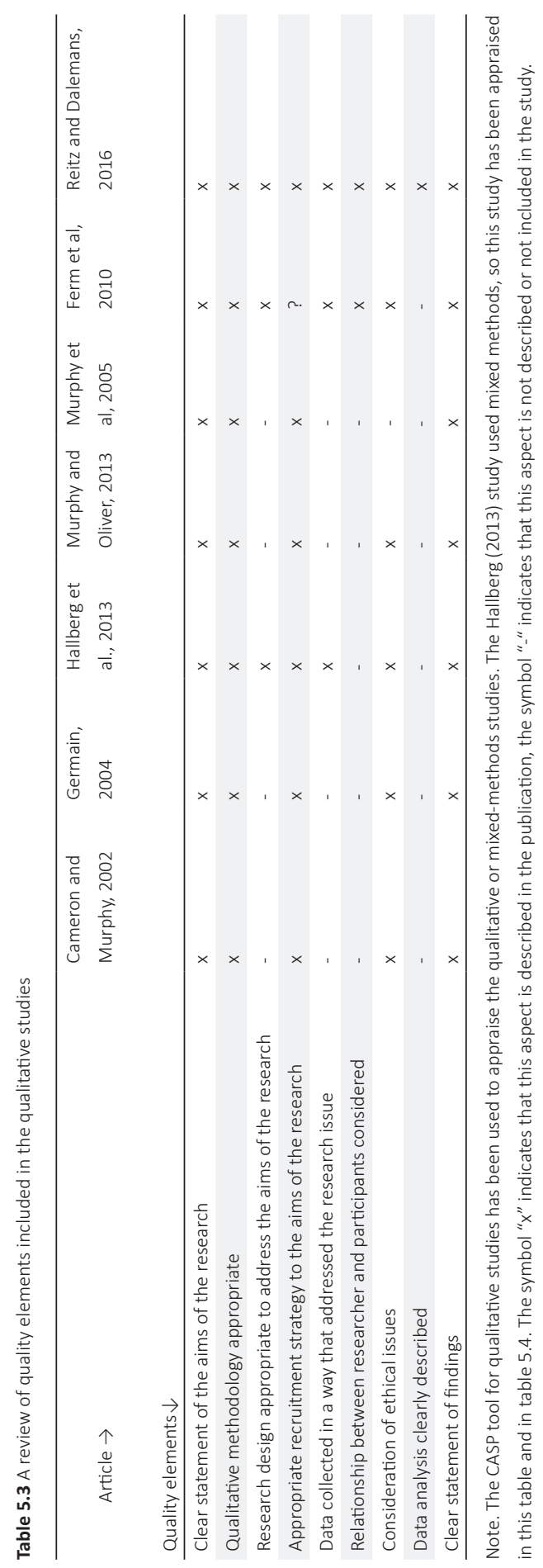




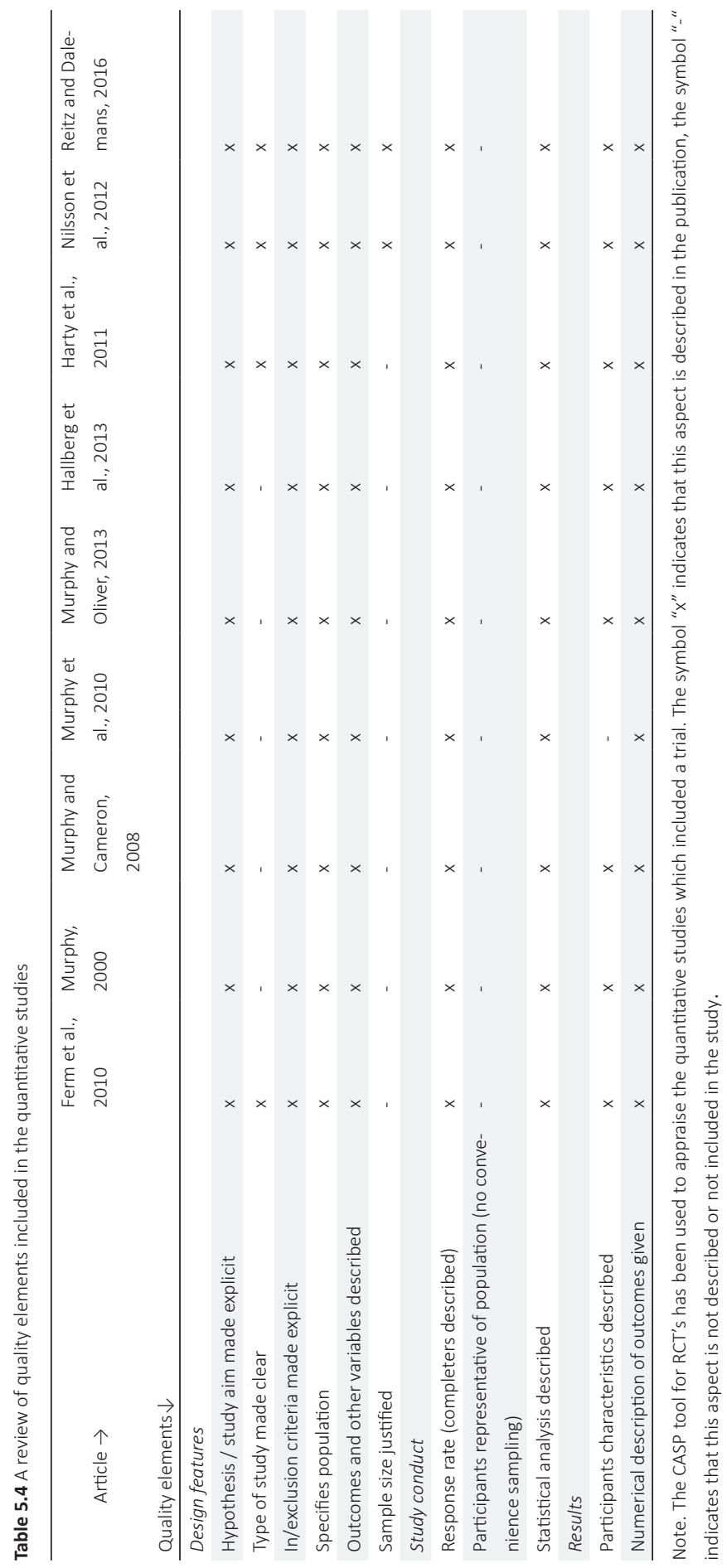

138 | Chapter 5 



\section{Chapter 6}

Choose to communicate: a web based guide to support communication between practitioners and communication vulnerable people

Als ik kon zeggen wat ik wilde,

Dat had ik dat al lang gedaan.

Als ik kon zeggen wat ik voelde,

Dan had ik dat al lang gedaan.

Als ik kon zeggen hoe jij mij kan helpen,

Dan had jij mij al lang geholpen. 


\section{Abstract}

\section{Aim}

This study aims to develop a guide that supports practitioners and communication vulnerable clients in selecting easy to use ad hoc AAC for their dialogue conversations, and to evaluate the usability of the guide.

\section{Background}

Communication vulnerable clients and practitioners have difficulties communicating in dialogue conversations. Augmentative and alternative communication (AAC) can support these conversations, however, choosing the right ad hoc AAC seems to be problematic.

\section{Methods}

An iterative user-centered design research project in which communication vulnerable clients and practitioners were involved. During three cycles, a guide was developed, and the usability was evaluated using semi-structured and think-aloud interviews, as well as questionnaires.

\section{Results}

The website 'Choose to Communicate' was developed, in which clients and practitioners answer questions about communication difficulties, based upon the responses, a specific AAC list is presented with details about each AAC. During usability testing, clients found the guide useful, but suggested to adjust questions and include a 'sometimes' answer. Practitioners see potential for use in daily practice, but recommended including questions about physical (dis)abilities.

\section{Conclusions}

'Choose to Communicate' could support practitioners and clients to choose an AAC solution together to support their dialogue conversation. Clients and practitioners are mostly satisfied with the structure and layout, and evaluate it as a useful guide. 


\section{Introduction}

Augmentative and alternative communication (AAC) has the potential to support communication vulnerable clients and practitioners to establish a shared dialogue. ${ }^{1}$ In particular, simple and readily accessible AAC could be ad hoc used for dialogue conversations. There are several definitions of AAC. We use the broad definition of Clarke and Bloch, ${ }^{2}$ which incorporates formal communication aid systems (eg, voice output communication aids), conventional semiotic systems (eg, handwriting), unaided resources (eg, gesture), and commonplace objects (eg, maps or letters). AAC thus involves any method, strategy or resource that can help people communicate more successfully, we will refer to any AAC system or approach as "AAC" hereafter. ${ }^{1}$ Some have argued that the use of AAC should be standard practice for adults with neurodegenerative diseases who experience communication difficulties, ${ }^{1}$ however, AAC should be considered also for the even larger target group of communication vulnerable adults.

When communicating with communication vulnerable clients, dialogue conversations appear to be difficult: on the one hand, these clients can have difficulties expressing themselves and/or understanding the practitioner; on the other hand, practitioners can have difficulties understanding these clients., Conversations between healthcare practitioners and clients play an important role in healthcare. ${ }^{5-7} \mathrm{We}$ define these conversations as dialogue conversations, in which essential exchanges between a client and any health-care professional take place which are of influence on the care process, and in which both play a significant role. These conversations can, for example, relate to diagnostics, health-related goals, activity and participation choices, or evaluation of treatment. ${ }^{8}$ Miscommunication in dialogue conversations can result in a deficiency in client-centered care and shared decision making, and can have negative influences on client satisfaction and client safety., ${ }^{5}$

Communication vulnerable people struggle to communicate in particular environments because they experience difficulties in expressing their needs and/or understanding information. Limitations in any one of the areas of functioning (for example, sensory, emotional, physical, and cognitive difficulties) can have an impact on communication. ${ }^{3,8}$ Communication vulnerable clients are acknowledged as amongst the most vulnerable groups in health care settings. ${ }^{9}$ The number of communication vulnerable clients can be underestimated, since professionals are often not aware of the communication vulnerability, especially when the client has not been diagnosed with a specific communication disorder (e.g. aphasia)

${ }^{3,8}$. Moreover, this group is increasing due to an aging population and medical advances. ${ }^{9,10}$ Practitioners are often not aware of the influence of sensory, emotional, physical, or cognitive (dis)abilities on communication, and consequently underestimate the need for communication support. ${ }^{3}$ Furthermore, a study by Parr ${ }^{11}$ found that practitioners often have feelings of anxiety or shame when communicating with people who have communication difficulties. Consequently, practitioners circumvent conversations, not being able to provide appropriate communication support to communication vulnerable clients. ${ }^{3,12}$ 
Although a variety of AAC are available, these are often not used due to a lack of awareness of communication vulnerability, a lack of understanding of the potential of AAC, or a lack of knowledge of available AAC. ${ }^{3,4}$ Practitioners, especially nurses and activity supervisors, do not know which AAC they might use for particular communication difficulties. ${ }^{3,8,9,11}$ Although some might think of AAC as complex systems, those who are communication vulnerable can also benefit from easily accessible and simple to use AAC, such as writing, drawing, or using visual aids. ${ }^{4}$ Such relatively simple and easy to use AAC might support dialogue conversations without the need for comprehensive training on the part of the client or practitioner. AAC might sometimes be seen as a last resort, but practitioners could involve their clients in choosing and using easily accessible AAC from the moment a difficulty in communication arises. ${ }^{3,8,9} \mathrm{~A}$ particular issue is that evidence on AAC does not provide practitioners with enough support to choose appropriate AAC for their dialogue conversations. ${ }^{13}$

Seeing the similarities between clients who have different diagnoses but who all share the experience of being communication vulnerable is important in choosing appropriate AAC and enabling adequate conversations. ${ }^{1}$ Focusing on the functional communication difficulties rather than on diagnosis can be valuable as practitioners have conversations with different communication vulnerable clients in daily healthcare. For example, clients can have word-finding problems due to different diagnoses such as aphasia or dementia, but may all benefit from low-tech AAC, such as writing or drawing. lacano and colleagues confirm this applicability of specific AAC for a broad range of diagnoses. ${ }^{14}$

A shift from diagnosis-based communication support, to communication support targeted at the clients' needs and goals in dialogue conversations is needed to place the person and his/her needs first, and acknowledge daily communication difficulties in practice..$^{1,15}$

Practitioners and clients need to be aware of communication vulnerability, to know which AAC can help them, and have access to a variety of readily available, simple AAC to improve their dialogue conversations. ${ }^{16}$ In addition, they need help in the decision process for selecting the appropriate guide or strategy. The better equipped clients and practitioners are to communicate with each other, the more likely it is that clients will be able to express their needs, wishes, and values, and obtain the care and support they need when they need it. ${ }^{9}$ For high-tech tailored AAC, an intensive diagnostic process is needed, but for ad hoc AAC to be used in dialogue conversations, a guide that supports choosing AAC could be valuable. This could support clients and practitioners in selecting AAC, and it should be developed in close collaboration with clients and practitioners to ensure its applicability in daily practice. ${ }^{17}$ Therefore, the objective of this study was to develop and evaluate the usability of a Dutch guide for selecting relatively simple ad hoc AAC, easy for practitioners and communication vulnerable clients to use together, to support them in their dialogue conversations. 


\section{Methods}

To structure the development and usability testing, an iterative user-centered design research project comprising three cycles was followed, cycle 1: development of a low-fidelity prototype, cycle 2: developing a high-fidelity prototype, cycle 3: developing a final guide (see Figure 6.1). ${ }^{18,19}$ User-centered design provides the opportunity to collaborate closely with users with the ultimate aim of developing a guide that is needed, usable, and suited to the setting. ${ }^{19}$ Several prototypes were developed and refined, informed by end-user and expert feedback. While the cycles were successive in terms of time, the process required iterations in which ongoing new requirements emerged that further guided the development of the guide.

In this study, usability was defined according to ISO: the extent to which a user can use a product to achieve specific goals with effectiveness, efficiency, and satisfaction. ${ }^{20,21}$ 


\section{User-centered design process}

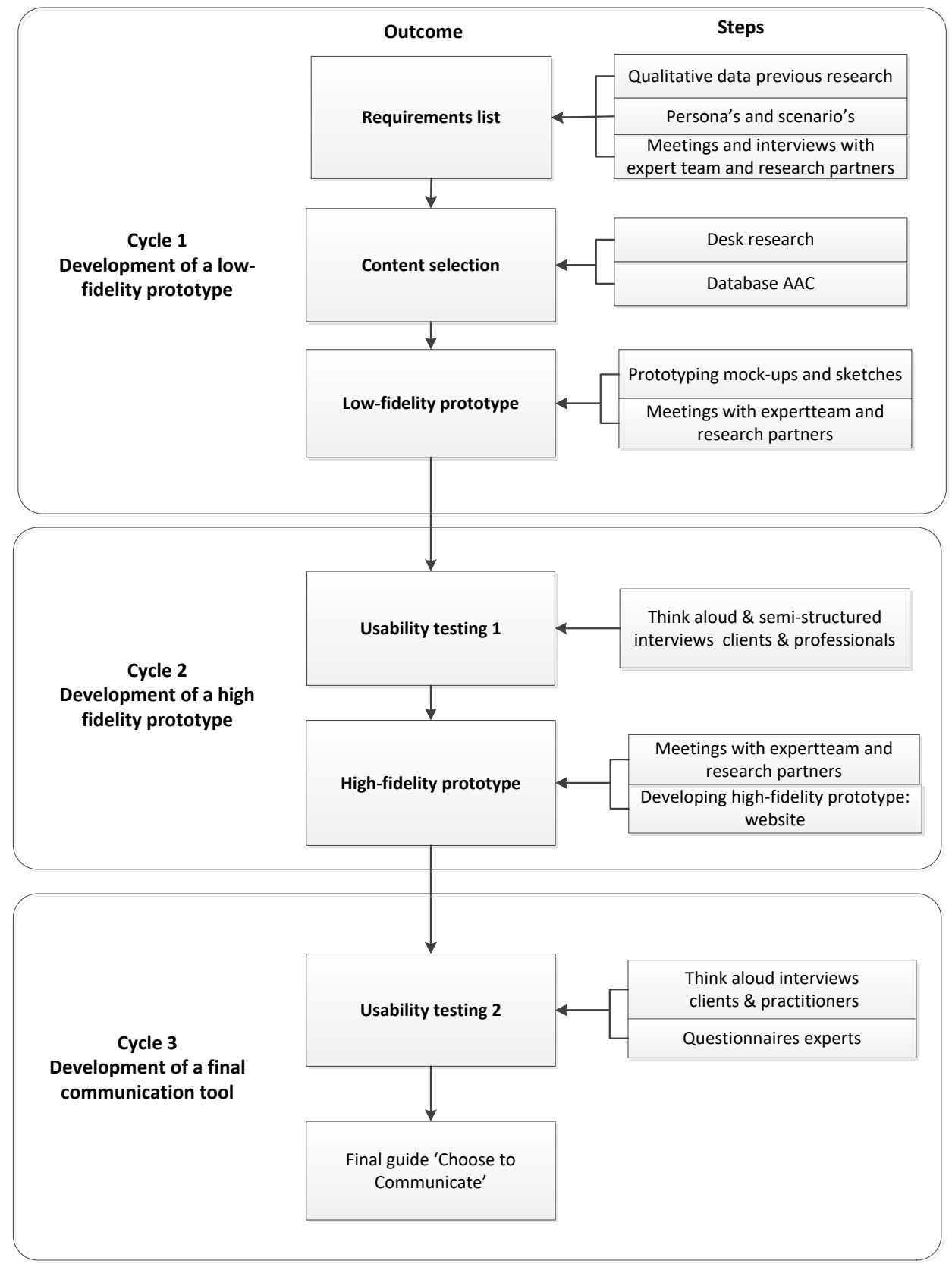

Figure 6.1 User-centered design process: three cycles of development and testing. 


\section{Participants}

To include users' perspectives in all cycles, we collaborated with communication vulnerable adults and health care practitioners, both as end users. ${ }^{17,22}$ We incorporated the broad target group of communication vulnerable people, using the definition described in the introduction. To include the natural setting in which the guide will be used, two care institutions in the south of the Netherlands were involved and constituted the context of this research: an institution for the support and care of older people and people with chronic illnesses, and an institution for the support and care of people with acquired brain injury and physical impairments.

Users and experts were involved at several levels of participation. ${ }^{23}$ The research team consisted of the authors of this paper and guided the entire process. At the partnership level, a client and a nurse were involved as research partners during the three cycles of the project, the researcher (SS) met with them several times during each cycle to discuss the next steps or adjustments. At the advisory level, an expert team was involved during the development of the prototypes, including the research team, one occupational therapist, and one speech and language pathologist. At the level of consultation, several clients, practitioners, caregivers, occupational therapists, and speech and language pathologists were involved as respondents during usability testing. The recruitment of participants is described per cycle, purposive sampling was used to ensure a heterogeneous group of participants.

\section{Cycle 1: Development of a Low-Fidelity Prototype}

The first cycle involved three steps: developing a list of requirements, content selection, and developing a low-fidelity prototype.

\section{List of requirements}

The results of an earlier study, about the experiences of communication vulnerable people in dialogue conversations, were used to provide insights into the context and characteristics of future users. ${ }^{8}$

This qualitative study performed in 2015, consisted of observations ( $n=11$ ) of dialogue conversations between practitioners and communication vulnerable clients, followed by interviews $(n=22)$. In the current study, two fictional persona's and scenarios for dialogue conversations were developed and discussed with the research partners. These were used only in this phase to guide the initial development of the first prototype using virtual storylines. ${ }^{24}$ With the context and characteristics of future users in mind, a list of requirements was developed in an iterative process, based upon: a group discussion with the research team, a group discussion with the expert team, explorative interviews with the research partners, and desk research.

\section{Content Selection}

A database of AAC available in the Netherlands was developed using desk research. The researcher 
gathered $A A C$ and relevant literature on $A A C$, searched several synonyms of $A A C$ in Google and known AAC websites, screened literature on AAC, and conducted a search in Cochrane in July 2016. A data extraction format was used to document information about each AAC in the database, including name, description, availability, price, target groups, and evidence. Eight communication experts (occupational therapists, and speech and language therapists) completed a list in which they prioritized the match between AAC types in the database and communication difficulties. The ICF classification was used to define functional communication difficulties. ${ }^{25}$ The lists were merged, and the research team made a final decision upon matching AAC types and communication difficulties.

\section{Low-fidelity Prototype}

Based upon the list of requirements and content selection, several sketches and mock-ups, and discussions with research partners and the expert team, a first prototype was drafted: a low-fidelity paper-based guide. ${ }^{19,26}$

\section{Cycle 2: Development of a high-fidelity prototype}

The second cycle involved usability testing of the first low-fidelity prototype, and adjusting the prototype into a high-fidelity prototype.

\section{Usability Testing 1}

The low-fidelity prototype was tested for usability by means of think-aloud and semi-structured interviews with client and practitioner dyads. These were recruited via research partners, the experts involved, and a speech and language pathologist. The heterogeneity of the communication difficulties of the clients included was monitored using the communication vulnerability screening list. ${ }^{8}$ Including a wide variety of people who had different communication difficulties would support the use of the guide for this broad target group. Bachelor students in occupational therapy were instructed in the data collection procedures and performed the interviews. They explained the objective of the prototype to the dyads, and thereafter the dyads were asked to use the prototype together and express their thoughts (think aloud) while using the prototype. ${ }^{27}$ Subsequently, they were asked additional questions during individual interviews. The interview guide consisted mainly of questions concerning the usability elements: effectiveness, efficiency, satisfaction, and errors. ${ }^{20,28}$ Effectiveness refers to the accuracy and completeness with which users achieve specified goals (understandability, navigation, content), efficiency to resources expended in relation to the accuracy and completeness with which users achieve goals, and satisfaction to freedom from discomfort and positive attitudes toward the use of the product. ${ }^{20}$ Data from both the think-aloud interviews and semi-structured interviews were analyzed together, by the research team, using directed content analysis using the same usability elements. ${ }^{29}$ First, the transcripts were read, and information relating to usability was highlighted. Second, the highlighted text was coded using the usability elements as themes, and discussed in the research team. Third, the definition of the elements and the information in the transcripts were used to develop subthemes, and 
for each subtheme the data was ordered in positive experiences and suggestions for improvement. The final analysis was again discussed in the research team.

\section{High-fidelity Prototype}

The results of the usability testing were discussed with research partners and the research team until consensus was reached on further development. Thereafter, the prototype was further developed into a high-fidelity web-based guide in collaboration with an ICT company. Readability was optimized by review of plain language principles by a patient communication expert (RD) and implementing the Dutch B1 reading level. ${ }^{30}$

\section{Cycle 3: Development of a Final Guide}

The third cycle involved the following two steps: usability testing of the high-fidelity web-based guide, and development of the final guide.

\section{Usability Testing 2}

Usability was tested through think-aloud interviews and questionnaires. For the interviews, clientpractitioner dyads were recruited during a client-meeting in one care institution, and via the speech and language pathologist in the second institution. The included dyads were asked to use the web-based guide together, in their own environment. The researcher (SS) was present and interviewed them using a think-aloud interview guide (see usability testing cycle 2). The interviews were audiotaped and analyzed using the same directed content analysis strategy as in usability testing $1 .^{29}$

In addition, an online questionnaire, using the tool 'Surveymonkey' was used to collect insights on usability from communication experts. The sample was specifically targeted at experts in AAC, occupational therapists and speech and language pathologists working in the Netherlands, to gather their critical opinion about the usability of the guide. The questionnaire was disseminated through the researchers' networks, the network of the occupational therapy and speech and language therapy schools, and placed on an aphasia network website. The questions were based upon the usability elements, using existing usability questionnaires and questions concerning use in daily practice. . $1,31,32^{2}$ The practitioners were also explicitly asked about the face validity: the relevance of the guides' questions, the completeness of the AAC guides, and the appropriateness of the recommended AAC in the guide. E-mail invitations were sent, and the practitioners were asked to use the web-based guide alone (with a specific client in mind) or together with a client, and thereafter fill in the questionnaire. Quantitative data were imported into an Excel file and analyzed descriptively, and qualitative data were analyzed using the directed content analysis. ${ }^{29}$

\section{Final Guide}

Based on the results decisions concerning necessary adjustments were discussed with the research partners, the expert team, and the research team. Thereafter, the prototype was amended to form the 
final communication guide.

\section{Ethical considerations}

The local Human Research Ethics Board Z (Heerlen, The Netherlands), which verifies if the study is conducted in accordance with the World Medical Association Declaration of Helsinki and other appropriate EU regulations and laws, approved this study. Clients and professionals willing to participate, first provided verbal consent to the professional or researcher, and additionally written or audiotaped informed consent to the researchers in accessible format. ${ }^{33}$ All communication during the study, including informed consent, was made accessible for communication vulnerable clients. ${ }^{3,33}$ All information is fully anonymized.

\section{Results}

\section{Cycle 1: Development of a Low-Fidelity Prototype}

\section{List of Requirements}

The group discussions with the research team and expert team led to several requirements for the guide, from the professionals' point of view. The explorative interviews with the research partners focused on the requirement from the clients' point of view. All requirements are summarized in table 6.1 . 
Table 6.1 List of requirements

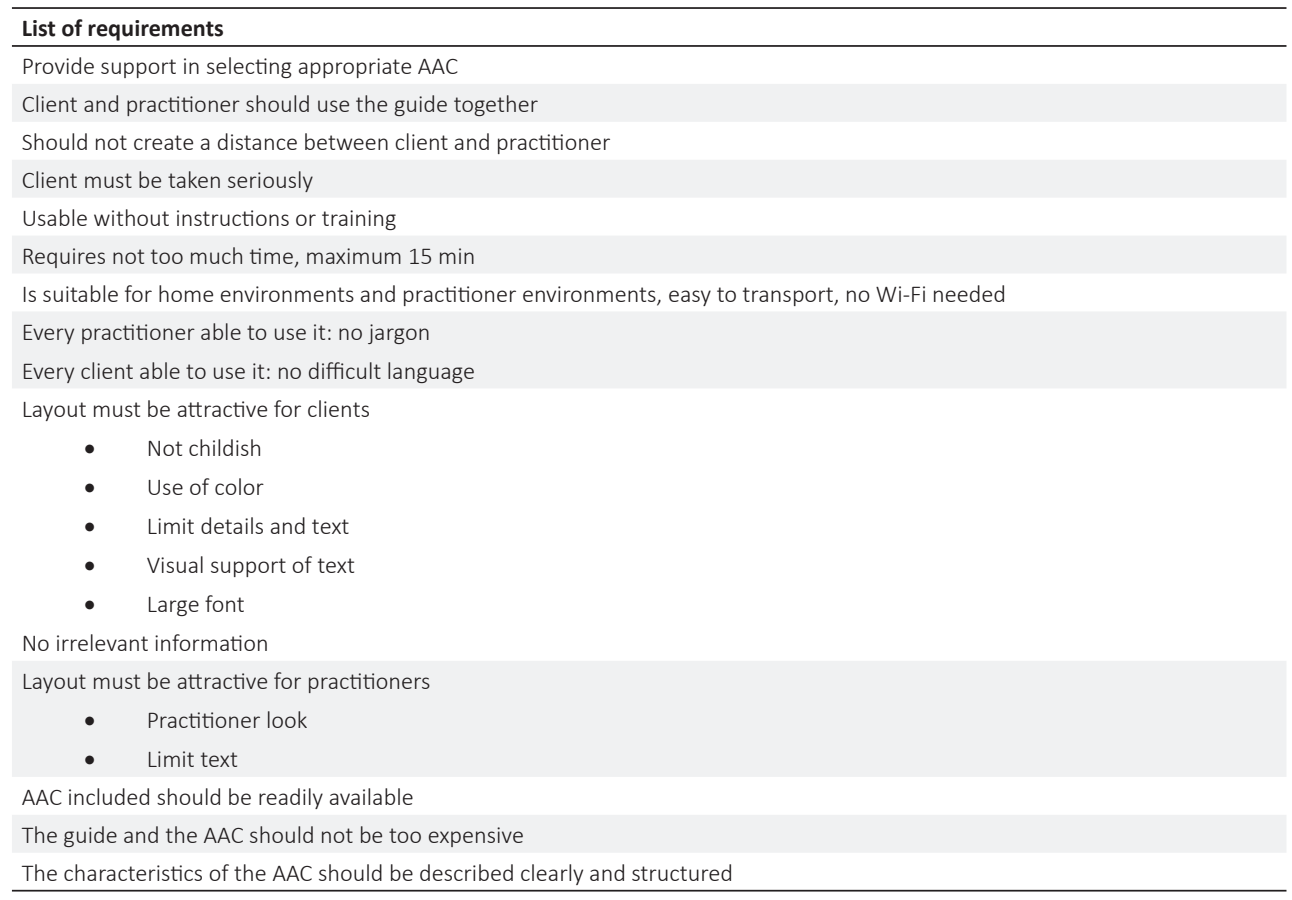

\section{Content Selection}

The desk research led to the inclusion of 63 AAC in the database, which were categorized into 24 types of AAC. A categorization of communication (dis)abilities was decided upon by the expert team, namely understanding, remembering, talking and loudness of talking, intelligibility, gestures, attention, vision, and hearing. The communication experts completed the list for the match between the communication (dis)abilities and AAC.

\section{Low-fidelity Prototype}

After prototyping several sketches and mockups for the underlying structure of the guide, the research team, together with the research partners, concluded that a website with a linked database of AAC would be the best solution, since a website provides the possibility of quickly linking disabilities to AAC, adjusting the font size, and updating information quickly. A print-option would be added for all pages of the website, to meet the requirement of "no Wi-Fi needed." Based on the list of requirements, a low-fidelity paper prototype of the website was developed (Figure 6.2). 

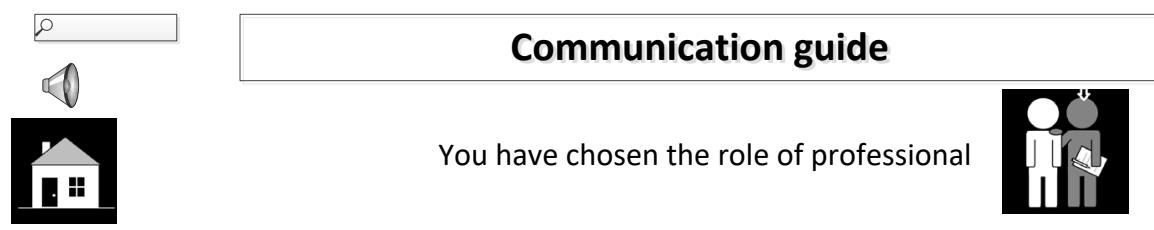

HOME

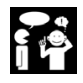

$$
\text { Understanding what other people say }
$$

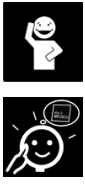

\section{Understanding gestures of other people}

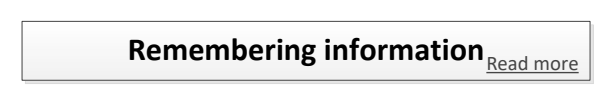

yes

no

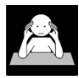

To have the attention at the conversation

yes no

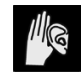

Hearing what other people say

Read more

$\underline{n}$

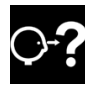

Being able to see everything

Read more

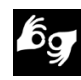

Using gestures

$\underline{\text { Read more }}$

yes no
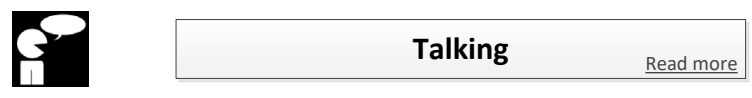

yes

no

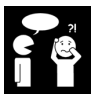

Understanding the client Read more 


\section{Cycle 2: Development of a high-fidelity prototype}

\section{Usability Testing 1}

The first paper-based prototype was used by clients $(n=6)$ and practitioners $(n=5)$ together. Their characteristics are presented in table 6.2. One interview was performed with a professional volunteer alone. The others were with client-practitioner dyads, among which two practitioners participated twice. The results of the think-aloud and semi-structured interviews are presented in table 6.3.

With regard to effectiveness, they found the guide difficult to use and needed explanation. Some questions were not understandable and needed to be adjusted. Clients emphasized that the check boxes for communication difficulties were not useful. They found the visual support of the pictograms and ICT icons (such as "home") valuable, but some had to be adjusted for understandability. Regarding efficiency, both clients and practitioners indicated that the amount of text per page was too much, and the information and questions needed to be spread over more pages. Clients and practitioners were mostly satisfied with the layout, but they suggested using one basic color. They had difficulties using the guide, some of which could be due to the fact that it was a paper-based prototype. Furthermore, the interviewers noticed that the clients were not always given time to respond to the questions themselves. This could also be due to the fact that it was a paper-based prototype and practitioners were still figuring out themselves how it worked.

Table 6.2. Characteristics of the participating clients and practitioners: usability testing 1.

\begin{tabular}{|c|c|c|c|c|c|}
\hline \multirow[b]{2}{*}{ Interview } & \multirow[b]{2}{*}{ Age } & \multicolumn{2}{|c|}{ Clients } & \multicolumn{2}{|c|}{ Practitioners } \\
\hline & & Gender & Diagnoses & Gender & Profession \\
\hline 1 & - & - & - & 우 & Professional volunteer \\
\hline 2 & 56 & $\sigma^{\prime \prime}$ & Stroke, dysarthria & $\sigma^{\prime \prime}$ & $\begin{array}{c}\text { Daily activity super- } \\
\text { visor }\end{array}$ \\
\hline 3 & 52 & $\sigma^{x}$ & Stroke & & ne person as in 2 \\
\hline 4 & 86 & 9 & Dementia & 우 & Nurse \\
\hline 5 & 37 & ㅇ & Cerebral Palsy & 우 & Nurse \\
\hline 6 & 82 & $\sigma^{\prime}$ & Dementia & ㅇ & Nurse \\
\hline 7 & 81 & ㅇ & Dementia and visual problems & & ne person as in 6 \\
\hline
\end{tabular}




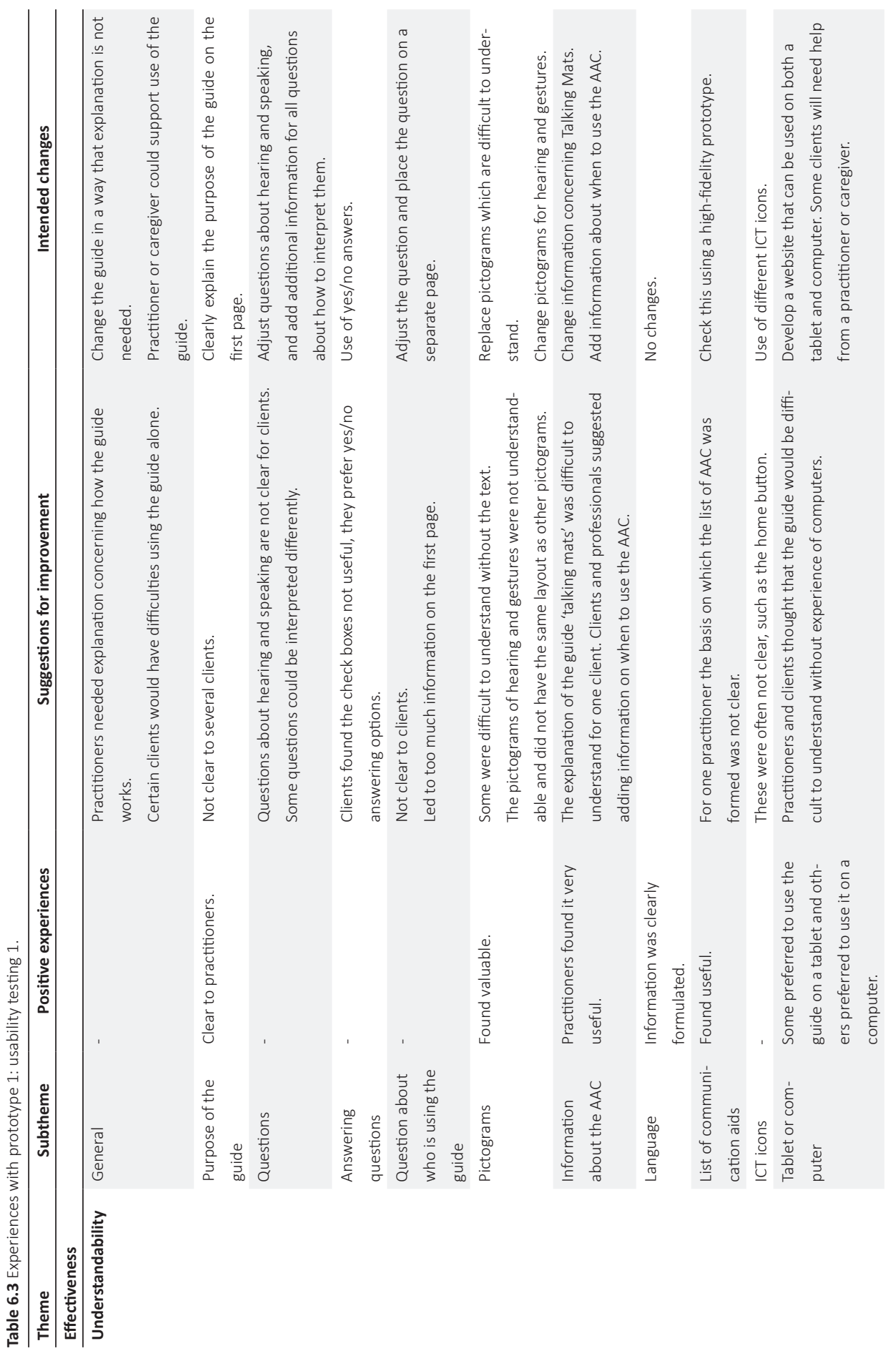




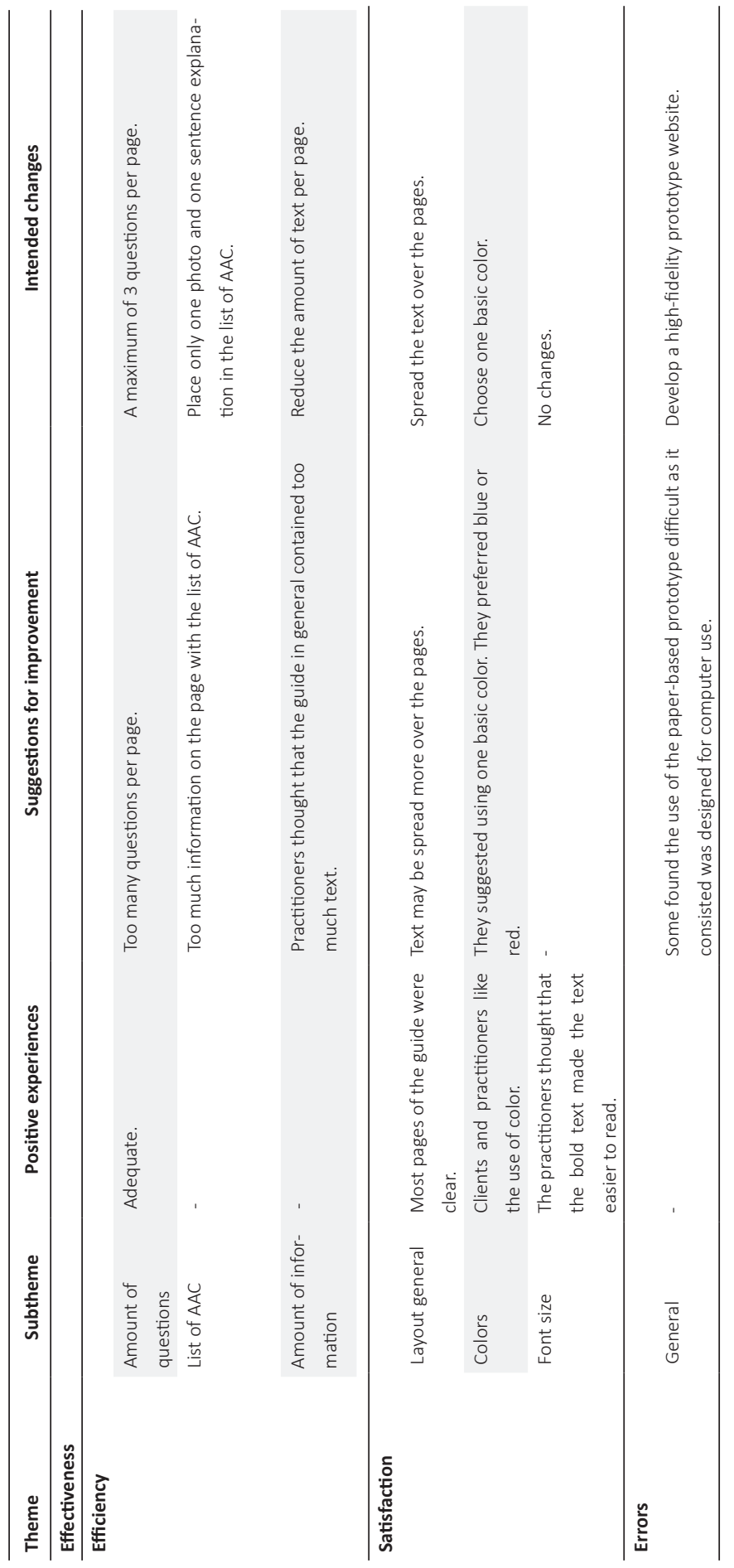




\section{Adjusting the Prototype}

The results of usability testing 1 were discussed with the research partners and researchers until consensus was reached about the required characteristics of the high-fidelity prototype. Design recommendations for connected health devices were followed when applicable, such as use of color, button sizes, and consistency. ${ }^{21}$ The website was made compatible for different devices such as smartphones, tablets, and computers.

The website consisted of the following steps (see figure 6.3):

1. The user clicks on the "start the guide".

2. The user sees a new page and can indicate whether he/she is a client or a practitioner/caregiver.

3. The user sees a new page with four questions, each asking whether the client has difficulties with a communication-related skill, such as talking or hearing, with the answering options "yes" or "no". Thereafter, an additional 5 questions are asked.

4. The user clicks on "results" and the AAC guides that the guide links to the communication difficulties are displayed. The user can click on an AAC, and the AAC is presented, comprising: description, for whom, characteristics, how to use, tips, availability, and price.

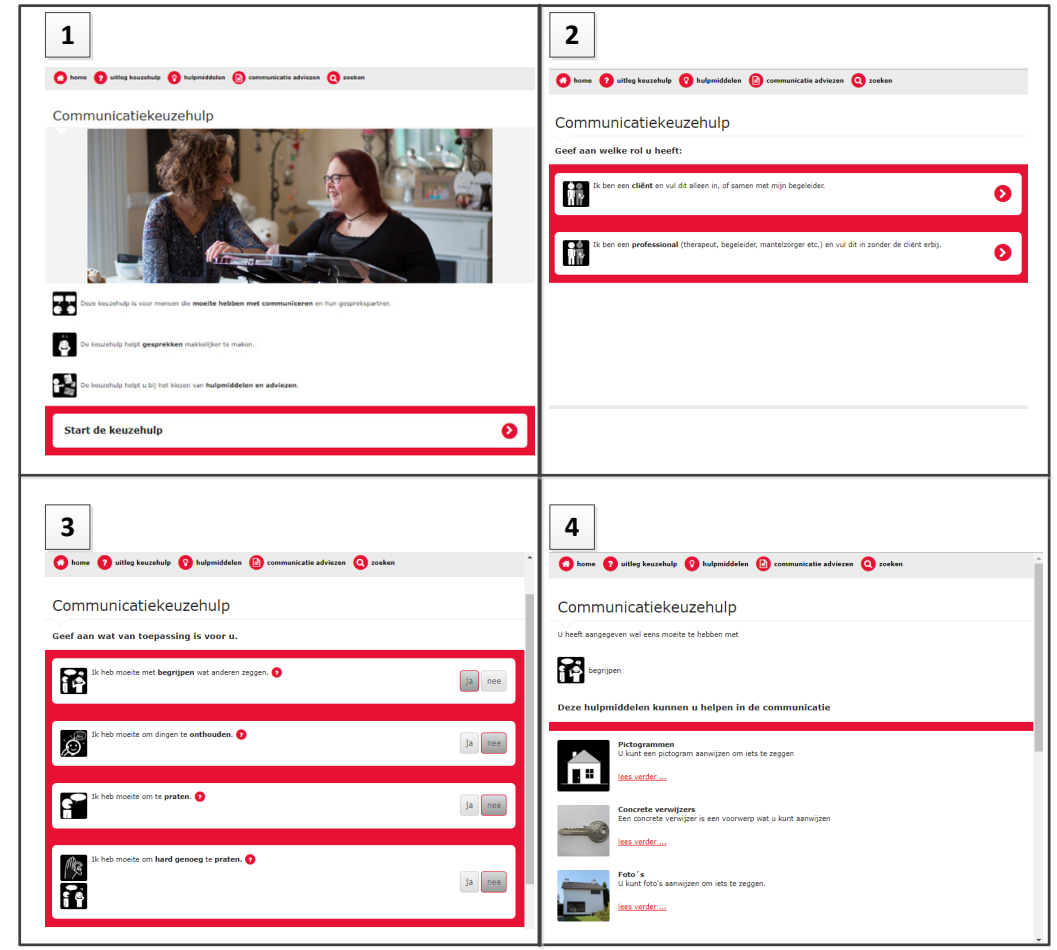

Figure 6.3 Four screenshots of the high-fidelity web-based prototype. 


\section{Cycle 3: Development of a Final Guide}

\section{Usability Testing 2}

The results of the think-aloud interviews are described in table 6.5. In the interviews, 13 clients, 1 caregiver, and 10 practitioners participated (table 6.4). Most think-aloud interviews were held with client-practitioner dyads, one with a client-caregiver dyad, and one client was interviewed alone.

Both clients and practitioners found the guide useful, they found the overview of AAC guides suitable as it helped them to know which AAC guide they could use. Clients and professionals indicated that they found it beneficial that the guide was designed for use together with clients. One client wanted to use the guide again with his own speech and language therapist.

The most important suggestions for improvement were related to the content. Some clients suggested the inclusion of questions concerning physical (dis)abilities, while others reported that they would like to decide themselves whether they physically could use an AAC. Furthermore, several clients insisted on adding the response "sometimes." During the think-aloud interviews, it became clear that without this option the answers were not valid as clients said "sometimes," and then chose "no."

With regard to use in practice, clients and practitioners mentioned several moments in their life or care process in which they would use the guide. Clients mentioned: "when my condition is aggravated," "if I couldn't find a solution myself," and "if I could not communicate anymore." Practitioners mentioned additional moments for using the guide: "every year in the evaluation of a client," "when a client cannot speak anymore," "when important decisions have to be made," and "with new clients, so you get to know them and learn about their needs."

Table 6.4 Characteristics of the participating clients and practitioners: usability testing 2.

\begin{tabular}{|c|c|c|c|c|c|}
\hline \multicolumn{4}{|c|}{ Clients } & \multicolumn{2}{|c|}{ Practitioners } \\
\hline Interview & Age & Gender & Diagnoses of client & Gender & Occupation \\
\hline 1 & 59 & $\sigma^{\pi}$ & MS & + & Nurse \\
\hline 2 & 45 & @ & Spina bifida, visual impairment & ? & Nurse \\
\hline 3 & 37 & 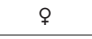 & $\mathrm{CP}$ & q & Nurse \\
\hline 4 & 45 & $0^{\pi}$ & Muscular dystrophy, Becker & 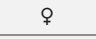 & Nurse \\
\hline 5 & 52 & $\sigma^{x}$ & Steinert disease & ? & Daily activity supervisor \\
\hline 6 & 58 & q & Stroke & @ & Daily activity supervisor \\
\hline 7 & 76 & ? & $\begin{array}{l}\text { Progressive supranuclear palsy } \\
\qquad \text { (PSP) }\end{array}$ & \$ & $\begin{array}{c}\text { Speech and language thera- } \\
\text { pist intern }\end{array}$ \\
\hline 8 & 67 & $\sigma^{\pi}$ & ALS & + & Daily activity supervisor \\
\hline 9 & 69 & $\sigma^{x}$ & Stroke & ? & Caregiver (wife) \\
\hline 10 & 85 & $\sigma^{x}$ & Stroke & - & - \\
\hline 11 & 37 & @ & Spastic tetraplegia & 운 & Nurse \\
\hline 12 & 46 & @ & Mitochondrial myopathies & 운 & Nurse intern \\
\hline 13 & 50 & $\sigma^{x}$ & ALS & 웅 & Nurse \\
\hline
\end{tabular}




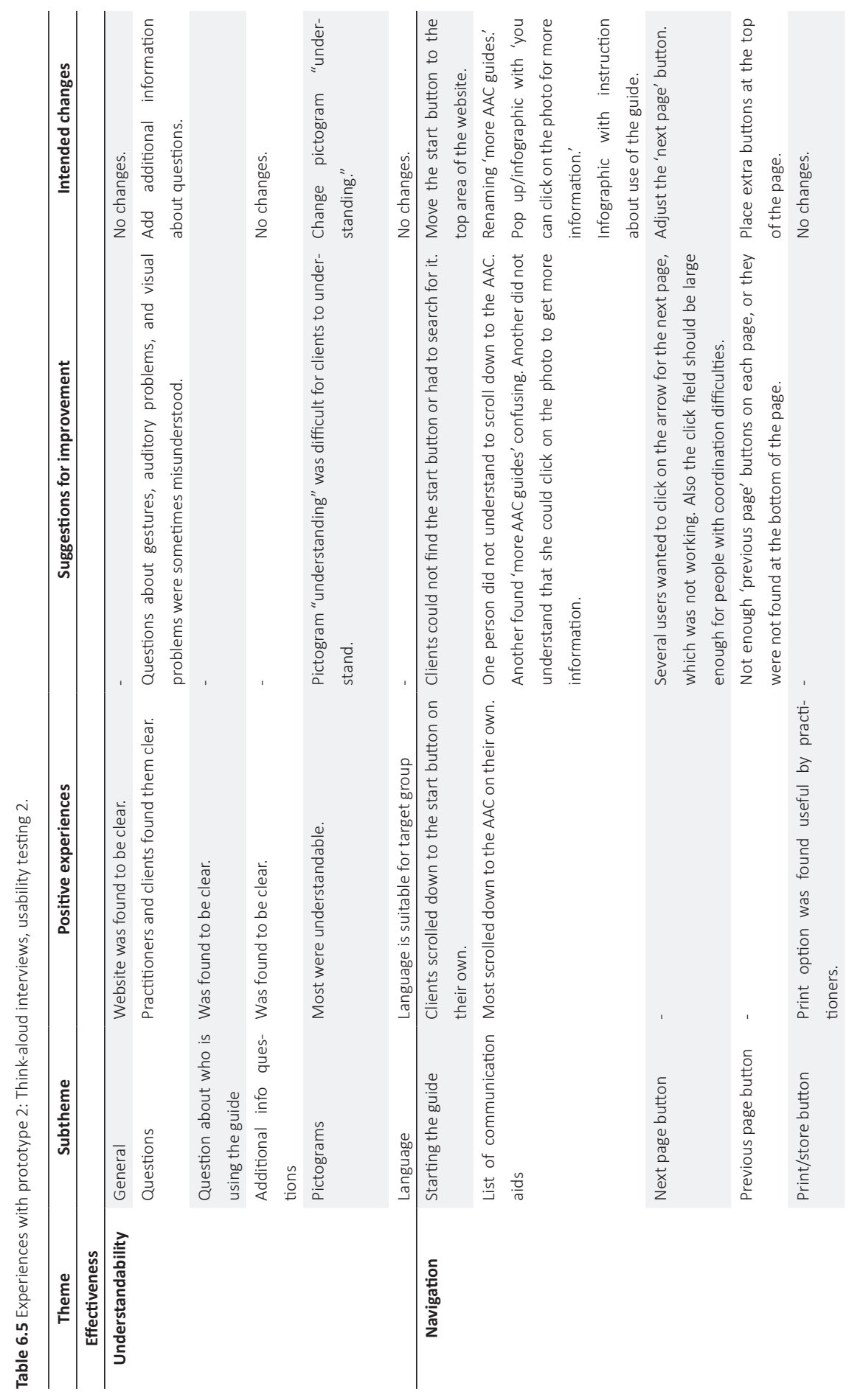




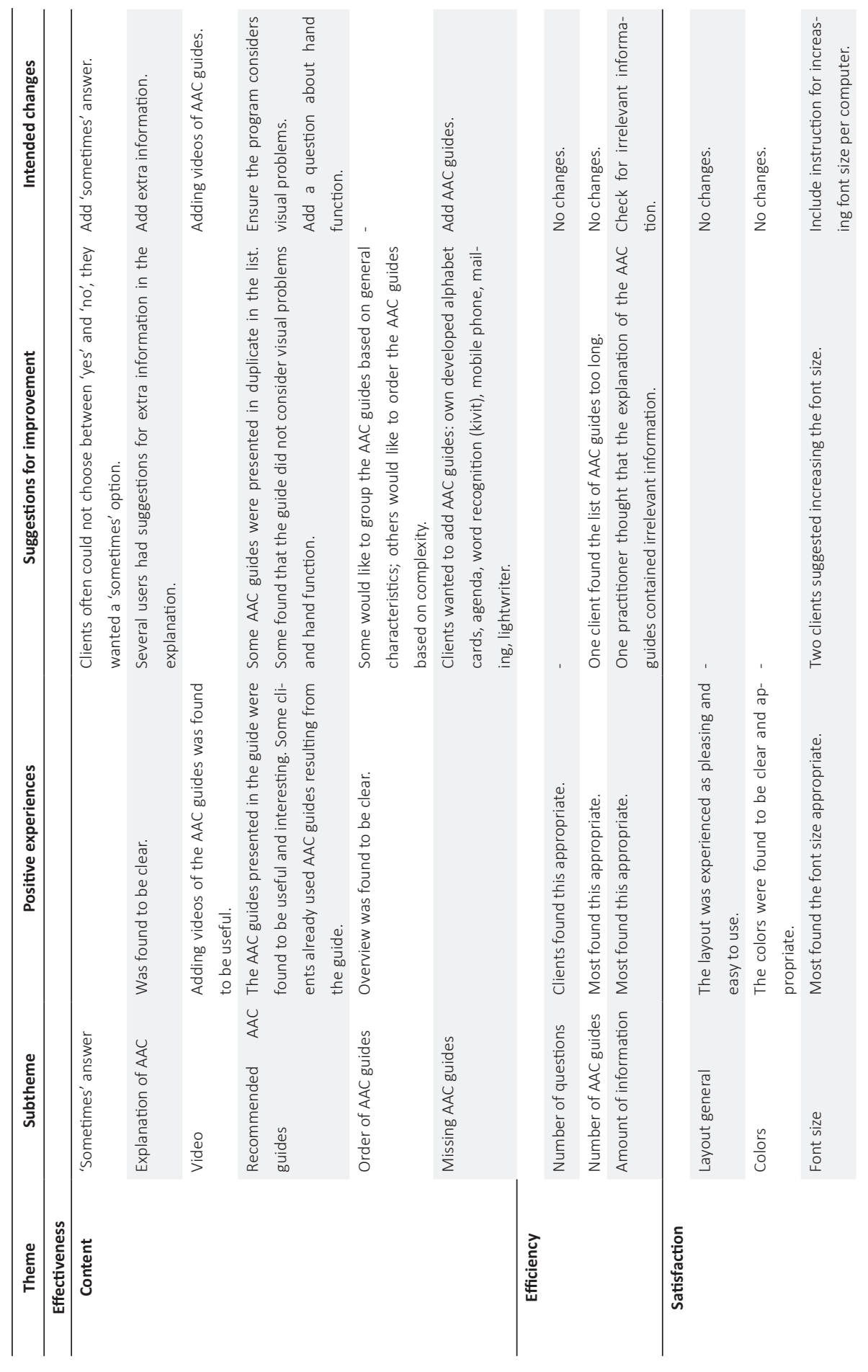




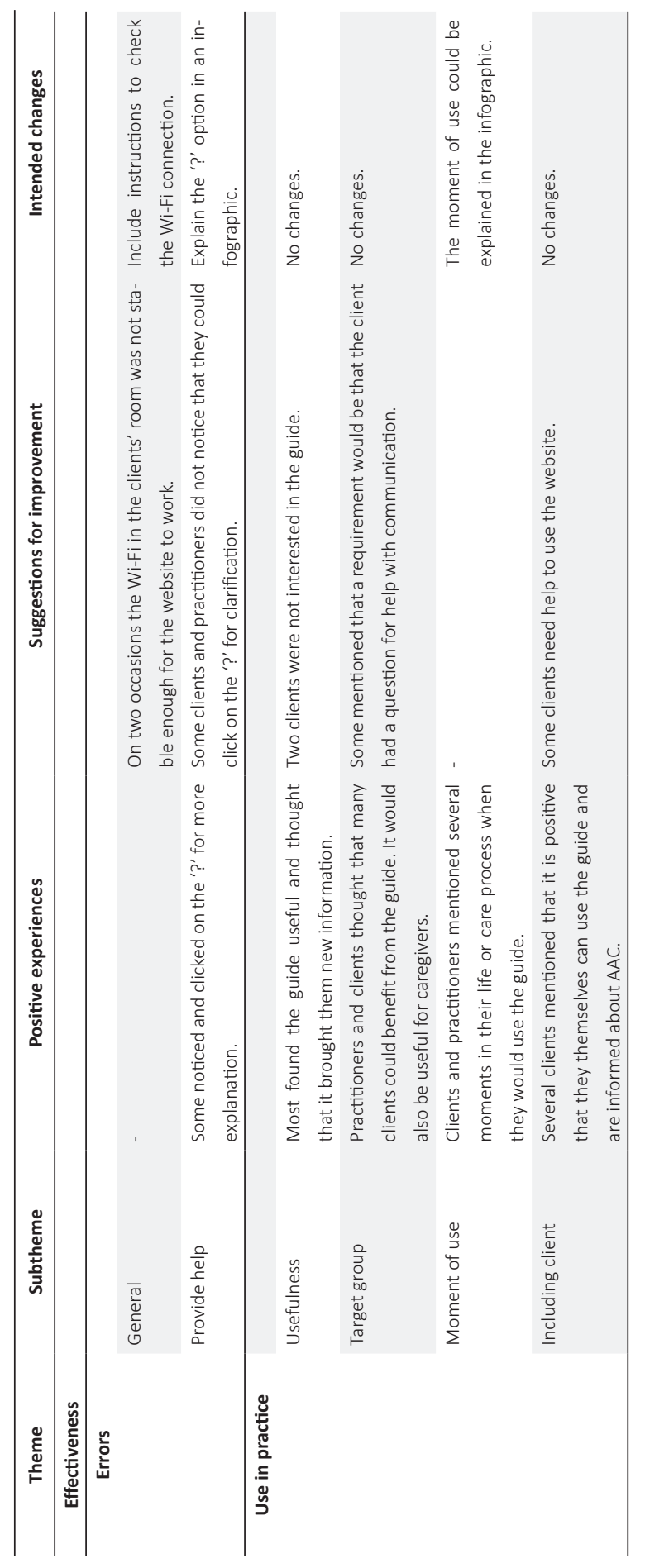


The online questionnaires were completed by 45 practitioners, comprising 27 speech and language therapists, 17 occupational therapists, and one AAC specialist. It was not possible to calculate a response rate because it was not possible to track all visitors of the questionnaires' website. Two of the practitioners used the guide together with a client, while the others completed it with a client in mind. These clients had disparate conditions, such as aphasia, dysarthria, Parkinson's disease, stroke, CP, learning disability, and Huntington's disease. Some practitioners explicitly mentioned that it was suitable for practitioners without much knowledge or experience of AAC, while others explicitly mentioned that it was suitable for practitioners with knowledge or experience of AAC.

In figure 6.4, the quantitative answers to the usability questions are presented. The last three questions in the figure are negatively formulated and have to be interpreted in reverse. Overall, the practitioners were positive about the usability, particularly about how easy it was to use and understand the guide. Although the scores for the length of the guide were positive, practitioners were less positive about the efficiency when using the guide. Practitioners differed in their opinions about the accessibility for communication vulnerable people.

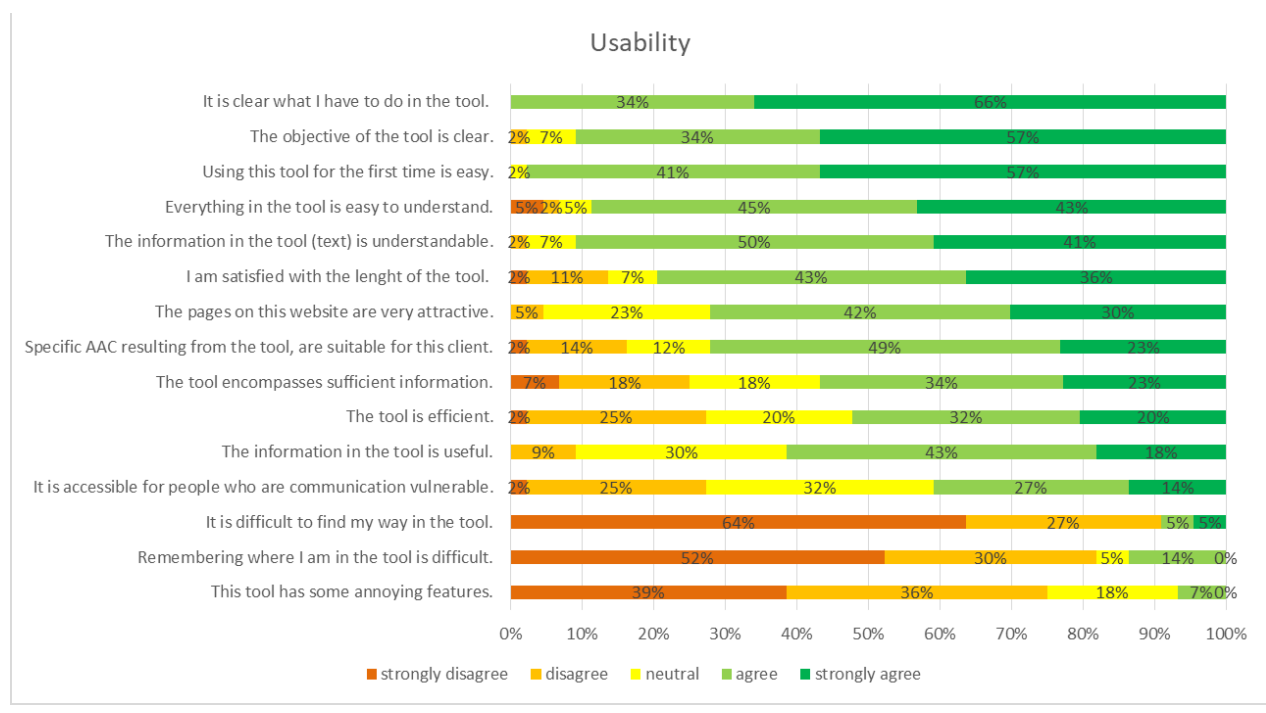

Figure 6.4 Results of usability questions, usability testing 2 .

Regarding the open usability questions, practitioners indicated that they were satisfied with the structure of the guide and emphasized that the guide was easy to use, encompassed a comprehensive overview of AAC, and presented different options for AAC. They considered it attractive and accessible for clients as the information is limited and there is enough visual support for the text. Twelve practitioners suggested adding questions about the hand function of the client: Is the client able to write, type, click or point? Six practitioners recommended questions about the sort of illness, for example which sort of aphasia a client had been diagnosed with. Furthermore, some practitioners wanted to include more 
$A A C$, others less. Other suggestions were: adding videos of $A A C$, adding categories of $A A C$, add more suppliers of AAC.

\section{Developing the Final Guide}

Based upon the testing, the list of intended changes was discussed with the experts and research partners, and prototype 2 was adjusted and developed into the final communication guide 'Choose to Communicate' (figure 6.5). Furthermore, an infographic will be developed to inform users about how to use the guide and about several functionalities.

\section{A home $?$ uitleg keuzehulp (8) hulpmiddelen (1) communicatie adviezen $Q$ zoeken}

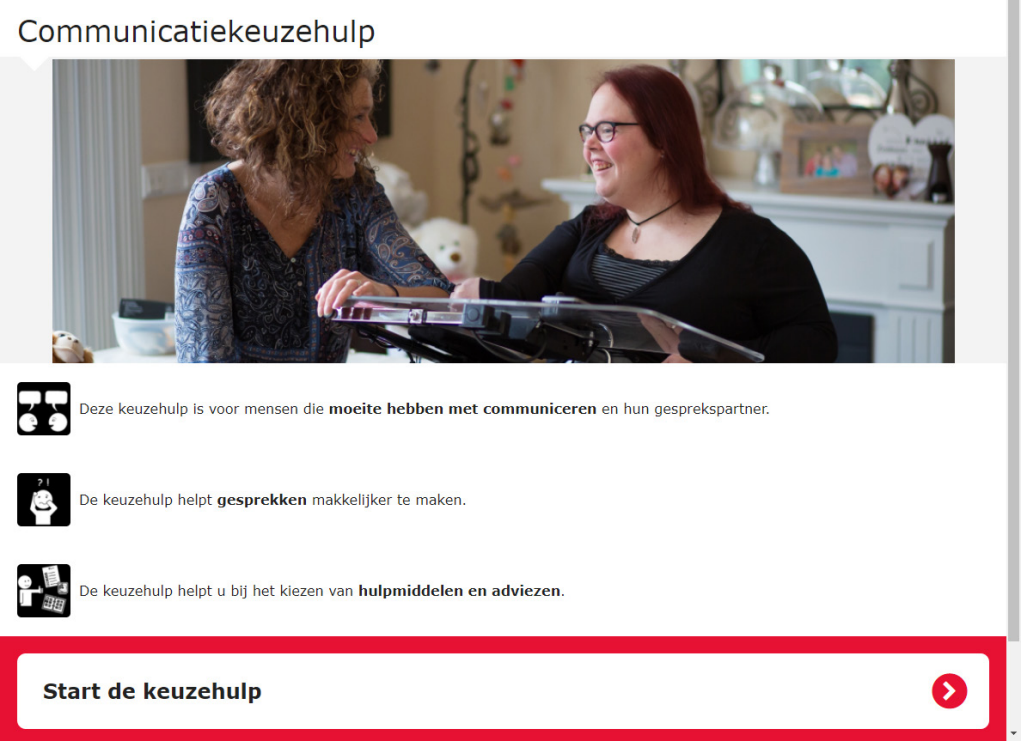

Figure 6.5 Final communication guide.

\section{Discussion}

The three cycles of development guided the user-based development of the communication guide, and resulted in the website 'Choose To Communicate' which supports communication vulnerable clients and practitioners in choosing an AAC solution together, to support their dialogue conversations. The website consists of 12 questions concerning communication difficulties. Based upon the responses, a list of AAC guides is presented and each AAC is described in detail. Most practitioners and clients were enthusiastic about the potential of 'Choose to Communicate'. It was considered a useful guide, and they were mostly satisfied with the structure and layout. Clients and practitioners were able to use the 
high-fidelity prototype and suggested improvements for the final guide.

The user-centered approach was appropriate. Cycle 2 and 3 revealed significant improvements, which guided the further development of the guide. A deliberate choice was made to test a low-fidelity prototype in cycle 2 to ensure that the focus would not center on the details too quickly, and to enable the research team to maintain an open and creative attitude toward the design of the guide. ${ }^{19}$ Furthermore, it ensured that end-users could have an important influence in the development of the guide.

The usability of the high-fidelity guide was further improved during cycle 3 . Similarities existed in the suggestions for improvements from the interviews with client-practitioner dyads and the responses to questionnaires for experts, such as the need for more questions concerning physical (dis)abilities, which can indicate whether a person would be able to use a certain AAC.

It is notable that some experts expressed the need to include more diagnosis-based elements in the guide, such as which type of aphasia someone has. However, we took a participation-based perspective on communication in this research, to enable clients to cope with their challenges in communication, rather than focusing on their illness. ${ }^{34}$ Moreover, clients did not express the need for diagnosis-related questions. Clients valued the fact that the guide presented not just one AAC but several, allowing them to make a choice based on their own insights and preferences.

Much attention was paid to developing a guide that is accessible for communication vulnerable clients. Practitioners and caregivers can support the client, but the assumption was that the client could take the lead if wished. During usability testing, professionals and clients appreciated this objective, and found it valuable to use the guide together. However, this objective could be emphasized more in the guide. To enhance accessibility, issues such as the layout and navigation were evaluated in each prototype, and several navigational issues were resolved in cycle 3. Based on the literature, a constrained linear navigation was chosen, which forced the users to answer all questions in the guide, as this is an accessible navigation format for elderly people. ${ }^{35}$ This also avoided users (unintentionally) skipping questions. As accessible simple language was an important consideration, ${ }^{35}$ questions and information were repeatedly changed to take account of clients' needs and ensure readability. Moreover, visualization was used to support accessibility, however it is extremely difficult to depict abstract issues such as understanding in pictograms. Therefore, some clients might still need support in understanding the questions.

While in cycle 2 the practitioners tended to take the lead in using the guide and answering the questions, in cycle 3 the practitioners encouraged the clients to answer the questions. This could be due to the skills of particular practitioners or the accessibility of the high-fidelity prototype in cycle 3 . During cycle 3 , we saw there was sometimes a difference in the opinions of the clients and practitioners regarding a certain difficulty, e.g. the client indicated having difficulties in remembering, while the practitioner thought the client did not have this difficulty. Nevertheless, the practitioners followed the lead of the 
client. Giving the client the opportunity to be involved in choosing the AAC is important in allowing them to make shared decisions about which AAC suits their needs and preferences. ${ }^{14}$

The guide focuses on easy to use and readily available AAC types, because the use of complex technological AAC requires a period of adjusting and learning. We should not forget the ease of use and simplicity of pen and paper, pointing, or drawing; such mainstream guides can open a door to communication and supports communication vulnerable people in expressing their wishes and needs and starting a conversation. They can also be used in addition to complex technological guides. However, practitioners might have difficulties using readily available $A A C,{ }^{36}$ and need some instruction on how to use them. Therefore videos of how to use these AAC guides should be added in the further development of the guide.

\section{Strengths and Limitations}

The current study developed a guide that supports clients and professionals in choosing AAC by providing them a list of AAC that suits their communication difficulties. Existing guides targeted at daily living aids, such as AskSARA, ${ }^{37}$ or Hulpmiddelenwijzer (dutch database of assistive technology), ${ }^{38}$ often focus on a widespread field of daily living, and do not pay particular attention to functional communication or dialogue conversations. Existing websites specifically related to AAC are often commercial or do not make a link between experienced functional communication difficulties and AAC.

Most studies on improving communication between clients (who are communication vulnerable) and practitioners focus on improving the skills of practitioners. ${ }^{39}$ However, other studies have elicited the need for the use of AAC in addition to enhancing practitioners' communication skills. ${ }^{3,4}$ This study has taken a unique view by involving the client and practitioner in adjusting communication using AAC, and guiding them toward AAC guides that they can use together.

We considered user-centered design to be suitable for developing and testing the guide as it is used in the development of technological guides, and continuously involves the users in all cycles. ${ }^{31,40}$ Furthermore, the process of prototyping ${ }^{26}$ was appropriate as we did not know in advance what the most accessible layout, structure, and content of the guide would comprise.

A strength of the study is that a client group with a wide variety of communication (dis)abilities and practitioners with different backgrounds participated, which supports the transferability of the results and the usefulness of the guide. Communication vulnerable people are often excluded from research because of their communication difficulties. ${ }^{33}$ In this study we worked together with this target group by adjusting our communication in all phases of the study. End users' perspectives are particularly important for the success of a guide, and acceptance by end users is crucial for implementation in practice and longevity. ${ }^{17}$ Furthermore, the guide was used in the real-life situation of the users, and 
not in a controlled laboratory situation, providing more in-depth and realistic information concerning usability. ${ }^{40}$

The communication difficulties of the target group affected the data collection, as the interviews were sometimes less in-depth, stopped earlier, or took place in an inconvenient situation (person lying in bed). The literature states that in order to use the think-aloud method, participants have to have an understanding of the focus of the study and skills in verbalization. ${ }^{27}$ However, we experienced that it was enough if the participants knew that they were expected to give an opinion about the website, and could do this through verbalization, gestures, typing or using the practitioner as an interpreter. While our adjustments to standard methods of (think-aloud) interviewing could lead to missed information, we ensured a comprehensive view of usability by using a large enough study sample and involving the practitioners. A number of five participants is seen as sufficient for usability testing, ${ }^{40}$ and we included 13 clients in the second usability testing. While this small sample is not enough to generalize the experiences of the users, previous research has emphasized that ease of use is a very important predictor of adherence in other target groups. ${ }^{41}$

During usability testing 2 we deliberately chose to include quantitative data from AAC experts, speech and language pathologists and occupational therapists. These practitioners provided valuable suggestions for alterations in the content of the guide. However, we focused on occupational therapists, speech and language therapists and an aphasia network, because we were in contact with these. Furthermore, we expected that professionals in the aphasia network would have expert-knowledge about AAC. However, we could have disseminated the questionnaire in other networks of experts related to other communication disabilities.

The different backgrounds of the practitioners and disparate abilities of the clients provoked debate regarding contradictory comments about the guide. For example, most found it important that there was not too much text, but others wanted to add more information. The balance between enough information and not too much text was difficult, but vital for this target group. Therefore, a button with "more information" was added. Furthermore, all significant changes were discussed with the researchers and with the research partners, ${ }^{31}$ and decisions were always made in favor of accessibility.

The reflexivity ${ }^{42}$ of the qualitative data collection was enhanced by using reflexive notes and critical conversations about own assumptions (regarding the guide and relationship with the interviewees) with the research team. 


\section{Clinical Implications and Future Research}

Communication vulnerable people and practitioners can already use the guide to support them to choose AAC. The next step would be a follow-up feasibility and effectiveness study. Some might worry if the guide would lead to a 'one size fits all' problem, as there is no feature matching involved in which the current way of communicating is matched to an AAC. However, one could question is such feature matching is necessary for ad hoc communication support in dialogue conversations.

Future research is needed to test whether the AAC recommended through the guide are indeed applicable to the specific client-practitioner relations, and are used adequately to lead to improved dialogue conversations. Multiple use periods should be tested to investigate the acceptance of the AAC guides and the impact on communication in the conversations between clients and practitioners. Such studies could further improve the guide and thereafter it could be linked with existing medical record systems.

The developed guide supports clients and practitioners in choosing AAC, adding to the knowledge and attitude of practitioners. However, the guide does not support practitioners in their skills in using AAC. Future research should explore if video instructions are enough, or if practitioners need more comprehensive training on using theses ad hoc AAC. Implementation of innovations has proven to be difficult, and therefore further research into effective implementation strategies for the guide in daily practice is also recommended.

\section{Conclusion}

The guide Choose to Communicate has been developed to guide practitioners and communication vulnerable clients in choosing and using AAC together. Usability issues were targeted in several cycles of testing. Further research could investigate whether the guide can improve dialogue conversations, and make shared decisions and client-centered care for this target group more accessible. 


\section{References}

1. Fried-Oken M, Mooney A, Peters B. Supporting communication for patients with neurodegenerative disease. NeuroRehabilitation. 2015;37(1):69-87.

2. Clarke M, Bloch S. AAC practices in everyday interaction. Augment Altern Commun. 2013;29(1):1-2.

3. Stans SE, Dalemans R, de Witte L, Beurskens A. Challenges in the communication between 'communication vulnerable' people and their social environment: An exploratory qualitative study. Patient Educ Couns. 2013;92(3):302-312.

4. Morris MA, Clayman ML, Peters KJ, Leppin AL, LeBlanc A. Patient-centered communication strategies for patients with aphasia: discrepancies between what patients want and what physicians do. Disabil Health J. 2015;8(2):208-215.

5. Hemsley B, Balandin S. A metasynthesis of patient-provider communication in hospital for patients with severe communication disabilities: informing new translational research. Augment Altern Commun. 2014;30(4):329-343.

6. Hemsley B, Georgiou A, Hill S, Rollo M, Steel J, Balandin S. An integrative review of patient safety in studies on the care and safety of patients with communication disabilities in hospital. Patient Educ Couns. 2015;99(4):501-511.

7. Lawrence M, Kinn S. Defining and measuring patient-centred care: an example from a mixed-methods systematic review of the stroke literature. Health Expect. 2012;15(3):295-326.

8. Stans SEA, Dalemans RJP, Roentgen UR, Smeets HWH, Beurskens A. Who said dialogue conversations are easy? The communication between communication vulnerable people and health-care professionals: A qualitative study. Health Expect. 2018.

9. Blackstone S, Pressman H. Patient Communication in Health Care Settings: new Opportunities for Augmentative and Alternative Communication. Augment Altern Commun. 2016;32(1):69-79.

10. Light J, McNaughton D. The changing face of augmentative and alternative communication: past, present, and future challenges. Augmentative and Alternative Communication. 2012;28(4):197-204.

11. Parr S, Pound C, Hewitt A. Communication access to health and social services. Top Lang Disorders. 2006;26(3):189-198.

12. Wylie K, McAllister L, Davidson B, Marshall J. Changing practice: implications of the World Report on Disability for responding to communication disability in under-served populations. Int J Speech Lang Pathol. 2013;15(1):1-13.

13. Light J, McNaughton D. Designing AAC Research and Intervention to Improve Outcomes for Individuals with Complex Communication Needs. Augment Altern Commun. 2015;31(2):1-12.

14. lacono T, Lyon K, Johnson $\mathrm{H}$, West D. Experiences of adults with complex communication needs receiving and using low tech AAC: an Australian context. Disabil Rehabil Assist Technol. 2013;8(5):392-401.

15. Paterson $\mathrm{H}$, Carpenter $\mathrm{C}$. Using different methods to communicate: how adults with severe acquired communication difficulties make decisions about the communication methods they use and how they experience them. Disabil Rehabil. 2015;37(17):1522-1530

16. Hemsley B, Sigafoos J, Balandin S, et al. Nursing the patient with severe communication impairment. J Adv Nurs. 2001;35(6):827-835

17. Shah SG, Robinson I, AIShawi S. Developing medical device technologies from users' perspectives: a theoretical framework for involving users in the development process. Int J Technol Assess Health Care. 2009;25(4):514-521.

18. Verwey R, van der Weegen S, Tange H, Spreeuwenberg M, van der Weijden T, de Witte L. Get moving: the practice nurse is watching you! A case study of the user-centred design process and testing of a web-based coaching system to stimulate the physical activity of chronically ill patients in primary care. Inform Prim Care. 2012;20(4):289-298.

19. Gulliksen J, Goransson B, Boivie I, Blomkvist S, Persson J, Cajander A. Key principles for user-centred systems design. Behaviour \& Information Technology. 2003;22(6):397-409.

20. ISO. IInternational Organization for Standardization. ISO 9241-S01: Guidance on Usability. Geneva, Switserland: ISO; 1998.

21. Harte RP, Glynn LG, Broderick BJ, et al. Human centred design considerations for connected health devices for the older adult. $J$ Pers Med. 2014;4(2):245-281.

22. De Vito Dabbs A, Myers BA, Mc Curry KR, et al. User-centered design and interactive health technologies for patients. Comput Inform Nurs. 2009;27(3):175-183.

23. Haarsma F, Moser A, Beckers M, van Rijswijk H, Stoffers E, Beurskens A. The perceived impact of public involvement in palliative 
care in a provincial palliative care network in the Netherlands: a qualitative study. Health Expect. 2015;18(6):3186-3200.

24. De Rouck S, Jacobs A, Leys M. A methodology for shifting the focus of e-health support design onto user needs: a case in the homecare field. Int J Med Inform. 2008;77(9):589-601.

25. WorldHealthOrganization. International classification of functioning, disability and health: ICF. 2001.

26. AAL. Toolbox AAL: Methods of user integrations for AAL innovations. 2013; http://www.aal-europe.eu/wp-content/ uploads/2015/02/AALA_ToolboxA5_online.pdf. Accessed 05-02, 2018.

27. Lundgren-Laine H, Salantera S. Think-aloud technique and protocol analysis in clinical decision-making research. Qual Health Res. 2010;20(4):565-575.

28. Ossebaard HC, Seydel ER, van Gemert-Pijnen L. Online usability and patients with long-term conditions: a mixed-methods approach. Int J Med Inform. 2012;81(6):374-387.

29. Hsieh HF, Shannon SE. Three approaches to qualitative content analysis. Qual Health Res. 2005;15(9):1277-1288.

30. ICT Aevt. Leesniveau tool. 2017; https://www.accessibility.nl/kennisbank/tools/leesniveau-tool. Accessed 0304, 2017.

31. Garvelink MM, Emond J, Menear M, et al. Development of a decision guide to support the elderly in decision making about location of care: an iterative, user-centered design. Research Involvement and Engagement. 2016;2(1):26

32. Wammi. Wammi questionnaire. 2016; http://www.wammi.com/using.html. Accessed 05-02, 2017.

33. Dalemans R, Wade DT, van den Heuvel WJ, de Witte LP. Facilitating the participation of people with aphasia in research: a description of strategies. Clin Rehabil. 2009;23(10):948-959.

34. Huber M, van Vliet M, Giezenberg M, et al. Towards a 'patient-centred' operationalisation of the new dynamic concept of health: a mixed methods study. BMJ Open. 2016;6(1):e010091.

35. Lee YK, Lee PY, Ng CJ, et al. Usability and utility evaluation of the web-based "Should I Start Insulin?" patient decision aid for patients with type 2 diabetes among older people. Inform Health Soc Care. 2017:1-11.

36. Stans S, Dalemans R, Roentgen U, Smeets H, Beurskens A. Who said dialogue conversations are easy? The communication between people who are communication vulnerable and healthcare professionals. submitted. 2017.

37. Disabled Living Foundation. AskSARA, Guided advice about daily living. http://asksara.dlf.org.uk/. Accessed 0504, 2017.

38. Vilans. Hulpmiddelenwijzer. http://www.hulpmiddelenwijzer.nl/. Accessed 03-04, 2018.

39. Machiels M, Metzelthin SF, Hamers JP, Zwakhalen SM. Interventions to improve communication between people with dementia and nursing staff during daily nursing care: A systematic review. Int I Nurs Stud. 2017;66:37-46.

40. Vermeulen J, Neyens JC, Spreeuwenberg MD, et al. User-centered development and testing of a monitoring system that provides feedback regarding physical functioning to elderly people. Patient Prefer Adherence. 2013;7:843-854.

41. Wade R, Cartwright C, Shaw K. Factors relating to home telehealth acceptance and usage compliance. Risk Manag Healthc Policy. 2012;5:25-33.

42. Korstjens I, Moser A. Series: Practical guidance to qualitative research. Part 4: Trustworthiness and publishing. European Journal of General Practice. 2017:1-5. 



\section{Chapter 7}

\section{Client participation in research through junior researchers' eyes: a qualitative analysis}

Wat als we het samen bedenken.

Wat als we het samen maken.

Wat als we het samen doen.

Wat als,

we samen onderzoeken?

Stans S,

Lenzen, $\mathrm{S}$

Dalemans RJ,

Beurskens $A$.

Moser, A. 


\section{Abstract}

\section{Background}

Although client participation in research has been valued in health care research, less attention has been paid to the experiences of researchers and the difficulties they encounter. The aim of this study is to report on how junior researchers apply and experience the process of client participation in their research projects, and the lessons learned.

\section{Methods}

A qualitative descriptive study design was applied, following the general tenets of naturalistic inquiry. Six junior researchers were recruited who, during their PhD trajectory, studied healthcare topics with regard to people with chronic illnesses. They followed a coaching program about client participation in research. The junior researchers were qualitatively interviewed about their experiences with client participation in their research projects. Data were analyzed using conventional content analysis.

\section{Results}

Researchers worked together with various clients (from individual clients, to parents of children with a disability, to patient counsels, to citizen counsels) in different levels (from consultation to control) in different research phases. The junior researchers' experiences reflect three important themes: collaboration between researcher and client, integrating client participation in the research project, and the impact of applying client participation and receiving coaching on the role development of the researcher. Several lessons learned are formulated with regard to the level of client participation, collaboration between researchers and clients, integrating client participation in the research project and coaching of researchers in client participation

\section{Conclusions}

Client participation in research is not self-evident. Junior researchers struggled with collaborating with clients and integrating client participation in the research project. However, coaching and actively applying client participation made junior researchers aware of the value of client participation, boosted their confidence and motivated them to advocate for client participation in the future. These insights might support researchers in applying client participation in future projects. It appears to be important for academic institutions to pay attention to junior researchers' experiences and to educate researchers using reflective sessions, co-learning, and individual coaching. 


\section{Background}

Public and Patient Involvement has become a rising topic of interest in health and social care research. ${ }^{1-4}$ It is defined by the UK National Institute for Health Care as "research being carried out 'with' or 'by' members of the public rather than 'to', 'about' or 'for' them" and is often used as a synonym of client participation in research. ${ }^{5}$ The core belief underlying client participation is that people who are affected by research have the right to be involved in the planning and execution of research. ${ }^{6}$ Furthermore, involving clients is thought to improve the quality of results and the acceptability and accessibility of services..$^{7-9}$ Although literature provides information about how to support clients in this process of participation, less attention is paid to how researchers apply client participation and how they experience this process. ${ }^{10,11}$ However, these insights could support future researchers in applying client participation. ${ }^{6,10}$

Client participation is complex as clients can be involved in all phases of the research cycle, from prioritizing research topics, to the analysis, and dissemination/translation of research findings. ${ }^{9}$ Moreover, clients can be involved on different levels, from consultation, to advising, to more collaborative forms where clients act as research partners, to user-controlled research, where clients act as leaders of the study. ${ }^{1}$ Several researchers ${ }^{10,12}$ used the ladder of citizen participation of Arnstein, to provide insights in client participation levels in research. ${ }^{13}$ Haarsma and colleagues developed a matrix which builds on the original concept of Arnstein forgoing the normative and hierarchical connotations. ${ }^{11}$ Using such visualizations may support researchers in developing a plan for client participation in research. ${ }^{10}$ De Wit and colleagues used this matrix in a 'serious game' during a coaching program for client participation. However, it is unknown how junior researchers experience the use of a participation matrix to apply client participation in their research.

Existing research about client participation often focusses on the impact/effect of client participation and not on the experiences of researchers. ${ }^{9}$ In her systematic review about the impact of client participation, Staley ${ }^{6}$ describes positive impacts on researchers, such as a better understanding of the community, more enjoyment and career benefits, as well as negative impacts, such as an increased demand on resources, slower pace of the research and loss of power. ${ }^{6}$ Other studies highlight the crucial role of resources and funding, workload, time pressure, lack of clear guidance for conducting and evaluating client participation, research team cohesion and tokenism, i.e. engaging clients only to meet funding requirements. ${ }^{14,15}$ However, less is known about how junior researchers doing their PhDs projects actually apply and experience client participation. Often researchers merely report results related to the outcomes or process of their research, rather than to reflect on how clients were involved during the research, including "lessons learnt" from a researchers' perspective. ${ }^{6,16}$ Moreover, as until now, client participation is rarely part of the basic research curriculum of $\mathrm{PhD}$ candidates.

This study specifically focused on junior PhD researchers who were trained, in order to gain a greater understanding about how they apply and experience client participation and how they can be 
supported in applying client participation from the beginning of their projects. Therefore, the following research question was formulated: How do junior researchers apply, and experience the process of client participation in their research project, and what are lessons learned?

\section{Methods}

A qualitative descriptive study design was used, following the general tenets of naturalistic inquiry. ${ }^{17-19}$ We chose this approach as it enabled us to gain insights into the contextual, junior researchers' subjective experiences with client participation.

\section{Setting}

The study was carried out at the Research Centre on Autonomy and Participation for People with Chronic Illness of the Faculty of Health of Zuyd University of Applied Sciences in Heerlen, the Netherlands. As client participation in research was a new policy development within the research center, a coaching program entitled "Preparing researchers for user involvement", aiming to guide researchers in implementing client participation, was organized for researchers. The training consisted of a masterclass, six coaching sessions with pre-session assignments, written feedback and several individual coaching sessions. ${ }^{10}$ Participating researchers were stimulated to reflect on their own attitudes with regard to client participation. Examples of learning elements were formulating criteria for recruitment and selection of clients, making role descriptions for clients and designing client participation for their own research using a participation matrix. Moreover, experiences and best practices with regard to (sustainable) implementation of client participation were discussed. ${ }^{10}$

\section{Participants}

To capture insights into junior researchers' experiences with regard to client participation in their own project, we purposefully sampled junior researchers in their PhD studies, who had followed the coaching program. Six junior researchers were approached and all agreed to participate. They were all female and aged between 28 and 57 years. They had different professional backgrounds (occupational therapy, physical therapy, nursing, cultural science) and were in different stages of their PhD projects at the time of data collection (from beginning to completing their PhD).

\section{Data collection}

Six semi-structured interviews were conducted by an independent trained interviewer between October 
and December 2015. In addition, informal communication with the researchers abou the topic was documented in field notes. The interviews were scheduled at a place and time that was convenient for the participants. The interviewer used an interview guide with open ended questions about researchers' experiences with conducting client participation. Their experiences related to their research projects as part of their PhD. Questions were asked about how they applied client participation, and about their experiences in their own research project. Probing was used to get a deeper insight into these experiences. The interviews lasted between 20 and 45 minutes. The interviews were audio-recorded and transcribed verbatim.

\section{Data analysis}

In line with descriptive qualitative research, we applied conventional content analysis and used the data analysis software Nvivo 11 to aid this process. ${ }^{19,20}$ Two researchers (SS and SL) repeatedly read the transcripts, divided the transcripts into fragments, and erased irrelevant text fragments. Subsequently, they independently coded the fragments based upon open coding, no predetermined format or categories were used. After this initial coding process the researchers discussed the coding and interpretation and searched for consensus. The codes were then ordered in higher level themes, which reflected overarching themes related to the experiences of the junior researchers. The codes and themes were constantly compared amongst the interviews, and diagrams were developed to provide insights into the relationships between codes and themes. ${ }^{20}$ Other researchers (AM, RD) were involved for peer debriefing sessions using reflective considerations. ${ }^{17}$ The themes were adjusted until a final thematic structure was decided upon by all researchers.

\section{Quality aspects}

The reflexivity of this study was influenced by the double role of two participants in this research, as they were also the authors of this paper. Their double role meant that the research was more reluctant to researchers' bias; specifically bias against how their own story will be told in the paper. However, to improve the trustworthiness of the study no researcher was involved in the initial coding of their own interview and regularly reflection meetings were held to enhance the reflexivity. Second, investigator triangulation was used, an external interviewer (a junior researcher not involved in the coaching program) was involved for the data collection. Third, independent coding by two researchers supported the credibility. ${ }^{21}$ Fourth, we enhanced the credibility of the results by a member check; we anonymously presented a summary of the results to the participants and asked for recognition. Fifth, to provide insights into transferability of the results, the participants and setting of the study were described in detail. $^{17}$ 


\section{Ethical considerations}

All researchers received written information and signed an informed consent.

\section{Results}

All junior researchers followed the coaching program as described in the article of de Wit and colleagues, ${ }^{10}$ and conducted a PhD research project involving clients with a chronic illness. During the interviews researchers described how they applied client participation and how they experienced this process related to one of their studies in their own research project.

\section{How did junior researchers apply client participation in their research project?}

For each study the way the junior researcher applied client participation will be described and illustrated using the participation matrix.

\section{Research 1: A study about the lived experience of parents enabling participation of their child with a physical disability}

In this research the lived experience of parents enabling participation of their child with a physical disability at home, at school and in the community, was studied. This study was part of a PhD research project about parents' role in enabling the participation of their child with a physical disability. A mother of a physically disabled child was involved as co-researcher, a patient panel advised the research team, and 13 parents were consulted in interviews (figure 1). The co-researcher followed an educational programme about client participation. The experiences described in the current article mostly relate to working together with her in the third study of the PhD research project, a phenomenological study. She joined the research team in the beginning of the thesis process. The co-researcher was involved during all phases of the study, on the level of partnership or control. She was, for example, involved in the analysis of interviews. Moreover, during the description of the findings she challenged the team to describe the findings understandably and accurate (i.e. to inhibit the understating of certain findings). The themes were changed accordingly. Furthermore, the patient panel advised the team or was consulted by the research team. They were, for example, involved in the recruitment of participants for interviews. 


\begin{tabular}{|c|c|c|c|c|c|c|c|}
\hline & 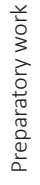 & 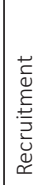 & 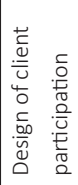 & 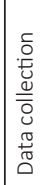 & 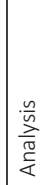 & 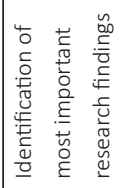 & 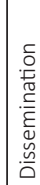 \\
\hline \multicolumn{8}{|l|}{ Control } \\
\hline \multicolumn{8}{|l|}{ Partnership } \\
\hline \multicolumn{8}{|l|}{ Advising } \\
\hline Consulting & & & & & & & \\
\hline
\end{tabular}

Figure 1. Participation matrix of research 1 about lived experience of parents enabling participation of their child with a physical disability

Research 2: A study about the development of a patient-specific method for goal setting within physiotherapy

In this study a patient-specific method for physiotherapy goal setting was developed in a user centered design, as part of a PhD research project. Three patients were involved as advisors in developing an intervention including a training course (figure 2). They advised the research team on the development of the draft version. Another example of their participation is their involvement in the training sessions in the final field test, providing feedback to the physiotherapists during role plays. Furthermore, twenty-three patients were consulted in interviews and observations in this particular study.

\begin{tabular}{|c|c|c|c|c|c|c|c|}
\hline & 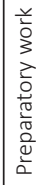 & 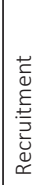 & 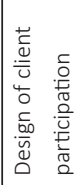 & 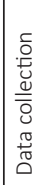 & $\frac{\frac{n}{n}}{\frac{n}{\frac{n}{n}}}$ & 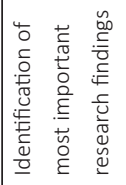 & 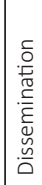 \\
\hline \multicolumn{8}{|l|}{ Control } \\
\hline \multicolumn{8}{|l|}{ Partnership } \\
\hline \multicolumn{8}{|l|}{ Advising } \\
\hline Consulting & & & & & & & \\
\hline
\end{tabular}

Figure 2. Participation matrix of research 2 about the development of a patient-specific method for physiotherapy goal setting

\section{Research 3: A study about the lived experience of the public concerning the phenomenon of public} involvement

In this study the aim was to explore the definition and meaning of public involvement from the lived experience of members of the public, as part of a PhD research project about client participation. One citizen was involved as a research partner during the qualitative study, and seven clients/citizens were consulted in interviews (figure 3). The research partner was involved from the beginning of the study up until the data analysis. Due to job changes the researcher's collaboration with the client was thereafter ended. Examples of the involvement of the research partner are the recruitment of respondents, drafting the information folder for citizens, developing the interview guide, and conducting and analyzing interviews. 


\begin{tabular}{|c|c|c|c|c|c|c|c|}
\hline & 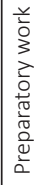 & 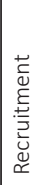 & 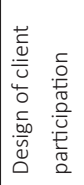 & 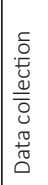 & 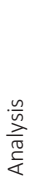 & 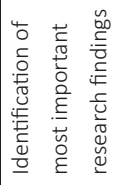 & 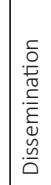 \\
\hline \multicolumn{8}{|l|}{ Control } \\
\hline \multicolumn{8}{|l|}{ Partnership } \\
\hline \multicolumn{8}{|l|}{ Advising } \\
\hline Consulting & & & & & & & \\
\hline
\end{tabular}

Figure 3. Participation matrix of research 3 about client participation in public.

\section{Research 4: A study about self-management goal setting and action planning in primary care}

In this study a conversation approach was developed for practice nurses aimed at making shared decisions on goals and action plans with primary care patients, as part of a $\mathrm{PhD}$ research project about self-management goal setting and action planning in primary care. Two patients were involved as advisors and ten patients were consulted in interviews and observations (figure 4). The two advisors participated during data analysis by means of engaging in brainstorm sessions about the conversation approach. Another example of their participation was their advice on a prototype of the conversation approach.

\begin{tabular}{|c|c|c|c|c|c|c|c|}
\hline & 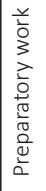 & 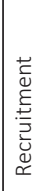 & 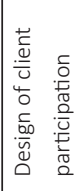 & 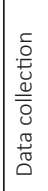 & 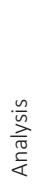 & 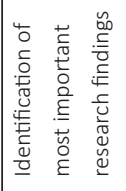 & 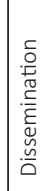 \\
\hline \multicolumn{8}{|l|}{ Control } \\
\hline \multicolumn{8}{|l|}{ Partnership } \\
\hline \multicolumn{8}{|l|}{ Advising } \\
\hline Consulting & & & & & & & \\
\hline
\end{tabular}

Figure 4. Participation matrix of research 4 about goal setting and action planning in primary care.

Research 5: A study about a conversation approach for shared goal setting and shared decision making by nurses in cancer aftercare

In this study a conversation approach for shared goal setting and shared decision making by nurses in cancer aftercare was developed in a user centered iterative development process. This study was part of a PhD research project that integrates evidence based practice and shared decision making in nursing. Three clients participated as advisors in the development of the conversation approach (figure 5). The two clients engaged in brainstorm sessions and advised as equal partners about the approach. Another example is the participation of one client in writing a script and playing the client role in an educational film. Furthermore, 40 clients were consulted in interviews in subsequent studies. 


\begin{tabular}{|c|c|c|c|c|c|c|c|}
\hline & 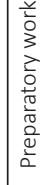 & 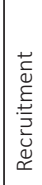 & 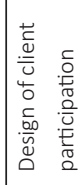 & 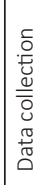 & 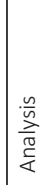 & 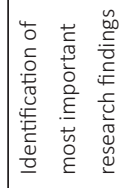 & 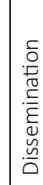 \\
\hline \multicolumn{8}{|l|}{ Control } \\
\hline \multicolumn{8}{|l|}{ Partnership } \\
\hline \multicolumn{8}{|l|}{ Advising } \\
\hline Consulting & & & & & & & \\
\hline
\end{tabular}

Figure 5. Participation matrix of research 5 about after care in oncology.

\section{Research 6: A study about the experiences with dialogue conversations between communication} vulnerable clients and professionals

In this study the experiences of communication vulnerable clients and professionals with their dialogue conversations were studied, as part of a $\mathrm{PhD}$ research project about communication between communication vulnerable clients and professionals. A client counsel was involved as advisors in this qualitative study, from recruitment to identification of most important research findings. Eleven clients were consulted in interviews and observations. The client counsel gave advice about recruitment of participants. A further example of their involvement was their participation during analysis of interviews, mostly identifying the most important themes.

\begin{tabular}{|c|c|c|c|c|c|c|c|}
\hline & 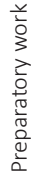 & 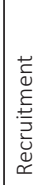 & 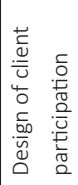 & 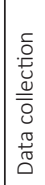 & $\begin{array}{l}\frac{n}{n} \\
\frac{n}{\pi 0} \\
\frac{\tilde{L}}{<}\end{array}$ & 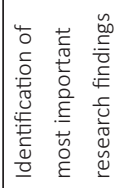 & 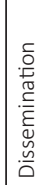 \\
\hline \multicolumn{8}{|l|}{ Control } \\
\hline \multicolumn{8}{|l|}{ Partnership } \\
\hline \multicolumn{8}{|l|}{ Advising } \\
\hline Consulting & & & & & & & \\
\hline
\end{tabular}

Figure 6. Participation matrix of research 6 about Dialogue conversations between communication vulnerable clients and professionals.

\section{Experiences of junior researchers with client participation}

The researchers all described a continuous search for applying client participation during their studies. The experiences of researchers with client participation relate to three themes, with subordinated sub-themes: 1) collaboration between client and researcher; 2) integration of client participation in the research project; and 3) impact on role development of the researcher (figure 1). 


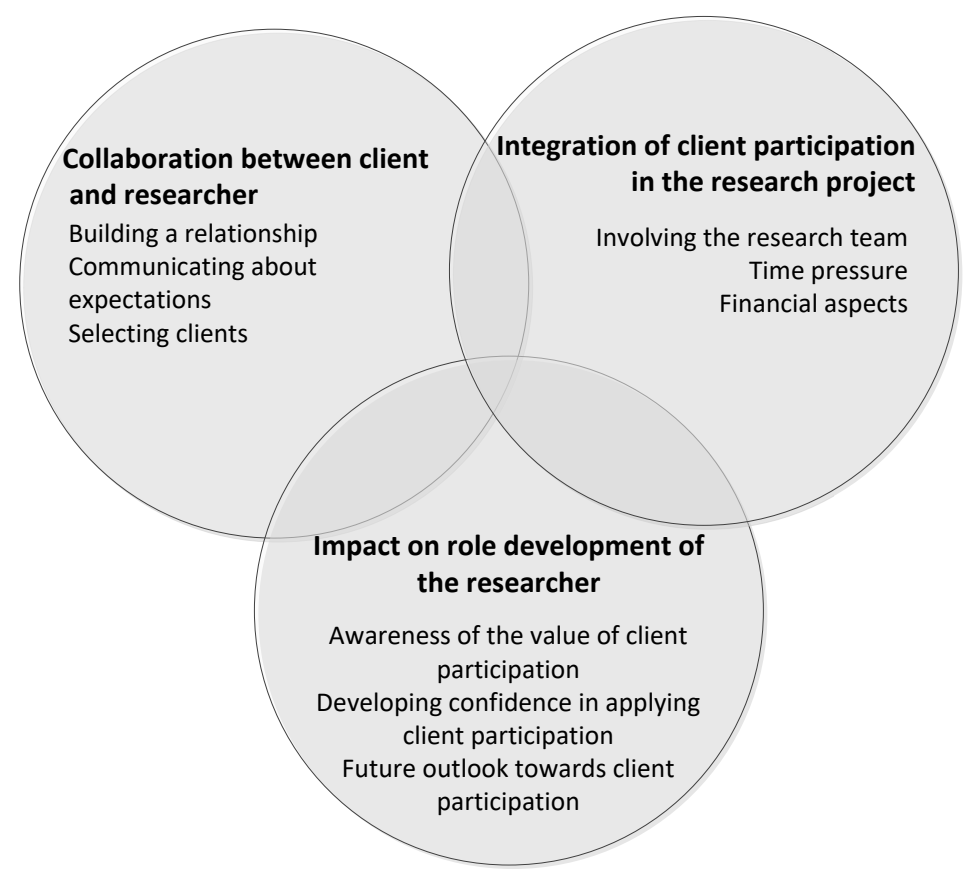

Figure 7.1 Visual representation of the experiences with client participation in research

\section{Collaboration between client and researcher}

The collaboration between the clients and researchers was experienced as important in client participation, including the elements a) building a relationship, b) communicating about experiences, and c) selecting clients.

\section{Building a relationship}

Researchers described that establishing a good relationship with clients was a supportive factor which facilitated learning to work together as a team. They felt that it was essential to show real appreciating for the input of the clients to the clients.

That I am open for..ehh that when I decide something, that I think, I actually want to take their opinion seriously. Hear them and then decide. Not acting on something just because I think it is methodologically sound, but because I really think we are doing this together. (Bianca)

Because if you don't truly appreciate it (...) then a collaboration is going to be difficult. (Kim)

Moreover, they experienced that a good relationship was established by getting to know each other, for example by doing multiple research projects together or by involving clients over longer periods. This created a band and helped them in deciding upon the nature of their collaboration. It also helped in finding a way of how to address each other respectively. 
I have the feeling that that is also how they would like to be 'approached', not as a client, but as a secretary or chairman of the client counsel. (Judith)

\section{Communicating about expectations}

All researchers emphasized the importance of clarifying expectations and making clear agreements right from the beginning of working together with clients. This to prevent irritations and missed opportunities for client participation. Several researchers reflected that they did not always had discussed their expectations with clients beforehand the start of the project, as they did not think about it or were, due to limited experience with client participation, unsure about the expectations. Researchers mentioned that they used the participation matrix, which was part of the coaching program, to decide upon the level of involvement. However, they did not mention that they discussed the matrix with patients. Retrospectively, they experienced that it was important to clarify expectations with regard to the role of the client, the timing of the research, the level of involvement, the objective of the research, and the capacities of the clients and wishes for involvement.

One researcher described that in her study the role of the client was not communicated sufficiently. Consequently, the client got the feeling that her input had no added value during lively discussions, since in these discussions, in which other researchers were also present, she did not have the chance to speak her mind. The client proposed to withdraw due to unclear expectations about her role. Yet, the researcher convinced her to keep being involved since her input was valuable.

She (client) said, 'yes it's ok to be here together, but can't you do without me?' (Sanne)

This is one of the most important things that I learned. You have to make clear agreements about roles and about what the client may do or is expected to do. (Sanne)

This researcher also experienced that the client expected that the research was still going on, while it had been paused. She felt ashamed that she did not adequately informed the timing of the project to the client.

I had told her everything about the project, but then the project was sort of put on hold, and then I saw her the other day and she asked me 'how is the project going?' I found that very difficult, because I had not informed her sufficiently. (Sanne)

Another researcher experienced that she did not adequately explained the objective of the study to clients, leading to miscommunications during the development of interview guides.

The second meeting I had in a research project in which a client counsel was involved. They said 'ok, but what is really important, is that the professionals and managers of this institution do not communicate with each other'. I thought ok, but this is not what this research project is about... (Judith) 
Furthermore, researchers retrospectively were aware that they sometimes also had 'wrong' expectations about clients' capacities and wishes for involvement. They sometimes underestimated clients and assumed that specific tasks were too difficult for them (e.g. interviewing other clients) or would bother them too much (e.g. travelling by train to a meeting). This led to missed opportunities to involve them in team meetings, training sessions and interviews.

I was thinking like 'oh that will be too much for them, or they probably don't want that or that would be too difficult for them'. But actually that was not the case. (Inge)

Sometimes researchers also had to high expectations of clients. One researcher described that clients were asked to give feedback to professionals in training sessions. However the given feedback did not reflect the training session adequately and she therefore chose to withdraw clients from participating in the training sessions.

I instructed them about how to give feedback to the professionals. However, in practice that did not really work out as I had expected. That is why I did not included them in the real training program, but instead included actors as clients. (Inge)

Another researcher experienced that discussing clear expectations about the means of communication was especially important when involving people with cognitive or communication difficulties. Wrong expectations from her side led to missed opportunities during a meeting about data analysis. Subsequently, another meeting had to be scheduled in which the information was presented in a way that was suitable for the clients.

I did a first initial analysis myself and I wrote down some topics for them, to make it easier. They were confused. They said 'These are just words. What do you want us to do?' (...) So in the end we did not really end up with a result in this meeting. (Judith)

\section{Selecting clients}

Researchers described their struggles with deciding what constituted a suitable client for their study, and selecting such clients. Researchers learned in the coaching program that the characteristics of the clients should suit the research question, the level of involvement, and the phase of the research process. Researchers described that defining a client role description (defining criteria that the client has to meet) in the coaching program supported them to think about how they wanted to involve the clients, and searching for a client who had the required characteristics.

Characteristics of clients which were regarded as important by the researchers were education level, literacy skills, belonging to the target group, and experience with client participation.

And making such a client role description right from the beginning the coach also provided feedback on it, like what do you want from the client? 'You must realize that not everybody can and wants to 
be involved at this level', so this was very helpful. (Inge)

However, they still experienced choosing the right clients as difficult, as clients with different characteristics would each have helpful contributions for the process of the study. Researchers involved clients either with a higher education and a helicopter view, or more vulnerable clients with less literacy skills. Some researchers thought that less vulnerable clients could look beyond their own experiences and understand the research process better. However, some also thought that more vulnerable clients probably could better represent the target group. Some researchers described to tend to involve clients with a high education level.

I had consciously chosen clients with a high education level for the expert meetings, but afterwards you think, was that the right decision? (...) so in each phase of the research you have to think how and which clients do you involve. (Amanda)

Another researcher explicitly involved clients with communication difficulties, but struggled to decide whether the clients involved had 'sufficient' communication difficulties to represent the target group.

(involving the client counsel) yes it had pro's and con's, the pro is that this lady had a good overview of issues in the organization. (...) On the other hand, it is a research about people who are communication vulnerable, but she is not very vulnerable. Is she really my target group? However, she did had good ideas about recruiting communication vulnerable people.' (Judith)

Researchers described that, next to the education level and literacy skills, the clients' experiences with client participation also influenced their collaboration. They experienced it as difficult to involve clients with no research experience; clients were for example not used to reading labeled interviews or lacked adequate interviewing skills.

He did not really stick to the plan. He asked other questions and he did not really listen to the persons' experiences. I tried to clarify that during the interview, but he went on and on. This was very difficult. (Kim)

One researcher worked with a client who had been trained to be a client representative by a client organization, and participated thereafter on the highest level of participation as a co-researcher. The researcher explained that the client knew what to expect and was much more confident in her role after the training.

She followed a training about participation in research. This was really helpful for her to really be a co-researcher. (Bianca) 


\section{Integrating client participation in the research project}

Researchers experienced several challenges with regard to integrating client participation in the research project, especially involving the research team, time pressure, and financial aspects.

\section{Involving the research team}

The researchers experienced that involving the research team was essential to integrate client participation in their research project. Most junior researchers saw themselves as part of two types of teams: 1) their regular research team, and 2) the team with the client. In five of the research projects clients did not attend regular research meetings with the whole research team, but junior researchers had separate meetings with them. Some researchers had not thought about the option of inviting them for regular research meetings. Others foresaw practical issues such as transportation, taking too much time of the client, or worries about the client's possibilities to understand the research teams' discussions. However, one researcher had involved the client in the regular research team. Involving the client in the regular research meetings was experienced as fun and an educational experience. Moreover, the client felt that she truly was appreciated and part of the team.

We decided in the first year that it would be best if she (mother of child with disability) would be part of our research team, truly as a co-researcher. (...) If I would have had meetings with her separately, it probably wouldn't be an equal position. (Bianca)

Researchers experienced that most of their senior team members were aware of the value of client participation, but were not used to applying client participation (except from consulting clients). Although the professor of the research group had motivated junior and senior researchers to attend the coaching program, senior researchers were often not (yet) aware of the importance and impact of client participation, and they therefore paid limited attention to the junior researchers' actions to involve clients.

I thought it was very tough. The team was not used to client participation and they had to learn it. (Bianca)

It is really an attitude change for some people, especially for people who work in research for a long time. (Judith)

The senior team members expressed to the junior researchers that they supported them and provided financial reimbursements for clients. However, junior researchers felt it as their task to motivate their research team to keep applying client participation as it was not self-evident. They sometimes put client participation on team meetings' agendas or included a client in team meetings. However they expressed that, as a junior researcher, it was difficult to put it on the agenda, due to own insecurities or time pressure.

I think it is the only way to keep it alive. As a junior researcher you always have to bring it up during 
team meetings, so that it becomes a self-evident topic for the whole team. (Judith)

I was struggling to integrate it. In team meetings we always have a lot to discuss. So it felt as something additional. I did not know how to bring it up. (Sanne)

\section{Time pressure}

Researchers experienced time pressure as an important challenge in the process of client participation. All researchers agreed that client participation takes additional time. A lot of time was spend in the planning and preparation of client participation, and the recruitment of clients and organizing meetings.

Yes it is also a little like, you have that pressure, you have to finish the research, you have to write articles. And then logistically you also have to arrange the meetings with the clients: when are they available? When are others involved available? (Sanne)

In the research with communication vulnerable clients additional time had to be spend on adjusting written information and interviews to make them accessible for this target group. Moreover, researchers expressed that grants often had to be written with a lot of time pressure which was not beneficial to involving clients during the agenda setting of studies.

\section{Financial aspects}

Another resource of concern were the financial aspects of client participation. Additional budget was necessary for the extra time spend by researchers, and for financial reimbursement of clients. Researchers experienced that it is important to make clear agreements about financial reimbursement with clients beforehand. However, although management supported reimbursement of clients, researchers struggled to define the appropriate payment for clients; they felt that the monetary value was difficult to define.

Yes you can solve it with presents and things, but sometimes it feels... when someone is intensively involved, but does not get paid for it. She said she doesn't mind, but it feels 'unfair'. (Bianca)

During the coaching program researchers were advised to ask clients themselves for their wishes for payment. Yet, researchers were afraid that clients would ask for payment which would extend their project resources. Mostly, gift vouchers were used as a reimbursement for clients, as other reimbursement would lead to difficulties with clients' social security benefits. Yet, researchers did not always feel comfortable about this, because they appreciated the time, effort and value of the clients' contribution to the project.

I notice that there is no agreement on this topic. I emailed several persons to ask what financial reimbursement was appropriate, but they said 'ask what other researchers give them'. I also do not want to insult the clients with a simple gift voucher. (Judith) 


\section{Impact on role development of researcher}

Researchers described that the process of applying client participation in addition to the coaching program, had an impact upon their role development as a researcher, with regard to their awareness of the value of client participation, their confidence in applying client participation, and their future outlook towards client participation.

\section{Awareness of the of value client participation}

Researchers described that through the coaching program and consciously applying client participation in their latest research projects, they became aware that before this research project, they had only involved clients on lower levels of the participation ladder, such as interviewing or observing clients. By applying client participation, they became more aware of the value of higher levels of client participation.

To be honest, looking back at earlier projects, we always looked at the professional but rarely really involved clients in the research, except for interviewing them. If you had asked me this question 1 year ago I would have been confident that I involved clients enough. (Inge)

Through the coaching program they had become more aware that clients can be involved in many more ways. Reflecting on their research projects, they could have involved clients more intensively (e.g. as a co-interviewer) or in different research phases (e.g. agenda setting).

It (coaching) makes you aware, aware of hey! You can include them during many phases in many ways! (Amanda)

Most researchers reported that they are planning to apply client participation in the preparation phase of their next projects, because they had seen the potential of involving the clients' view. Furthermore, they thought that involving them from the beginning could support the clients' understanding of the research project.

I will be busy with this right from the beginning and go one step further. I want to involve them while thinking about the research questions and the design and I also want to think about their involvement earlier, so how and when will I involve them (Amanda).

Researchers also described that by applying client participation they became aware that client participation is challenging. It requires time, effort and knowledge about different client participation methods and influencing factors. It was not as easy as expected.

I think only by really doing it, I learned more about the difficulties. I learned how difficult it can be. (Sanne)

Overall, all researchers felt that involving clients was important and necessary, especially in research 
that aimed to develop tools or interventions for clients. They were of the opinion that a lack of client participation in research projects had a negative impact upon the implementation of tools and interventions in health care research.

Developing confidence in applying client participation

Researchers experienced that the individual coaching by an expert and the exchange with peers boosted their confidence to apply client participation. The individual coaching was highly appreciated since it gave them the opportunity to discuss individual struggles, such as in the collaboration with the clients. The expert gave them practical advice, and reassured them that client participation was possible in their specific research project.

I liked the individual coaching a lot. The trainer gave me practical guidance. I was worrying about a lot of things.(...) She took my worries away and we went through my plans step by step. (Sanne)

Researchers also valued co-learning of client participation. The exchange of experiences with colleagues made them aware that they were not the only ones who experience challenges in applying client participation. Furthermore, co-learning gave them new ideas about different ways of how to work together with clients.

That really helps I think. Than you can ask them how did you do this, or ehh they say I had this sort of meeting with clients, and then I think ooh that's a nice idea, I should also do this! (Judith)

Moreover, researchers explained that since client participation was not part of their previous education, practical examples in the coaching program motivated them to include clients.

\section{Future outlook towards client participation}

Researchers described that the coaching program and including clients in their research project made them aware that they wanted to advocate for more client participation in research, as they truly became aware of the value of it. They thought that client participation might not get its full potential if there are no people who actively promote and facilitate it within research teams or organizations as a whole.

I think it is very important to actively stand up for client participation to keep client participation alive within our research community. We do it once in a while, but it is surely not a common activity for every researcher. If we do not promote it pro-actively, it will not become a standard research activity (Kim)

One researcher proposed the idea of using organizational client panels to apply client participation in research agenda setting.

I think we have to come up with ideas that facilitate applying client participation, like a departments' 
client panel or something like this. (Judith)

Moreover, researcher emphasized the importance of integrating client participation within the scientific education of health professional students. They themselves were not educated in client participation before, and experienced that education is needed to have a client participation-mindset and learn about the levels and methods of client participation.

And I think it is also important to stimulate bachelor and master students to apply client participation in their projects. In fact, all important stakeholders, such as researchers, professionals and students have to be aware of the importance of client participation. (Judith)

\section{Lessons learnt about client participation}

From the experiences of junior researchers with applying client participation several lessons can be learnt which are described in table 7.1.

Table 7.1. Lessons learnt from experiences of junior researchers

\section{Level of client participation}

- The level of client participation should be meaningful, it should fit the research question and context of research.

- Using a participation matrix helps to visualize the level of client participation per research phase.

- The level of client participation should be discussed with the client(s) using the participation matrix.

- $\quad$ Consider to start with client participation from the phase of agenda setting.

\section{Collaboration between researchers and clients}

- Invest in the relationship with clients

- Let clients know that you appreciate their input and respect their point of view

- Communicate honestly about expectations, be aware of the risk of underestimating or overestimating clients.

- Collaborate with clients whose characteristics suit the research question, the level of involvement, and the phase of the research process.

- Using a client role description when recruiting clients helps.

\section{Integrating client participation in the research project}

- Junior and senior researchers should be educated in client participation.

- $\quad$ Researchers should be supported in client participation with resources such as time and financial aspects.

- Decide with clients and the research team together if clients are part of the research team and attend meetings.

- Frequently place client participation on the agenda during team meetings

- Be aware that client participation takes additional time, for example to organize meetings or adjust written information.

- Discuss appropriate financial reimbursement with clients.

- Establish institutional guidelines for client participation, including coaching and financial reimbursement.

\section{Coaching of researchers in client participation}

- Use coaching or peer support when starting client participation as a researcher

- In coaching important elements are reflective sessions, co-learning, individual coaching, and practical examples.

- Use the participation matrix and the client role description in coaching. 


\section{Discussion}

This study provides insights into how different junior researchers applied client participation in various research projects, how they experienced the process of learning to apply client participation, and the lessons learned from their experiences. The results show that researchers worked together with various clients, from individual clients, to parents of children with a disability, to patient counsels, to citizen counsels. These clients were involved on different levels (from consultation to control) in different research phases. The experiences of junior researchers reflected three important themes: collaboration between researcher and client, integrating client participation in the research project, and the impact of applying client participation and receiving coaching on the role development of the junior researcher. From the experiences several lessons were learned for junior and senior researchers, which can be supportive when (planning to) working together with clients in research.

The importance of a good relationship between the researcher and the participating clients, including clear communication about mutual expectations and respecting clients, was reported in our study. Researchers in the current study experienced doing multiple projects within the PhD research together and working together for a longer period of time as helpful. Moreover, researchers in our study described that mutual respect and appreciation were preconditions for a good relationship and working together. Researchers emphasized that when involving clients, their opinions should be taken serious. This power-relationship between researchers and clients is also highlighted in earlier studies about client participation. ${ }^{4,22,23}$ Howe and colleagues found that communicating expectations and continuous reflection about client participation are beneficial for a good relationship. ${ }^{23}$ Researchers should be aware that relationship building with clients is necessary and takes time.

Moreover, researchers in our study struggled to decide on how to select the right clients. They valued the use of a client role description (defining characteristics of clients) to select clients, which was developed during their coaching program. ${ }^{10}$ Researchers also emphasized that the participation matrix ${ }^{10,11}$ could help in aligning the level of participation to the client's skills and the research phase. Garfield and colleagues emphasize the danger of tokenistic application of client participation. ${ }^{24 n}$ It is important to realize that meaningful client participation is better than maximum participation. ${ }^{10}$ To avoid tokenistic application, an important lesson learned is to ask clients themselves in which phase they can or want to be involved using the participation matrix. Moreover, institutions should invest in organizational guidelines for a meaningful role of clients in research projects. 4,16,22,23,25

Financial reimbursement was another important topic for researchers. Researchers did often not know how to financially reimburse clients. In other studies, clients are given a small salary or are provided with a short-term contract at a university. ${ }^{12}$ Institutional guidelines about financial reimbursements would guide junior researchers and clients. Researchers, supervisors and clients themselves should be involved in such decisions, as several factors can be influential, such as social security benefits of clients and available budget in subsidies. ${ }^{10}$ 
Involving clients in the early stages of grant applications and decision making about study designs has also been considered as best practice in research. ${ }^{16,23,26}$ Researchers in the current study reflected that they had not involved clients in the phase of agenda setting, but were planning to do this in the future. Client participation in early phases of research is complex and therefore requires preparation both from clients, junior and senior researchers, as from research institutions. Moreover, a client participation-mindset right from the start of research projects proved to be important. Researchers in this study suggested to install client counsels in research institutions which may support in these decisions. Other literature recommends to use experts who can support and ensure partnership between clients and researchers. ${ }^{23}$

Although there is research about the insecurity of clients in research, one should also pay attention to the insecurity of researchers. ${ }^{12}$ In our study junior researchers reflected upon their struggles, and dared to describe their honest experiences, which are important to support other researchers. Junior researchers described that individual coaching and collaboration with peers could help them get more confidence in applying client participation. Price and colleagues argued that researchers might be unwilling to report unsuccessful client participation, ${ }^{16}$ but that such outcomes can be valuable lessons for other researchers.

Client participation should not be 'just' an option, but embedded in standard practice and education in healthcare research institutions. ${ }^{27}$ Also subsidy providers begin to demand client participation in research projects. However, as client participation has been rarely part of the PhD curricula, junior and senior researchers have not learned to apply client participation. The current study shows that additional coaching about client participation facilitates researchers to have confidence, to apply client participation, and has an impact upon their role development as a researcher. The study of de Wit and colleagues described that also senior researchers are insecure about client participation and are in need of support and institutional guidelines. ${ }^{10}$ De Wit and colleagues therefore developed a separate training for junior and senior researchers. ${ }^{10}$ The current study shows that indeed both these groups have to be trained and that client participation should be uniformly on the research agenda of institutions. Furthermore, to achieve implementation of meaningful client participation, client participation should be an integral part on all levels of research education in healthcare, from bachelor, master, to PhD.

\section{Strengths and limitations}

Our study has several strengths, but the results may also have been subject to certain limitations. Two researchers had a double role in this study, as they are the first two authors of this article and also participated in the interviews. We are aware that this situation might have led to data being influenced by the researchers. Therefore, the interviews were done by an independent researcher, as the authors already knew some of the participants' experiences, to enable the participants to tell their whole story and diminish social desirable answers. The analysis were done by the authors because in this phase 
they could use context information which supported the in-depth analysis of the interviews. The two researchers constantly reflected upon their reflexivity during all phases of the research, and peer review sessions were held with other independent researchers.

In retrospect the interviews and data collection could have been more in-depth. During the interviews additional questions could have been asked to the participants, more specifically about what they experienced as benefits and negative aspects of certain strategies (e.g. involving client in research team, using a client role description). Moreover, in-depth information could have been gathered by performing additional individual or focus group interviews or involving the senior researchrs. However, the data gathered and analysis of the experiences presents important insights into how junior researchers experience client participation in research. Such experiences through the eyes of the researchers themselves are needed to get a better understanding of client participation and the support researchers need. ${ }^{12}$ Moreover, the current study presents important lessons for (junior) researchers who want to involve clients in their research.

This study includes a small number of participants from one research setting. Future research could study different research settings as to provide more insights in struggles and supporting factors. The limited amount of researchers might have influenced the transferability of the results. However, an exploration of their experiences was valuable since other studies mostly reflect on the amount of client participation or only describe methods of client participation. ${ }^{16}$

The inside-view on the experiences of junior-researchers is beneficial as it emphasizes that junior-researchers (when supported through coaching) are able to initiate crucial changes of perspectives in research. The view of clients was not included in this study as the research question was aimed to provide insights into the junior researchers' experiences. It would be interesting to compare the experiences of researchers with that of clients in future research.

\section{Conclusion}

Junior researchers have applied client participation in various ways during their research projects. However, one should not ignore the struggles and insecurities of junior researchers while applying client participation. For (junior) researchers it proved to be important to invest in the researcher-client collaboration, including valuing the contribution of clients and clarifying expectations. Integrating client participation in the research project was also experienced as important. Of specific importance was the role of the client in the research team. Furthermore, the coaching and actively working together with clients made them aware of the value of client participation, boosted their confidence and motivated them to advocate for client participation in the future. For institutions it appears to be important to educate junior and senior researchers using reflective sessions, co-learning, and individual coaching. 


\section{References}

1. Staniszewska S, Brett J, Mockford C, Barber R. The GRIPP checklist: strengthening the quality of patient and public involvement reporting in research. Int J Technol Assess Health Care. 2011;27(4):391-399.

2. Farrell C. Citizen and consumer involvement in UK public services. International Journal of Consumer Studies. 2010;34:503-507.

3. Hunter DJ, Kieslich K, Littlejohns P, et al. Public involvement in health priority setting: future challenges for policy, research and society. J Health Organ Manag. 2016;30(5):796-808.

4. Page-Reeves J, Regino L, McGrew HC, et al. Collaboration and Outside-the-Box Thinking to Overcome Training-Related Challenges for Including Patient Stakeholders as Data Collectors in a Patient-Engaged Research Project. J Patient Exp. 2018;5(2):88-91.

5. Involve. What is public involvement in research? Available at: http://www.invo.org.uk/find-out-more/what-is-public-involvement-in-research-2/. Accessed 2018-7-10

6. Staley K. Exploring Impact: Public Involvement in NHS, Public Health and Social Care Research. . INVOLVE, Eastleigh. 2009.

7. Crawford MJ, Rutter D, Manley C, et al. Systematic review of involving patients in the planning and development of health care. BMJ. 2002;325(7375):1263.

8. Domecq JP, Prutsky G, Elraiyah T, et al. Patient engagement in research: a systematic review. BMC Health Serv Res. 2014;14:89.

9. Shippee ND, Domecq Garces JP, Prutsky Lopez GJ, et al. Patient and service user engagement in research: a systematic review and synthesized framework. Health Expect. 2015;18(5):1151-1166.

10. de Wit M, Beurskens A, Piskur B, Stoffers E, Moser A. Preparing researchers for patient and public involvement in scientific research: Development of a hands-on learning approach through action research. Health Expect. 2018.

11. Haarsma F, Moser A, Beckers M, van Rijswijk H, Stoffers E, Beurskens A. The perceived impact of public involvement in palliative care in a provincial palliative care network in the Netherlands: a qualitative study. Health Expect. 2015;18(6):3186-3200.

12. Abma TA, Nierse CJ, Widdershoven GA. Patients as partners in responsive research: methodological notions for collaborations in mixed research teams. Qual Health Res. 2009;19(3):401-415.

13. Arnstein SR. A Ladder Of Citizen Participation. Journal of the American Planning Association. 1969;35(4):216- 224.

14. Thompson J, Bissell P, Cooper C, Armitage CJ, Barber R. Credibility and the 'professionalized' lay expert: reflections on the dilemmas and opportunities of public involvement in health research. Health (London). 2012;16(6):602-618.

15. Snape D, Kirkham J, Britten N, et al. Exploring perceived barriers, drivers, impacts and the need for evaluation of public involvement in health and social care research: a modified Delphi study. BMJ Open. 2014;4(6):e004943.

16. Price A, Schroter S, Snow R, et al. Frequency of reporting on patient and public involvement (PPI) in research studies published in a general medical journal: a descriptive study. BMJ Open. 2018;8(3):e020452.

17. Lincoln YS, Guba EG, eds. Naturalistic Inquiry. Beverly Hills: CA: SAGE; 1985.

18. Sandelowski M. What's in a name? Qualitative description revisited. Res Nurs Health. 2010;33(1):77-84.

19. Sandelowski M. Whatever happened to qualitative description? Res Nurs Health. 2000;23(4):334-340.

20. Hsieh HF, Shannon SE. Three approaches to qualitative content analysis. Qual Health Res. 2005;15(9):1277-1288.

21. Korstjens I, Moser A. Series: Practical guidance to qualitative research. Part 4: Trustworthiness and publishing. Eur J Gen Pract. 2018;24(1):120-124.

22. Brett J, Staniszewska S, Mockford C, et al. A systematic review of the impact of patient and public involvement on service users, researchers and communities. Patient. 2014;7(4):387-395.

23. Howe A, Mathie E, Munday D, et al. Learning to work together- lessons from a reflective analysis of a research project on public involvement. Res Involv Engagem. 2017;3:1.

24. Garfield S, Jheeta S, Jacklin A, Bischler A, Norton C, Franklin BD. Patient and public involvement in data collection for health services research: a descriptive study. Research Involvement and Engagement. 2015;1(1):8.

25. Price A, Albarqouni L, Kirkpatrick J, et al. Patient and public involvement in the design of clinical trials: An overview of systematic reviews. J Eval Clin Pract. 2018;24(1):240-253.

26. Abma TA, Broerse JE. Patient participation as dialogue: setting research agendas. Health Expect. 2010;13(2):160-173.

27. Staniszewska S, Brett J, Simera I, et al. GRIPP2 reporting checklists: tools to improve reporting of patient and public involvement in research. BMJ. 2017;358:j3453. 



\section{Chapter 8}

General Discussion 


\section{General Discussion}

Meaningful dialogue conversations between clients and professionals are important to realise client-centred care and shared decision making specifically, and good quality of care in general..$^{1-3}$ However, a large number of clients in long-term care settings experience functional communication difficulties, making it challenging for them and the professionals who work with them to achieve meaningful dialogue conversations.

The aim of this research was to explore how communication vulnerable clients and professionals experience their communication in dialogue conversations in long-term care and how they can best be supported in improving their communication in these conversations. In this dissertation, the following research questions were addressed:

1. Which challenges do communication vulnerable clients and those in their social environment experience in their communication in dialogue conversations in the context of long-term care settings?

2. How can communication vulnerable clients and professionals together support their communication using ad hoc usable Augmentative and Alternative Communication (AAC) during dialogue conversations in long-term care settings?

3. How can researchers include (communication vulnerable) clients in research projects?

This chapter addresses the main findings of the studies in this research project, and highlights a number of methodological considerations. In addition, the chapter shares insights about lessons learnt from the research project concerning awareness of communication vulnerability, communication support, and collaboration with communication vulnerable people. The last section of this chapter discusses further implications of this research project for research, practice, and education.

\section{Main findings}

\section{Dialogue conversations between communication vulnerable clients and healthcare professionals}

Current practice was investigated by means of two qualitative studies about communication involving communication vulnerable clients in long-term care settings. The first study revealed that, in long-term care settings, communication vulnerable clients and those in their social environment face many challenges when communicating in three types of social relationships: communication amongst clients; communication between professionals and family members; and communication between clients and professionals. The latter appeared to be the most complex. The main influencing factors in the communication between clients and professionals were: the effort put into improving the communication, the knowledge of the professional, AAC, time for communication and the influence and power of the client. The results show that communication vulnerable clients and those in their environment experience daily challenges when it comes to communication, and more research was needed to get a deeper understanding of the communication between communication vulnerable clients and professionals. 
Therefore, the second qualitative study explored the experiences in communication during dialogue conversations of communication vulnerable clients and professionals, using interviews and observations. The findings of this study, revealed several factors that clients and professionals experienced as beneficial to their communication in dialogue conversations: putting effort into adjusting communication, preparing conversations from both sides, giving time to clients, and providing a quiet and familiar environment. Both clients and professionals experienced difficulties in communication during their dialogue conversations. On the one hand, the extent to which clients played an equal part in conversations as the professionals they were speaking with, varied, and some clients were not able to express themselves sufficiently. On the other hand, professionals were not always aware of the impact of the communication vulnerability of clients in the specific dialogue conversations and struggled to tailor communication to clients. The strategies they used mostly consisted of adjusting their own communication, using verbal strategies that turned out to be challenging for their clients, such as talking (too) fast, using sentences that were (too) long, or providing a lot of (or rather too much) information, while strategies focussing on empowering clients to express themselves were hardly used. Observations showed that while professionals thought they supported clients by using closed questions, this strategy sometimes led to a restriction in the depth of conversations and resulted in one-sided control over the topic of conversations.

And overall, professionals were not aware that their communication adjustments were often not supportive. This might explain why they did not search for other solutions during the observed conversations. Interviews and observations showed that Augmentative and Alternative Communication (AAC) were not used during dialogue conversations, even though they have potential to facilitate these conversations. Clients who had difficulties with speech mostly used nonverbal communication (e.g. gestures and facial expressions) to express themselves, professionals did not offer AAC to support them in expressing themselves using other means. Professionals as well as clients were often unaware of the potential of AAC in supporting their conversations, expressed negative attitudes towards AAC, had not used AAC before, or lacked knowledge regarding which AAC would be suitable for dialogue conversations. All in all, then, the two qualitative studies into communication in long-term care settings, showed that professionals need more knowledge and skills concerning communication vulnerability in general, and ways in which to offer communication support to communication vulnerable clients in specific, to accommodate improved and high quality communication with this target group.

\section{Opportunities for communication support in dialogue conversations}

In addition to looking into the nature of and issues surrounding communication between communication vulnerable clients and professionals in long-term care settings, studies were also conducted to provide insight into how the physical environment can be shaped to support dialogue conversations. More specifically, two scoping reviews were conducted: one about the physical environment in general, and another about a specific AAC tool (as AAC tools can be considered as parts of the physical environment). The first review included qualitative, quantitative, mixed-method, and literature studies. The findings indicated that strategies to adjust the physical environment, such as lighting, acoustic 
environment, humidity and temperature, setting and furniture placement, providing and adjusting written information, and availability of (ad hoc usable) AAC tools, could (be used to) support dialogue conversations with communication vulnerable people.

In this thesis, ad hoc usable AAC are regarded as AAC that can be readily available in long-term care settings and can be used by professionals and clients to support their conversations without a comprehensive individual advisory process by an AAC expert, as is needed for individual dedicated communication devices. Such AAC can be low-tech or high-tech tools or strategies. Examples of ad hoc usable AAC tools that are recommended based upon the scoping review of the physical environment are pen and paper, pictures, graphic topic setters, pictographic books, and Talking Mats.

In order to further explore the potential of AAC tools in dialogue conversations, studies and other available literature about Talking Mats were reviewed in the second scoping review. Talking Mats was selected (as an example of an ad hoc usable AAC tool) for this purpose because of its applicability in different settings and its potential for supporting dialogue conversations in which a wide range of communication vulnerable clients take part. This review showed that Talking Mats could be appropriate to supplement nonverbal as well as verbal communication, since it is based upon visualization and provides structure for a conversation. Researchers who conducted empirical studies reported that Talking Mats has a positive influence on technical communication aspects, facilitates communication, and encourages clients to be more involved in communication as well as decision making. However, no firm conclusions could be made since these empirical studies were in this review evaluated as of lower levels of evidence. In addition, it should be mentioned that the results of these empirical studies might be biased as some of them were conducted by the developers or distributors of Talking Mats.

Talking Mats is only one of many AAC tools that can be useful for dialogue conversations. It is clear from the results that were described in chapter 2, 3, 4 and 5 of this thesis that, although there is a definite need for (and there is great potential in) the use of different AAC in dialogue conversations, clients and professionals need support in the process of selecting suitable AAC. Therefore, a user-centred design (UCD) study was conducted as a part of this overarching research project, to help develop a guide (website) that could support clients and professionals in jointly identifying the communication difficulties of clients, and to guide them towards ad hoc usable AAC, that can help improve their dialogue conversations.

An iterative process of three cycles was used to develop the guide, consisting of collecting knowledge, developing prototypes of the guide, evaluation of prototypes and adjusting the guide. All of the cycles were performed in collaboration with experts and future users. In the third cycle of the UCD study the high-fidelity prototype of the guide (website) was subjected to usability testing. Overall, clients, professionals and experts experienced the guide to be useful: they found it easy to use, attractive and accessible, and appreciated the comprehensive overview of ad hoc usable AAC. The most important improvements for the guide, based upon the experiences of clients, professionals and experts in this 
third cycle, were: changing the phrasing of questions, adding a 'sometimes' answering option, and including questions about physical (dis)abilities (e.g. hand function).

An interesting observation of the researchers was that most professionals empowered clients to take the lead in using the guide. This approach could be related to the fact that the questions in the guide are directed at the client, or the fact that the guide was catered to the understanding of clients. The final guide is a website which clients and professionals can use together: www.communicatiekeuzehulp.nl. The guide gives, based upon the experienced communication difficulties, advice on ad hoc usable AAC tools that can be used in dialogue conversations. Whereas existing guides focus on individual dedicated communication devices (e.g. personalized communicator), the guide developed in this study includes AAC suitable as ad hoc tools (e.g. general pictobook) to support dialogue conversation, and explains how to use them. The guide aims to enable clients to participate in making shared decisions about communication support in dialogue conversations, and eventually to facilitate their participation in their own healthcare process.

\section{Client participation in research}

In order to provide (communication vulnerable) clients with a voice in their own healthcare process, it is important to get insights into their experiences, opinions and perspectives. It is only possible to gain an understanding of the struggles they experience, and explore useful tools and strategies that can be used in daily practice, if clients are involved in research projects in a significant way.

Including clients in research is, however, not standard practice and can lead to challenges for (junior) researchers. To provide insights into the process of including clients in research, a qualitative study was conducted into how junior researchers apply client participation in their research project and how they experience this. The findings revealed that junior researchers experience it as essential to invest in the researcher-client collaboration. Valuing the contribution of clients was experienced crucial for this relationship. Furthermore, they experienced that they had not always clarified the expectations with clients sufficiently. Retrospectively, expectations with regard to the role of the client, the timing of the research, the level of involvement, the objective of the research, and the capacities of the clients and wishes for involvement, have to be discussed. Integrating client participation in the research project was also experienced as important but also difficult, of specific importance was the role of the client in the research team. Furthermore, receiving coaching and actively working together with clients made them aware of the value of client participation, boosted their confidence and motivated them to advocate for client participation in the future. 


\section{Methodological considerations}

In this section, methodological considerations of the studies in this thesis are discussed with regard to the complexity and conceptualisation of the target group, use of qualitative methods, the user-centred design approach, and client participation in research.

\section{Complexity and conceptualisation of the target group}

In this thesis communication vulnerability is defined as: adults who experience functional communication difficulties (expressing their needs and wishes, and/or understanding information) in particular situations, due to medical conditions. A strength of using this definition is that diagnoses directly linked to communication (e.g. aphasia) are not used to set boundaries to the definition, forgoing standard medically-based diagnostic labels.

The definition reflects daily healthcare practice, since clients in long-term care settings often experience communication difficulties due to the combination of a medical condition and environmental factors, or due to multiple medical conditions. Furthermore, this focus on the experiences with functional elements of daily life (conversations) of individuals, is in line with the vision of the biopsychosocial perspective, the World Health Organization, and the recent model of positive health..$^{4-6}$ However, the disadvantage of using this definition for communication vulnerable people is the lack of clear boundaries to the definition. As it is focussed on experiences with functional communication, which can change between periods of time, communication partners and places, the boundaries of who falls inside and outside the definition are rather fluid. This may limit classical diagnosis-based generalisation from sample to population. However, by focussing on communication vulnerable clients, the results reflect the authentic contextual conditions which enhances understanding communication in long term care settings, and may enhance the transferability of these insights. ${ }^{7}$

To describe and select communication vulnerable participants in our studies, a screening list was developed which focussed on functional communication difficulties. Existing screening tools could not be used since they were too comprehensive to administer in this study (by a communication expert), or focussed on one particular diagnosis. ${ }^{8-11}$ However, elements of these tools, which fit with the definition of communication vulnerable people, were used in the development of the screening list. The face validity of this list was good as communication experts were of the opinion that the questions reflected the concept of communication vulnerability. Moreover, the communication vulnerability screening list was useful because every healthcare professional could use it, it was suited for long-term care settings, it was applicable as recruitment tool for research purposes, and, as it consisted of just 24 questions, it was easy to use. However, the screening list also had a few disadvantages. First, it was not evaluated whether this screening list truly makes a valid difference between people who are and people who are not communication vulnerable, it was unclear what an appropriate cut-off point is in this assessment, and it was not clear if the list encompassed all communication difficulties. However, after the screening list had been applied, the research team ascertained that the selected participants did mirror the 
definition of communication vulnerable people.

A second disadvantage of the screening list was that it cannot be used by communication vulnerable clients, and it could be valuable to let them self-assess whether they are communication vulnerable. This was taken into account during the development of the guide for AAC (described in chapter 6). In the guide accessible questions are asked to clients about functional communication difficulties to enable them to self-assess their communication difficulties.

\section{Use of qualitative methods in research with communication vulnerable clients}

A qualitative approach based on assumptions of naturalistic inquiry was used to provide in-depth understanding of communication between communication vulnerable clients and professionals in long-term care settings. ${ }^{12}$ This kind of communication research in natural contexts, including experiences of clients and professionals, is needed to continue to enhance the quality of care. ${ }^{12,13}$

We are aware that the trustworthiness of the findings described in this thesis might have been affected because the conducted studies relied on information from people with communication and cognitive difficulties. Participants may not have understood questions correctly, and/or may have had difficulties remembering things correctly, and researchers may have interpreted information gathered from these participants differently than it was intended. Although these possibilities limit the trustworthiness of this study, a strength of the study lies in the fact that these possibilities were taken into account and an attempt was made to limit their influence by using several strategies.

First, data triangulation was used to enhance the credibility and provide a thick description. Clients' experiences were supplemented (not replaced) by observations made by researchers as well as information from interviews with family members and professionals. Another valuable option would have been to perform a prolonged observation in which a researcher would be part of the setting for a period of time, this could have provided even more contextual information.

Second, all communication with clients during the studies was adjusted to enhance the credibility. Researchers used their own experience, expert opinion (including clients), and evolving insights from the studies in this thesis, to support clients to express themselves and understand researchers. Information that was shared with clients in a written form, including informed consent, member check and information letters, was adjusted. Standard documents often include a lot of information, making it difficult for people with communication vulnerability to comprehend. We adjusted the form of information presentation (e.g. font, font size, visualization) in these documents. Furthermore, interview guides were prepared in several versions, in which different answering options were provided: from open questions, to closed questions, to visual answering options. Although different kinds of questions were asked, care was taken to make sure they all conveyed the same content. During interviews the researchers supported the clients to express themselves by using AAC, such as pen and paper, a tablet, pictograms and visual answering options. Other communication strategies that were included: 
providing extra time for clients to comprehend information or express themselves, asking short and simple questions, providing intermediary summaries during the interviews, checking nonverbal communication of the client, and reducing the cognitive load during the interview. Sometimes, a family member or professional was present as a 'translator' to help the researcher understand the client. ${ }^{14,15}$ The time at which and place in which the interviews were held, were also adjusted to the individual needs of the clients, so as to enhance their concentration or limit tiredness. Despite these efforts, in some interviews we only managed to gather limited information. Although this can be seen as a weakness of the study, the limited information that was gathered was still valuable for answering the research questions.

A third way in which the authors of this study tried to safeguard the trustworthiness of the study, which could potentially be compromised as a result of misunderstanding information from people with communication difficulties, was to ensure the confirmability and reflexivity by practicing constant self-reflection. This included making field notes and diary notes, and by having weekly peer-debriefing sessions. ${ }^{12,16}$ Moreover, researcher triangulation was used by involving researchers with different backgrounds during interviews, observations and extensive peer-debriefing sessions during all phases of the studies. In our UCD study, which is described in chapter 6, peer debriefing sessions were also held with the research partners, providing not only reflections from a researchers' point of view, but also from the perspective of clients and professionals. It should be noted that, despite having used these reflective strategies, it cannot be unequivocally stated that the information gathered from clients with communication and cognitive difficulties was interpreted correctly.

Furthermore, to enhance the transferability of the findings and to stay close to the context of long-term care settings, a combination of purposive and criterion sampling was used to ensure that a heterogeneous sample of clients with a wide variety of communication difficulties participated in all studies. ${ }^{17}$ In addition, trustworthiness across studies in this thesis was reflected in the findings from the two qualitative studies and first scoping review, since these resembled comparable themes related to communication between clients and professionals and the lack of AAC use. ${ }^{7}$

\section{A user-centred approach in research with communication vulnerable clients}

Several methods, such as User-Centred design (UCD), the International Patient Decision Aid Standards (IPDAS) framework and Intervention Mapping, were considered to develop a usable guide for communication support in the context of the study described in chapter 6. ${ }^{18-20} \mathrm{UCD}$ was chosen since it seemed to be the most appropriate method to develop a practice based guide that was tailored to the needs of future users, and it seemed to be most suitable for involving such a vulnerable group of clients. ${ }^{20}$ A strength of the UCD process, is that it involves several cycles in which new requirements emerge that further guided the development of the guide. The use of iterative cycles of prototyping that the UCD approach offers, appeared to be well-suited for the sketching out of different ideas and presenting them to vulnerable users, both of which were required for the study described in chapter 6 . Furthermore, involving the interdisciplinary research team as recommended in UCD, and the data collection methods 
including different stakeholders, appeared to be valuable to develop a practice-based guide. Although the method 'think aloud' used in the UCD study might seem difficult for communication vulnerable clients, it proved to be appropriate for the target group. It was often easier for clients to describe experiences while using a guide, than it was to describe experiences with conversations that had taken place at another time. From our experiences in the study described in chapter 6, UCD appeared to be very suitable for conducting research involving communication vulnerable clients, as the data collection techniques involved are flexible, creative and often include visualizations.

A strength of the developed guide is that clients are involved during the identification of functional communication problems and searching for communication support. Other websites often skip this step, and begin by presenting AAC tools, instead of identifying issues, or they basically provide an overview of AAC tools. ${ }^{21-23}$ Moreover, other websites about AAC tools or individual internet searches for AAC tools are often too complicated for communication vulnerable clients or do not focus on ad hoc usable AAC tools to be used in dialogue conversations. However, a weakness of the guide is that clients who have major cognitive disabilities might still need support from a professional or caregiver to help them use it, because they might not be able to read or understand the pictograms used. A further weakness is that the guide only supports clients and professionals up until the point that several AAC options are presented, and does not support the process of testing AAC tools to see which ones best match the clients' characteristics, the professionals' characteristics, and the context of their dialogue conversation. $^{24}$

A limitation of the study described in chapter 6 is that the benefit for communication in dialogue conversations is yet to be tested and a comprehensive process evaluation has not been done yet. Future research is needed to investigate the effectiveness of the guide with larger groups of client-practitioner dyads and insights into long-term acceptance.

\section{Client participation in research}

A strength of the studies described in this thesis is that the perspective of healthcare professionals as well as communication vulnerable clients are included. To make sure the researchers were sufficiently prepared for conducting these studies, they followed a coaching programme about client participation in research. ${ }^{25}$ This coaching programme was developed at Zuyd University of Applied Sciences and involved several meetings with experts and peers, and was meant to contribute to the creation of awareness about the importance of client participation as well as providing guidance and strategies for researchers. During the studies described in this thesis the researchers became more aware of, and skilled in client participation, resulting in the use of various levels of participation of clients, professionals and experts: consulting, advising and partnership.

The coaching program provided guidance in transparency about these different levels of participation using the participation matrix. The level of participation of each of the stakeholders is illustrated in Figure 8.1, using elements of the participation matrix of the coaching program of de Wit and colleagues..$^{25}$ 
The objective of patient participation in these studies was that the level of participation should be meaningful, instead of maximum, in order to fit the context and research question. ${ }^{25}$

\begin{tabular}{|c|c|c|c|}
\hline $\begin{array}{l}\text { Studies in this thesis } \\
\text { Level of } \\
\text { participation }\end{array}$ & $\begin{array}{l}\text { Chapter } 2 \\
\text { Qualitative study about com- } \\
\text { munication in long term care } \\
\text { settings }\end{array}$ & $\begin{array}{l}\text { Chapter } 3 \\
\text { Qualitative study about com- } \\
\text { munication in dialogue conver- } \\
\text { sations }\end{array}$ & $\begin{array}{l}\text { Chapter } 6 \\
\text { UCD study about developing a } \\
\text { guide for choosing AAC }\end{array}$ \\
\hline Control & & & \\
\hline Partnership & & & 色品 \\
\hline Advising & & $q$ & $\mathbb{R} q$ \\
\hline Consulting & $q$ & $q$ & 象吊 \\
\hline
\end{tabular}

q

Figure 8.1. Levels of participation across the studies described in this thesis set up using the participation matrix ${ }^{25}$.

Looking back on the studies, clients could have been involved more intensively. They could have been involved during the agenda setting of the research project in general, and of the individual studies in specific. Additionally, clients could have been involved in making the research process itself accessible, for example by checking if communication strategies used during the data collection phases were suitable and effective, by reading informed consents and by participating in pilot interviews. Several client groups could have participated more intensively in the development of prototypes in the UCD study, instead of relying mostly on the two research partners.

\section{Lessons learnt}

The research project has resulted in a number of lessons learnt concerning awareness of communication vulnerability, communication support, and collaboration with communication vulnerable people.

\section{Awareness of communication vulnerability}

The results of this thesis reveal that more awareness is needed about the challenges and difficulties experienced by the large group of communication vulnerable clients. For this awareness to increase, a mind shift is needed in the sense that professionals, clients and researchers start acknowledging the need for a focus on functional communication and participation, ${ }^{26-28}$ as well as start using the term 'communication vulnerability' more frequently and consistently (where appropriate). 
From diagnosis, to functional communication and participation

A shift from a focus on diagnosis to a focus on functional communication support is important to enable communication vulnerable clients to use competences and strengths to talk about 'what really matters ${ }^{\prime 13}$ in dialogue conversations and participate in their own healthcare process. ${ }^{13,29}$ With the introduction of the ICF in 2001, the World Health Organization aimed to facilitate such a shift by introducing a model that encompasses not only illnesses, but also personal and environmental factors and includes both disease, activity and participation. ${ }^{5}$ However, the ICF places health conditions at the top of the model, which, in some people's eyes, may still indicate a central place of health conditions and hamper attention for activity and participation. ${ }^{30}$ The model of 'positive health' was introduced to place a person's experiences and needs more at the centre of their care than their disease. In this model the focus is on a person's strengths rather than his weakness, and views health as the ability to adapt and self-manage. ${ }^{6,31}$ This broad perspective receives a lot of positive attention and might be new for many people. However, in the field of occupational therapy a central place has been given to this broader perspective and participation of people for a long time already. In addition, models in occupational therapy has long since acknowledged the influence of the environment on participation of people, such as in the Model Of Human Occupation ( $\mathrm{MOHO})^{32}$, the Canadian Model of Occupational Performance and Engagement (CMOP-E) ${ }^{33}$, and the Person-Environment-Occupation-Performance Model (PEOP). ${ }^{34,35}$ All of these models, including the ICF, positive health and the occupational therapy models use visualisation and there is a lively discussion about the best visual model. A model similar to the ICF has been developed for people with aphasia: Living with Aphasia: Framework for Outcome Measurement (AFROM). In this model the domains of intervention and outcome that are relevant for people with aphasia are visualized in a format that is supposed to allow for easy practical application. ${ }^{36}$ Heerkens and colleagues recently proposed to adjust the ICF model to a visualisation which places a person's health condition as part of their personal factors, places participation more central, and places the environmental factors as encircling all other elements. ${ }^{30}$ Van der Velde and Vriendt ${ }^{37}$ commented $^{2}$ on the model of Heerkens and proposed an even better 'new' transactional model, in which the elements overlap. This model suits the perspective used in this thesis and is basically the same as the occupational therapy PEO model, introduced in 1996 by Law and colleagues. ${ }^{38}$ In Figure 8.2 the ICF model, the adjusted ICF by Heerkens, the adjusted ICF by Van der Velde, the PEO(P) model, and the A-from model, are all aligned. 


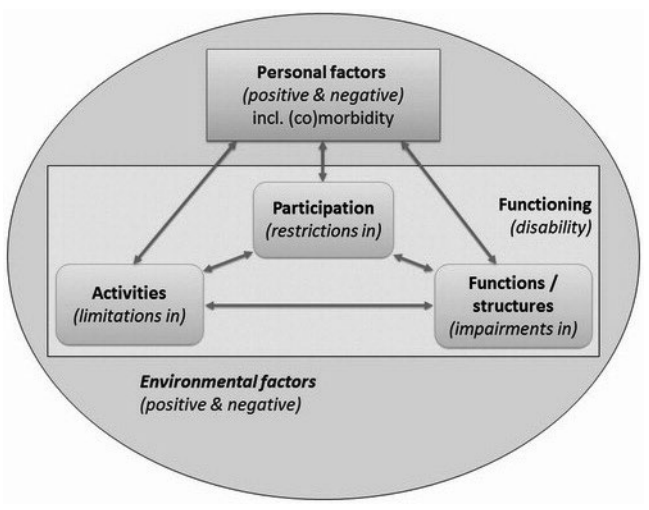

Adjusted ICF by Heerkens and colleagues (2018)

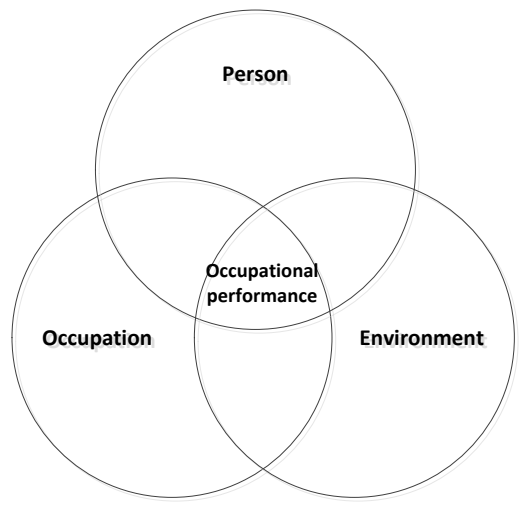

PEO model by Law and colleagues (1996)

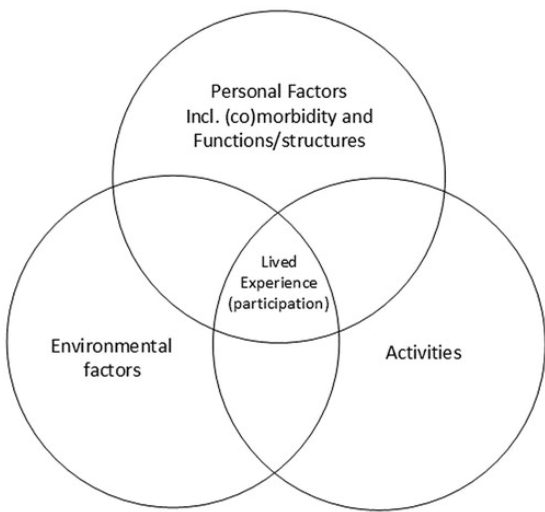

Adjusted ICF by Van der Velde and Vriendt (2018)

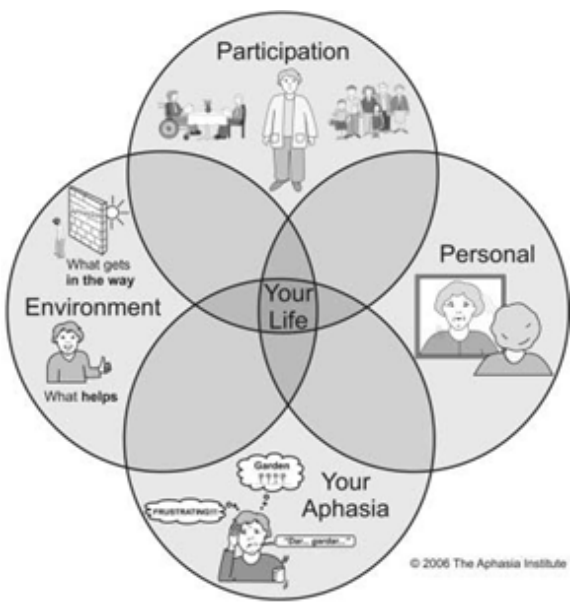

AFROM model Kagan and colleagues (2011)

Figure 8.2 Models by Heerkens and colleagues, ${ }^{30}$ Van der Velde and Vriendt, ${ }^{37}$ Law and colleagues ${ }^{38}$, Kagan and colleagues $^{36}$

Although these models originate from different fields of healthcare they all represent a broad perspective with a focus on (the participation of) the person, including personal factors, factors related to activity and participation and environmental factors. In this thesis this broad perspective is used to describe communication vulnerable people, to explore their experiences in communication, and to guide them in supporting communication. In figure 8.3 this broad perspective on communication vulnerability is visualized using the reflections of the dialogue conversation between Mieke and Carla, which were described in the introduction of this thesis. 


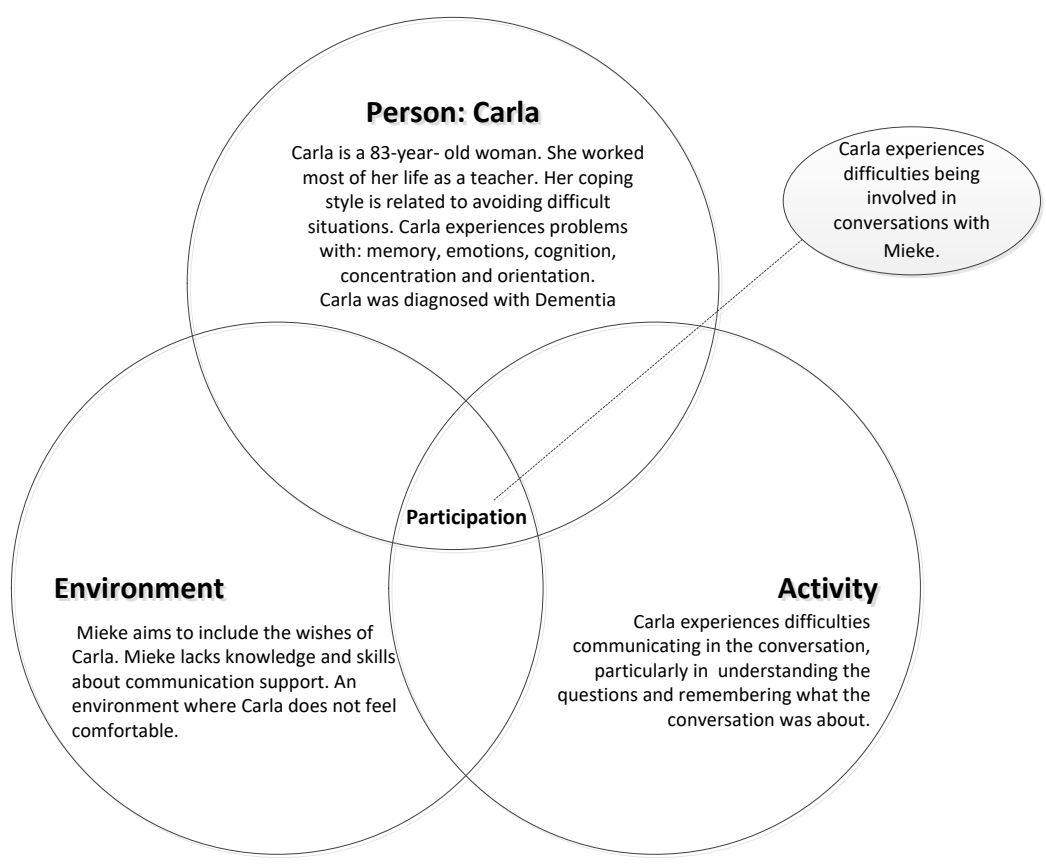

Figure 8.3. The dialogue conversation between Carla and Mieke, from a PEO(P) / adjusted ICF perspective. ${ }^{37,38}$

It is important that such a broad perceptive towards health and communication is used in healthcare in general. Specific attention should be paid to the ability to adapt and self-manage of clients, as this is not self-evident. A recent Dutch governmental report ('Weten is nog geen doen') advocates that self-management and participating in the healthcare process by clients is also related to skills such as acting, coping with difficult situations, and perseverance..$^{39}$

\section{Identifying communication vulnerable people}

Available estimates of the amount of communication vulnerable people in healthcare institutions are probably not accurate because of the narrow focus on sensory difficulties, and a disorder-based view of communication. ${ }^{26}$ It would be interesting to verify if the communication vulnerability screening list, developed in the study described in chapter 3, could provide an indication of the amount of communication vulnerable clients in long-term care settings. It could be compared with the IFCI-SQ, a recently studied screening tool which has been shown to be specific and sensitive enough to detect communication difficulties in a hospital setting. ${ }^{27}$

Moreover, the concept communication vulnerability can be defined in different, including broader, ways than was done for this particular research project. The definition of Blackstone and colleagues also includes people with limited health literacy and people who do not speak the same language as, or have 
a different cultural background than the professional. ${ }^{28}$ The major difference between health literacy and the definition of vulnerability used in this thesis (due to a medical diagnosis) is probably that health literacy is a competency that could be taught and learned ${ }^{40}$ whereas people who are communication vulnerable in long-term care settings are often in a chronic phase where much improvement in speech, cognitive abilities, hearing, or vision are mostly not to be expected. Although there are no statistics available about overlapping or converging communication vulnerability, many people probably experience more than one factor placing them at risk for miscommunication in dialogue conversations. ${ }^{28}$

For example, a client might experience difficulties in speech due to an acquired brain injury, have migrated from Africa to Europe, have limited proficiency in the language of the professional, and little knowledge about the Dutch healthcare system. Although a number of specific skills and specific knowledge is needed to communicate with clients who speak a different language, have a different cultural background, or have low health literacy skills, insights gathered from our research project might also be useful for supporting communication with these target groups. And, conversely, materials that were developed for these target groups, might be useful for conversations with the specific kind of communication vulnerable people this thesis focusses on. Professionals should be equipped with, and educated in communication support for different communication vulnerable clients in dialogue conversations.

\section{Communication support}

This thesis reveals that communication vulnerable clients need communication support to participate in dialogue conversations in their healthcare processes. ${ }^{41}$ This is also recommended by the Convention on the Rights of Persons with Disabilities of the United Nations ${ }^{42}$ which states that people with communication difficulties should be enabled to participate through different forms of communication support. The interactive nature of communication, and the two-way process it involves, requires interventions which do not only 'treat' the communication vulnerable person, nor only 'educate' the professional, but rather interventions that take a holistic approach to communication support. Speech and language therapists, occupational therapists and other AAC experts can assume leadership roles to implement adequate communication support. ${ }^{28}$ They should look beyond providing communication therapy and specialist communication tools, towards acting as a facilitator for communication accessible healthcare environments. ${ }^{29}$ Moreover, other professionals such as in medicine, nursing and social work should also engage in communication support, and inter-professional collaboration is essential to ensure accessible healthcare organisations. ${ }^{13,43,44}$ Important elements which have to be considered when supporting accessibility of healthcare environments are the competencies of professionals, and adjusting the physical environment.

\section{Competencies of professionals}

This research project has uncovered that competencies related to communication vulnerability, communication skills, and AAC, are needed for healthcare professionals. These competencies should be integrated in standard education programmes of future health professionals in modules about 
communication, shared decision making and self-management. Furthermore, professionals working in healthcare practice should be trained in up to date knowledge and skills. Existing training programmes which focus on communication support, which have been evaluated in research intensively, have had positive outcomes. Examples are Communication Partner Training ${ }^{45,46}$ and Supported Conversation for Adults with Aphasia. ${ }^{47}$ However, these programmes mainly concentrate on people with a specific diagnosis, while this thesis shows that professionals should be educated about the large group of communication vulnerable people. The recently developed IPAACKS framework can be used to indicate training needs for professionals who work with a wide range of communication vulnerable clients. ${ }^{48}$ Such a framework could be used together with the developed guide to equip professionals with knowledge, skills, and attitudes to support communication.

\section{Adjusting the physical environment for communication support}

In this dissertation a broad interpretation of the physical environment was used. ${ }^{49}$ The findings showed that professionals are not always aware that, next to more common factors such as adjusting the acoustic environment and lighting, there are other changes that can be made in the environment to support dialogue conversations, such as adjusting written information and using ad hoc usable AAC.

In healthcare, different tools presented in written information, are used to work together with clients in their healthcare process, such as shared decision making tools and patient reported outcome measurements. However such written information is often inaccessible for communication vulnerable people because they cannot read, comprehend, or process the information. Therefore, such tools have to be adjusted to become accessible for all clients in healthcare. Important adjustments for written information are available from the aphasia research field ${ }^{14,15,50}$ and low health literacy research field. ${ }^{51}$ Visualisation, the complexity of the language, and the presentation of language appear to be important factors which can support or diminish a client's understanding of information..$^{52-55}$ These factors have been taken into account when collaborating with clients in this research project and should be used in daily practice. However, more research is needed to provide sufficient evidence about the effect of different combinations of strategies and their impact on the comprehension of information by communication vulnerable people.

Although the use of ad hoc usable AAC is widely recommended in the AAC research field, this research project, as well as other studies, shows that AAC is often not used in dialogue conversations. .4,56,57 $^{-10}$ Screenings instruments and the guide that was developed as part of the current study could be used to create awareness among clients, professionals, and healthcare institutions about communication vulnerability and the potential of AAC. Furthermore, a shift in (organisational) culture towards more positive attitudes about the use of AAC is needed, $, 57,58$ as results of Chapter 2 and 3 are in line with other research regarding prejudices and misconceptions about the use of $A A C^{59}$. For example, AAC is often seen as a last resort, because of the misconceptions that AAC is childish or can decrease motivation or skill in natural speech. ${ }^{60,61}$ Moreover, professionals and clients do not have enough knowledge about the potential and variety of (available) AAC and, in addition often lack experience with AAC, ${ }^{44,57}$ instead 
getting by with their effort in understanding clients and using nonverbal communication. Using the tailored approach that the developed guide offers could support clients' and professionals' knowledge and confidence, and thereby enlarge positive attitudes towards AAC and support the implementation of ad hoc usable AAC.

The guide comprises a combination of low- and high-tech AAC tools that are often based upon visualisation (such as Talking Mats). The communication technologies that people in general use in daily life are often based upon visualisation, however, people often forget to use visualisations as AAC when communicating with communication vulnerable people. Low-tech modalities such as old fashioned pen and paper and printed pictograms can have a huge benefit in dialogue conversations, while high-tech modalities provide even more opportunities for visualized communication support. ${ }^{57,61}$ Mobile technologies such as mobile phones and tablets have many universal features that can be used in visualising communication, such as a camera, photo gallery, and internet access. Moreover, these technologies have mainstream applications that can be used as alternative communication (e.g. Pinterest, WhatsApp emoticons), or applications can be installed that are specifically designed to be used as AAC tools (e.g. Proloque2go, Predictable). These technologies are available ad hoc, and are therefore suitable for dialogue conversations. Furthermore, using mainstream technology 'hides' the communication vulnerability, which clients may find comforting. ${ }^{57,62}$

\section{Collaboration with communication vulnerable people}

We learned that (communication vulnerable) clients can provide inside information about what real daily challenges and influencing factors are, they can indicate which tools and strategies are needed, useable and useful, and they can give valuable feedback that can enhance effective implementation. Qualitative research (in which interviews play a role) can often have a tendency of excluding people who are communication vulnerable.

Too often during this research project, we encountered researchers and students who think they should not interview communication vulnerable people because they cannot communicate in depth or cannot concentrate for long enough. A mind-shift is necessary: research on healthcare should take the context of care into account ${ }^{63}$ and, as such, participants should not be selected based upon their communication skills, but based upon their engagement and involvement with the topic of research.

This thesis showed that it is possible to include perspectives of communication vulnerable people in research concerning their communication needs. Flexible and client-centred research designs, such as qualitative research and UCD, can be used to support the inclusion of communication vulnerable clients in research. An apt example of patient participation is the participation of a local client advisory board (including communication vulnerable clients) in the study described in chapter 3 . The members of the advisory board were involved during the sampling, the development of the interview guide, as well as during the data analysis. Another example is the participation of a client and a professional during the research in the study described in chapter 6 . The client took a prominent role as a research partner 
during sampling, by taking the lead in sampling clients without involvement of professionals. However, client participation was experienced as challenging by the researchers. For example, in the study described in chapter 3 , researchers struggled to collaborate with the clients during data analysis, they found it difficult to adjust the data analysis process to persons who are not educated in doing research and/or are communication vulnerable. Our experiences and the findings of the study in chapter 7 reveal that (junior) researchers need education or coaching about client participation, both for general inclusion of clients as for specific strategies for inclusion of communication vulnerable clients.

\section{Implications}

This section summarises the implications of the findings of this research project for practice, research and education.

\section{Implications for practice}

Healthcare organisations should take the responsibility of making their services communication accessible by providing adequate communication support in dialogue conversations, following the convention on the rights of persons with disabilities. ${ }^{28,42}$ To enable clients to participate in dialogue conversations and, as such, to participate in their own healthcare process, it is recommended that professionals and healthcare institutions:

- Become aware that many clients are or can become communication vulnerable, especially in long-term care settings. Clients and professionals should be involved in identifying who is communication vulnerable and in exploring which communication difficulties are experienced.

- Become aware that one cannot assume that we understand a client from merely non-verbal signs, or that we adjusted our communication sufficiently, without confirming this with the client.

- Focus on functional communication problems and focus on providing communication support that meet needs, instead of communication support that is linked to a certain diagnosis.

- Assess the gap(s) in and needs for knowledge, skills, and attitude of professionals about communication vulnerability and communication support and provide applicable training(s) or guides.

- Involve clients in searching and selecting adequate communication support. The developed guide is freely available and can be used by people who speak Dutch to involve clients in making shared decisions about choosing AAC tools to use in dialogue conversations. Involving the future users can support the use of AAC tools in practice.

- Ensure that the environment is communication accessible by adjusting the physical environment, including providing AAC and adjusting all written information. Patient reported outcomes (PROM's) and evaluations should always be communication accessible by adjusting written and verbal communication.

- Become aware that, besides standard verbal and nonverbal communication, AAC is an accessible solution to support dialogue conversations. Ad hoc usable AAC tools can support these 
conversations and should be readily available in rooms where dialogue conversations take place. Talking Mats, communication boards, alphabet boards, picto-books and other tools should be bought by healthcare organisations, and considering their low cost, these should not be locked up in a closet on the therapy department, but readily available on every department. ${ }^{57}$

- Collaborate in inter-professional teams to provide communication support, and make cultural changes in organisations towards acceptance of the widespread use of AAC tools. Professionals should be open to a change of habits in communication. For example, using Talking Mats to explore the goals of a client might require some adjustments to normal practice, but may enable clients to express their wishes.

- Reflect on the use of insights in this thesis in other healthcare settings. While this thesis focussed on dialogue conversations in long-term care settings, communication support is needed in all sorts of healthcare settings. The findings of the studies and the guide that was developed could also be used in primary care or hospital settings, in which dialogue conversations are equally as important as in long-term care settings.

\section{Implications for research}

- Future research should study the feasibility of the guide that was developed as part of the current research project in a larger process and effect evaluation and should incorporate the clients' and professionals' perspective in this evaluation. Important aspects to study are: if the guide is used in daily practice, the (level of) satisfaction and effectiveness of the AAC tools that were chosen as a result of using the guide, as well as the level of (actual) shared decision making that takes place while using the guide (for example, using the OPTION scale ${ }^{64}$ ).

- Future research should provide insight which accessibility strategies for written information are most effective for communication vulnerable clients.

- Research into effective implementation of the developed guide in daily practice is needed to enable the widespread availability of communication support for communication vulnerable people in healthcare settings.

- This research project focussed on communication vulnerability due to a medical condition. A broader approach can be used to explore whether our findings are also applicable to clients who are communication vulnerable due to cultural background, language or limited health literacy and vice versa.

- This study shows that communication vulnerable people should be enabled to participate in research projects instead of communication vulnerability being listed as exclusion criteria of studies. To enhance the trustworthiness of research with communication vulnerable people, all communication with them should be made accessible, and mixed-method designs or comprehensive data triangulation should be used. Clients should be involved in different research stages, dependent upon the research question and setting. The exact decisions that are taken in this regard should, however, be taken together with clients. When involving clients, it is paramount that researchers invest in the relationship with clients and are open-minded to allow for alternative ideas and opinions of clients. 


\section{Implications for education}

This thesis challenges all educational institutions in the field of healthcare to integrate in standard education programs of (future) healthcare professionals:

- Recognising communication vulnerable clients and adjusting communication to the experienced functional communication difficulties. Students should practice their communication skills with communication vulnerable people in the education programmes they follow, as well as during internships.

- Understanding the complex interplay of factors influencing communication vulnerability using the ICF, Positive Health, Person-Environment-Occupation model, or adjusted visualisations as presented in this discussion (Figure 8.2, 8.3).

- Knowing about AAC and being skilled in using AAC. Education programmes could use the guide that was developed in this research project to create (more) awareness about communication vulnerability, AAC tools, and the importance of shared decisions in communication support.

- Knowing why it is important to include (communication vulnerable) clients in (research) projects and teach in strategies to include clients in general and communication vulnerable clients more specifically. If we acknowledge the shared needs, expectations and characteristics of communication vulnerable people, new opportunities arise for their inclusion in dialogue conversations, in research and in society in general. 


\section{References}

1. de Haes $\mathrm{H}$, Bensing J. Endpoints in medical communication research, proposing a framework of functions and outcomes. Patient Educ Couns. 2009;74(3):287-294.

2. Lawn S, Schoo A. Supporting self-management of chronic health conditions: common approaches. Patient Educ Couns. 2010;80(2):205-211.

3. Lewin S, Skea Z, Entwistle VA, Zwarenstein M, Dick J. Interventions for providers to promote a patient-centred approach in clinical consultations. The Cochrane library. 2009(1).

4. Blackstone S, Beukelman D, Yorkston K. Patient-provider communication roles for speech-language pathologists and other health care professionals. San Diago, CA: Plural; 2015.

5. WorldHealthOrganization. International classification of functioning, disability and health: ICF. 2001.

6. Huber M, van Vliet M, Giezenberg M, et al. Towards a 'patient-centred' operationalisation of the new dynamic concept of health: a mixed methods study. BMJ Open. 2016;6(1):e010091.

7. Polit DF, Beck CT. Generalization in quantitative and qualitative research: Myths and strategies. International Journal of Nursing Studies. 2010;47(11):1451-1458.

8. Garett KL, Beukelman DR. Aphasia Needs Assessment. Available at: https://cehs.unl.edu/aac/aphasia-assessment-materials/. Accessed 2018-6-13.

9. Sevat RG, Heesbeen IME. Nazorg: ervaringen vanuit een praktijkgerichte behandeling. Boekblok Handboek stem- spraak- en taalpathologie. Houten: Bohn Stafleu van Loghum; 2008:1523-1530.

10. Hoedemaekers M, Looman-Bruijstens M, Cox E, van der Vloed J, Kunst-Verberne EIM. Handreikingen voor kwaliteitskringen communicatie bij dementie. 2013.

11. DynaVoxMayer-Johnson. Communication success screening tool. Available at: http://www.dynavoxtech.com/ implementation-toolkit/details.aspx?id=484. Accessed 2018-4-11.

12. Lincoln YS, Guba EG, eds. Naturalistic Inquiry. Beverly Hills: CA: SAGE; 1985.

13. Light J, McNaughton D. Designing AAC Research and Intervention to Improve Outcomes for Individuals with Complex Communication Needs. Augment Altern Commun. 2015;31(2):1-12.

14. Dalemans R, Wade DT, van den Heuvel WJ, de Witte LP. Facilitating the participation of people with aphasia in research: a description of strategies. Clin Rehabil. 2009;23(10):948-959.

15. Swinburn, K. Including People with Communication Disability in Stroke Research and Consultation. Connect Press. 2007.

16. Creswell JW. Qualitative inquiry and research design. Choosing among five approaches. Thousand Oaks, California: Sage Publications Ltd.; 2006.

17. Polit D, Beck C. Nursing research: gnerating and assessing evidence for nursing practice. 9th ed. Philedelphie (PA): Lippincott, Wiliams \& Wilkins; 2011

18. Coulter A, Stilwell D, Kryworuchko J, Mullen P, Ng C, Weijden T. A systematic development process for patient decision aids. BMC Med Inform Decis Mak. 2013;13.

19. Bartholomew LK, Parcel GS, Kok G, Gottlieb NH, ME F. Planning health promotion programs: An Intervention Mapping approach.3rd ed. San Francisco: Jossey-Bass; 2011.

20. Gulliksen J, Goransson B, Boivie I, Blomkvist S, Persson J, Cajander A. Key principles for user-centred systems design. Behaviour \& Information Technology. 2003;22(6):397-409.

21. Disabled Living Foundation. AskSARA, Guided advice about daily living. Available at: http://asksara.dlf.org.uk/. Accessed 2018-6-13.

22. Modem. Ondersteunde Communicatie. Available at: https://www.modemadvies.be/oc.html. Accessed 2018-6-13

23. Vilans. Hulpmiddelenwijzer. Available at: http://www.hulpmiddelenwijzer.nl/. Accessed 2018-6-05.

24. Governance Cla. Augmentative and Alternative Communication (AAC) Guideline for speech pathologists who support people with a disability. Family and community services, Australia; 2014.

25. de Wit M, Beurskens A, Piskur B, Stoffers E, Moser A. Preparing researchers for patient and public involvement in scientific research: Development of a hands-on learning approach through action research. Health Expect. 2018. 
26. Wylie K, McAllister L, Davidson B, Marshall J. Changing practice: implications of the World Report on Disability for responding to communication disability in under-served populations. Int J Speech Lang Pathol. 2013;15(1):1-13.

27. O'Halloran R, Coyle J, Lamont S. Screening patients for communication difficulty: The diagnostic accuracy of the IFCl staff questionnaire. Int J Speech Lang Pathol. 2017;19(4):430-440.

28. Blackstone S, Pressman H. Patient Communication in Health Care Settings: new Opportunities for Augmentative and Alternative Communication. Augment Altern Commun. 2016;32(1):69-79.

29. Taskforce JZodJP. De Juiste Zorg op de Juiste Plek. Ministerie van Volksgezondheid, Welzijn en Sport;2018.

30. Heerkens $\mathrm{YF}$, de Weerd M, Huber M, et al. Reconsideration of the scheme of the international classification of functioning, disability and health: incentives from the Netherlands for a global debate. Disabil Rehabil. 2018;40(5):603-611.

31. Huber M, Knottnerus JA, Green L, et al. How should we define health? BMJ. 2011;343:d4163.

32. Kielhofner G. Model of Human Occupation. Baltimore: Lippincott Williams \& Wilkins; 2008.

33. Townsend EA, Polatajko HJE. Enabling Occupation II: Advancing an Occupational Therapy Vision of Health, Well-being, \& Justice through Occupation. Ottawa, ON: CAOT Publications ACE; 2007.

34. Wong SR, Fisher G. Comparing and Using Occupation-Focused Models. Occup Ther Health Care. 2015;29(3):297-315.

35. Stamm TA, Cieza A, Machold K, Smolen JS, Stucki G. Exploration of the link between conceptual occupational therapy models and the International Classification of Functioning, Disability and Health. Australian Occupational Therapy Journal. 2006;53(1):9-17.

36. Kagan A. A-FROM in action at the Aphasia Institute. Semin Speech Lang. 2011;32(3):216-228.

37. Van de Velde D, De Vriendt P. Comment on: Reconsideration of the scheme of the International Classification of Functioning, Disability and Health: incentives from the Netherlands for a global debate. Heerkens et al, 2017. Disability and Rehabilitation. 2018;40(5):612-614.

38. Law M, Cooper B, Strong S, Stewart D, Rigby P, Letts L. The Person-Environment-Occupation Model: A Transactive Approach to Occupational Performance. Canadian Journal of Occupational Therapy. 1996;63(1):9-23.

39. WRR. Weten is nog geen doen. Een realistisch perspectief op redzaamheid. Den Haag: Wetenschappelijke raad voor het regeringsbeleid; 2017

40. Rademakers J. Gezondheidsvaardigheden, Niet voor iedereen vanzelfsprekend. NIVEL;2014.

41. Clarke M, Bloch S. AAC practices in everyday interaction. Augment Altern Commun. 2013;29(1):1-2.

42. United Nations. Convention on the Rights of Persons with Disabilities. 2006.

43. O'Halloran R, Lee YS, Rose M, Liamputtong P. Creating communicatively accessible healthcare environments: perceptions of speech-language pathologists. Int J Speech Lang Pathol. 2014;16(6):603-614.

44. Hemsley B, Balandin S. A metasynthesis of patient-provider communication in hospital for patients with severe communication disabilities: informing new translational research. Augment Altern Commun. 2014;30(4):329-343

45. Simmons-Mackie N, Raymer A, Cherney LR. Communication Partner Training in Aphasia: An Updated Systematic Review. Arch Phys Med Rehabil. 2016;97(12):2202-2221 e2208.

46. Wielaert S, van de Sandt-Koenderman M, Dammers N, Sage K. ImPACT: a multifaceted implementation for conversation partner training in aphasia in Dutch rehabilitation settings. Disabil Rehabil. 2018;40(1):76-89.

47. Heard R, O'Halloran R, McKinley K. Communication partner training for health care professionals in an inpatient rehabilitation setting: A parallel randomised trial. Int J Speech Lang Pathol. 2017;19(3):277-286.

48. IPAACKS. Informing and Profiling Augmentative and Alternative Communication (AAC) Knowledge and Skills. 2014. Available at: https://www.nes.scot.nhs.uk/media/2507407/nesd0214aacframework-re.pdf

49. Stans SE, Dalemans RJ, de Witte LP, Smeets HW, Beurskens AJ. The role of the physical environment in conversations between people who are communication vulnerable and health-care professionals: a scoping review. Disabil Rehabil. 2016:1-12.

50. Herbert R, Haw C, Brown C. Accessible Information Guidelines: Making Information Accessible for People with Aphasia. Stroke Association;2012.

51. Pharos. Pharos Checklist Toegankelijke informatie. 2018; http://www.pharos.nl/nl/kenniscentrum/participatie-en-eigen-regie/ empoweren-met-toegankelijke-informatie.

52. Dalemans RJ, de Witte LP, Beurskens AJ, van den Heuvel WJ, Wade DT. Psychometric properties of the community integration questionnaire adjusted for people with aphasia. Arch Phys Med Rehabil. 2010;91(3):395-399.

53. Sohlberg MM, Griffiths GG, Fickas S. An evaluation of reading comprehension of expository text in adults with traumatic brain 
injury. Am J Speech Lang Pathol. 2014;23(2):160-175.

54. Brown J, Thiessen A. Using Images With Individuals With Aphasia: Current Research and Clinical Trends. Am J Speech Lang Pathol. 2018;27(1S):504-515.

55. Thiessen A, Brown J, Beukelman D, Hux K, Myers A. Effect of Message Type on the Visual Attention of Adults With Traumatic Brain Injury. Am J Speech Lang Pathol. 2017;26(2):428-442.

56. Yorkston KM, Bourgeois MS, Baylor CR. Communication and aging. Phys Med Rehabil Clin N Am. 2010;21(2):309-319.

57. Sharpe B, Hemsley B. Improving nurse-patient communication with patients with communication impairments: hospital nurses' views on the feasibility of using mobile communication technologies. App/ Nurs Res. 2016;30:228-236.

58. Brunner M, Hemsley B, Togher L, Palmer S. Technology and its role in rehabilitation for people with cognitive-communication disability following a traumatic brain injury (TBI). Brain Inj. 2017;31(8):1028-1043.

59. Hemsley B, Balandin S, Worrall L. Nursing the patient with complex communication needs: time as a barrier and a facilitator to successful communication in hospital. J Adv Nurs. 2012;68(1):116-126.

60. Millar DC, Light JC, Schlosser RW. The impact of augmentative and alternative communication intervention on the speech production of individuals with developmental disabilities: a research review (Structured abstract). Journal of Speech Language and Hearing Research. 2006;49(2):248-264.

61. Iacono T, Lyon K, Johnson $H$, West D. Experiences of adults with complex communication needs receiving and using low tech AAC: an Australian context. Disabil Rehabil Assist Technol. 2013;8(5):392-401.

62. McNaughton D, Light J. The iPad and mobile technology revolution: benefits and challenges for individuals who require augmentative and alternative communication. Augment Altern Commun. 2013;29(2):107-116.

63. The Dutch Counsil for Public Health and Society (Raad voor Volksgezondheid en Samenleving R. No evidence without context. About the illusion of evidence-based practice in healthcare. The Hague. 2017.

64. Nicolas $C$, Sophie D, Hubert R, et al. Assessments of the extent to which health-care providers involve patients in decision making: a systematic review of studies using the OPTION instrument. Health Expectations. 2015;18(4):542-561. 
Summary 


\section{Summary}

This dissertation describes a research project about the communication between communication vulnerable people and health care professionals in long-term care settings. Communication vulnerable people experience functional communication difficulties in particular situations, due to medical conditions. They experience difficulties expressing themselves or understanding professionals, and/ or professionals experience difficulties understanding these clients. Dialogue conversations between clients and professionals in healthcare, which for example concern health-related goals, activity and participation choices, diagnostics, treatment options, and treatment evaluation, are, however, crucial for successful client-centred care and shared decision making. Dialogue conversations facilitate essential exchanges between clients and healthcare professionals, and both clients and professionals should play a significant role in the conversation. It is unknown how communication vulnerable people and their healthcare professionals experience dialogue conversations and what can be done to support successful communication in these conversations.

The aim of this research is to explore how communication vulnerable clients and professionals experience their communication in dialogue conversations in long-term care and how they can best be supported in improving their communication in these conversations.

To achieve this, the following questions are addressed:

1. Which challenges do communication vulnerable clients and those in their social environment experience in their communication in dialogue conversations in the context of long-term care settings?

2. How can communication vulnerable clients and professionals together support their communication using ad hoc usable AAC during dialogue conversations in long-term care settings?

3. How can researchers include (communication vulnerable) clients in research projects?

The broad perspective in this thesis on communication vulnerability, regardless of the underlying diagnosis, provides new chances and possibilities to facilitate communication in long-term care.

Chapter 1 starts with an introduction of the concept of communication and highlights the importance of communication in dialogue conversations in healthcare. The chapter then focusses on the target group of communication vulnerable people, it describes communication vulnerability using the ICF framework and two case examples. Further insight is given into the need for communication support for dialogue conversations in which communication vulnerable clients participate, and the potential of AAC to support these conversations. AAC includes any method, strategy or resource that can help people communicate more successfully, such as formal assistive devices (e.g. speech generating devices), communication tools (e.g. picto-books), conventional semiotic communication (e.g. handwriting), unaided resources (e.g. gesture), and commonplace objects (e.g. maps or smartphones). Furthermore, client participation is introduced as a central topic in this research project At the end of the first chapter the objective, research questions and outline of this thesis are delineated. 
Chapter 2 presents the study and findings concerning the first research question about the experiences with communication in long-term settings of communication vulnerable clients and people in their immediate environment. It also provides insights concerning the factors that influence the communication in long term care settings. By means of a qualitative study using the critical incident method we aimed to contribute to the understanding of communication challenges in long-term care. Thirty-nine individuals, of which fourteen were clients, in three settings participated in the interviews. Specific challenges with communication are described for three different (kinds of) relationships, communication between clients and professionals, communication among clients, and communication between family members and professionals. The main influencing factors in the communication between clients and professionals were: the effort put into improving the communication, the knowledge of the professional, AAC, time for communication and the influence and power of the client. The results show that communication vulnerable clients and those in their environment experience daily challenges when it comes to communication. And while AAC has the potential for meaningfully improving communication, it is only rarely used.

Chapter 3 describes a qualitative study which provides an in-depth exploration of the experiences in communication between communication vulnerable clients and professionals during dialogue conversations in long-term care settings. It aims to further answer the first research question by providing insight into how communication vulnerable clients and health-care professionals experience communication in dialogue conversations, and how they adjust their conversations using ad hoc usable AAC or other communication strategies. This qualitative study used a naturalistic approach consisting of interviews ( $n=22)$ and observations of dialogue conversations $(n=11)$. The study shows that professionals have difficulties using appropriate communication strategies tailored to the communication vulnerability of clients. Professionals relied mostly on verbal and nonverbal strategies and did not use AAC. Key themes that emerged from the analysis of the experiences of clients and professionals were: clients blame themselves for miscommunications, the relevance of both parties preparing the conversation, a quiet and familiar environment benefits communication, giving clients enough time, the importance and complexity of nonverbal communication, and the need to tailor communication to the client. The study highlights the prejudices towards and inexperience with AAC of professionals and clients. We conclude that professionals and clients need to be informed about the potential of AAC, and about how it can help them achieve equal participation in dialogue conversations in addition to other communication strategies.

In addition to looking into the nature of and issues surrounding communication between communication vulnerable clients and professionals in long-term care settings, studies were also conducted to provide insight into how the physical environment can be shaped to support dialogue conversations. Chapter 4 focusses on the role of the physical environment in dialogue conversations with communication vulnerable people. In order to assess what factors in the physical environment influence such dialogue conversations a scoping review was conducted. The PubMed, PsycINFO, CINAHL and Cochrane Library databases were screened for relevant literature, and a descriptive and thematic analysis was completed 
of the selected literature. Sixteen articles reported on factors in the physical environment during dialogue conversations. The articles relied upon the observations of researchers, the views of healthcare professionals, the existing literature or the knowledge of the authors. Only four studies included the views of communication vulnerable people. Barriers and strategies in the physical environment that were identified in the sixteen articles can be categorised in one of six categories: lighting, acoustic environment, humidity and temperature, setting and furniture placement, written information, and availability of AAC tools. We conclude that relatively small and simple strategies to adjust the physical environment (such as adequate lighting, a quiet environment, the availability and use of AAC tools) can support communication vulnerable people to be more involved in conversations.

A second scoping review was done in order to further explore the potential of using AAC tools in dialogue conversations, and this scoping review and its results are described in Chapter 5. More specifically, this second scoping review focussed on one specific AAC tool, Talking Mats, as this tool seemed to be a promising, accessible and ad hoc usable AAC tool for communication vulnerable people.

The objective of the review was twofold: first, to provide an overview of the objectives and the target groups with which, and settings in which Talking Mats has been used (part 1), and, secondly, to provide an overview of empirical scientific knowledge on the use of Talking Mats (part 2). For both part 1 and 2 scientific and grey literature was searched in PubMed, Cinahl, Psychinfo, Google, and Google Scholar. For part 2, additional selection criteria were applied to focus on empirical scientific knowledge. Information in the selected articles were synthesised using descriptive data and conventional content analysis. Seventy-three publications were included in part 1, of which 12 were empirical studies and included in part 2 of the study. Part 1 of the scoping review illustrates that Talking Mats can be used for functional objectives such as goal setting and improving communication and involvement. The included studies used Talking Mats in different settings for people with communication difficulties, learning disabilities, dementia, Huntington's disease, frail older people, and children. The second part of the scoping review shows that Talking Mats had positive influences on technical communication, effectiveness of conversations, and involvement and decision making in conversations. However, the level of research evidence of the included studies was often limited, and the included studies might be biased as some of them were conducted by the developers or distributors of Talking Mats. Future rigorous research should consist of in-depth qualitative user-reported studies on the feasibility and effectiveness of Talking Mats and other AAC tools.

The results of the studies described in chapters 2-5 were used as input for the development of a guide (website) that is described in Chapter 6. This guide (website) was developed to support professionals and communication vulnerable clients in selecting easy to use ad hoc usable AAC for their dialogue conversations. Chapter 6 describes the development and the evaluation of the usability of the guide (third research question). An iterative user-centred research design was followed to involve professionals and communication vulnerable clients intensively during the development and usability testing. The website was developed by means of three cycles. During these cycles the usability of prototypes was 
evaluated in semi-structured and think-aloud interviews with clients, professionals and experts, as well as questionnaires with experts.

The second cycle of usability testing showed that clients found the guide useful, but that they suggested to adjust answering options. Practitioners saw potential for use in daily practice, but recommended including questions about physical (dis)abilities. Much attention was paid to developing a guide that is understandable for communication vulnerable clients, for example by using visualisations and by adjusting the amount and complexity of text. In the final version of the website (as far as this research project is concerned) clients and practitioners answer questions about communication difficulties and, based upon their responses, a list of specific ad hoc usable AAC is presented with details about each of the tools. Examples of AAC that are included in the website are pen and paper, communication boards and Talking Mats. Further research is recommended to investigate whether the guide can improve dialogue conversations.

In order to improve healthcare processes such as dialogue conversations, it is important to include the voice of clients in research. To provide insights into the process of including clients in research, a qualitative study was conducted about the experiences that six junior researchers have had with client participation during various research projects with different client groups. The findings of this study are presented in chapter 7. Qualitative interviews were conducted and data were analysed using the method of conventional content analysis. The results show that researchers worked together with various clients, (from individual clients, to parents of children with a disability, to patient counsels, to citizen counsels) on different levels (from consultation to control) in different research phases.

The experiences of junior researchers reflect three important themes, collaboration between researcher and client, integrating client participation in the research project, and the impact (of applying client participation and receiving coaching) on the role development of the researcher. Several lessons learned are formulated with regard to the level of client participation, collaboration between researchers and clients, integrating client participation in the research project and coaching of researchers in client participation. For institutions it appears to be important to have attention for the experiences of junior researchers and to educate junior and senior researchers using reflective sessions, co-learning, and individual coaching.

In chapter 8, the main findings related to the three research questions are presented, followed by a discussion of the methodological considerations of the research project with regard to the complexity and conceptualisation of communication vulnerability, the use of qualitative methods in research with communication vulnerable people, the user-centred approach, and client participation in research. Involving communication vulnerable people in research is regarded as valuable is this research project. However, trying to involve and effectively involving them can lead to methodological challenges. This chapter describes strategies that can be (or are already being) used to target these challenges, and that might, as such, be useful for other researchers in this field. The chapter also outlines the lessons that 
were learnt with regard to awareness of communication vulnerability, communication support, and research in collaboration with communication vulnerable people. Chapter 8 closes with an insight into implications of the findings of this research project for practice, research and education. An important implication of the research project is that more awareness of communication vulnerability is needed. Although attention is given to communication with clients in healthcare (education), extra attention should be paid to (developing) knowledge, skills, and tools to communicate with communication vulnerable people, especially in dialogue conversations. Furthermore, AAC should be used to support communication vulnerable people to express themselves and to enable them to understand others in dialogue conversations. Many easily available tools and strategies in the physical environment have potential for improving dialogue conversations, but are not used in daily practice yet. The guide that was developed as part of this research project could support communication vulnerable people and professionals in long-term care settings to jointly identify communication difficulties and search for adequate communication support. Still, further research is needed to assess the effectiveness and implementation of the guide. 
Samenvatting 


\section{Samenvatting}

Dit proefschrift beschrijft een onderzoeksproject over de communicatie tussen communicatiekwetsbare personen en gezondheidszorgprofessionals in de langdurige zorg. Communicatiekwetsbare personen ervaren functionele communicatieve moeilijkheden in bepaalde situaties als gevolg van een medische aandoening. Ze ervaren moeilijkheden in het uiten van zichzelf en/of het begrijpen van professionals. Professionals kunnen moeilijkheden ervaren in het begrijpen van deze personen. Gesprekken tussen cliënten en professionals zijn echter essentieel voor gezamenlijke besluitvorming en succesvolle cliënt-gecentreerde zorg. Dialooggesprekken zijn belangrijke gesprekken in het zorgproces van de cliënt waarin zowel cliënt als professional een belangrijke rol dient te hebben en die van invloed zijn op het vervolg van het zorgproces. Voorbeelden van dialooggesprekken zijn gesprekken over activiteiten en participatiekeuzes, gezondheid gerelateerde doelen, diagnostiek, behandelopties en evaluatie van behandeling. Het is niet bekend hoe communicatiekwetsbare cliënten en professionals dialooggesprekken ervaren en hoe zij ondersteund kunnen worden om te komen tot succesvolle communicatie tijdens deze gesprekken.

Het doel van dit onderzoeksproject is om te achterhalen hoe communicatiekwetsbare cliënten en professionals hun communicatie in dialooggesprekken in de langdurige zorg ervaren en hoe zij optimaal ondersteund kunnen worden in het verbeteren van de communicatie in deze gesprekken. Om dit doel te bereiken worden de volgende vragen gesteld:

1. Welke communicatieve uitdagingen ervaren communicatiekwetsbare cliënten en de personen in hun directe sociale omgeving tijdens dialooggesprekken in de langdurige zorg?

2. Hoe kunnen communicatiekwetsbare cliënten en professionals samen hun communicatie tijdens dialooggesprekken in de langdurige zorg verbeteren, middels de inzet van ad hoc te gebruiken ondersteunde communicatie?

3. Hoe kunnen onderzoekers (communicatiekwetsbare) cliënten betrekken bij onderzoeksprojecten? De brede kijk op de doelgroep communicatiekwetsbare cliënten biedt nieuwe kansen en mogelijkheden om deze doelgroep te ondersteunen bij communicatie in de langdurige zorg.

Hoofdstuk 1 begint met een introductie in het onderwerp communicatie en beschrijft het belang van effectieve communicatie in dialooggesprekken in de gezondheidszorg. Daarna wordt de doelgroep communicatiekwetsbare personen geïntroduceerd door middel van het ICF model en twee fictieve casussen. Vervolgens wordt de noodzaak voor het gebruik van ondersteunde communicatie voor deze doelgroep beschreven. Ondersteunde communicatie wordt in dit proefschrift beschouwd als elke methode, strategie of middel die personen kan helpen om effectiever te communiceren. Voorbeelden zijn communicatiehulpmiddelen (zoals pictogrammenboekjes), reguliere communicatie (zoals praten, schrijven), communicatie zonder hulpmiddelen (zoals gebaren) en dagelijkse voorwerpen (zoals foto's of telefoons). In dit hoofdstuk wordt tevens het onderwerp cliëntparticipatie in onderzoek geïntroduceerd. Aan het einde van het hoofdstuk worden het doel, de onderzoeksvragen en structuur van het proefschrift beschreven. 
Hoofdstuk twee beschrijft de eerste studie, gerelateerd aan de eerste onderzoeksvraag. Middels een kwalitatief onderzoek werd getracht de communicatieve uitdagingen van communicatiekwetsbare personen en hun omgeving beter te begrijpen. Negenendertig personen, waaronder 14 cliënten, werden geïnterviewd volgens de 'critical incident' methode. De resultaten beschrijven de ervaringen van communicatiekwetsbare personen en personen in hun omgeving met communicatie in zorginstellingen. Ook wordt inzicht gegeven in de factoren die communicatie met deze doelgroep in zorginstellingen beïnvloeden in drie communicatieve relaties: communicatie tussen cliënten en professionals, communicatie tussen cliënten onderling, communicatie tussen professionals en mantelzorgers. Het meest prominent zijn de factoren die de communicatie tussen cliënten en professionals beïnvloeden: de moeite die wordt gestoken in het verbeteren van de communicatie; de kennis van de professional; het gebruik van ondersteunde communicatie; de tijd die wordt gebruikt voor communicatie; de invloed en rol van de cliënt. De resultaten van deze studie laten zien dat communicatiekwetsbare cliënten en personen in hun omgeving dagelijks moeilijkheden ervaren in de communicatie. Ondersteunde communicatie heeft veel potentie om deze moeilijkheden op te lossen, maar wordt zelden gebruikt.

Hoofdstuk drie beschrijft een tweede kwalitatieve studie welke dieper ingaat op de ervaringen tussen cliënten en professionals, specifiek in dialooggesprekken. In deze studie wordt ook onderzocht welke communicatieve strategieën zij gebruiken om communicatie te verbeteren in dialooggesprekken. De methode 'naturalistic inquiry' werd gebruikt om inzicht te krijgen in ervaringen tijdens alledaagse situaties. Elf observaties van dialooggesprekken werden uitgevoerd en 22 interviews werden afgenomen met cliënten en professionals. De resultaten laten zien dat professionals moeite hadden om hun communicatie af te stemmen op de communicatieve moeilijkheden van de cliënten. Terwijl cliënten vaak moeite hadden met praten of begrijpen, vertrouwden professionals met name op verbale en non-verbale communicatie en gebruikten geen ondersteunde communicatie. Belangrijke thema's in de ervaringen van cliënten en professionals zijn: cliënten geven zichzelf de schuld van miscommunicaties; de relevantie van het voorbereiden van dialooggesprekken door beide partijen; een rustige en vertrouwde omgeving; cliënten voldoende tijd geven; het belang en de complexiteit van non-verbale communicatie; de noodzaak tot het aanpassen van de communicatie aan de cliënt. Deze studie onthult tevens de vooroordelen over en gebrek aan ervaring met ondersteunde communicatie van cliënten en professionals. Geconcludeerd wordt dat cliënten en professionals geïnformeerd moeten worden over hoe communicatiehulpmiddelen gebruikt kunnen worden, om betekenisvolle dialooggesprekken te voeren waarin de cliënt actief participeert.

Hoofdstuk vier draagt bij aan de tweede onderzoeksvraag, door te onderzoeken hoe de fysieke omgeving ingezet kan worden om dialooggesprekken met communicatiekwetsbare cliënten te verbeteren. Een literatuuronderzoek middels de methode 'scoping review' werd uitgevoerd om factoren in de fysieke omgeving te identificeren die invloed hebben op dialooggesprekken met de doelgroep. De databanken PubMed, PsycINFO, CINAHL en COCHRANE werden doorzocht op relevante artikelen. Zestien artikelen bleken te voldoen aan de selectiecriteria en relevante informatie werd geëxtraheerd middels een thematische en beschrijvende data-analyse. Van deze 16 artikelen bleken maar 4 artikelen 
de ervaringen van cliënten mee te nemen in hun resultaten. De andere artikelen baseerden hun informatie op basis van observaties van onderzoekers, inzichten van professionals, bestaande literatuur of de kennis van de auteurs zelf. De factoren in de fysieke omgeving die belangrijk blijken, zijn: licht, geluid, vocht en temperatuur, inrichting van de ruimte, geschreven informatie en beschikbaarheid van communicatiehulpmiddelen. Op basis van de resultaten van dit literatuuronderzoek kan gesteld worden, dat relatief kleine of simpele strategieën in de fysieke omgeving communicatiekwetsbare cliënten kunnen ondersteunen om te participeren in dialooggesprekken.

De resultaten van een tweede literatuuronderzoekzijn beschreven in hoofdstuk 5. Dit literatuuronderzoek werd uitgevoerd om meer zicht te krijgen op de potentie van het communicatiehulpmiddel Talking Mats. Talking Mats leek namelijk veelbelovend en toegankelijk te zijn voor communicatieve ondersteuning voor deze brede doelgroep. Het doel van dit literatuuronderzoek (scoping review) was tweeledig: een overzicht geven in voor wie en in welke setting Talking Mats gebruikt kan worden en voor welke doeleinden enerzijds (deel 1); en een overzicht van de empirische wetenschappelijke kennis over het gebruik van Talking Mats anderzijds (deel 2). Literatuur werd gezocht in de databanken PubMed, Cinahl, Psyclnfo, Google en Google Scholar. Voor deel 1 werd zowel grijze als wetenschappelijke literatuur gebruikt, voor deel 2 enkel empirisch wetenschappelijke literatuur. Voor deel 1 werden 73 artikelen gebruikt, waarvan er 12 werden gebruikt voor deel 2. De resultaten van deel 1 laten zien dat Talking Mats wordt gebruikt voor het verbeteren van de communicatie en het verbeteren van de betrokkenheid van de cliënt, maar ook voor functionele doeleinden zoals doelen stellen. Talking Mats wordt in verschillende settingen voor verschillende doelgroepen die communicatiekwetsbaar zijn gebruikt, zoals voor mensen met een verstandelijke beperking, dementie of de ziekte van Huntington. Maar ook voor kwetsbare ouderen of kinderen. Deel 2 van het literatuuronderzoek laat zien dat Talking Mats een positieve invloed kan hebben op technische aspecten van communicatie, effectiviteit van gesprekken, en betrokkenheid en besluitvorming van de cliënt in gesprekken. Deze resultaten moeten echter met zorg worden geïnterpreteerd. De studies waarop deze gebaseerd waren konden beïnvloed zijn door de ontwikkelaars van Talking Mats, die namelijk vaak ook optraden als gesprekspartner of als onderzoeker. Vervolgonderzoek naar Talking Mats en andere communicatiehulpmiddelen is nodig, in dergelijke onderzoeken dient de ervaring van cliënten en de effectiviteit en bruikbaarheid van hulpmiddelen onderzocht te worden.

De resultaten van de studies in hoofdstuk 2 tot en met 5 werden gebruikt om een keuzehulp-website te ontwikkelen. Deze keuzehulp kunnen cliënten en professionals gebruiken om ad hoc ondersteunde communicatie hulpmiddelen te selecteren die hun dialooggesprek kan verbeteren. De ontwikkeling en evaluatie van deze keuzehulp is volgens een 'user centred design' beschreven in hoofdstuk $\mathbf{6}$. In dit onderzoeksproject werden communicatiekwetsbare cliënten en professionals intensief betrokken. Het project bestond uit drie fasen, waarin de keuzehulp werd geëvalueerd middels semigestructureerde interviews, 'think aloud' interviews en vragenlijsten. Tijdens de ontwikkeling van de keuzehulp werd er veel aandacht besteed aan het toegankelijk maken van de keuzehulp voor communicatiekwetsbare cliënten, bijvoorbeeld middels het gebruik van afbeeldingen en korte zinnen. Tijdens evaluaties gaven 
cliënten, professionals en experts aan dat de keuzehulp bruikbaar was voor de dagelijkse zorgpraktijk. Tevens werden verschillende suggesties voor verbetering doorgevoerd. Zo wilden cliënten graag een 'soms' optie toevoegen aan de vragen over communicatieve moeilijkheden. In de laatste versie van de keuzehulp (www.communicatiekeuzehulp.nl), vormgegeven in een website, beantwoorden cliënten en professionals samen 11 vragen, daarna wordt op basis van hun antwoorden een lijst van ondersteunde communicatie hulpmiddelen gepresenteerd die hen kan helpen om hun dialooggesprek te verbeteren. Voorbeelden van ondersteunde communicatie hulpmiddelen die in de lijst kunnen voorkomen zijn Talking Mats, pictogrammenboekjes en pen en papier. Verder onderzoek is noodzakelijk om te achterhalen of de keuzehulp dialooggesprekken daadwerkelijk kan verbeteren.

Hoewel cliënten veel bij de onderzoeken uit dit proefschrift zijn betrokken, is dit niet vanzelfsprekend. Om meer inzicht te verkrijgen in hoe onderzoekers het ervaren om cliëntparticipatie toe te passen in onderzoek, is er een kwalitatief onderzoek uitgevoerd. In dit onderzoek, beschreven in hoofdstuk 7, werden zes junior onderzoekers bevraagd naar hun ervaringen met cliëntparticipatie tijdens hun promotieonderzoek. Data werden verzameld middels semigestructureerde interviews en geanalyseerd middels 'conventional content analysis'. De resultaten laten zien dat de onderzoekers met een variëteit aan cliënten samenwerkten (individuen tot ouders tot cliëntenraden) in verschillende onderzoeksfases (van vraagverheldering tot data-analyse) op verschillende niveaus van participatie (van consultatie in interviews, tot samenwerking in publicaties). De ervaringen van de onderzoekers zijn beschreven in drie thema's: samenwerking tussen cliënt en onderzoeker; integreren van cliëntparticipatie in het onderzoekproject; en de impact van cliëntparticipatie op de ontwikkeling van de onderzoeker. De ervaringen van junior onderzoekers geven implicaties voor coaching van junior en senior onderzoekers over cliëntparticipatie in onderzoek.

In hoofdstuk 8 wordt een discussie van dit proefschrift beschreven. In deze discussie komen de belangrijkste resultaten naar voren, worden de methodologische overwegingen besproken, de lessen die geleerd zijn gepresenteerd en de implicaties van de resultaten besproken. In de methodologische overwegingen is er met name aandacht voor de complexiteit van het betrekken van een communicatiekwetsbare doelgroep in dit onderzoek. Methodologische uitdagingen, maar ook gebruikte strategieën om de doelgroep te betrekken worden besproken. De lessen die geleerd zijn worden beschreven met betrekking tot: bewustzijn over de doelgroep communicatiekwetsbare cliënten, potentie van ondersteunde communicatie, en onderzoek met communicatiekwetsbare cliënten. Het hoofdstuk concludeert dat meer bewustzijn nodig is over de grote doelgroep communicatiekwetsbare cliënten en over de kennis, vaardigheden en hulpmiddelen die nodig zijn om effectief met hen te communiceren in dialooggesprekken. Elementen in de fysieke omgeving kunnen gebruikt worden om dialooggesprekken te ondersteunen. De communicatiekeuzehulp kan cliënten en professionals ondersteunen bij het identificeren van communicatieve moeilijkheden en het selecteren van bijpassende ondersteunde communicatiehulpmiddelen. De effectiviteit van de communicatiekeuzehulp dient in verder onderzoek te worden aangetoond vooraleer de keuzehulp geïmplementeerd kan worden in de praktijk. 


\section{Toegankelijke samenvatting}




\section{Toegankelijke samenvatting}

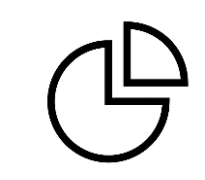

Dit boek gaat over meerdere onderzoeken.
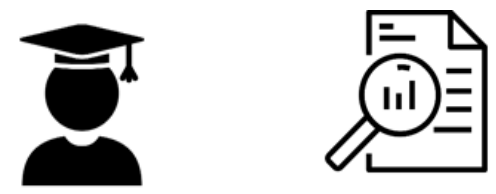

De onderzoeken gaan over communicatie in de zorg.

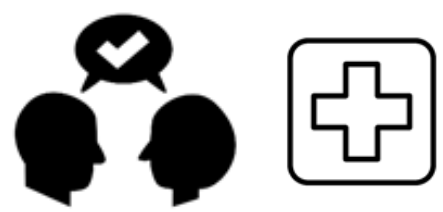

Over mensen die moeite hebben met praten of begrijpen.

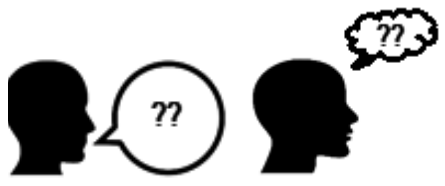

Als mensen ziek zijn, is communiceren soms moeilijk.

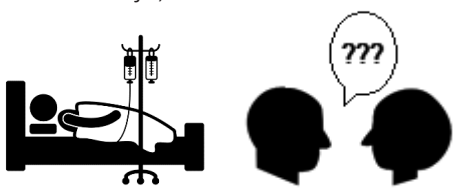


Wij noemen deze mensen: communicatie-kwetsbaar

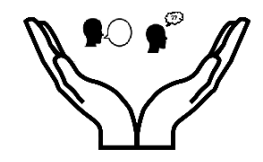

Het doel is verbeteren van de communicatie.
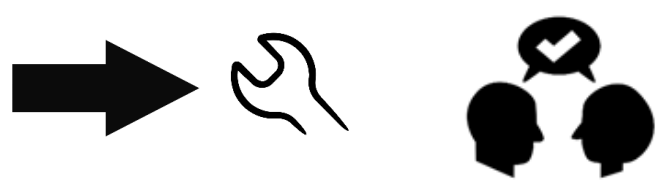

De communicatie tussen cliënten en zorgverleners.
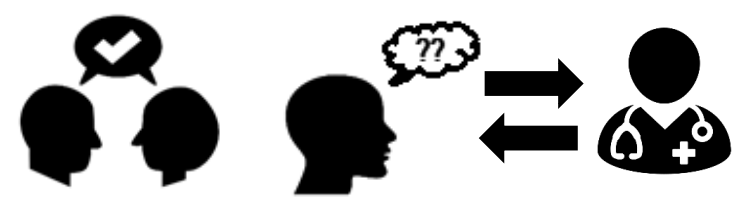

Het gaat over communicatie in de langdurige zorg.
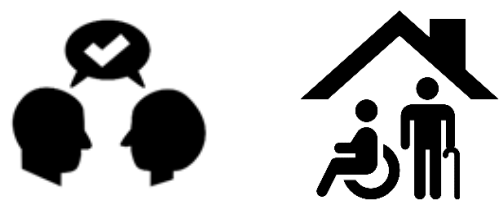
De zorg moet passen bij de behoeften van cliënten.
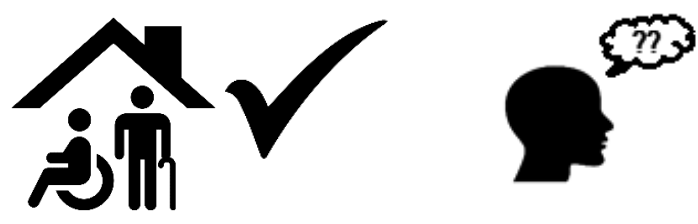

Het onderzoek bestaat uit $\mathbf{6}$ deel onderzoeken.

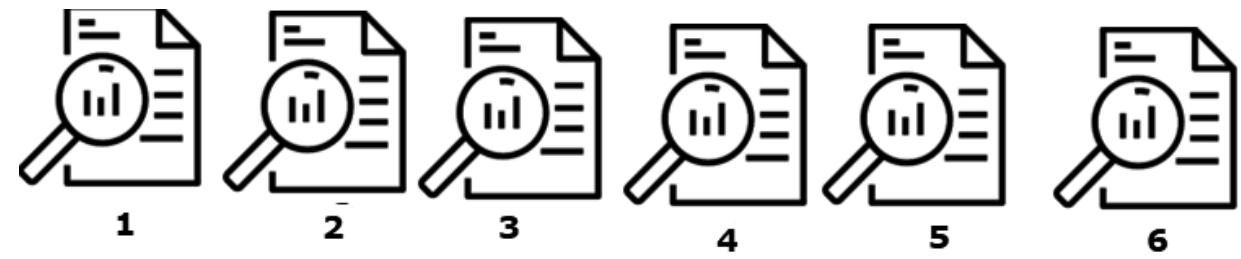




\section{Onderzoek 1}

Communicatie in de langdurige zorg

Onderzoek met cliënten, zorgverleners en familie.
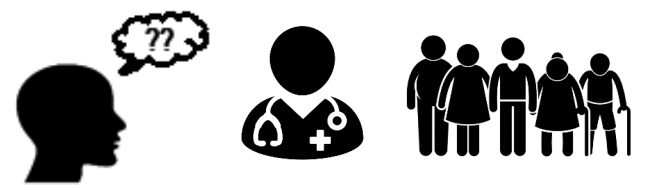

Zij zijn geïnterviewd.

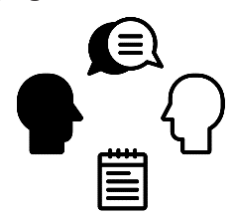

Over hoe zij de communicatie ervaren.

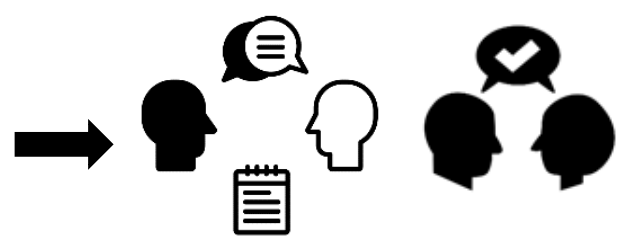




\section{Resultaten}

Communicatie tussen cliënten is soms moeilijk.

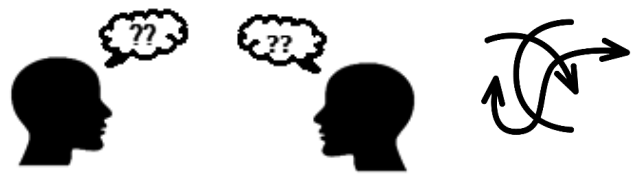

Mantelzorgers willen betrokken worden.

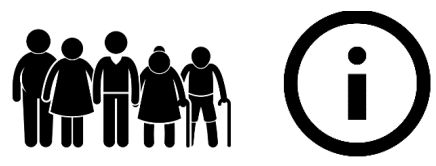

Communicatie tussen cliënten en zorgverleners is moeilijk.

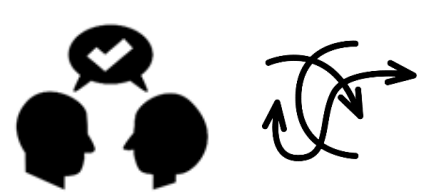

Cliënten hebben tijd nodig om te communiceren.

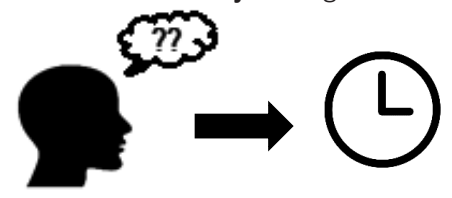


Zorgverleners hebben niet altijd voldoende kennis.

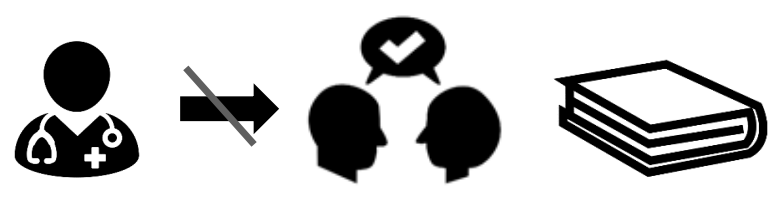

Er worden geen hulpmiddelen gebruikt voor communicatie.

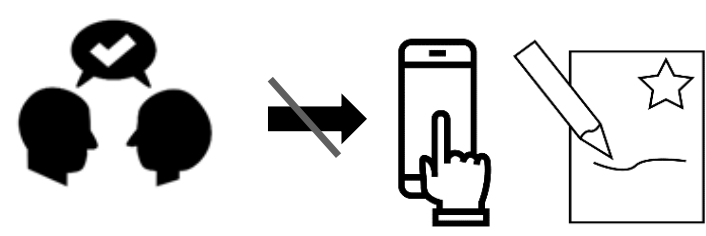




\section{Onderzoek 2}

Gesprekken tussen cliënten en zorgverleners.

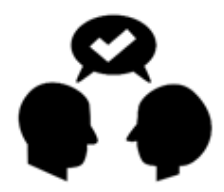

Het onderzoek bestaat uit interviews en observaties.

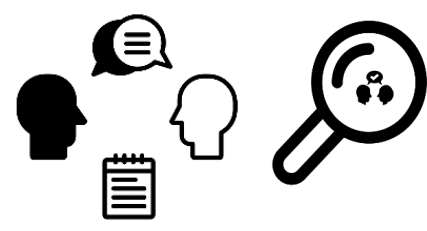

\section{Resultaten}

Het helpt als je een gesprek voorbereidt.

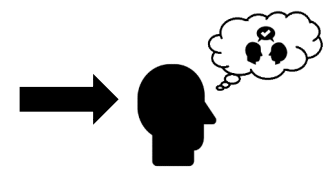

Een rustige en vertrouwde omgeving helpt.

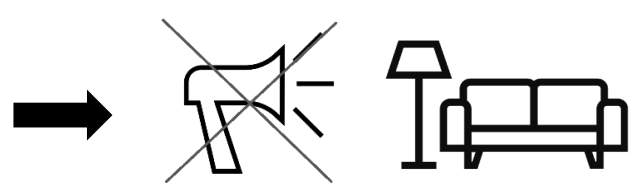

Communicatie zonder woorden is belangrijk

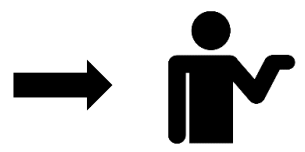


Er worden geen hulpmiddelen gebruikt voor communicatie.
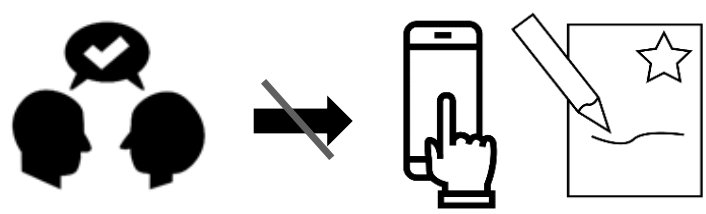


\section{Onderzoek 3}

De omgeving van gesprekken

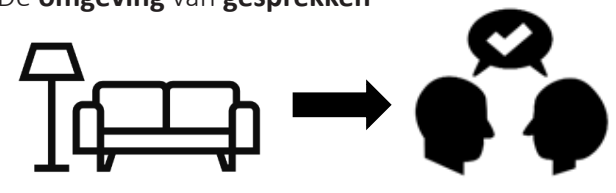

Het onderzoek bestaat uit het lezen van boeken en artikelen

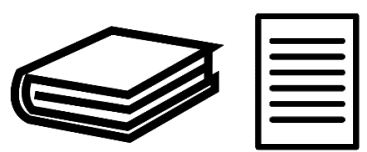

Resultaten

De omgeving kan communicatie verbeteren:

Licht

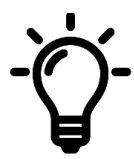

Weinig Geluid

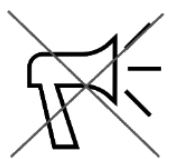

Vocht en temperatuur

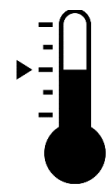


Inrichting van de ruimte

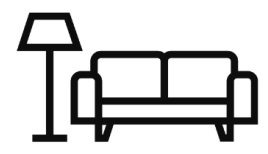

Geschreven informatie

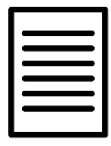

Hulpmiddelen voor communicatie

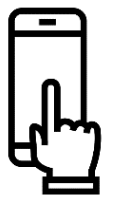




\section{Onderzoek 4}

Het hulpmiddel Talking Mats

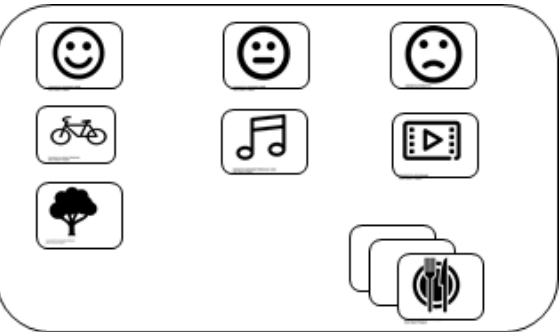

Het onderzoek bestaat uit het lezen van boeken en artikelen

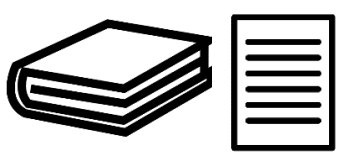

Resultaten

Talking Mats kan de communicatie verbeteren

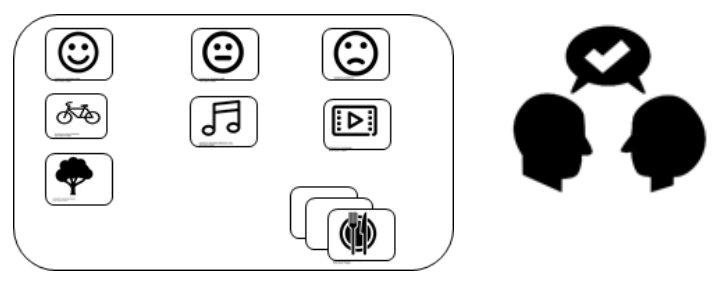

Met Talking Mats kan je beter meedoen in het gesprek

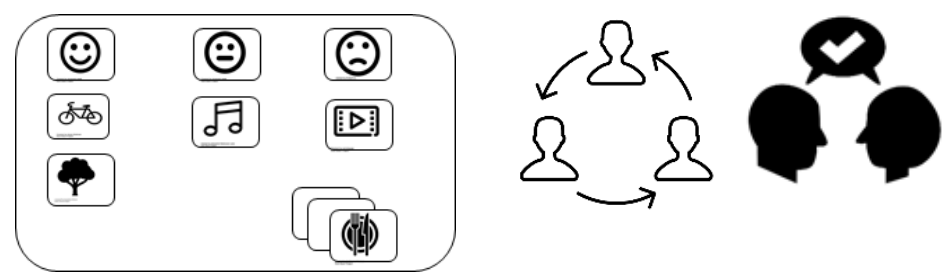




\section{Onderzoek 5}

\section{De communicatie-keuzehulp}

In het onderzoek is een communicatie-keuzehulp gemaakt.

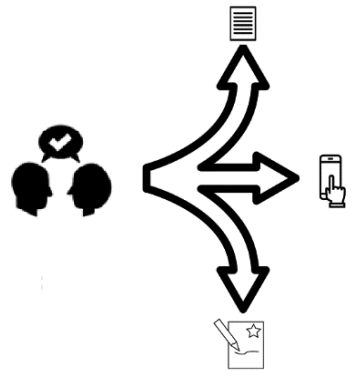

De keuzehulp helpt communicatie hulpmiddelen te kiezen
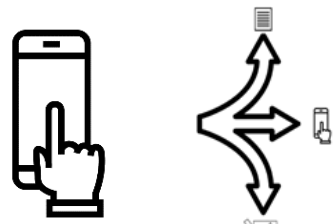

Cliënten en zorgverleners hebben de keuzehulp getest
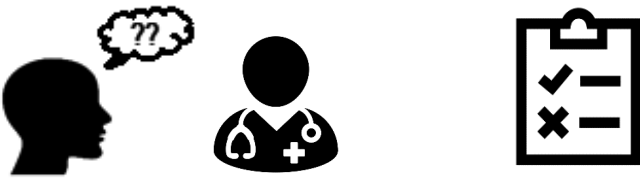
Resultaten

Cliënten en zorgverleners gaven tips
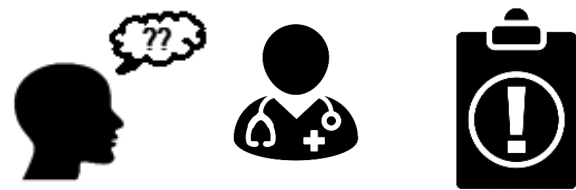

De keuzehulp is aangepast

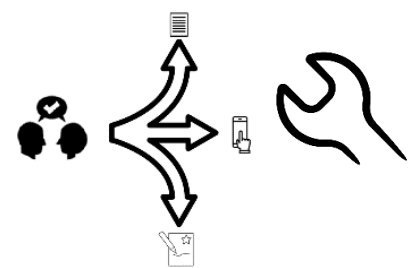

Cliënten en zorgverleners vonden de keuzehulp goed.
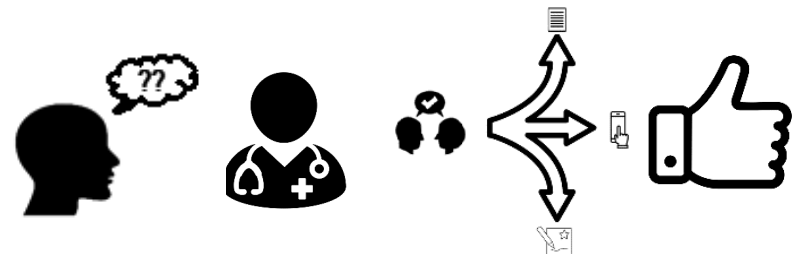

www.communicatiekeuzehulp.nl 


\section{Onderzoek 6}

Cliënten werken samen met onderzoekers

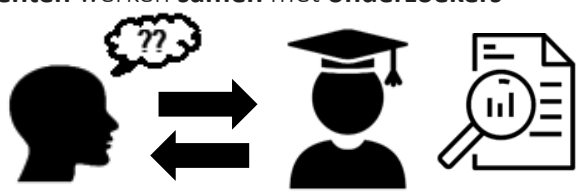

Resultaten

Samenwerking tussen cliënt en onderzoeker is belangrijk.

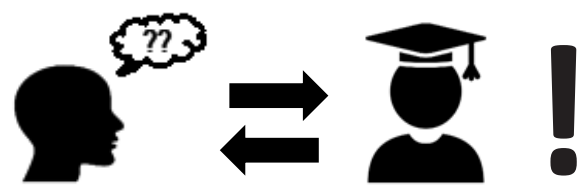

Tijd en geld zijn nodig.
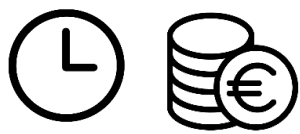

Het hele onderzoeks-team moet meedoen.

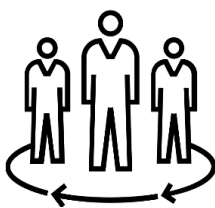

Onderzoekers moeten leren samenwerken met cliënten.
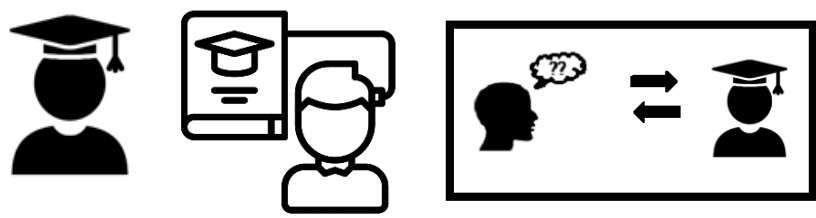


\section{Conclusie Boek}

Veel mensen zijn communicatie-kwetsbaar.
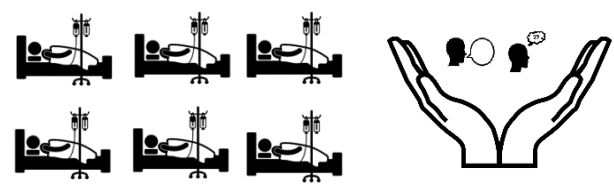

Men is zich niet bewust van communicatie-kwetsbaren
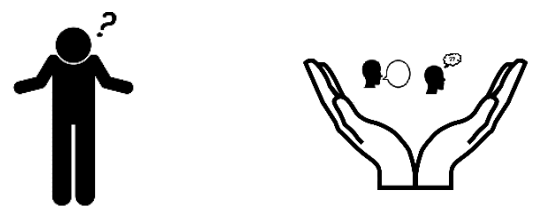

We moeten hulpmiddelen gebruiken voor communicatie
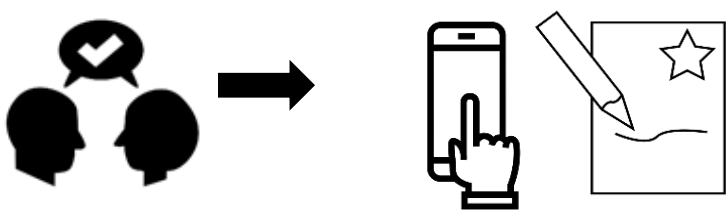

De communicatie-keuzehulp kan helpen kiezen

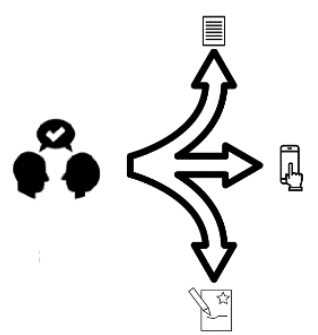




\section{Cliënten moeten meer meedoen in onderzoek}
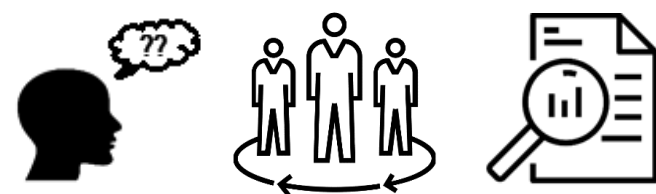

Deze samenvatting is ontwikkeld met gebruik van symbolen van The Noun Project. De symbolen zijn ontwikkeld door de volgende leden van The Noun Project: By Gan Khoon Lay, Makaranko Andrey, Marie Van den Broeck, Marek Polakovic, Studiographic, Weltenraser, Ami, SBTS, Jennifer Morrow, Maxim Kulikov, y Numero Uno Josh Sorosky, Mat fine, ID, Rockicon, Creative Stall, PK, Lastspark, RU. 


\section{Valorisation}




\section{Valorisation}

The aim of the research project in this dissertation was to explore how communication vulnerable clients and professionals experience their communication in dialogue conversations in long-term care, and how they can best be supported in improving their communication. Our findings reveal that widespread awareness of communication vulnerability, and more communication support in dialogue conversations is needed to enable communication vulnerable people to participate in dialogue conversations and in their healthcare process. The findings of this dissertation provide insights and practical tools that clients, professionals and researchers can use to give clients a voice in their healthcare process and in research projects. In this chapter the relevance and innovativeness of the findings and the value of the findings for different stakeholders is described. Furthermore, activities for implementation and further dissemination are presented.

\section{Relevance and innovativeness}

Communication vulnerability makes it difficult for clients to engage in conversations with their healthcare professionals, they experience difficulties expressing themselves and/or understanding the professional. The acknowledgement of this broad target group is relevant, since, due to the complexity and multimodality of communication, a large number of clients in healthcare environments are communication vulnerable. Moreover, this group is expected to increase due to medical advances, an aging population, and an increase in the amount of people with chronic conditions. Our studies raise awareness of the complexity of the target group of communication vulnerable people. Their vulnerability does not only relate to diagnostic factors, but relates to functional communication difficulties due to the interplay of personal and environmental factors. The focus on functional communication difficulties in this target group, rather than on diagnosis, was innovative. During the publication process of articles in this dissertation, several journal reviewers had difficulties with acknowledging this broad target group, and advised to focus on individual medical diagnoses. However, to improve communication with communication vulnerable people in long-term care, it is beneficial to look at which communication difficulties are experienced, rather than to look only at the diagnosis that is the cause of the communication difficulty. Moreover, perspectives on the concept of health are changing, and the concept of communication vulnerability suits to recent developments in the Netherlands and internationally with regard to the perception of health and acknowledgement of vulnerable groups. ${ }^{1-3}$ Recently attention has been given to adjusting communication for people with limited health literacy, however, the group of people who are communication vulnerable due to a medical condition is mostly overlooked.

The acknowledgement of the broad target group of communication vulnerable people is rather unknown, while the use of the term 'communication vulnerability' can contribute to awareness of communication vulnerability both in health care institutions as in society. Communication vulnerability puts a strain upon meaningful communication in dialogue conversations, which can result in deficits in goalsetting, shared decision making, self-management and client centred care. Dialogue conversations 
are important conversations between clients and professionals which are of influence on the care process. It is important that everybody can have a voice in his own care process. The convention of the Rights of Persons with Disabilities of the United Nations, which has been acknowledged in 2016 by the Dutch Government, states the importance of the right for people to express themselves and understand others. ${ }^{4}$

Article 21 of the Convention on the Rights of Persons with Disabilities (United Nations, 2006) acknowledges the importance of people with disability being able to exercise their right to freedom of expression and opinion, including the freedom to seek, receive and impart information and ideas on an equal basis with others, and through all forms of communication of their choice. An essential element of making this right real is for countries to genuinely take all appropriate measures and steps to provide information in accessible formats. ${ }^{4}$

This dissertation provides insights in the struggles in dialogue conversations of the broad target group of communication vulnerable people. Dialogue conversations are becoming more and more important, since clients are expected to participate actively in conversations with healthcare professionals and take responsibility for their own care (process). While existing research often focuses on doctor-client consultation, this dissertation covers conversations between clients and any healthcare professional. Furthermore, the communication between family members and professionals is part of the first qualitative study, and provides insights in important elements in their communication.

This dissertation is innovative for its attention to environmental factors, instead of only paying attention to general communication skills in dialogue conversations. Communication vulnerable people should be enabled by the environment to communicate during dialogue conversations. Adjustments to the physical environment can be used to support communication with this target group. Augmentative and Alternative Communication (AAC) is one specific aspect of the physical environment, and this dissertation shows that AAC is often unknown, and therefore unloved and not used, leaving communication opportunities unconcerned. The application of ad hoc usable AAC for this broad target group is a rather unexplored area.

This dissertation points out that the process of choosing and using AAC for communication support in dialogue conversations is difficult. Therefore, the guide 'Choose to Communicate' was developed which clients and professionals can use to collaboratively acknowledge communication difficulties and search for ad hoc usable AAC that can support these difficulties. The guide has been developed in a thorough iterative design process involving clients, professionals and experts. However, further evaluation and subsequent implementation of the guide is necessary, therefore, a future research project including a process evaluation of the guide is planned. 


\section{Valorisation per Stakeholder}

The results of this dissertation are relevant for several stakeholders, including communication vulnerable clients, healthcare professionals, health care institutions, policy makers, students and lecturers in healthcare education, researchers and research institutions.

\section{Communication vulnerable clients}

In current practice communication vulnerable clients are not sufficiently supported in their communication during dialogue conversations with professionals. Participation in meaningful dialogue conversations is crucial for them to have power over, and to be responsible for their care process, and autonomy and participation in daily life. This dissertation gives insights in communication support that can be used to enable them to participate in these conversations. The guide 'Choose to Communicate' is specifically developed for clients to be used, and is made accessible for them. The guide matches experienced functional communication difficulties with AAC. The use of the guide can support communication vulnerable clients to have a voice in their own healthcare process.

\section{Healthcare professionals}

This dissertation shows that healthcare professionals are often not aware and enough equipped in terms of knowledge, attitude, skills and available tools, to support communication vulnerable clients to participate successfully in dialogue conversations. The findings provide professionals with an overview of a wide variety of strategies that they can use to support dialogue conversations. The guide 'Choose to Communicate' can be used by professionals to identify communication challenges of clients and collaboratively search for AAC that can support their dialogue conversation. During the development of the guide professionals were intensively involved. The guide might contribute to more awareness of communication vulnerability as it can be used when in need of a short and easy to use screening of communication vulnerability in which the clients' views are taken into account. It may also contribute to a more positive or accepting attitude towards the use of AAC by professionals and clients. Beneficial for the acceptance of AAC would be the timely introduction of a specific AAC. Future research into the effectiveness of the guide could further support more high-level evidence based practice concerning support of communication vulnerable clients. Furthermore, all health care professionals should be aware and trained about communication vulnerability and support. Although training programs which focus on specific diagnosis have reported positive outcomes, ${ }^{5,6}$ training for the broader target group of communication vulnerable people is necessary. The guide 'Choose to Communicate' should be integrated in such training and professionals should practice with ad hoc usable AAC.

This thesis is not rooted in the clinical practice of speech and language therapy or occupational therapy, but instead takes a holistic approach on communication support regardless of a professional discipline. This holistic approach for communication support should be adopted by healthcare professionals, and different disciplines should work together to support clients in communication. Such interprofessional collaboration and a generalist perspective for healthcare professionals is also advised by the Dutch governmental report 'Naar nieuwe zorg en zorgberoepen'. ${ }^{7}$ 


\section{Healthcare institutions}

Several long-term care institutions in the South of the Netherlands have participated in this research project. Based on the qualitative inquiry described in chapter 2, researchers coached the participating institutions in follow up actions to improve communication. Two long-term care institutions currently work together with the Research Center of Autonomy and Participation within research projects and proposals concerning communication vulnerability.

Although the research project was performed in long-term care settings, the findings are also relevant for other healthcare institutions. Dialogue conversations are important conversations between clients and professionals concerning the care process, and these take place in all sorts of institutions. Therefore, the suggested factors to improve dialogue conversations would also be valuable in other settings, such as preparing the conversation, adjusting the physical environment, and using AAC. The guide 'Choose to Communicate' would probably also be valuable in other care settings, such as in primary care where professionals have prolonged contact with communication vulnerable clients, e.g. in general practice, occupational therapy, physical therapy, and speech and language therapy.

The insights about adjustments in the physical environment should be used to adjust rooms in which conversations take place and to adjust written information. Furthermore, healthcare organizations should be aware that AAC, such as communication boards, Talking Mats, and apps on mobile phones and tablets provide a wide range of communication support, and organizations should make sure that such AAC are available on every department.

\section{Policy makers}

The insights from this dissertation should also be used to make governmental and societal services more communication accessible, such as municipalities, community services, social security organisations, and healthcare insurance organizations. Although there is often attention for physical accessibility of public spaces, communication accessibility is often overlooked. ${ }^{8}$ Recently more attention has been given to health literacy, this should be expanded with attention for communication vulnerability. Chapter 4 provides advice for adjusting the physical environment, including written information. The guide 'Choose to Communicate' could also be used in governmental and societal services when a communication vulnerable person or a professional notices that there are difficulties understanding each other.

\section{Students and lecturers in healthcare education}

Healthcare education institutions should be aware that meaningful communication comprehends more than standard communication skills. Undergraduate and graduate students in the field of healthcare should be taught about communication vulnerability, and how to engage in meaningful dialogue conversations with communication vulnerable people. Students should interact with communication vulnerable people across their study projects, not only during internships. Students have participated in this research project as a research assistant and during their bachelor thesis. At Zuyd University the 
insights of this dissertation are being implemented in the faculty of Health, students are being taught to recognize communication vulnerability, and to use the guide 'Choose to Communicate' and different AAC. Furthermore, students will be educated about involving (communication) vulnerable clients in their Bachelor thesis. Dissemination to other universities nationally and internationally have and will further involve publication of articles and presentations on congresses.

\section{Researchers and research institutions}

This dissertation displays the relevance and value of client participation in research. Moreover, it provides advice on several adjustments in written and verbal communication to enable communication vulnerable clients to be involved in different phases and on different levels of research projects. Currently, the researchers involved in this dissertation coach other researchers about how they can involve vulnerable groups of clients in research. The feedback is positive, and coaching and publication are therefore extended.

The expertise about communication vulnerability gained from this dissertation is also used in several research projects and proposals initiated by the Research Centre of Autonomy and Participation of Zuyd, and by the Department of Family Medicine, Maastricht University. The concept of communication vulnerability has already been adopted in several research proposals and research projects. During a two-year project funded by ZonMw (Netherlands Organisation for Health Research and Development), tools have been developed to measure the care relationship between client and professional, that are specifically accessible for communication vulnerable people. Furthermore, the expertise gained from this dissertation is being used in a large research project funded by the provincial government, Limburg Meet (LIME), specifically in the project about accessible measurements 'Anders Meten'. Additionally, a research proposal is being written which will focus on expanding the guide 'Choose to Communicate' for use by people with limited health literacy, in collaboration with Maastricht University and various health care organizations in cure and care. Moreover, to provide professionals and researchers with knowledge about which adjustments in written information are most valuable for communication vulnerable people, a research proposal has been written in collaboration with Maastricht University, Rotterdam University of Applied Sciences and various health care organizations.

\section{Activities and further dissemination}

This dissertation focusses on people who are communication vulnerable due to medical conditions. It is relevant to further investigate whether the findings of this dissertation can be used for a larger group of communication vulnerable people, including people with a different language or culture, and people with limited health literacy. There is an increasing group of migrants all over the world; the WHO reports that globally, there are an estimated 250 million international migrants ${ }^{9}$. Professionals and these clients might not understand each other's language, culture or religion, which make meaningful dialogue conversations difficult ${ }^{10}$. Furthermore, recent research of the NIVEL institute shows that one out of three Dutch people have limited health literacy, which can have negative consequences for participation in the care process. ${ }^{11}$ Available tools concerning health literacy mostly focus on the 
client understanding the professional: on making written information available and on adjusting the language of the professional. What the tools for health literacy often lack, is attention for clients to express themselves and the collaboration of client and professional during a dialogue conversation. The guide 'Choose to Communicate' described in this dissertation aims to support both professional and client to come to a joint establishment of meaning in dialogue conversations, supporting understanding and expression from both parties. This guide could have potential for conversations with people with low health literacy and people with a different language/culture as they could also benefit from AAC that support them in expressing themselves, such as visual support using Talking Mats or pictograms. Therefore, in a follow up research proposal there will be investigated if the guide 'Choose to Communicate' can improve communication with communication vulnerable people due to a medical conditions and/or due to limited health literacy.

Although tokenistic use of the guide should be avoided, integration of the guide in standard procedures in healthcare settings could enable early detection of communication difficulties and immediate communication support. It could for example be used when a new client is registered, or during scheduled evaluations. Further steps that have to be taken for implementation are: keeping the guide up to date in terms of new AAC and technological advances, adding videos for instructions of AAC, and adjusting the guide for different healthcare settings. For this, we will collaborate with partner institutions in the field of communication such as Modem, ISAAC-NF and Afasienet. Furthermore, the extensive network of healthcare institutions of Zuyd University and Maastricht University will be used to implement findings of this dissertation in daily healthcare practice.

The findings presented in this thesis will be used as input for other research projects within Zuyd University and Maastricht University. Researchers have already and will be further informed about the importance of including communication vulnerable people in their projects, and how they can make their projects communication accessible.

We already have and will further attempt to spread the knowledge gained from this dissertation by means of national and international articles and presentations at conferences. 


\section{References}

1. Huber M, Knottnerus JA, Green L, et al. How should we define health? BMJ. 2011;343:d4163.

2. Huber M, van Vliet M, Giezenberg M, et al. Towards a 'patient-centred' operationalisation of the new dynamic concept of health: a mixed methods study. BMJ Open. 2016;6(1):e010091.

3. WRR. Weten is nog geen doen. Een realistisch perspectief op redzaamheid. Den Haag: Wetenschappelijke raad voor het regeringsbeleid; 2017.

4. United Nations. Convention on the Rights of Persons with Disabilities; 2006

5. Simmons-Mackie N, Raymer A, Cherney LR. Communication Partner Training in Aphasia: An Updated Systematic Review. Arch Phys Med Rehabil. 2016;97(12):2202-2221 e2208.

6. Wielaert S, van de Sandt-Koenderman M, Dammers N, Sage K. ImPACT: a multifaceted implementation for conversation partner training in aphasia in Dutch rehabilitation settings. Disabil Rehabil. 2018;40(1):76-89.

7. Kaljouw M, van Vliet, K. Naar nieuwe zorg en zorgberoepen. Commissie Innovatie Zorgberoepen \& Opleidingen; 2015.

8. Neijenhuis, K. Zorg voor communicatie. Een goed gesprek is in balans. Openbare les Hogeschool Rotterdam. 2018.

9. World Health Organization. Refugee and migrant health; 2018. Available at: http://www.who.int/migrants/en/.

10. International Organization for Migration. International Migration, Health and Human Rights 2013. Available at: https:// publications.iom.int/books/international-migration-health-and-human-rights

11. M. Heijmans, A. Brabers \& J. Rademakers, Health Literacy in Nederland. Utrecht: Nivel, 2018. Available at: https://www.nivel.nl/ $\mathrm{nl} /$ nieuws/ruim-\%C3\%A9\%C3\%A9n-op-de-drie-nederlanders-heeft-lage-gezondheidsvaardigheden 
List of publications and presentations 


\title{
List of publications and presentations
}

\author{
International peer-reviewed publications
}

Stans S, Dalemans R, de Witte L, Beurskens A. Challenges in the communication between 'communication vulnerable' people and their social environment: an exploratory qualitative study. 2013. Patient Education and Counselling. 92(3):302-12.

Stans S, Stevens J, Beurskens A. Interprofessional practice in primary care: development of a tailored process model, case report. Journal of Multidisciplinaire Healthcare 2013. 17;6:139-47.

Stans S, Dalemans R, Smeets H, de Witte L, Beurskens A. The role of the physical environment in conversations between people who are communication vulnerable and health-care professionals: a scoping review. 2017. Disabil Rehabil, 39(25):2594-2605.

Stans S, Dalemans R, Roentgen U, Beurskens A. Who said dialogue conversations are easy? The communication between people who are communication vulnerable and healthcare professionals. 2017. Health Expect, 21(5):848-857.

Stans S, Dalemans R, Roentgen U, Beurskens A. Choose to Communicate: a Guide to Support Communication between Practitioners and Communication Vulnerable People. 2018. Submitted.

Stans S, Dalemans R, de Witte L, Beurskens A.Using Talking Mats to support conversations with people who are communication vulnerable: a scoping review. 2018. Submitted

Stans S, Lenzen S, Dalemans R, Beurskens A, Moser A. Client participation in research through junior researchers' eyes: a qualitative analysis. 2018. Submitted

\section{National publications}

Kremer I, Göertz E, Thilmann M, Stans SEA, Werrij M. Elementen in de fysieke omgeving ter bevordering van de communicatie: een systematisch literatuuronderzoek. 2012. Wetenschappelijk Tijdschrift voor Ergotherapie:5,3.

HGZO. Inspiratiebrief Interprofessioneel Samenwerken in Zorg \& Welzijn. In: Inspiratiebrief voor alle hoger gezondheidszorg opleidingen in Nederland. Juni 2015

Riegman L, Roumans R, Moser A, Stans S. Interprofessioneel samenwerken: Ervaringen, mogelijkheden en uitdagingen. 2015 sept. Ergotherapie Wetenschap. 
Stans S, van rossem C, Dalemans R, Moser A. Co-creation with people who are communication vulnerable. In: Collaboration of Dutch Expertise Centres. Shared insights on co-creation in healthcare from four Dutch centres of expertise. 2016.

\section{Oral presentations}

Dalemans R, Stans S, Stevens A. In dialoog: uitdagingen in de communicatie tussen zorgverleners en cliënten met een communicatieve beperking. Kennis in Bedrijf 2011 Heerlen. 24 november 2011.

Stans S, Dalemans R, de Witte L, Beurskens A. Challenges in the daily communication. EACH congress St. Andrews, United Kingdom, 5 september 2012.

Stans S. Project in dialoog. Netwerkbijeenkomst SGL, Kerkrade, 1 november 2012.

Stans S, Dalemans RJP. Communicatietoolkit. Zuyd Kennis In Bedrijf, 29 november 2012.

Stans S, Driessen M. Integrale toegankelijkheid. Zuyd Kennis In Bedrijf, 29 november 2012.

Stans S. Bridging the gap between communication vulnerable people and their environment. Afasie jongerendag, Groningen, 7 juni 2013.

Stans S, Dalemans R, de Witte L, Beurskens A. Talking Mats: an overview of the literature. Communication Matters National AAC Conference, Leeds, UK, 14 september 2014

Stans S, Dalemans R, Moser A. Together shaping healthcare: Participation of people who are communication vulnerable in research. European Public Health Association (EUPHA), Vienna, Austria, 20 oktober 2016.

Stans S, Dalemans R. Communicatie-keuzehulp. Afasieconferentie, Zeist, 7 oktober 2016.

Stans S, Dalemans R, Roentgen U, Beurskens A. How people who are communication vulnerable and professionals experience their dialogue conversations. EACH, Heidelberg, 7 september 2016.

\section{Poster presentations}

Stans S, Dalemans R, , Beurskens A. Talking Mats, an overview of the literature. International Conference on Communication in Healthcare (ICCH), Amsterdam, 29 september 2014.

Stans S, Dalemans R, Roentgen U, Beurskens A. Including People who are Communication Vulnerable in Dialogue Conversations with Professionals: a Decision Aid for Communication Tools. ISOQOL 
Kopenhagen, Denmark, 19 oktober 2016

Stans S, Dalemans R, Roentgen U, Beurskens A. Tools to communicate with people who are communication vulnerable: the development of a communication decision aid. WFOT, Cape Town, South Africa, 23 mei 2018.

\section{Courses for professionals}

Dalemans R, Stans S. In Dialoog SGL. Wekelijkse cursus over communicatie. Zuyd Hogeschool 2014-2015.

Dalemans R, Stans S. Coachingstraject communicatie aandachtsfunctionarissen SGL. Coachingstraject bestaande uit 5 dagdelen. Zuyd Hogeschool 2015. 

Dankwoord 


\section{Dankwoord}

Onderzoek doe je nooit alleen. Daarom wil ik iedereen die aan dit proefschrift heeft bijgedragen bedanken, en een aantal mensen in het bijzonder.

Als eerste mijn interprofessioneel, intercultureel en kundig team. Ruth, bedankt voor je positieve insteek en jouw geloof in mijn kunnen. Zonder jouw opbeurende en complimenterende woorden was dit proefschrift er waarschijnlijk niet gekomen en had ik er niet zoveel plezier in gehad. Je passie voor communicatie is aanstekelijk. Ik ben er nog niet van genezen, we gaan samen nog veel leuke projecten doen! Sandra, vanaf mijn masterthesis heb je mij veel kansen gegeven om mij te ontwikkelen in onderzoek. Je staat altijd klaar om het beste uit mensen te halen. Je hebt me altijd gesteund, of ik nu linksom (ergotherapie) of rechtsom (communicatie) ging. Jouw passie voor praktijkgericht onderzoek heeft mij laten zien hoe leuk en waardevol onderzoek kan zijn. Je gaf mij ook de kans om even er tussenuit te gaan. Bedankt voor alle energie, kennis en kunde die je in mijn promotieonderzoek hebt gestoken. Uta, ik was heel blij dat er twee jaar geleden ook een ergotherapeut in het team kwam. Jouw kennis over designs gerelateerd aan hulpmiddelen en recente ontwikkelingen in de ergotherapie, was zeer waardevol in discussies en artikelen. Je staat altijd klaar voor kritische feedback op de stukken en hebt voor alles een oplossing (een echte ergotherapeut). De rust en positiviteit die je uitstraalt hielpen mij om weer verder te gaan na een grote feedbackronde. Luc, bedankt voor de kritische vragen en het aanzetten tot nadenken in eerste twee jaar van de promotie. Ook daarna was je nog altijd bereikbaar voor vragen en een opbeurende noot tijdens publicatie processen.

De leden van de beoordelingscommissie (Prof. Schols, Prof. Van Balkom, Prof. Feron, Dr. Neijenhuis en Prof. Rademakers), bedankt voor het beoordelen van dit proefschrift.

Hester, jij kwam als eerste trainee op de promovendi-kamer en ik had het geluk dat je bij mijn onderzoek betrokken kon zijn. Je kritische kijk en motivatie waren zeer waardevol tijdens de literatuuronderzoeken. Heel veel plezier en succes gewenst bij jouw eigen promotieonderzoek.

Stephie, we hebben nogal wat gemene delers, behalve onze naam delen we ook een passie voor ergotherapie en cliënt-gecentreerd onderzoek. Ik vind het heel fijn om met jou samen te werken! Ik hoop dat het stephie/ffy duo nog veel no-pressure onderzoeken samen gaat doen!

Albine, bedankt voor de ondersteuning bij het onderzoek over cliëntparticipatie en voor het sparren over kwalitatief onderzoek.

Maar zeker ook het secretariaat bedankt voor alle hulp. Heel fijn dat ik altijd even bij jullie binnen mag lopen (al is het voor een chocolaatje). Stephanie, weet je nog, toen ik bij jou en Erik op de kamer kwam zitten? Een fijne plek om kennis te maken met het lectoraat! Maar ook Marja, Jacqueline en Prisca bedankt voor al jullie secretariële ondersteuning en interesse in het onderzoek en mij. 
Daarnaast wil ik natuurlijk de cliënten en professionals uit het werkveld en de instellingen bedanken die betrokken zijn geweest bij het onderzoek. Personen die altijd open stonden voor een observatie of interview. Cliënten die het veel moeite/tijd/energie kost om te communiceren, maar zich toch hebben ingezet voor dit onderzoek. Mensen die op een bewonderenswaardige wijze zelf op zoek zijn gegaan naar manieren om zich te uiten en te kunnen participeren. Wendy van Horck en Daniëlle Jacobs. Tijdens een interview enkele jaren geleden merkte ik hoe geïnteresseerd jullie waren in het onderwerp van mijn promotie. Ik heb jullie daarna ook gevraagd betrokken te zijn bij het laatste onderzoek. Wendy, jouw doorzettingsvermogen om het maximale uit het leven te halen is bewonderenswaardig. Je hebt een zeer waardevolle bijdrage geleverd aan de communicatie-keuzehulp door je oprechte meningen, het betrekken van cliënten en je goede ideeën. Daniëlle, ik ben blij dat ik zo'n enthousiaste, gemotiveerde en oprechte zorgprofessional als jij heb ontmoet en heb mogen betrekken in het onderzoek. Je passie voor cliëntgericht werken is heel mooi en dit vertaal je ook door in de onderzoeksprojecten waarbij je betrokken bent. Egbert Janssen zou ik ook willen bedanken voor alle hulp bij het beginstadium van de communicatiekeuzehulp. Ook zou ik graag de andere cliënten en professionals binnen SGL willen bedanken voor het delen van hun ervaringen, en de tijd en moeite die ze hebben gestoken in interviews en observaties. Rianne Cuppen, bedankt voor je ondersteuning in het praktijkgerichte onderzoek binnen SGL. Je bent kritisch en staat open voor innovatieve ideeën voor onderzoeksprojecten of scholingen.

Betrokken professionals en cliënten bij Meander en Sevagram wil ik bedanken voor de tijd en moeite die jullie hebben gestoken in de interviews. Raymond Clement, wie had gedacht dat de eerste manager die ik interviewde (je was niet de makkelijkste interview respondent ) later mijn faculteitsdirecteur zou worden. Daarnaast wil ik cliënten en professionals van Envida bedanken die hebben geparticipeerd in de interviews en observaties. In het bijzonder Marga Hofman en het logopedieteam welke kritisch hebben meegedacht tijdens de ontwikkeling van de communicatiekeuzehulp en hebben ondersteund in de werving van respondenten.

De promovendi-kamer, voor de tips en tricks in promoveren, lotgenoten-contact, acute hulp bij domme vragen ('weet jij het engels woord voor...') en EHBP (Eerste Hulp Bij Promotie-problemen). Maar ook voor onze fijne wandelingen waardoor ik altijd weer met een frisse blik verder kon. Het is niet bij te houden wie er allemaal op onze kamer zat en zit, maar Linda, Stephie, Jerome, Jolanda, Li-Juan, Kim, Kyra, Darcy, Renee, Esther, Iris, Ruth, Anita...bedankt!

Collega's van de cluster lectoraten, bedankt voor jullie interesse en ondersteuning.

De opleiding Ergotherapie. Annerie, vanaf het moment dat ik bij de opleiding mocht komen werken heb je mij altijd op de achtergrond gesteund om te promoveren, bedankt voor je flexibiliteit. Het gehele team van de opleiding Ergotherapie bedankt voor de down to earth gesprekken, afleiding, en jullie vragen zoals 'hoe is het met je promotie?' en 'ben je al bijna klaar?'. Na 3 jaar was mijn standaard antwoord: 'nog een jaartje ongeveer', gelukkig waren jullie altijd tevreden met dit antwoord. Jullie denken dat ik nooit gestrest ben, maar dat heeft ook te maken met de fijne werkomgeving en collega's! 
Maar ook de studenten bedankt. Wat is het toch leuk om samen met jullie in afstudeergroepjes aan de slag te gaan met praktijkgericht onderzoek. Ik zal eerlijk bekennen dat het goed is voor je zelfvertrouwen als promovenda om tevens feedback te mogen geven in plaats van alleen maar te ontvangen. In het bijzonder wil ik de studenten van de opleiding Ergotherapie en Logopedie bedanken die hebben bijdragen aan dit onderzoek in het kader van hun afstuderen of persoonlijke studieruimte.

Marluuke en Linda, bedankt dat jullie mijn paranimfen willen zijn. Mijn omgeving heeft bij dit woord vele associaties, van bosfee tot paranormaal, maar eigenlijk zijn jullie gewoon twee mensen die altijd super geïnteresseerd zijn in mijn onderzoek en bij wie ik altijd terecht kon voor goede ideeën en afleiding.

Mijn familie, neven en nichten, ooms en tantes die altijd geïnteresseerd vragen: 'hoe gaat het met je studie?', 'ben je al bijna klaar?', 'je was toch bijna klaar?', 'wanneer is het feestje?'. Dat feestje is er nu eindelijk! Pa (opa) zou trots geweest zijn dat ik 'hellop veur de speegel' heb geoefend.

Mijn 'schoonfamilie' voor de fijne afleiding en met name Isa voor de totale afleiding met jouw never-ending energie en vrolijkheid.

Mijn ouders voor de no-nonsense opvoeding die mij helpt om nuchter te blijven, zelfs in een promotieonderzoek. Hoe doen jullie dat, je kinderen stimuleren maar ook totaal geen verwachtingen scheppen? Voor jullie kan ik nooit iets verkeerd doen. Pap, bedankt voor de mooie kaft van dit proefschrift, gelukkig heb je wat geduld. Sjors en Kirsten bedankt voor jullie interesse en het meedenken over de kaft.

Mijn vrienden die juist niet te veel vragen naar promoveren. Heerlijk om het juist niét over werk te hebben en gewoon lol te hebben. Mijn 'highwine groepje', wat zijn we toch allemaal verschillend, dat maakt het zo leuk om met jullie gezellige avonden te hebben. Monique, voor de relaxte vrijdagmiddagen na weer de hele dag achter de computer gezeten te hebben. Marluuke en Laura voor onze gezellige avonden (sinds de minor Science) en jullie oprechte interesse in het proefschrift.

Patrick, jij zet mij altijd weer met beide benen op de grond. Je hebt eindeloos veel presentaties beluisterd (of gedaan alsof) die altijd weer over hetzelfde leken te gaan. Ook heb je vaak (onder lichte dwang) stukken van mijn artikelen gelezen ('heb ik dit niet al eens gelezen'?) en mocht ik mijn frustraties altijd op jou afreageren (en anders was er nog altijd de bokszak in de garage). Je weet altijd een mooie balans te vinden tussen mij stimuleren om aan de promotie te werken en tegelijkertijd om voldoende rust en afleiding te nemen. Naast elkaar thuis achter de computer, of in de 'Library of Melbourne' achter de laptop. Je herinnert mij er altijd weer aan dat, ondanks dat werk vaak ook leuk is, er zoveel meer is dan werk: samen lol hebben, samen sporten, samen klussen, samen reizen. 

About the author 


\section{About the Author}

Steffy Stans was born on November 29, 1986 in Buchten, the Netherlands. In 2005 she completed secondary school at Trevianum Sittard. She studied Occupational Therapy at Zuyd University of Applied Sciences and graduated as Bachelor in 2009. Thereafter, she studied Health Innovation Services at Maastricht University. Steffy graduated as a Master of Science in 2010 with a thesis about Integrated primary care for children with complex care demands. From 2009 until 2012 she worked as an occupational therapist in two primary care practices, mostly with children and adults with chronic conditions.

In 2010 Steffy started working at Zuyd University of Applied Sciences as a junior researcher in a project about interprofessional collaboration in childcare. Since 2011 Steffy also works as a lecturer for the faculty of Occupational Therapy at Zuyd University. In 2012 she started her PhD project that resulted in this dissertation. This is a collaborative project of the Research Centre for Autonomy and Participation of Persons with a Chronic Illness (Zuyd University), the Department of Family Medicine (Maastricht University) and CAPHRI School (Maastricht University).

Currently, her work involves a combination of research and lecturing in different educational programs at Zuyd University, mostly for Occupational Therapy. Her work focusses on communication, communication vulnerability, client participation in healthcare and research, interprofessional collaboration in practice and in education, patient-professional relationship, and accessible measurements in healthcare.

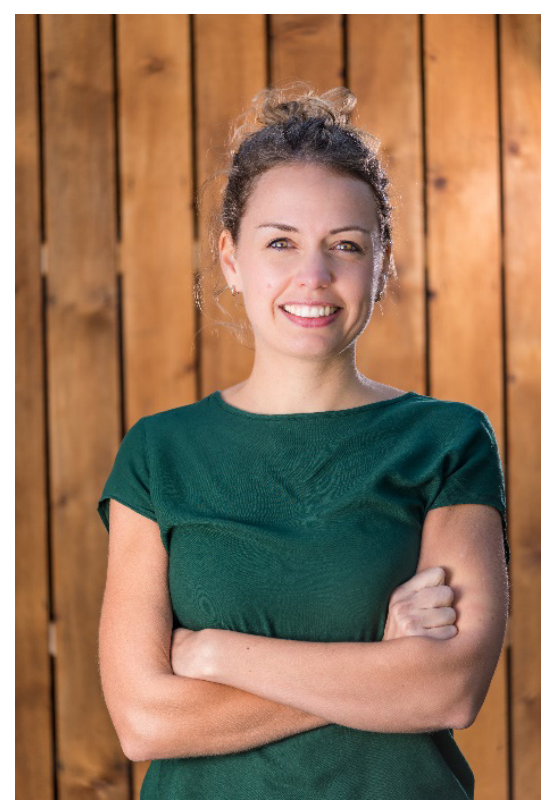




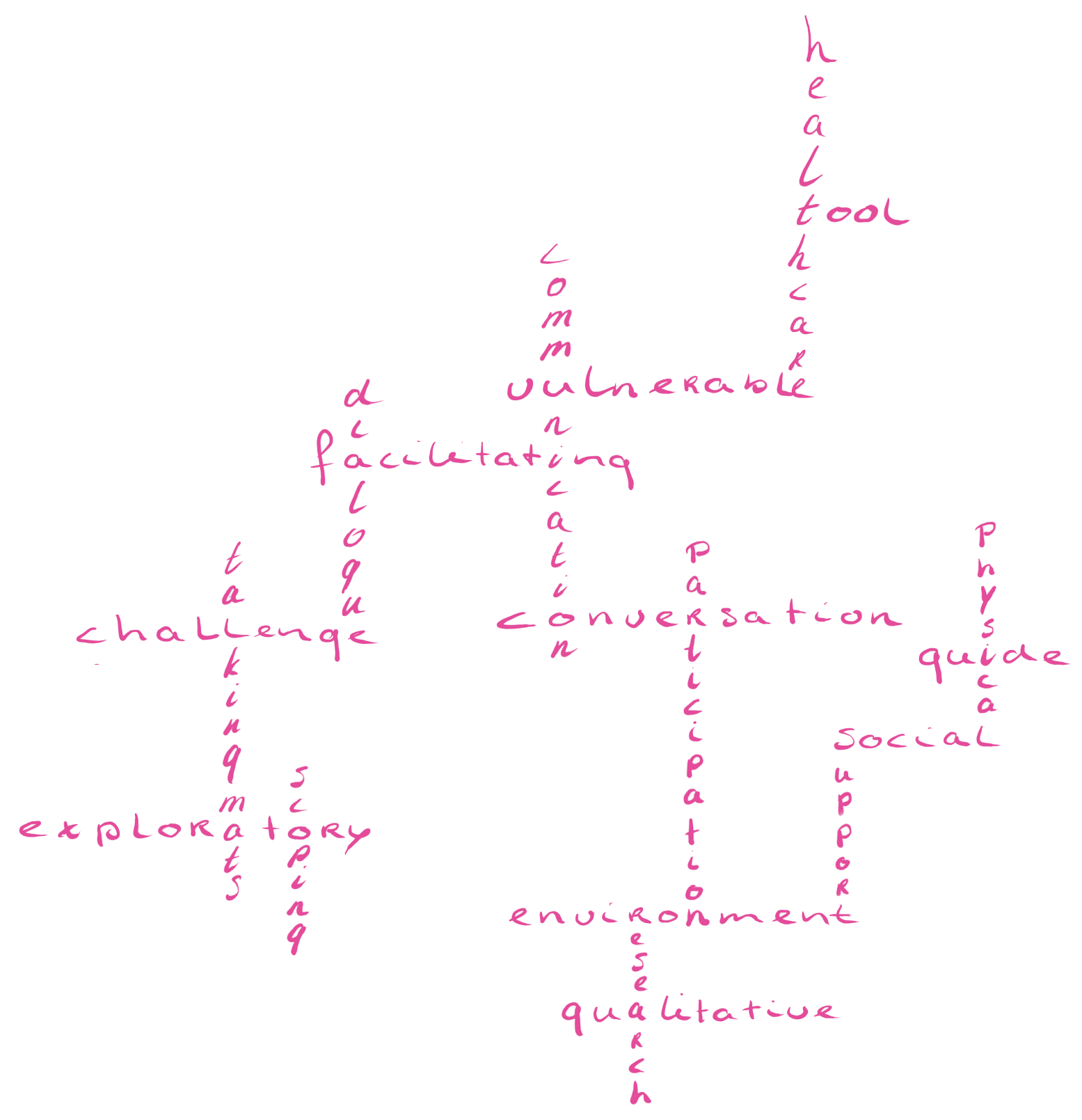

